\title{
Untersuchungen zur Funktion der Gene MPH1 und MMS2 aus Saccharomyces cerevisiae bei der fehlerfreien Umgehung von repli- kationsarretierenden DNA-Schäden
}

\section{Dissertation}

zur Erlangung des Doktorgrades

der Mathematisch-Naturwissenschaftlichen Fakultäten der Georg-August-Universität zu Göttingen

vorgelegt von

Christopher Ede

aus

Göttingen

Göttingen 2009 
Diese Arbeit wurde durch ein Stipendium der FAZIT-Stiftung gefördert.

D7

Referent: PD Dr. Wilfried Kramer

Korreferent: Prof. Dr. Hans-Joachim Fritz

Tag der mündlichen Prüfung: 13.02.2010 
"It has probably got something to do with quantum""*

${ }^{*}$ Kann Spuren von Wissen enthalten. 



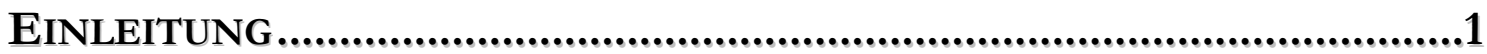

Gefährdung der DNA durch endogene und exogene Einflüsse .....................1

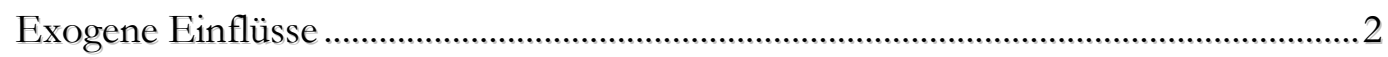

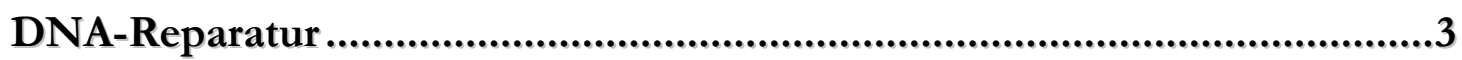

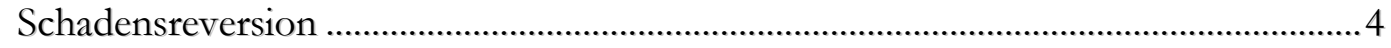

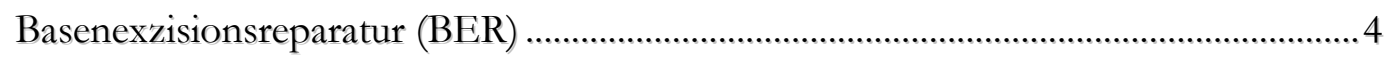

Nukleotidexzisionsreparatur (NER) …...............................................................

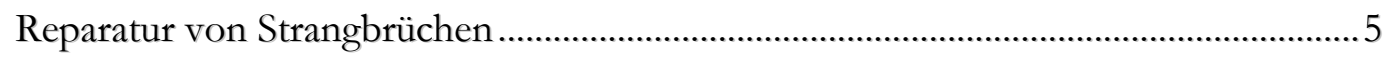

Reparatur nicht ligierbarer Einzelstrangbrüche ..................................................... 5

Reparatur von Doppelstrangbrüchen ........................................................... 5

Synthesis-Dependent-Strand-Annealing und Double-Strand-Break-Repair..................5

Single-Strand-Annealing ............................................................................. 8

Non-Homologous-End-Joining ......................................................................... 8

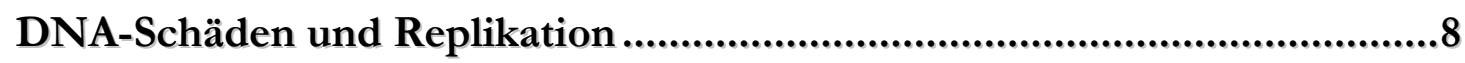

Reinitiation der Replikation an einer kollabierten Replikationsgabel........................... 8

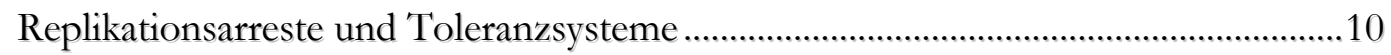

Die Genauigkeit der Polymerasen kann zu Replikationsarresten führen .........10

Schadensumgehung durch Transläsionssynthese (TLS).....................................12

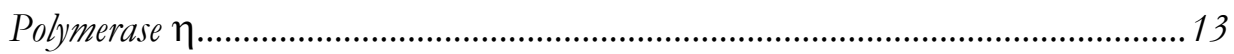

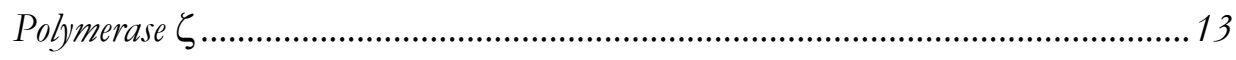

Desoxycyctidyltransferase Rev1 .......................................................................13

Schadensumgehung durch fork regression ..........................................................14

Schadensumgehung durch homologe Rekombination (HR) ..............................15

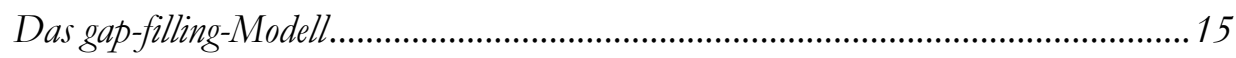

Reinitiation einer arretierten Replikationsgabel durch bomologe Rekombination ..........17

Der Ausfall von Reparatur- oder Toleranzsystemen kann fatale Konsequenzen für

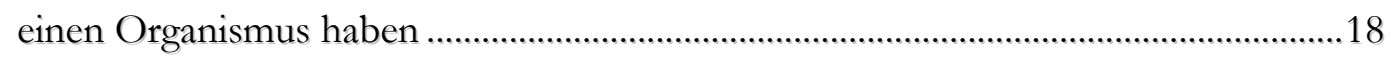

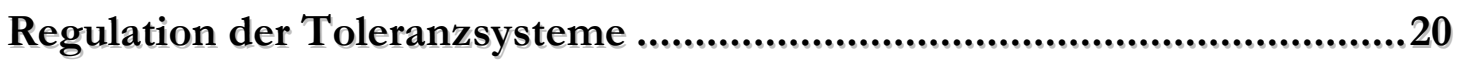

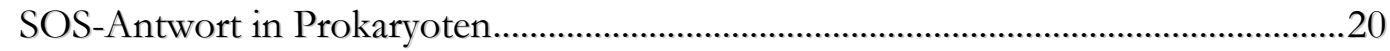

Regulation des Zellzyklus in Eukaryoten: DNA-Damage-Checkpoint............................21 


\section{INHALT}

Regulation von Transläsionssynthese und fehlerfreier Schadens-Umgehung............22

Modifikation des PCNA reguliert die Postreplikative Reparatur.

Monoubiquitinierung ist vermutlich ein Signal zur Transläsionssynthese: fehlerbehaftete PRR.

Polyubiquitinierung ist das Signal für eine fehlerfreie Umgebung von DNA-Schäden: fehlerfreie PRR.

PCNA kann SUMOyliert werden, was möglicherweise suppressiv auf homologe Rekombination wirkt

MATERIALIEN

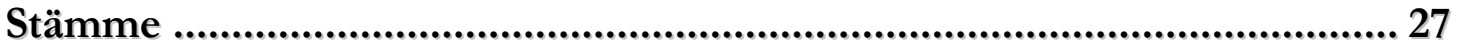

E.coli: .27

S. cerevisiae:

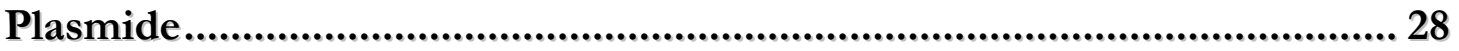

Primer für Deletionen und PCR-Screens ................................................31

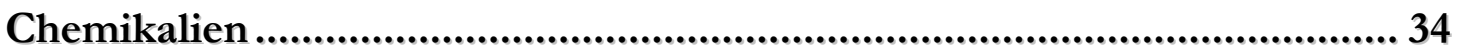

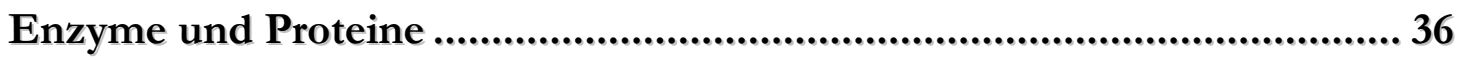

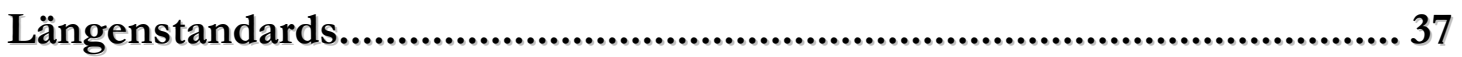

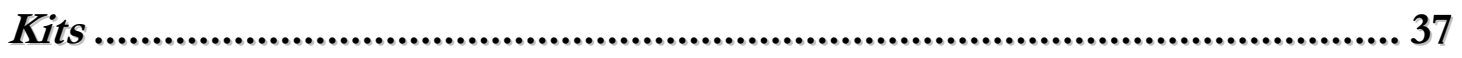

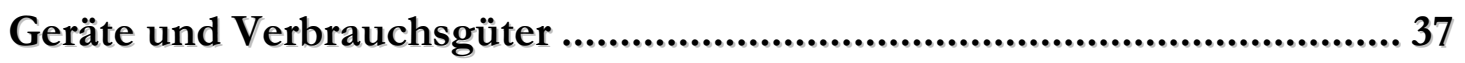

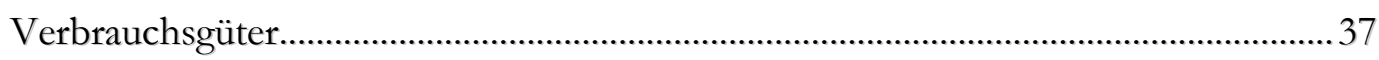

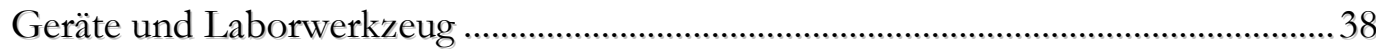

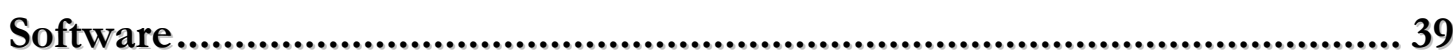

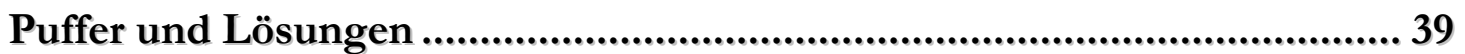

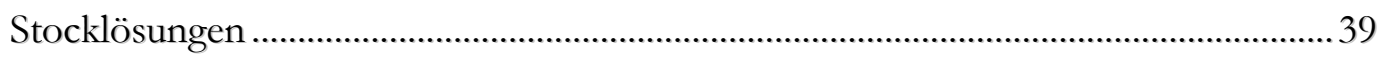

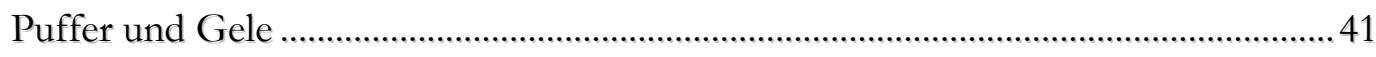

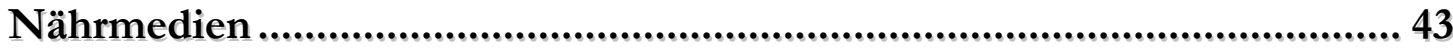

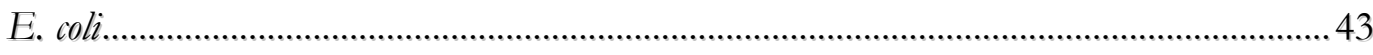

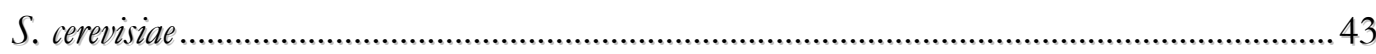


METHODEN

Molekularbiologische Methoden .45

Allgemeine Methoden . .45

Klonierungen . .45

Extraktion chromosomaler DNA aus Saccharomyces cerevisiae als Matrize für PCR .....47

Mikrobiologische Methoden.........................................................................48

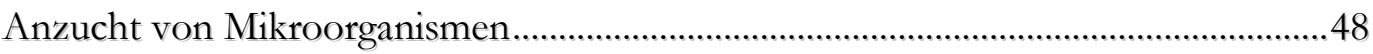

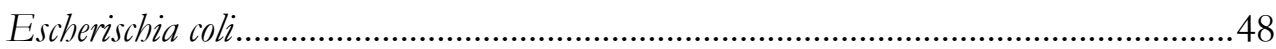

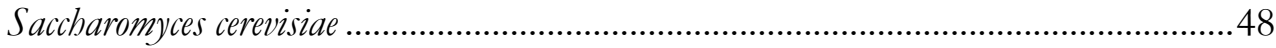

Methoden zur genetischen Manipulation von Mikroorganismen..................................48

Transformation von chemisch kompetenten E. coli nach Hanahan....................48

Transformation von S. cerevisiae nach Gietz \& Wodds, 2002..............................49

PCR-basierte Gendeletion ..................................................................................50

Chromosomale Integration von YIplac211 bzw. YIplac128_..............................52

Kreuzung von Hefestämmen ............................................................................53

Methoden zur phänotypischen Untersuchung von Hefestämmen ...............................54

Messung induzierter Reversionsfrequenzen.......................................................54

Messung spontaner Reversions- bzw. Mutationsraten ............................................56

Messung der UV-Sensitivität per Strahlungsgradient .............................................57

Messung der Überlebensrate nach UV-Strahlung................................................58

Bestimmung der Sensitivität durch einen drop-dilution-assay ..................................59

Messung der Überlebensrate nach Inkubation mit DNA-schädigenden

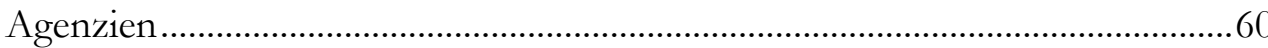

Messung der Verdopplungszeit.....................................................................61

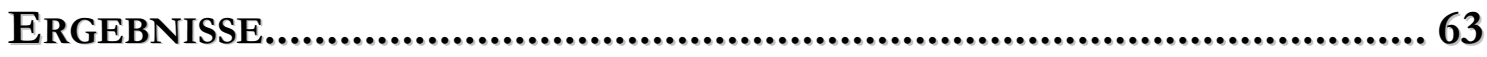

Messung von Schwesterchromatid-Interaktionen...................................63

Untersuchungen zur Entstehung von Reversionsereignissen im ................................64

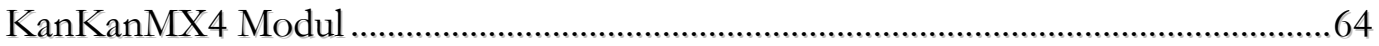

Modelle zur Deletion von Sequenzduplikaten..................................................64

Deletion durch Springen des primers auf dem template-Strang...................................65

Deletion durch Single Strand Annealing.................................................................65

Deletion durch die Reparatur kollabierter Replikationsgabeln nach run off-Synthese...66 


\section{INHALT}

Deletion durch homologe Rekombination bei der Doppelstrangbruchreparatur. 66

Deletion durch Schwesterchromatid-Interaktion baw. Schwesterchromatid-Austausch bei

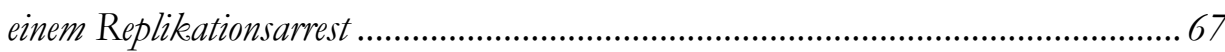

Untersuchungen zur Entstehung der Reversionsereignisse in vivo ..................... 69

Messung spontaner Reversionsraten .........................................................................69

Messung schadensinduzierter Reversionsfrequenzen im Wildtyp ................................. 70

Messung schadensinduzierter Reversionsfrequenzen in rekombinationsdefekten Mutanten .73

Messung schadensinduzierter Reversionsfrequenzen in yen $1 \Delta$-Mutanten...................... 75

Messung Schadens-induzierte Reversionsfrequen₹ in rad304-Mutanten..................... 76

Messung Schadens-indu₹ierter Reversionsfrequenæen in rev3 3 -Mutanten .................... 78

Messung spontaner Reversionsraten von rad304- und rev34-Mutanten ...................... 81

Untersuchungen zur Beteiligung von Mph1 an der fehlerfreien Umgehung von DNA-Schäden.

Ermittlung der Reversionsfrequenzen in mph1 $\Delta$-Mutanten

4-NQO-induqierte Reversionsfrequen₹ in mph1D-Mutanten....

Messung der induzierten Reversionsfrequenzen von mph1 $1 \Delta$ mit dem his3- $\Delta 5^{\prime} /$ his3-

$\Delta 3^{\prime}-M o d u l$ 84

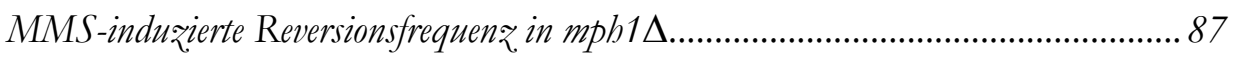

Camptothecin-indurierte Reversionsfrequenz in mph1 ............................................. 89

Spontane Reversion in mph1 $1 \Delta$............................................................................ 92

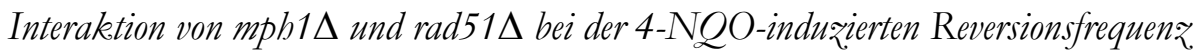

\section{Untersuchungen zum Mechanismus der Fehlerfreien Postreplikativen}

Reparatur..

Untersuchung der fehlerfreien Postreplikativen Reparatur anhand von mms $2 \Delta$ und $u b c 13 \Delta$.

Rückblick: $u b c 13 \Delta$ und $m m s 2 \Delta$ weisen verringerte 4-NQO induzierte

Reversionsfrequenzen auf. .96

Untersuchungen zur Funktion von mms $2 \Delta$ und $u b c 13 \Delta$ anhand des

KanKanMX4-Moduls .97

Messung 4-NQO-induðierter Reversionsfrequenzen einer ubc13 C87S-Mutante....... 97

Messung 4-NQO-induəierter Reversionsfrequenzen einer ubiK63R-Mutante ............ 99 
Messung 4-NQO-induzierter Reversionsfrequenzen von Modifikations-defizienten PCNA-Mutanten.

Messung der Sensitivität einer ubc13D pol30 K164R-Mutante..... .103

Untersuchung zur Funktion von Mms2 anhand der Analyse genetischer Interaktionen

Untersuchungen zur Interaktion von mms $2 \Delta$ mit der Transläsionssynthese..104

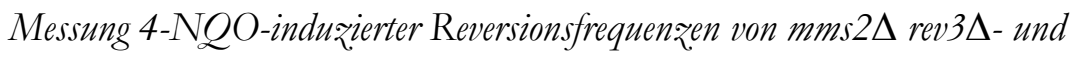
mms $2 \Delta$ rad30D-Mutanten. .104

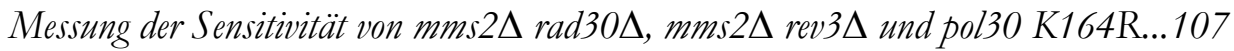

Untersuchungen zur Interaktion von Mms2 mit der homologen

Rekombination

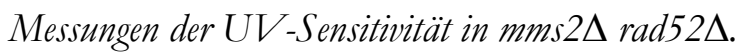

Messung der Sensitivität und Überlebensrate nach UV-Bestrablung von

$m m s 2 \Delta \operatorname{rad} 51 \Delta$.

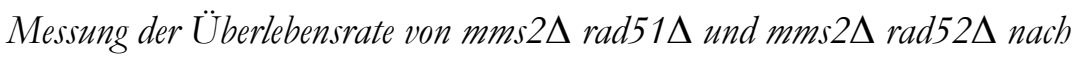

Inkubation mit 4-NQO.

Genetische Interaktion von mph1 $1 \Delta$ und mms $2 \Delta$

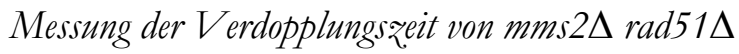

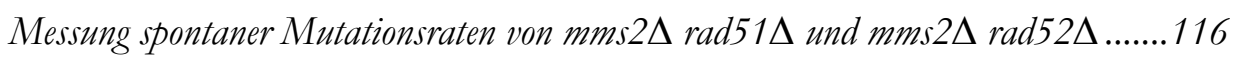

Untersuchungen zur Beteiligung der Photolyase (Phr1) an der fehlerfreien PRR...

Untersuchungen zur Interaktion zwischen Mms2, homologer Rekombination und Transläsionssynthese

Untersuchungen $2 u$ mms $2 \Delta \operatorname{rev} 3 \Delta \operatorname{rad} 51 \Delta$

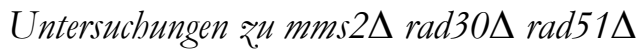

Untersuchungen ₹u mms $2 \Delta$ rev3 3 mph1 $1 \Delta$.

DiskUSsion .125

\section{Untersuchung von Schwesterchromatid-Interaktionen anhand des}

KanKanMX4-Moduls

Das KanKanMX4-Modul kann SSA-, SDSA- und DBSR-Ereignisse detektieren..125

Die spontanen Reversionen im KanKanMX4 stellen vermutlich zum großen Teil Rad51-abhängige Ereignisse dar, welche alternativ durch SSA ersetzt werden können 


\section{INHALT}

Durch Inkubation mit DNA-schädigenden Agenzien kann die Anzahl an

Reversionen gesteigert werden

Die induzierten Reversionsfrequenzen sind abhängig von der homologen

Rekombination, jedoch nicht von einer Resolvase

Der Ausfall der Transläsionssynthese führt möglicherweise zu einer

geringfügig verstärkten Anhäufung an Reversionsereignissen.

Mph1 ist vermutlich an der Prozessierung von D-Loops beteiligt

Die Helikase Mph1 ist an der HR-abhängigen fehlerfreien Umgehung von

replikationsarretierenden DNA-Schäden beteiligt.

Genetische Evidenzen für die Funktion von Mph1

Die induqierten Reversionsfrequenzen einer mph1D-Mutante weisen auf eine Funktion bei der fehlerfreien Umgehung von DNA-Schäden hin

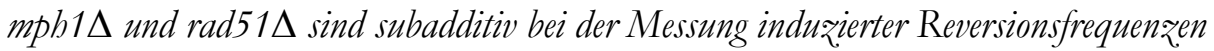

Mph1 ist vermutlich an der Prozessierung eines D-Loops beteiligt. 134

Die Auflösung eines D-Loops als ein₹ige Funktion von Mph1 ist nicht hinreichend, um alle Phänotypen zu erklären 134

Mph1 hat vermutlich eine Funktion bei der Stabilisierung oder Vergrößerung eines D-

Loops 134

Mph1 und Rad54 sind möglicherweise beides Faktoren für die effiziente

Bildung eines D-Loops. 135

Das Rad54-Protein 136

Mph1 und Rad54 sind Faktoren, welche die Synthese am D-Loop erleichtern. 136

\section{Untersuchungen zum Mechanismus der fehlerfreien Postreplikativen}

Reparatur.

Die fehlerfreie PRR scheint nicht unabhängig von homologer Rekombination zu sein

Die Reduktion induzierter Reversionsfrequenzen ist abhängig von der katalytischen Funktion des Mms2/Ubc13-Heterodimers

mms 2 und rev3 sind synergistisch in Bezug auf die spontane Reversionsrate.139 Polyubiquitinierung von PCNA scheint sowohl einen Rad51- als auch einen Rev3abhängigen Prozess zu beeinflussen

rad51 $\Delta$ ist synergistisch mit mms $2 \Delta$ in Bezug auf die Sensitivität gegen UV-

Bestrahlung und MMS, jedoch epistatisch bei 4-NQO

Polyubiquitinierung von PCNA könnte sowohl HR als auch einen Rev3-

abhängigen Mechanismus positiv stimulieren 
Genetische Evidenzen für die Beteiligung der homologen Rekombination an der fehlerfreien PRR wurden kürzlich gezeigt.

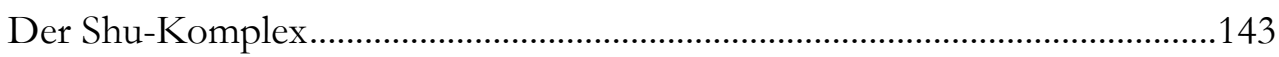

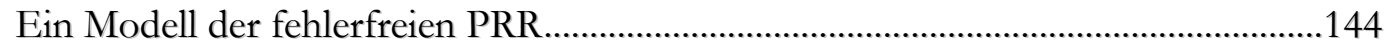

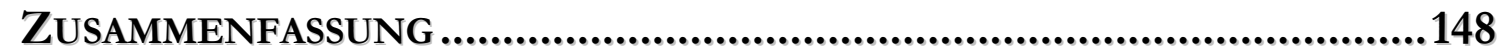

LITERATURVERZEICHNIS .......................................................150

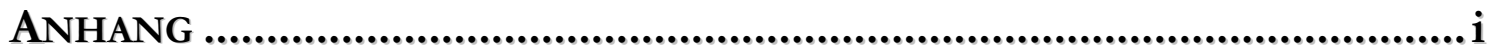

Testspaltungen der durch Klonierung erhaltenen Plasmide........................ i

Verzeichnis nicht gebräuchlicher Abkürzungen ........................................ iii

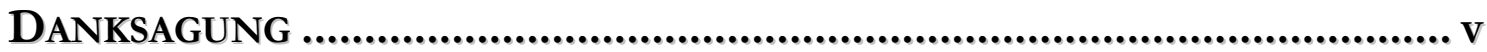

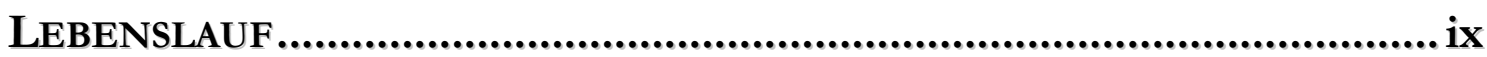





\section{EINLEITUNG}

\section{GEFÄHRDUNG DER DNA DURCH ENDOGENE UND EXOGENE EIN- FLÜSSE}

Etwa 80.000 DNA-Schäden werden in einer einzelnen Säugerzelle pro Tag durch spontane Reaktionen hervorgerufen (Lindahl \& Barnes, 2000; Tice \& Setlow, 1985). Der größte Teil dieser Schäden ist auf Reaktionen der DNA mit dem in der Zelle allgegenwärtigen Wasser zurückzuführen. Alleine der Verlust von Purinen durch Hydrolyse der N-glykosidischen Bindung wird auf ca. 18.000 Verluste pro Zelle und pro Tag geschätzt (Lindahl \& Barnes, 2000). Die Hydrolyse der Esterbindungen zwischen Phosphat und Desoxyribose des DNA-Rückgrats führt zu Brüchen im Einzelstrang. Die Anzahl solcher Einzelstrangbrüche in einer Säugerzelle wird auf etwa 55.000 pro Tag geschätzt, wobei diese jedoch teilweise auch auf andere Reaktionspartner als Wasser zurückgehen (s.u.). Hydrolytische Desaminierung der Basen führt dagegen zu veränderten Wasserstoffbrückenbindungsfähigkeiten derselben. Aus Cytosin wird so bspw. Uracil, welches mit Adenin anstatt mit Guanin paart, was zu einer $\mathrm{C}<>\mathrm{T}$-Transition führt. Durch Desaminierung von Guanin entsteht Xanthin, welches zwar die gleichen Wasserstoffbrücken ausbilden kann wie Thymin, jedoch weder mit Thymin noch mit Adenin stabile Basenpaare bildet (Maher et al., 1991). Desaminierung von Adenin führt zur Bildung von Hypoxanthin, welches mit Cytosin paaren kann (Friedberg et al., 2006; Lindahl, 1993). Allein durch Wasser entsteht demnach eine Vielzahl unterschiedlichster DNA-Schäden. Dazu kommen weitere endogene Substanzen, welche während des Stoffwechsels entstehen und mit der DNA auf vielfältige Art reagieren können. Während der Atmung treten reaktive Sauerstoffspezies auf (ROS), welche mit annähernd allen organischen Makromolekülen in einer Zelle reagieren können (Saran \& Bors, 1990). Die Reaktion mit DNA führt dabei zu teilweise sehr unterschiedlichen Resultaten. Reaktion mit der Desoxyribose bspw. resultiert in Strangbrüchen und Basenverlusten (Rhaese \& Freese, 1968). Durch Reaktion von Guanin mit reaktiven Sauerstoffspezies dagegen wird unter anderem 8-Oxo-Guanin gebildet, welches in der syn-Konformation mit Adenin anstelle von Cytosin paaren kann. Allein diese Reaktion findet in Säugerzellen pro Tag jeweils ca. 1.000-2.000 mal statt. Insgesamt sind über 80 verschiedene Reaktionsprodukte für die Reaktion von reaktiven Sauerstoffspezies mit DNA bekannt (Bjelland \& Seeberg, 2003). Neben der direkten Reaktion mit ROS kann DNA aber auch mit durch reaktive Sauerstoffspezies sekundär hervorgerufenen Molekülen reagieren: Die Reaktion von ungesättigten Fettsäuren mit Hydroxylradikalen kann zu Fettsäureperoxiden führen, welche wiederum zu Aldehyden weiter reagieren können. Diese Aldehyde können Basenaddukte bilden, wodurch die Paarung mit anderen Basen unterbunden werden kann (Marnett, 2000). Auch solche Addukte entstehen in einer Säugerzelle ca. $1.000 \mathrm{mal}$ pro Tag. Interessanterweise wird dieses zerstörerische Potential von reaktiven Sauerstoffspezies gleichzeitig von Organismen benutzt, um pathogene Parasiten wie Bakterien oder Vieren zu töten: Leukozyten schütten solche reaktiven Moleküle ins Phagosom aus (Badwey \& Karnovsky, 1986). Eine weitere bei der Zellatmung entstehende Substanz, welche die chemische Integrität der DNA gefährden kann, ist Glukose-6-Phosphat. Dieses bei der Glykolyse entstehende Mo- 


\section{EINLEITUNG}

lekül kann mit den Aminogruppen der DNA reagieren und so Addukte bilden (Bucala et al., 1984). Darüber hinaus kann Glukose-6-Phosphat auch mit den Aminogruppen von Proteinen reagieren, was zu reaktiven Intermediaten führt, welche wiederum mit DNA reagieren können und somit Protein-DNA-cross-links hervorrufen können (Lee \& Cerami, 1987). Weitere Quellen endogener Substanzen, welche die DNA schädigen können, sind alkylierende Substanzen wie S-Adenosylmethionin (Rydberg \& Lindahl, 1982), oder Hormone wie die Östrogene: Alkylierung der Basen führt unter anderem zu einem erhöhten Basenverlust oder zu kleinen Verzerrungen der räumlichen DNA-Struktur (Wyatt \& Pittman, 2006). Östrogene wie Estron und Estradiol können metabolisch zu Chinonen umgesetzt werden, welche mit N3 und N7 der Purine reagieren können und so instabile Basenaddukte bilden (Cavalieri et al., 2000).

\section{Exogene Einflüsse}

Diese Vielzahl endogener Schäden zeigt, wie sehr die Integrität der in der DNA gespeicherten Information allein durch ständig im Organismus vorkommende Substanzen gefährdet ist. Darüber hinaus ist die chemische Integrität der DNA aber auch durch exogene Einflüsse gefährdet. UV-Strahlung und ionisierende Strahlung bspw. sind allgegenwärtig. Studien in den USA zeigten, dass ca. $3 \mathrm{mSv}$ ionisierende Strahlung pro Jahr pro Individuum auf natürliche Ursprünge zurückzuführen sind, wobei Radonisotope ca. ein Drittel hiervon ausmachen (National Research Council, 1998). Trotz der Epidermis können solche Strahlen teilweise in lebendes Gewebe und damit auch in funktionsfähige Zellkerne vordringen. Trifft diese Strahlung direkt auf die DNA, können Basen und Desoxyribose ionisiert werden, was u.a. zu Reaktionen mit dem umgebenden Wasser oder anderen Basen führen kann (Ward, 1988). Allerdings ist ein solcher Vorgang weniger relevant im Vergleich zu dem Auftreten von reaktiven Sauerstoffspezies nach ionisierender Strahlung. Ein einzelnes Photon $\gamma$-Strahlung (ausgehend von ${ }^{60} \mathrm{Co}$ ) kann bis zu 36.000 solcher reaktiver Moleküle durch Ionisierung von Wassermolekülen erzeugen (Breen \& Murphy, 1995). Durch radioaktive Strahlung entstehen daher große Mengen an reaktiven Sauerstoffspezies innerhalb eines kleinen Volumensegments, welche in der Lage sind, DNA auf begrenztem Raum stark zu schädigen. Durch Reaktionen mit dem Zucker-Rückgrat der DNA können so durch ionisierende Strahlung indirekt gehäuft Einzelstrangbrüche hervorgerufen werden. Liegen diese Brüche nahe beieinander, was aufgrund der hohen Schadensdichte vorkommen kann, so können auf diese Weise Doppelstrangbrüche entstehen (Ward, 1988). Neben radioaktiver Strahlung kann aber auch UV-Strahlung die DNA stark schädigen. Das Absorptionsmaximum der DNA liegt bei $260 \mathrm{~nm}$, weshalb ein Großteil des Lichts im UV-Bereich von DNA absorbiert wird. Als UV-Licht werden Photonen mit einer Wellenlänge zwischen 100 und $400 \mathrm{~nm}$ bezeichnet, wobei es in UV-A (380-320 nm), UV-B (280-320 nm) und UV-C (100-280 nm) unterteilt wird. Während UV-C von der Ozonschicht absorbiert wird und somit nur in sehr geringen Dosen auf die Erdoberfläche gelangt, sind UV-A und UV-B durchaus biologisch relevant (Setlow, 1974). Hauptsächliches Produkt der Absorption von UV-Strahlung (vor allem UV-B) durch DNA sind Cyclobutanringe zwischen nebeneinander liegenden Pyrimidinen, was zur Dimerisierung der Basen führt. Häufigstes Dimer ist dabei vermutlich ein Cyclobutanthymindimer (Setlow \& Carrier, 1966). Ein weiteres ge- 
häuft auftretendes Produkt durch UV-induzierte Reaktion zwischen Pyrimidinen ist das 64-Photoprodukt (Mitchell \& Nairn, 1989). Sowohl ionisierende als auch UV-Strahlung haben darüber hinaus das Potential, sogenannte cross links in der DNA hervorzurufen, bei denen zwei Basen unterschiedlicher DNA-Stränge miteinander kovalent querverknüpft sind (Lett et al., 1961; Love et al., 1986).

Eine weitere exogene Ursache von DNA-Schäden sind aus der Umgebung aufgenommene aromatische Substanzen, welche metabolisch aktiviert werden können und in aktivierter Form sogenannte sperrige Basenaddukte (bulky adducts) bilden. Solche Substanzen finden sich unter anderem in Nahrungsmitteln oder als Partikel in der Luft. Am besten untersucht ist dies für den polycyclischen Aromaten Benzo(a)pyren, welcher durch unvollständige Verbrennung von organischen Verbindungen entsteht. Benzo(a)pyren besitzt ein sehr hohes Potential zur Bildung reaktiver Intermediate durch metabolische Aktivierung über den Cytochrom-P450-Komplex. Einige dieser Intermediate sind elektrophile Epoxide und reagieren mit nukleophilen Zentren in der DNA, wie bspw. mit N7 von Guanin (Phillips, 1983). Eine besondere Bedeutung bekommen Substanzen wie Benzo(a)pyren beim Menschen, da ihr hauptsächlicher Ursprung anthropogene Vorgänge wie die industrielle Verarbeitung von Kohlenstoffen, Rauchen, Automobilabgase und Essenszubereitung sind (Schoket, 1999). Vor allem letzteres ist nicht nur Ursprung für Benzo(a)pyren, welches überwiegend in verbrannten Nahrungsmitteln zu finden ist, sondern auch bereits bei leichter Bräunung des Essens werden diverse Substanzen gebildet, welche potentiell mit DNA reagieren können (Kim et al., 1991). Interessanterweise werden auch solche Basenadduktbildende Substanzen teilweise in der Natur benutzt, um Fraßfeinde oder Konkurrenten abzutöten. Der Pilz Aspergillus flavus produziert Aflatoxine, welche effizient Basenaddukte bilden können und mit zu den stärksten bekannten Karcinogenen gehören. Auch solche Substanzen können, obwohl sie nicht anthropogen erzeugt werden, für den Menschen ein relevantes Risiko darstellen, da Verunreinigung von Reis und anderen Getreidesorten mit Aspergillus flavus zur Aufnahme von Aflatoxinen über die Nahrung führen kann (Smela et al., 2001).

\section{DNA-REPARATUR}

Die Vielfalt an möglichen DNA-Schäden hat wesentliche Konsequenzen für die genetische Stabilität eines Organismus. Viele der Produkte können Mutationen hervorrufen, was zu einem Informationsverlust führen kann. Durch Doppelstrangbrüche oder großflächig auftretende DNA-Schäden, wie sie bei ionisierender Strahlung entstehen, können teilweise sogar komplette Abschnitte der genetischen Information verloren gehen. Da der Verlust an genetischer Information jedoch zu einem Verlust an essentiellen Funktionen und somit zum Zelltod führen kann, ist es notwendig, die auftretenden Schäden möglichst zu verhindern. Dies geschieht zum Teil durch das Abfangen von reaktiven Molekülen mithilfe von alternativen Reaktionspartnern wie bspw. dem Radikalfänger Ascorbinsäure. Teilweise werden reaktive Moleküle auch enzymatisch zu weniger reaktiven Produkten umgesetzt wie es bspw. durch die Superoxiddismutase geschieht (Alscher et al., 2002; Kc et al., 2005). Dennoch entstehen trotz dieser Maßnahmen deutliche Mengen an Schäden in der DNA, welche in irgendeiner Form repariert werden müssen. Es haben sich daher Mechanismen ent- 


\section{EINLEITUNG}

wickelt, welche es Zellen ermöglichen, Schäden im Genom mit hinreichender Effizienz zu reparieren. Die vier grundlegenden Mechanismen der Reparatur sind sowohl in Eu- als auch Prokaryoten zu finden und im Folgenden aufgeführt:

- Schadensreversion

- Basenexzisionsreparatur

- Nukleotidexzisionsreparatur

- Reparatur von Strangbrüchen

\section{Schadensreversion}

Die direkte Reversion eines Schadens umfasst einzelne spezifische Mechanismen, welche direkt das entstandene Produkt wieder in den Ursprungszustand zurückführen. Am einfachsten ist hierbei vermutlich die Ligation von Einzelstrangbrüchen durch eine DNALigase. Da Einzelstrangenden mit 3-OH und 5'-Phosphat auch bei der Replikation zwischen Okazakifragmenten entstehen, muss eine Zelle per se in der Lage sein, solche freien Enden zu ligieren. Insofern Einzelstrangbrüche demnach ein intaktes 3'-OH und ein 5'Phosphat aufweisen, können diese also direkt wieder religiert werden (zur Reparatur von nicht direkt religierbaren Enden siehe „Reparatur von Strangbrüchen“; Gardner et al., 1991). Ein weiteres Beispiel für die direkte Schadensreversion sind Photolyasen. Diese Enzyme sind in der Lage, unter Nutzung sichtbaren Lichts die kovalenten Bindungen in Pyrimidindimeren bzw. 6-4-Photoprodukten zu spalten und somit die Dimerisierung rückgängig zu machen. Photolyasen sind annähernd über die gesamten Domänen des Lebens verbreitet. Sowohl bei Archaen als auch Eukaryoten und Bakterien sind sie zu finden, wobei sie in Plazenta-Tieren jedoch nicht mehr vorkommen (Essen \& Klar, 2006). Eine weitere Form der direkten Schadensreversion ist die Abspaltung einer Alkylgruppe von AlkylBasenaddukten. Dies geschieht durch das Protein O6-Alkylguanin-DNA-Transferase (Ada in E. coli). Ada überträgt die Alkylgruppe eines Basenaddukts auf den Schwefel eines proteininternen Cysteins. Anschließend bleibt das Protein bis zum proteolytischen Abbau alkyliert und wird nicht reaktiviert, indem es die Alkylgruppe weiter überträgt. Aus diesem Grund wird Ada auch als „Suizidprotein“ bezeichnet (Samson, 1992). Auch diese Form der Schadensreversion ist sowohl in Pro- als auch Eukaryoten verbreitet (Kanugula \& Pegg, 2001; Kooistra et al., 1999; Nakatsuru et al., 1987; Sassanfar \& Samson, 1990).

\section{Basenexzisionsreparatur (BER)}

Bei der Basenexzisionsreparatur werden beschädigte Basen direkt aus der DNA entfernt, indem die N-glykosidische Bindung zwischen Base und Desoxyribose durch eine schadensspezifische Glykosylase hydrolysiert wird. An der dabei entstehenden AP-site wird der DNA-Strang durch eine AP-Endonuklease geschnitten. Der Desoxyribosephosphatrest wird anschließend aus der DNA entfernt, die so entstehende Einzelstranglücke in der DNA wieder aufgefüllt und die Einzelstrangenden werden ligiert. Für das Entfernen des Riboserests wird dabei eine RPase bzw. eine DNA-Polymerase mit 5'-3'-Exonukleaseaktivität (z.B. PolI in E. coli) benötigt, welche direkt während der Synthese über die Lücke hinaus die verdrängten Nukleotide entfernt (Duncan et al., 1976; Lindahl et al., 1997). Da die Gly- 
kosidasen spezifisch beschädigte Basen erkennen müssen, ist die Reparatur durch Basenexzision auf definierte Schadenstypen beschränkt. Hauptsächlich durch BER prozessiert werden Deoxyuracil, diverse Alkylierungen, Formamidopyrimidine sowie häufig auftretende Schäden wie 8-Oxo-Guanin (Friedberg et al., 2006).

\section{Nukleotidexzisionsreparatur (NER)}

Bei der Reparatur durch Nukleotidexzision wird nicht zunächst die Base aus der DNA entfernt, sondern direkt der beschädigte Bereich inklusive Zuckerphoshatrückgrat. Der Schaden wird dabei vermutlich durch die strukturelle Verzerrung der DNA an der beschädigten Stelle erkannt. Anschließend wird jeweils upstream und downstream des Schadens ein Schnitt im beschädigten Strang gesetzt. Der Einzelstrang zwischen diesen Schnittstellen wird durch eine Helikase entfernt und die so entstehende Lücke durch eine Polymerase aufgefüllt. Abschließend werden eventuell vorhandene Überhänge durch eine flap-Endonuklease entfernt und die Einzelstrangenden durch eine DNA-Ligase ligiert (Howard-Flanders et al., 1966; Lindahl et al., 1997). Da die Erkennung des DNA-Schadens anhand einer Veränderung der DNA-Struktur erfolgt, kann grundsätzlich jeder Schaden durch die Enzyme der NER erkannt und entfernt werden, insofern der Schaden die DNA-Struktur verändert. Die NER ist somit nicht wie die BER auf spezifische DNA-Schäden beschränkt. Einige Beispiele für Schäden, welche durch NER entfernt werden, sind UV-induzierte Schäden wie Cyclobutandimere und 6-4-Photoprodukte sowie bulky adducts, cross links und AP-sites (Friedberg et al., 2006).

\section{Reparatur von Strangbrüchen}

\section{Reparatur nicht ligierbarer Einzelstrangbrüche}

Wie zuvor erwähnt, können Einzelstrangbrüche direkt ligiert werden, wenn die Enden ein $3^{6}-\mathrm{OH}$ und ein 5'-Phosphat aufweisen. Bei Strangbrüchen infolge der Reaktion des Desoxyribosephosphatrückgrats mit reaktiven Sauerstoffspezies ist dies aber häufig nicht der Fall. Bei nicht direkt ligierbaren Enden wird vermutlich zunächst das 3'-Ende prozessiert, um ein freies 3'OH zu erhalten und anschließend analog zur BER das 3'-Ende verlängert, wobei das 5'-Ende verdrängt und anschließen durch eine flap-endonuklease entfernt bzw. direkt durch eine Polymerase mit 5'-3'-Exonukleaseaktivität ersetzt wird. Vermutlich sind an dem Prozess im Menschen die Proteine PARP1 und PARP2 sowie XRCC1 beteiligt (Friedberg et al., 2006).

\section{Reparatur von Doppelstrangbrüchen}

Synthesis-Dependent-Strand-Annealing und Double-Strand-Break-Repair

Die Reparatur von Doppelstrangbrüchen stellt für eine Zelle ein vergleichsweise großes Problem dar. Die Bruchstücke sind hierbei voneinander getrennt und es existiert keine Information darüber, wie die beschädigte Stelle zu reparieren ist. Bei der NER oder BER wird die beschädigte Information mithilfe des unbeschädigten Komplementärstrangs rekonstruiert. Bei Doppelstrangbrüchen ist dies jedoch nicht möglich. Um die Information für das korrekte Zusammenfügen von Doppelstrangbrüchen zu erhalten, bzw. um even- 


\section{EINLEITUNG}

tuell verloren gegangen Information zu rekonstruieren kann allerdings das Schwesterchromatid oder bei Diplonten auch das homologe Chromosom herangezogen werden. Die Information wird dabei über homologe Rekombination abgefragt. Eine schematische Darstellung der Modelle hierzu ist in Abb. 1 zu finden. Für die Interaktion mit dem Schwesterchromatid werden zunächst an den Abbruchenden 3'-Überhänge generiert. Dies geschieht in E. coli mithilfe des RecBCD-Komplexes (Dillingham \& Kowalczykowski, 2008) und in Eukaryoten vermutlich mithilfe des MRN-Komplexes (Abb. 1 A ii; Mimitou \& Symington, 2009). Dieser 3'-Überhang wird zunächst von einem Einzelstrang-bindenden Protein (Ssb in Pro-, RPA in Eukaryoten) gebunden. Anschließend wird dieses ProteinssDNA-Filament von einer Rekombinase gebunden, welche das 3'-Ende in eine homologe Stelle des Schwesterchromatids oder des Homologen invadieren kann (Abb. 1 A iii). Dabei wird der identische bzw. homologe Strang verdrängt und gleichzeitig der invadierte Strang mit dem komplementären Gegenstück hybridisiert, wobei es zur Ausbildung eines Displacement-Loops (D-Loop) kommt. In E. coli ist RecA die hierfür benötigte Rekombinase (Bell, 2005), in Eukaryoten ist es Rad51 (Krogh \& Symington, 2004). Darüber hinaus sind in Eukaryoten noch weitere Proteine an dem Prozess beteiligt. Für die Bindung des mit RPA besetzten Überhangs wird Rad52 benötigt, welches RPA vom Einzelstrang verdrängt und die Bindung von Rad51 an den Überhang ermöglicht (Sugiyama \& Kowalczykowski, 2002). Zusätzlich sind an der Bildung bzw. Stabilisierung des D-Loops die Proteine Rad55, Rad57 und Rad54 beteiligt (Fortin \& Symington, 2002). Die Funktion von Rad54 ist nach neuesten Erkenntnissen möglicherweise die Auflösung des Rad51-dsDNA-Filaments im D-Loop (Li \& Heyer, 2009). Rad55 und Rad57 unterstützen als Heterodimer möglicherweise die Stabilität bzw. Bildung des D-Loops, indem der Komplex sowohl ssDNA als auch Rad51 bindet (Johnson \& Symington, 1995).

Nach der Invasion wird das invadierte 3'-Ende verlängert, indem der komplementäre Strang des Schwestechromatids bzw. Homologen als template für eine DNA-Polymerase benutzt wird (Abb. $1 \mathrm{~A}$ iv und vi). Durch anschließendes Auflösen des D-Loops wird so ein 3'-Überhang generiert, welcher komplementär zum 3'-Überhang des zweiten Bruchstücks ist und mit diesem hybridisieren kann (Abb. $1 \mathrm{~A} \mathrm{v}$ ). Anschließend werden eventuell vorhandene Überhänge, welche aus dem Doppelstrang herausragen (flaps), durch eine flapEndonuklease entfernt sowie eventuell verbliebene Lücken durch eine DNA-Polymerase aufgefüllt. Die verbleibenden Einzelstrang-Bruchstellen werden durch eine DNA-Ligase ligiert, wodurch der Doppelstrangbruch repariert wird. Diese Form der Doppelstrangbruchreparatur wird als Synthesis Dependent Strand Annealing (SDSA) bezeichnet. Anstelle der direkten Auflösung des D-Loops kann jedoch auch der 3'-Überhang des zweiten Bruchstücks mit dem Schwesterchromatid oder dem Homologen hybridisieren (Abb. 1 A vi). Durch Verlängerung beider invadierter Enden werden zum einen größere komplementäre Überhänge generiert, welche das Hybridisieren erleichtern (Abb. 1 A, Pfeil von vi nach v), und zum anderen ist es möglich, dass eine doppelte Holliday-Junction entsteht, indem auch das 5'-Ende des zweiten Bruchstücks mit dem Schwesterchromatid bzw. Homologen hybridisiert (Abb. 1 A vii). Durch eine Resolvase (RuvABC in E. coli, Yen1 in S. cerevisiae) können die junctionss geschnitten werden (Abb. 1 A vii, angedeutet durch graue Keile), was je nach Schnittrichtung $\mathrm{zu}$ einem cross over oder einer Genkonversion führen kann 
(Abb. $1 \mathrm{~A}$ ix bis xii). Alternativ kann die doppelte Holliday-Junction durch branch migration in ein Hemikatenan umgewandelt werden (Abb. 1 viii), welcher durch eine Topoisomerase des Typs III aufgelöst werden kann (Wu \& Hickson, 2003). So können die Stränge ohne einen materiellen Austausch voneinander getrennt werden (Abb. 1 viii). Diese Form der Doppelstrangbruchreparatur wird als Double-Strand-Break-Repair bezeichnet (DSBR). Allerdings setzt sie das Vorhandensein von zwei Fragmenten voraus, welche wieder zusammengefügt werden können. Fehlt eines der Fragmente, bzw. ist es nicht zugänglich, so kann DSBR nicht stattfinden. In diesem Fall ist es jedoch möglich, nach der Invasion im Schwesterchromatid die Synthese an selbigem bis zum Ende des Chromosoms fortzuführen und somit das fehlende Fragment zu ersetzen, wie es in Abb. 2 dargestellt ist (für Details siehe auch „Reinitiation der Replikation an einer kollabierten Replikationsgabel“).

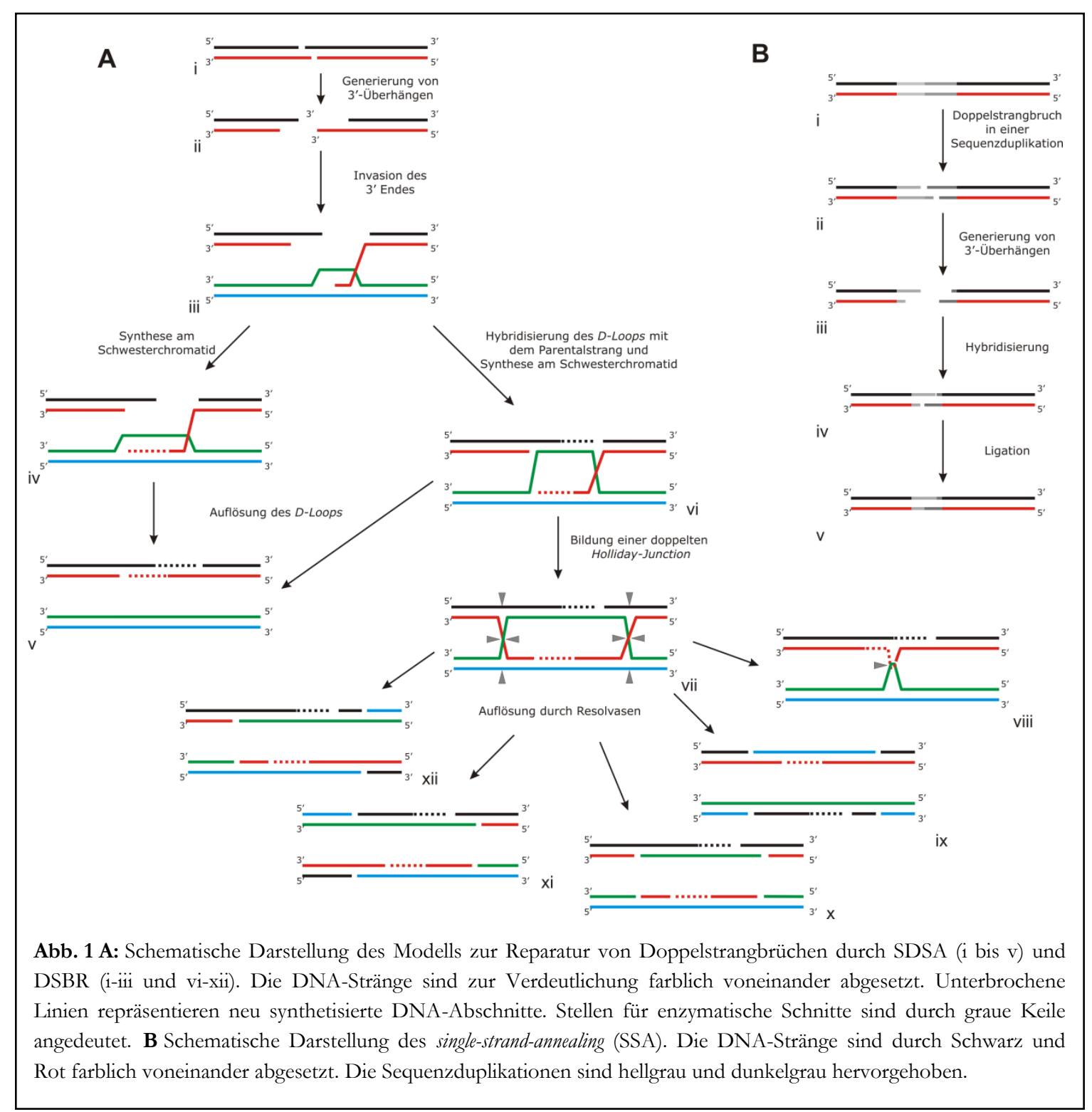




\section{EINLEITUNG}

Single-Strand-Annealing

Bei einem Doppelstrangbruch innerhalb oder zwischen zwei Sequenzduplikationen kann es durch das Generieren der 3'-Enden bereits zu komplementären Einzelstrangbereichen kommen (Abb. $1 \mathrm{~B}$ i bis iii). In diesem Fall ist eine Invasion in das Schwesterchromatid oder das Homologe nicht mehr notwendig. Die Überhänge können direkt hybridisieren. Anschließend werden nur noch eventuell vorhandene flaps entfernt bzw. Lücken aufgefüllt und die verbleibenden Einzelstrangunterbrechungen durch eine DNA-Ligase geschlossen (Abb. 1 B iv und v). Bei diesem als Single-Strand-Annealing (SSA) bezeichnetem Vorgang geht sowohl eine der Duplikationen als auch eine eventuell zwischen den Sequenzen liegender Bereich verloren. In Eukaryoten ist SSA abhängig von Rad52, welches vermutlich zunächst RPA von den Einzelstrangüberhängen verdrängt und anschließend die direkte Bindung komplementärer Einzelstränge fördert (Smith \& Rothstein, 1999). Da SSA Rad52abhängig ist, wird es als ein spezieller Fall der Reparatur von Doppelstrangbrüchen durch homologe Rekombination betrachtet.

\section{Non-Homologous-End-Joining}

Neben der Reparatur von Doppelstrangbrüchen über homologe Rekombination können solche Brüche auch direkt durch das Ligieren der Enden repariert werden. Dieser Vorgang wird als Non-Homologous-End-Joining (NHEJ) bezeichnet und wird vermutlich vor allem in höheren Eukaryoten benutzt (Jeggo, 1998). Neben dem MRX-Komplex (in Hefe) bzw. DNA-PK (in höheren Eukaryoten) sind hierbei die Proteine KU70 und KU80 beteiligt, welche die DNA-Ligase IV an die Bruchstelle rekrutieren (Yano et al., 2009). Bei der homologen Rekombination wird die Information zum korrekten Ligieren der Bruchstücke durch die Sequenz im Schwesterchromatid oder Homologen rekonstruiert. Beim NHEJ wird diese Information jedoch nicht abgefragt, so dass ein vergleichsweise hohes Potential besteht, durch NHEJ Fehler bei der Reparatur von Doppelstrangbrüchen zu erhalten.

\section{DNA-SCHÄDEN UND REPLIKATION}

Trotzdem die DNA-Schäden durch unterschiedliche Reparaturmechanismen effizient aus der DNA entfernt bzw. repariert werden können, kann es vorkommen, dass Schäden während der Replikation vorliegen und die Replikationsmaschinerie auf eine solche Läsion trifft. Je nach Art des Schadens kann dies unterschiedliche Konsequenzen wie bspw. eine Mutation zur Folge haben. Ein wesentliches Problem in Bezug auf die Replikation stellen vermutlich vor allem Einzelstrangbrüche, $A P$-sites und bulky adducts dar:

\section{Reinitiation der Replikation an einer kollabierten Replikationsgabel}

Existiert in dem Matrizenstrang ein Einzelstrangbruch, so fällt die DNA-Polymerase bei der Replikation am 5'-Ende vom template herunter (run off-Synthese), was, wie in Abb. 2 i dargestellt, in einem unvollständigen Chromosom mit Doppelstrangende resultiert. Im Gegensatz zu Doppelstrangbrüchen fehlt im Falle einer run off-Synthese jedoch das zweite Bruchstück, mit dem das unvollständige Chromosom wieder ligiert werden könnte. Um die Replikation in so einem Fall wieder starten zu können und das Fragment zu vervollständi- 
gen, können ebenfalls die Mechanismen der homologen Rekombination genutzt werden. Dazu wird wie bei einem Doppelstrangbruch zunächst ein 3'-Überhang generiert (Abb. 2 ii). Dieser kann in das Schwesterchromatid invadieren (Abb. 2 iv und vii), wodurch ein D-Loop entsteht, welcher anschließend an der Verzweigung zwischen Schwesterchromatid und invadiertem Chromatid geschnitten werden kann (Abb. 2 vii, angedeutet durch einen grauen Keil). Die durch den Schnitt entstehende Struktur ähnelt einer Replikationsgabel und ermöglicht somit vermutlich eine Reinitiation der zuvor kollabierten Replikation (Abb. 2 viii). Eine endonukleolytische Aktivität, wie sie für diesen Vorgang notwendig ist, konnte in vitro bereits für das Heterodimer Mus81/Mms4 aus S. cerevisiae gezeigt werden (Osman et al., 2003). Alternativ zu dem direkten Schneiden des D-Loops kann auch der verdrängte Strang mit dem 5'-Ende des unvollständigen Fragments hybridisieren, wodurch eine Holliday-Junction entsteht (Abb. 2 v). Diese junction kann anschließend über eine Resolvase geschnitten werden (Abb. 2 v), was ebenfalls zu einer Struktur führt, welche für die Reinitiation der Replikation geeignet ist (Abb. 2 vi; Krogh \& Symington, 2004).

(i)
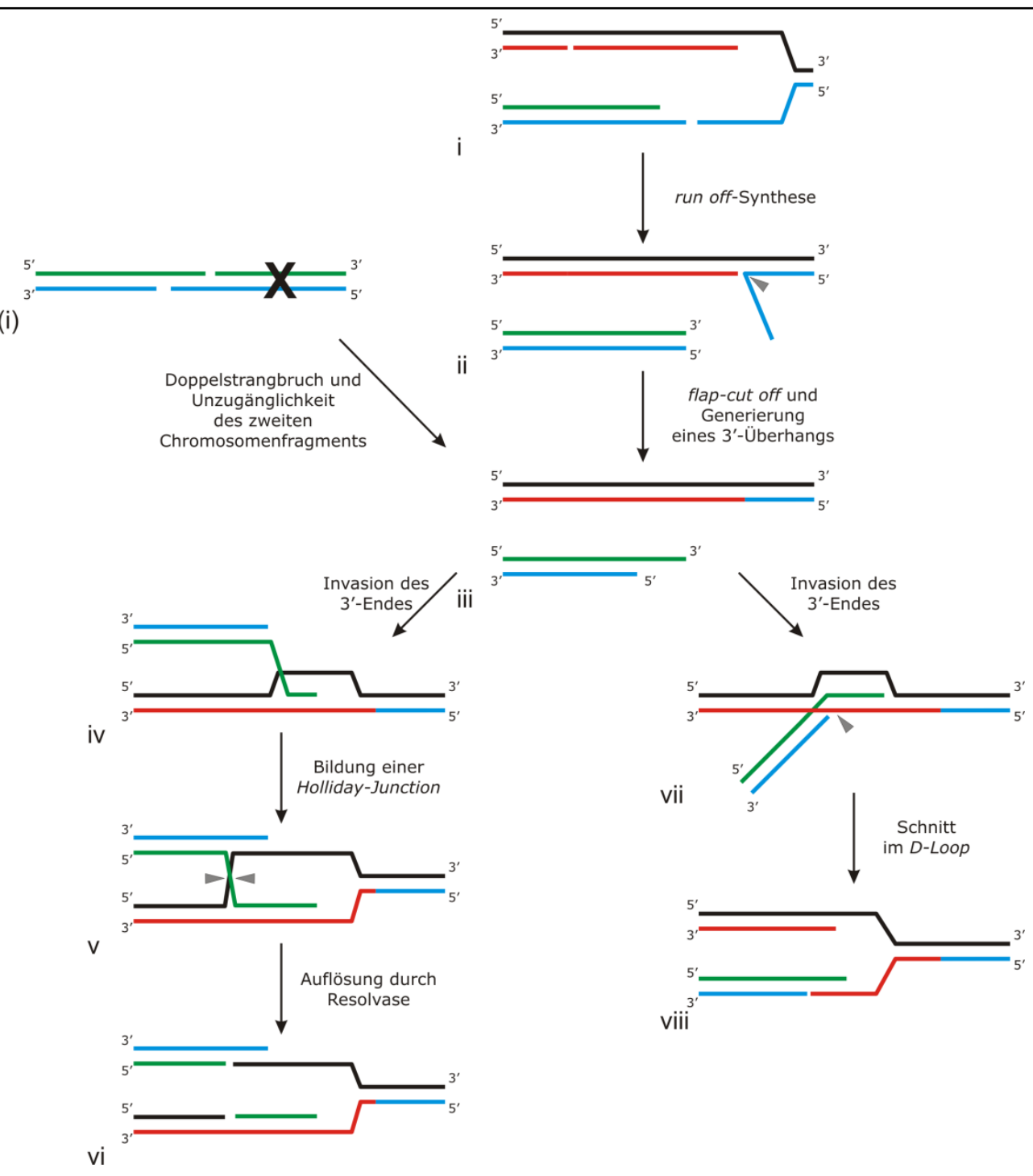

Abb. 2: Schematische Darstellung der Reparatur einer kollabierten Replikationsgabel nach run off-Synthese (i-viii) und Reparatur eines Doppelstrangbruchs ohne zweites Bruchstück (i)-viii). Die DNA-Stränge sind zur Verdeutlichung farblich voneinander abgesetzt. Stellen für enzymatische Schnitte sind durch graue Keile angedeutet. 


\section{EINLEITUNG}

\section{Replikationsarreste und Toleranzsysteme}

\section{Die Genauigkeit der Polymerasen kann zu Replikationsarresten führen}

DNA-Polymerasen „lesen“ den template-Strang und hängen an das 3'-Ende eines primers das komplementäre dNTP an. Die Wahl der richtigen Base geschieht dabei vermutlich durch eine geometrische Einpassung des Basenpaars in das aktive Zentrum der Polymerase: Die Katalyse der Esterbindung zwischen dem 5'-Phosphat des hereinkommenden dNTP's und dem 3'-OH des primer-Endes geschieht nur effizient, insofern beide Gruppen in korrekter Lage zueinander liegen (Kool, 2002). Bei einem fehlgepaarten Basenpaar ist die Geometrie verzerrt, so dass die beiden Basen nicht mehr korrekt in das Zentrum hineinpassen. Die Katalyse der Esterbindung kann daher, wenn überhaupt, in einem solchen Fall nur sehr ineffizient erfolgen. Somit werden korrekte Basenpaare gegenüber inkorrekten Basenpaaren aufgrund der Enzymkinetik bevorzugt (Kool, 2002). Die geometrische Anpassung des aktiven Zentrums wird dabei durch drei wesentliche Faktoren bestimmt: 1. Die Länge des korrekten Basenpaars wird durch Kollision der Basen bzw. des Rückgrats mit dem Protein direkt abgefragt. 2. Durch das vorletzte Nukleotid des primers wird gleichzeitig ein Ausweichen der Basen nach unten verhindert. 3. Das Ausweichen der Basen nach oben wird gleichzeitig durch einen aromatischen Rest in der O-Helix verhindert, welcher durch Stapel-Wechselwirkung mit dem hereinkommenden dNTP letzteres in die richtige Position zwingt (Tyrosin 526 in T7-Polymerase und Phenylalanin in Taq-Polymerase; Doublie et al., 1998; Li et al., 1998). Gleichzeitig wird durch diese Stapel-Wechselwirkung vermutlich die geschlossene Konformation der Polymerase stabilisiert. In dieser Konformation wird die Esterbildung vermutlich wahrscheinlicher, da ein in der O-Helix vorliegendes Lysin möglicherweise den nukleophilen Angriff des 3'-OH auf das $\alpha$-Phosphat des hereinkommenden dNTP's erleichtert, indem eine negative Ladung des Sauerstoffs im Übergangszustand stabilisiert wird. Bei fehlgepaarten Basen ist die Stapel-Wechselwirkung mit dem aromatischen Aminosäurerest geschwächt und die geschlossene Konformation daher nicht stabilisiert. Somit wird ebenfalls eine Katalyse bei inkorrekten Basenpaaren erschwert (Doublie et al., 1998; Li et al., 1998). Korrekte Wasserstoffbrückenbindungen zwischen den Basen spielen interessanterweise vermutlich nur eine untergeordnete Rolle bei der Erkennung und Selektion der korrekten dNTP's. Möglicherweise wird das Entfernen der Hydrathülle durch korrekte Wasserstoffbrücken erleichtert, indem die Ausbildung derselben den für die Entfernung des Wassers notwendigen Energiebetrag verringert (Kool, 2002).

Trotz dieser Mechanismen ist ein fehlerhafter Einbau nicht ausgeschlossen, sondern nur weniger wahrscheinlich als ein korrekter. Bspw. können Pyrimidinpaare leicht in das Zentrum eingepasst werden, da sie kürzer sind als ein korrektes Basenpaar. Einzig die Entfernung der Hydrathülle ist hierbei durch den Wegfall der Wasserstoffbrücken erschwert. Ebenfalls kann gegenüber einer $A P$-site leicht eine beliebige Base eingepasst werden, da hier komplett das Gegenstück fehlt. Zwar ist in beiden Fällen eine gewisse Beweglichkeit der Basen im aktiven Zentrum vorhanden, weshalb auch in diesen Fällen die Katalyse erschwert ist, dennoch kann solch ein fehlerhafter Einbau vermutlich durchaus gehäuft auftreten. Um diese Fehler zu beheben, werden falsch eingebaute dNMP's während der Replikation direkt durch die 3'-5'-Exonukleaseaktivität der replikativen DNA-Polymerasen wie- 
der entfernt. Das exonukleolytisch aktive Zentrum der DNA-Polymerasen befindet sich räumlich getrennt von dem synthetisch aktiven Zentrum. Wird das primer-Ende leicht vom template gelöst, kann es in das exonukleolytische Zentrum gelangen, in der das zuletzt eingebaute Nukleotid abgespalten wird (Kunkel, 1988). Dieser Vorgang wird als proof reading bezeichnet und wird durch fehlgepaarte Basen begünstigt. Durch eine Fehlpaarung wird die Stapel-Wechselwirkung des primer-Endes geschwächt, was das Ablösen erleichtert. Zusätzlich werden in der minor groove Wasserstoffbrücken zwischen den vorhergehenden Basenpaaren und der Polymerase gebildet. Bei fehlgepaarten Basen können diese jedoch an der betreffenden Stelle nicht mehr korrekt ausgebildet werden, was ebenfalls eine Destabilisierung des primer-Endes zur Folge hat (Doublie et al., 1998). Da gleichzeitig die Fehlpaarung am primer-Ende durch die inkorrekte Lage des 3'-OH's die nachfolgende Verlängerung erschwert, erhöht sich somit stark die Wahrscheinlichkeit, dass die zuletzt eingebaute Base in das Exonuklease-Zentrum gelangt und abgespalten wird. Durch das proof reading wird die Genauigkeit einer DNA-Polymerase um einen Faktor von ca. 100 verbessert (Kunkel, 1988).

Das Zusammenspiel dieser Mechanismen ermöglicht eine sehr hohe Genauigkeit der replikativen DNA-Polymerasen $\left(1 \times 10^{-5}\right.$ Fehler/bp ohne proof reading, mit 1x 10 $0^{-7}$ Kool, 2002; Kunkel, 1988). Gleichzeitig hat dies jedoch erhebliche Konsequenzen für die Replikation von DNA-Schäden. Trifft eine DNA-Polymerase bspw. auf ein bulky adduct, so kann dieses vermutlich nicht in die katalytische Tasche des Enzyms eingepasst werden. Die Katalyse kann daher nicht oder nur ineffizient erfolgen. Auch wenn ein Nukleotid gegenüber dem Schaden eingebaut wird, ist dennoch das primer-Ende nicht korrekt gepaart, was die weitere Verlängerung sehr erschwert. Durch das proof reading wird somit die zuletzt eingebaute Base wieder entfernt und es muss erneut gegenüber dem Schaden etwas eingebaut werden. Die Polymerase wird aus diesem Grund vermutlich an einem Schaden in der DNA, in einem permanenten Zyklus aus Einbau und darauf folgendem Ausschneiden einer Base regelrecht gefangen gehalten, was zu einem andauernden Replikationsarrest führt (Pages et al., 2005). Bei AP-sites stellt sich ein entsprechendes Problem. Zwar ist hierbei nicht die Base verzerrt, sondern komplett entfernt, aber auch dies kann die Verlängerung über die beschädigte Stelle hinaus erschweren und somit einen Arrest der Replikation hervorrufen. Gleichzeitig können solche DNA-Schäden nicht durch Exzisionsreparatur aus der DNA entfernt werden, da hierbei die beschädigten Nukleotide nicht in einem Doppel-, sondern in einem Einzelstrang vorliegen. Zwar kann eine direkte Schadensreversion prinzipiell auch in Einzelsträngen stattfinden, jedoch können hiermit nur einige wenige spezifische Schäden repariert werden. Es müssen daher andere Mechanismen genutzt werden, um Arreste aufzuheben und die DNA-Schäden zu umgehen. Drei gängige Modell hierzu, welche teilweise gut durch experimentelle Daten gestützt werden, sind die Umgehung des Schadens durch Transläsionssynthese, fork regression und homologe Rekombination. 


\section{EINLEITUNG}

\section{Schadensumgehung durch Transläsionssynthese (TLS)}

Da Replikationsarreste aufgrund der zuvor dargestellten Mechanismen entstehen, ist es möglich, einen Replikationsarrest zu umgehen, indem eine DNA-Polymerase genutzt wird, welche diese Mechanismen nicht oder in eingeschränkter Form aufweist. Sowohl in Eu- als auch Prokaryoten sind solche zur Transläsionssynthese fähigen DNA-Polymerasen bereits gefunden worden (Jarosz et al., 2007; Waters et al., 2009). Im Gegensatz zu den replikativen Polymerasen weisen diese Transläsionspolymerasen eine geringe Substratspezifität auf. Die katalytische Tasche ist weniger eng aufgebaut, was z.B. durch das Fehlen der O-Helix erreicht wird, und lässt somit auch eine Katalyse bei fehlgepaarten Basen bzw. beschädigter template-Base zu (Trincao et al., 2001). Ebenfalls fehlt den Transläsionspolymerasen die für das proof reading zuständige 3'-5'-Exonukleasedomäne. Ohne proof reading kommt es an einem beschädigten Nukleotid nicht wie bei replikativen Polymerasen zu einem Zyklus aus Baseneinbau und anschließendem Entfernen der Base. Sowohl die geringere Substratspezifität als auch der Verlust des proof readings führen dazu, dass Transläsionspolymerasen in der Lage sind, das primer-Ende über einen DNA-Schaden hinaus zu verlängern (Waters et al., 2009). Allerdings ist der Einbau gegenüber einer beschädigten Base tendenziell fehlerhaft, da die Information weiterhin nicht rekonstruiert und somit das korrekte komplementäre dNTP nicht ohne Weiteres selektiert werden kann. Gleichzeitig sind jedoch, wie unten ausgeführt, einige Transläsionspolymerasen in der Lage, gegenüber spezifischen DNASchäden präferentiell die korrekte komplementäre Base einzubauen und somit den Schaden fehlerfrei zu umgehen (Waters et al., 2009). Die verringerte Substratspezifität führt jedoch nicht nur zu einer erhöhten Fehlerrate gegenüber der Läsion, sondern gleichzeitig auch zu einem Verlust der Genauigkeit gegenüber unbeschädigten Basen. Während die replikativen Polymerasen mit proof reading auf unbeschädigtem template eine Fehlerrate von etwa $1 \times 10^{-7}$ Fehlern/bp aufweisen, haben Transläsionspolymerasen eine Fehlerrate zwischen $1 \times 10^{-4}$ und $1 \times 10^{-1}$ Fehlern/bp (Kool, 2002). Gleichzeitig sind Transläsionspolymerasen um ein Vielfaches weniger prozessiv als die replikativen DNA-Polymerasen, was vermutlich notwendig ist, um einer erhöhten Mutationsrate auf unbeschädigtem template vorzubeugen.

Die meisten Transläsionspolymerasen gehören zu der Y- oder X-Familie der Polymerasen (Ausnahme: Pol $\zeta$, siehe unten; Goodman, 2002; Waters et al., 2009). In Bakterien sind drei Transläsionspolymerasen bekannt (PolII, PolIV und PolV), welche in E. coli über die SOSAntwort reguliert sind (Goodman, 2002; Janion, 2008). In Eukaryoten sind bisher acht solcher DNA-Polymerasen gefunden worden: Pol $\zeta$, Pol $\kappa$, Pol $\eta$, Pol $\iota$, Pol $\sigma$, Pol $\mu$, Pol $\lambda$ und Rev1 (Waters et al., 2009). In der Bäckerhefe existieren von diesen acht jedoch nur Pol $\zeta$, Pol $\eta$ und Rev1. Da sich die vorliegende Arbeit mit den Vorgängen in S. cerevisiae befasst, sollen im Folgenden nur die drei in Hefe vorkommenden an der TLS beteiligten Enzyme vorgestellt werden: 


\section{Polymerase $\eta$}

Polymerase $\eta$ wird in Hefe durch $\mathrm{R} A D 30$ codiert und ist in Hefe die einzige derzeit bekannte Transläsionspolymerase. Sie kann spezifisch Cyclobutanthymindimere korrekt überlesen (Johnson et al., 1999). Des Weiteren kann sie eine Vielzahl anderer Schäden fehlerbehaftet überlesen, darunter 8-Oxo-Gunain und O6-Methylguanin (Haracska et al., 2000a; Haracska et al., 2000b) sowie möglicherweise Benzo(a)pyren-Addukte (Zhang et al., 2000). Gleichzeitig weist sie eine sehr geringe Genauigkeit gegenüber unbeschädigtem template auf (Kool, 2002; Waters et al., 2009). Interessanterweise zeigen Mutanten von RAD30 in vivo kaum eine Reduktion der Mutationsrate (Roush et al., 1998), was möglicherweise auf den spezifischen Einsatz von Rad30 bei bestimmten DNA-Schäden zurückzuführen ist. Die Transkription von RAD30 ist vermutlich UV-induziert (Roush et al., 1998) und rad30Zellen zeigen eine deutliche Sensitivität gegenüber UV-Strahlung (Gangavarapu et al., 2007), weshalb vermutet wird, dass Rad30 ein wichtiger Bestandteil der Umgehung von UV-Schäden ist. (Haracska et al., 2001)

\section{Polymerase $\zeta$}

Pol $\zeta$ ist ein Heterodimer, bestehend aus Rev3 und Rev7. Sowohl rev3-als auch rev7-Mutanten weisen eine stark reduzierte Mutationsrate auf und Mutatorphänotypen, beruhend auf dem Ausfall fehlerfreier Mechanismen, lassen sich durch Mutationen im REV3 oder REV7 vollständig supprimieren (Schürer, 2003; Zhong et al., 2006). Aus diesem Grund wird für Pol $\zeta$ eine Beteiligung an der Transläsionssynthese angenommen. Dennoch stellt Pol $\zeta$ keine Transläsionspolymerase im engeren Sinne dar. Sie gehört wie die replikativen Polymerasen zur B-Familie der DNA-Polymerasen (Morrison et al., 1989), allerdings fehlt die für das proof reading notwendige 3'-5'-Exonukleasedomäne (Lawrence, 2004). Vermutlich ist die Hauptfunktion von Pol $\zeta$ die Verlängerung von fehlgepaarten primer-Enden, wie sie beim Einbau eines Nukleotids gegenüber einer beschädigten Base bspw. durch Rad30 entstehen können. Transläsionspolymerasen wie pol $\eta$ sind dazu vermutlich nicht oder nur sehr ineffizient in der Lage, da zwar eine Base gegenüber der Läsion eingebaut wird, aber anschließend dennoch das primer-Ende fehlgepaarte Basen aufweist und die Verlängerung so erschwert wird. Pol $\zeta$ ist dagegen vermutlich zu einer solchen Verlängerung in der Lage und daher auch für die Entstehung von Mutationen über TLS notwendig (Haracska et al., 2001).

\section{Desoxycyctidyltransferase Rev1}

Rev1 ist im Gegensatz zu Pol $\zeta$ und Pol $\eta$ keine Polymerase im eigentlichen Sinne, da sie nicht zu einer kontinuierlichen Synthese am template in der Lage ist. Jedoch baut sie gegenüber Guanin, chemisch modifiziertem Guanin sowie gegenüber AP-sites Cytosin ein. Dabei wird das Guanin im template aus der katalytischen Tasche des Enzyms durch ein Arginin verdrängt, welches anstelle des Guanins mit dem hereinkommenden dCTP paart (Nair et al., 2005). Im Falle von AP-sites bauen andere DNA-Polymerasen präferentiell Adenin ein, was vermutlich auf die höhere Stapelwechselwirkung von Adenin im Vergleich zu den anderen Basen zurückzuführen ist (Goodman et al., 1994). Da jedoch die hydrolytische Depu- 


\section{EINLEITUNG}

rinierung von Gunain möglicherweise eine der Hauptquellen für $A P$-sites in vivo ist, stellt der Einbau von Cytosin gegenüber einer $A P$-site vermutlich in den meisten Fällen eine fehlerfreie Umgehung des Schadens dar (Lindahl \& Nyberg, 1972; Wyatt \& Pittman, 2006). Zusätzlich zu der Funktion als Desoxycytidyltransferase ist Rev1 vermutlich auch regulativ bei der Transläsionssynthese beteiligt. Bspw. ist Rev1 unter anderem für eine effiziente Umgehung von 6-4-Thymindimeren notwendig, obwohl es selbst nicht in der Lage ist, solche Schäden zu umgehen (Nelson et al., 2000). In Hefe kann Rev1 sowohl mit Pol $\eta$ als auch mit Pol $\zeta$ interagieren (Acharya et al., 2005; Acharya et al., 2007) und für Rev1 aus Maus wurde postuliert, dass es vor allem andere an der Transläsionssynthese beteiligte Faktoren an DNA-Schäden rekrutiert (Guo et al., 2003). Möglicherweise hat Rev1 daher in Hefe neben der Funktion als spezifische Transläsionspolymerase auch Anteil an der Regulation der Transläsionssynthese (Waters et al., 2009).

\section{Schadensumgehung durch fork regression}

Eine weitere Möglichkeit den Schaden zu umgehen ist das Benutzen einer alternativen und unbeschädigten Informationsquelle. Eine solche Quelle ist prinzipiell das sequenzidentische Schwesterchromatid. Während der Replikation werden die beiden Parentalstränge voneinander getrennt und an jedem Strang wird mehr oder weniger unabhängig vom jeweils anderen der komplementäre Strang durch eine DNA-Polymerase synthetisiert. Zwar sind die DNA-Polymerasen vermutlich über einen Proteinkomplex verbunden (Pomerantz \& O'Donnell, 2007), dennoch kann wahrscheinlich der leading-strand auch bei einem Arrest der lagging-strand-Polymerase, bzw. der lagging-strand bei einem Arrest der leading-strand-Synthese zumindest begrenzt weitersynthetisiert werden (Pages \& Fuchs, 2003). Aus diesem Grund liegt die benötigte Information für eine korrekte Umgehung im Schwesterchromatid in einem Doppelstrang und damit auch in einem komplementären Strang vor. Dieser Strang kann somit prinzipiell als alternatives template genutzt werden, um den in der Synthese arretierten Strang zu verlängern. Ein Modell der Mechanismen, mit denen die Information vom Schwesterchromatid abgefragt werden kann, ist in Abb. 4 dargestellt. Als erster Schritt würde die Replikationsgabel, wie in Abb. 4 ii gezeigt, rückwärtig geschlossen werden. Dabei rehybridisieren sowohl die Parental- als auch die Filialstränge jeweils miteinander und es entsteht eine Holliday-Junction-ähnliche Struktur, welche in der Literatur oft als „Chicken Foot“ bezeichnet wird (Higgins et al., 1976). Ist der komplementäre Strang des Schwesterchromatids über die Stelle mit der beschädigten Sequenz hinaus verlängert, so kann das 3'-Ende des in der Synthese arretierten Stranges mit dem Schwesterstrang als Matrize verlängert werden (Abb. 4 iii). Durch anschließende branch migration kann der Chicken Foot wieder aufgelöst werden und die resultierende Struktur kann zur Reinitiation der Replikation dienen. Da das 3'-Ende so über den Schaden hinaus verlängert wurde, kann die Replikation hinter dem Schaden erneut einsetzen und der Schaden wurde fehlerfrei umgangen (Abb. 4 (iv)). Ebenfalls ist es möglich, dass der Schaden im Chicken Foot durch NER oder BER entfernt wird, da hier der Schaden wieder in einem Doppelstrang vorliegt. Da es sich bei dem Chicken Foot im Prinzip um eine Holliday-Junction handelt, ist es auch denkbar, dass dieser durch eine Resolvase geschnitten wird (Abb. 4 iv). Somit entstehen ähnlich wie bei einer run off-Synthese ein intaktes Chromosom sowie ein unvollständiges Chromo- 
somenfragment (Abb. $4 \mathrm{v}$ und vi), welches anschließend über homologe Rekombination repariert werden kann, wie es in Abb. 2 dargestellt ist. Auch hierbei wurde jedoch der Strang am Schwesterchromatid möglicherweise bereits verlängert, weshalb der Schaden fehlerfrei umgangen werden kann. Eine weitere Möglichkeit ist die direkte Invasion des 3'Endes vom Chicken Foot aus in den homologen Doppelstrangbereich der Parentalstränge (Abb. 4 vii). Wird der Chicken Foot anschließend, wie in Abb. 4 vii dargestellt, durch eine Resolvase geschnitten, entsteht direkt eine der Replikationsgabel ähnelnde Struktur, in der der Schaden ebenfalls umgangen ist (Abb. 4 viii). Fork regression an einem Replikationsarrest kann demnach die fehlerfreie Umgehung eines replikationsarretierenden DNA-Schadens ermöglichen. Allerdings wurden bisher kaum experimentell Evidenzen für dieses Modell gefunden. Zwar wird für RecG aus E. coli und dem menschlichen BLM postuliert, dass sie eine solche fork regression katalysieren können (Machwe et al., 2006; McGlynn \& Lloyd, 2000) und auch für Rad5 aus S. cerevisiae konnte eine solche Aktivität biochemisch gezeigt werden (Blastyak et al., 2007), allerdings fehlen bisher in vivo-Daten, welche die biologische Relevanz dieser Aktivität bestätigen können.

\section{Schadensumgehung durch homologe Rekombination (HR)}

Eine weitere Möglichkeit, die unbeschädigte Information des Schwesterchromatids abzufragen, ist eine Interaktion durch homologe Rekombination. Wie bereits bei der Reparatur von Doppelstrangbrüchen vorgestellt, können freie 3'-Enden mithilfe einer Rekombinase in Doppelstrangregionen mit homologer Sequenz invadieren, wodurch ein D-Loop entsteht. Durch anschließende Synthese am Schwesterchromatid kann über die Bruchstelle hinweg verlängert werden, was das Schließen der Bruchstelle ermöglicht (siehe „Reparatur von Doppelstrangbrüchen"). Über diese Mechanismen ist es ebenfalls möglich, replikationsarretierende DNA-Schäden zu umgehen. Zwei gängige Modelle hierfür sind denkbar und sollen im Folgenden näher beschrieben werden: Die Umgehung des Schadens durch gapfilling (Abb. 3) und die Reinitiation einer arretierten Replikationsgabel (Abb. 4).

Das gap-filling-Modell

Bei einem Arrest der lagging-strand-Synthese ist zwar die Synthese über den Schaden hinaus nicht möglich, dennoch ist die Replikation insgesamt vermutlich nicht gefährdet, da nach einiger Zeit unabhängig von der Läsion ein neuer Primer synthetisiert wird und somit die Synthese am lagging-strand weiterlaufen kann (Gardner et al., 1991). Übrig bleibt anschlieBend eine Einzelstranglücke hinter dem beschädigten Nukleotid, wie in Abb. 3 A i und ii angedeutet. Um diese Lücke zu füllen, kann zum einen eine Transläsionspolymerase, oder zum anderen die Information vom Schwesterchromatid genutzt werden. Dazu wird das 3'Ende des unvollständigen Stranges vom template abgelöst, was spontan oder durch eine Helikase geschehen kann. Anschließend folgt eine Invasion des 3'-Endes in die homologe Sequenz des Schwesterchromatids, wie in Abb. 3 A iii dargestellt. Durch die Synthese mit dem Schwesterchromatid als unbeschädigtes template kann das primer-Ende über den Schaden hinaus verlängert werden (Abb. 3 A iv). Der D-Loop wird aufgelöst und der Schaden ist somit fehlerfrei umgangen (Abb. 3 A v). Durch die Synthese am Schwesterchromatid wird das Ende jedoch vermutlich nicht exakt um die Nukleotide verlängert, welche in der Einzelstranglücke noch fehlen. Vielmehr ist es wahrscheinlich, dass das resultierende 3'-Ende 


\section{EINLEITUNG}

zu lang oder zu kurz geraten ist. In letzterem Fall kann die Lücke anschließend einfach durch eine Polymerase aufgefüllt werden. Ist das Fragment zu lang, kann der Überhang durch eine flap-Endonuklease abgeschnitten werden (Abb. $3 \mathrm{Av}$ ). Abschließend wird die noch verbleibende Einzelstrangunterbrechung durch eine Ligase geschlossen. Alternativ zu dem direkten Auflösen des D-Loops kann es auch zur Entstehung einer doppelten HollidayJunction kommen, wie in Abb. 3 (v) dargestellt. Durch einen Schnitt derselben durch Resolvasen entsteht eine Struktur, in welcher der Schaden ebenfalls umgangen ist (vergleiche Abb. 3 (v) und Abb. 1 A ix bis xii). Alternativ zu der Invasion des 3' Endes ins Schwesterchromatid kann auch prinzipiell der hinter dem Schaden entstandene Einzelstrangbereich für eine Invasion genutzt werden. In E. coli sind für die Besetzung eines solchen Einzelstrangbereichs mit RecA die Proteine RecF, RecO und RecR notwendig (Morimatsu \& Kowalczykowski, 2003). Für Hefe wird bisher jedoch für gängige Modelle zur Invasion im Schwesterchromatid oder Homologen eher eine Invasion des 3'-Endes angenommen (Krogh \& Symington, 2004).

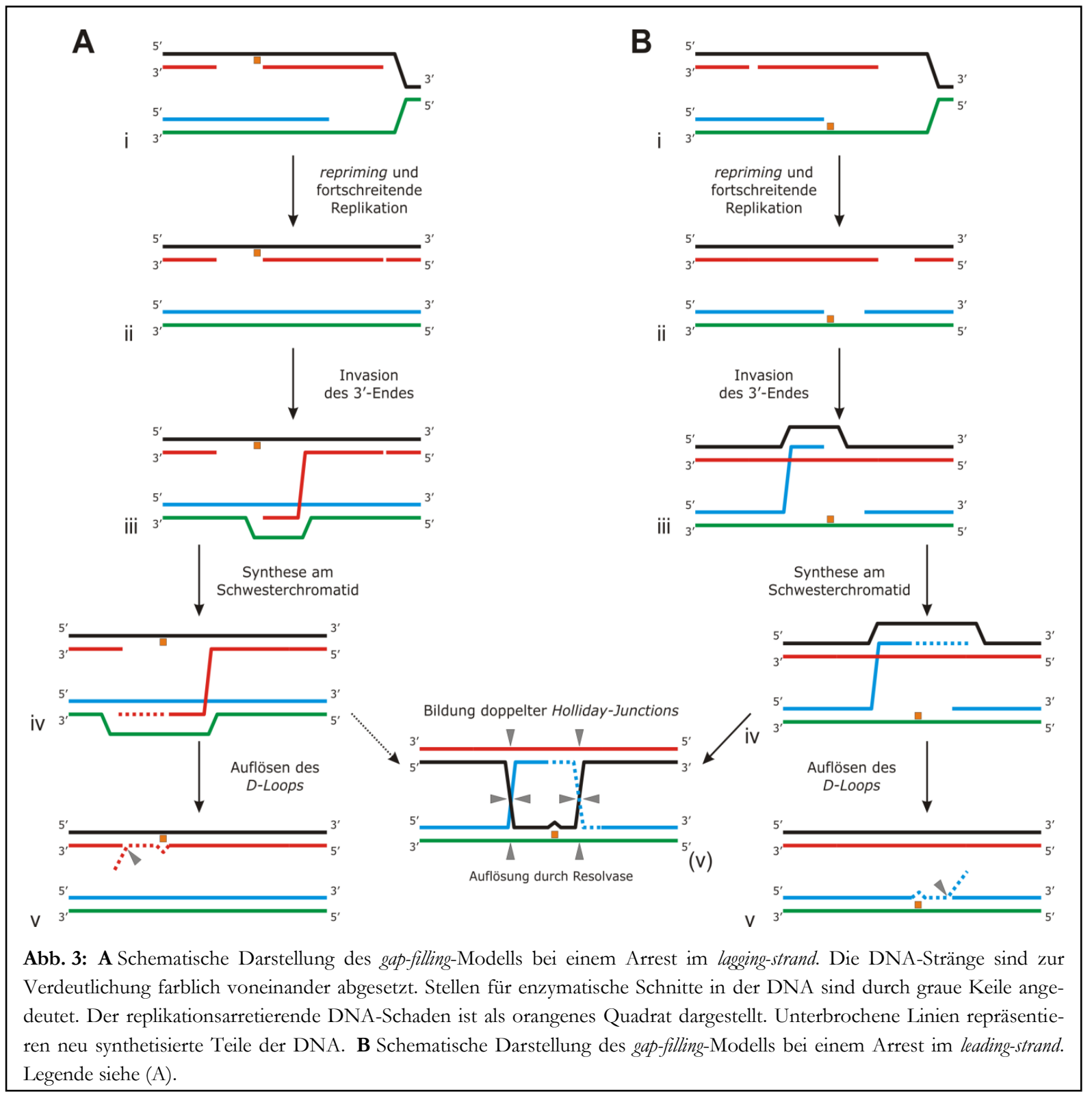


Im Wesentlichen ist eine Umgehung von replikationsarretierenden DNA-Schäden nach diesem Modell vor allem im lagging-strand möglich, da hier in regelmäßigen Abständen ein neuer primer synthetisiert wird. Im leading-strand dagegen ist ein erneutes priming nach der Replikationsinitiation eigentlich unnötig, da immer ein primer-Ende zugänglich ist. In E. coli konnte jedoch gezeigt werden, dass eine in vitro assemblierte Replikationsmaschinerie auch nach einem Arrest auf dem leading-strand die Synthese wieder aufnehmen kann (Heller \& Marians, 2006). Es wäre daher durchaus möglich, dass auch im Falle eines Arrests der leading-strand-Synthese ein weiterer primer hinter einem Schaden synthetisiert wird und die Replikation hier wieder aufgenommen wird. Unterstützt wird dies zusätzlich durch elektronenmikroskopische Aufnahmen von Hefe-DNA aus NER-defekten Mutanten. Hierbei konnten sowohl im leading- als auch im lagging-strand Einzelstranglücken gefunden werden, wie sie bei einer Wiederaufnahme durch repriming downstream des Schadens entstünden. Nach Bestrahlung der Zellen mit UV-Licht, nahm die Anzahl solcher Lücken zu. Diese Daten machen es daher plausibel, dass in vivo auch ein repriming des leading-strands hinter einem DNA-Schaden stattfinden kann. In einem solchen Fall wäre der für den lagging-strand dargestellte Mechanismus auch für einen Arrest im leading-strand denkbar (Abb. 3 B).

\section{Reinitiation einer arretierten Replikationsgabel durch homologe Rekombination}

Wie zuvor dargelegt, gibt es Evidenzen, dass die für das gap-filling-Modell vorgestellten Mechanismen möglicherweise auch bei einem Arrest im leading-strand relevant sind. Jedoch ist derzeit nicht völlig klar, inwiefern repriming im leading strand in vivo relevant ist und unter welchen Umständen es einsetzt. Zumindest für den leading-strand ist es daher durchaus möglich, dass ein alternativer primer nicht immer vorhanden ist und ein replikationsarretierender DNA-Schaden somit direkt umgangen werden muss. Prinzipiell kann dies über homologe Rekombination mit dem Schwesterchromatid stattfinden, wie in Abb. 4 dargestellt. Dabei invadiert wie auch im vorherigen Modell das 3'-Ende des in der Synthese arretierten Stranges an homologer Stelle in das Schwesterchromatid (Abb. 4 ii'). Anschließend wird das 3'Ende am Schwesterchromatid verlängert, wobei der Strang über den Schaden im ursprünglichen template hinaus synthetisiert wird (Abb. 4 iii'). Durch Auflösen des D-Loop (bspw. durch eine Helikase) kann so der Schaden umgangen werden und es entsteht eine Struktur, an der die Replikation reinitiiert werden kann (Abb. 4 iv'). Alternativ zu einer direkten Auflösung des D-Loop kann die Struktur auf unterschiedliche Art weiter prozessiert werden. Z.B. kann die Synthese am Schwesterchromatid bis zum 5'-Ende des Okazakifragments andauern. In diesem Fall können die Parentalstränge teilweise rehybridisieren und es entsteht ein Chicken Foot (Abb. 4 [iv] und iv), welcher entsprechend der Struktur, welche durch fork regression entsteht, aufgelöst werden kann (Abb. 4 iv bis vi). Als weitere Alternative kann der im D-Loop verdrängte Parentalstrang mit dem beschädigten template-Strang hybridisieren. Hybridisiert zusätzlich das 3'-Ende des invadierten Stranges wieder mit dem ursprünglichen template, so kommt es zur Ausbildung einer doppelten Holliday-Junction (Abb. 4 v'). Diese kann wiederum auf unterschiedliche Art aufgelöst werden. Zum einen können Resolvasen die junctionss schneiden, was je nach Schnittrichtung zu einem cross over oder einer Genkonversion führen kann (Abb. 4 v', vii' und viii'). Zum anderen können die junctions durch branch migration zu einem Hemikatenan prozessiert werden, welcher durch eine To- 


\section{EINLEITUNG}

poisomerase auflösbar ist (Abb. 4 ix’). Dieser Prozess wird als Holliday-Junction-dissolution bezeichnet und in Hefe ist hierfür vermutlich die Zusammenarbeit von Sgs1 und Top3 nötig, wobei Sgs1 für die branch migration verantwortlich ist, während Top3 den Hemikatenan auflöst. Für das Sgs1 Homologe BLM und Topoisomerase 3 konnte dies bereits sowohl im Menschen als auch in Drosophila gezeigt werden (Plank et al., 2006; Wu \& Hickson, 2003). Durch branch migration beider junctions in Richtung der Replikationsgabel können diese jedoch auch direkt aufgelöst werden (Abb. 4 v'nach vi). Unabhängig davon wie die doppelten Holliday-Junctions aufgelöst werden, kann jedoch in jedem Fall eine DNA-Struktur resultieren, an der eine Reinitiation der Replikation möglich ist.

Zwar sind die hier vorgestellten Mechanismen nur Modelle, jedoch machen es die Sensitivität von rad51- und rad52-Mutanten gegenüber UV und den DNA-schädigenden Agenzien MMS und 4-NQO sehr wahrscheinlich, dass eine Umgehung von replikationsarretierenden DNA-Schäden durch homologe Rekombination in vivo durchaus stattfindet. Darüber hinaus weisen rad51- und rad52-Mutanten einen Rev3-abhängigen Mutatorphänotyp auf. Dieser beruht wahrscheinlich auf dem Wegfall der fehlerfreien Umgehung von replikationsarretierenden DNA-Schäden und der damit einhergehenden Häufung von Transläsionssynthese.

\section{Der Ausfall von Reparatur- oder Toleranzsystemen kann fatale Konse- quenzen für einen Organismus haben}

Wie wichtig die zuvor vorgestellten Reparatur- und Toleranzsysteme für die Überlebensfähigkeit eines Organismus sind, lässt sich an vielen Beispielen zeigen. Der Ausfall der Nukleotidexzisionsreparatur bspw. führt beim Menschen unter anderem zu Xeroderma pigmentosum. Patienten mit dieser Krankheit weisen eine extreme Sensitivität gegenüber UV-Licht, ein erhöhtes Hautkrebsrisiko und teilweise neurodegenerative Symptome auf (Tanaka \& Wood, 1994). Auch der Ausfall von Pol $\eta$ führt zu einem sehr ähnlichen, wenn auch schwächer ausgeprägten Krankheitsbild: der Xeroderma pigmentosum variant (XPV; Cordonnier \& Fuchs, 1999). Mutationen im ATM-Gen führen im Menschen zum Louis-BarSyndrom. Patienten mit diesem Syndrom weisen ein erhöhtes Krebsrisiko sowie neurodegenerative Defekte auf und sind sensitiv gegen ionisierende Strahlung (Canman \& Lim, 1998). ATM ist ein Protein, welches an der Regulation der zellulären Antwort auf DNASchäden beteiligt ist (Branzei \& Foiani, 2008). Die Gene BRCA1 und BRCA2 gelten als Determinanten für Brustkrebs (Futreal et al., 1994; Miki et al., 1994; Wooster et al., 1995). Beide Gene sind vermutlich an der Reparatur von DNA-Schäden durch homologe Rekombination beteiligt (Branzei \& Foiani, 2008). Weitere Beispiele für Krankheiten, welche mit an der DNA-Reparatur beteiligten Proteinen assoziiert sind, sind das Bloom-Syndrom (BLM), Werner-Syndrom (WRN) und die Fanconi Anämie (FANC-Komplementationsgruppe German, 1993; Gurtan \& D'Andrea, 2006; Yu et al., 1996). Zu den Symptomen dieser Krankheiten gehören angeborene Deformationen, ein erhöhtes 


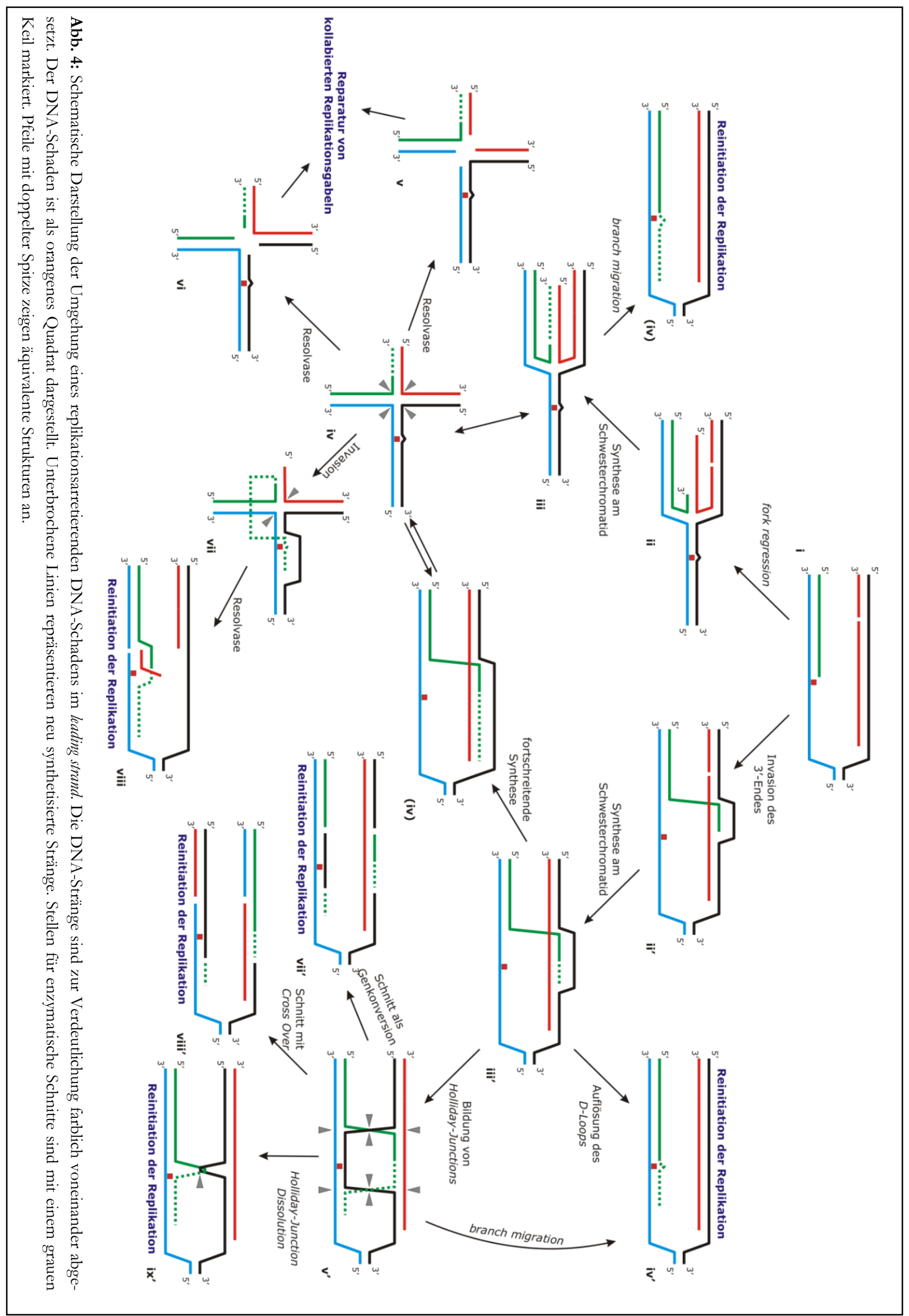




\section{EINLEITUNG}

Krebsrisiko sowie degenerative Defekte. Auch in anderen Organismen kann der Ausfall der Reparatur- und Toleranzsysteme fatale Konsequenzen haben. In Mäusen führt ein knock out von RAD51 und REV3 zu einer embryonalen Letalität (Lim \& Hasty, 1996; Wittschieben et al., 2006). Dasselbe gilt für Gene des MRN-Komplexes (Luo et al., 1999; Xiao \& Weaver, 1997). Diese Beispiele verdeutlichen, wie wichtig der Erhalt der genetischen Integrität durch Reparatur- und Toleranzsysteme ist.

\section{REGULATION DER TOLERANZSYSTEME}

Obwohl die vorgestellten Mechanismen zur Umgehung von replikationsarretierenden DNA-Schäden notwendig sind und ein Ausfall gravierende Folgen haben kann, ist der Einsatz solcher Mechanismen nicht ohne Risiko. Transläsionspolymerasen weisen eine geringere Genauigkeit auf und ihr Einsatz erhöht somit das Risiko, Punktmutationen zu erhalten. Der Einsatz von Transläsionspolymerasen sollte daher möglichst auf das notwendigste beschränkt sein und nicht auf unbeschädigtem template erfolgen. Andernfalls wäre die Konsequenz eine erhöhte Mutationsrate. Auch homologe Rekombination kann nachteilig für eine Zelle sein. Bei Prokaryoten mit ringförmigen Chromosomen kann bspw. ein cross over zwischen Schwesterchromatiden zu Konkatameren führen, welche bei der Zellteilung nicht ohne Weiteres auf zwei Zellen aufgeteilt werden können. Aber auch für die Chromosomen in Eukaryoten kann ein ähnlicher Effekt problematisch sein. Werden Holliday-Junctions nicht aufgelöst, bevor die Chromatiden bei der Mitose voneinander getrennt werden, so können auch diese möglicherweise durch den Spindelapparat zerrissen werden. Das vermutlich größte Problem jedoch besteht bei repetitiven Sequenzen. Durch homologe Rekombination zwischen diesen Sequenzen kann es zu der Vervielfachung der Sequenz oder dem Verlust einer oder mehrerer Kopien kommen (Näheres hierzu ist im Kapitel „Untersuchungen zur Entstehung von Reversionsereignissen im KanKanMX4-Modul“ zu finden). Die Anzahl solcher Sequenzen kann daher stark variieren, weshalb häufig im Chromosom auftretende Sequenzen, wie bspw. die für die rRNA codierenden Bereiche, eine gewisse Instabilität aufweisen (Kobayashi \& Horiuchi, 1996). Durch unkontrollierte Rekombination innerhalb solcher Regionen wäre die Anzahl der repetitiven Sequenzen daher einer starken Schwankung unterworfen. Ein ebenfalls großes Problem besteht bei diploiden Organismen. Hier liegen Genabschnitte teilweise heterozygot vor. Durch Rekombination zwischen den homologen Chromosomen in diesen Bereichen kann es infolge eines cross over oder einer Genkonversion zum Verlust der Heterozygotie kommen, was unter anderem als eine mögliche Ursache für die Entstehung von Krebs vermutet wird (Lasko et al., 1991; Wijnhoven et al., 2001).

\section{SOS-Antwort in Prokaryoten}

Es erscheint daher sinnvoll, dass sowohl homologe Rekombination als auch Transläsionssynthese in ihrer Aktivität reguliert werden. In Prokaryoten wird dies vermutlich über die SOS-Antwort erreicht. Reguliert wird diese im Wesentlichen durch die Aktivierung von RecA (RecA*) durch Bindung an ssDNA-Bereiche und die anschließende RecA*-beschleunigte autolytische Spaltung des LexA-Repressors, welcher eine Vielzahl an Genen zur Um- 
gehung und Reparatur von DNA-Schäden reprimiert. Unter anderem werden so die zwei Untereinheiten der Transläsionspolymerase PolV (UmuD und UmuC) in Reaktion auf vermehrt auftretende DNA-Schäden gebildet. Zusätzlich wird die Untereinheit UmuD zunächst autolytisch gespalten, wodurch UmuD' entsteht. Erst zwei UmuD' und ein UmuC bilden die aktive PolV. Auf diese Weise wird der Einsatz der potentiell mutagenen Transläsionspolymerase hinausgezögert: Bis zum Auftreten des aktiven Komplexes dauert es in etwa 45 Min. (Goodman, 2002). Neben PolV wird noch eine Vielzahl weiterer Gene durch die SOS-Antwort reguliert, unter anderem Gene für die NER, BER, den Abschluss des Zellzyklus und für homologe Rekombination (Courcelle et al., 2001; Friedberg et al., 2006).

\section{Regulation des Zellzyklus in Eukaryoten: DNA-Damage-Checkpoint}

Während die Regulation der zellulären Antwort auf DNA-Schäden durch die SOS-Antwort in Prokaryoten bereits sehr gut untersucht und verstanden ist, ist das Wissen über die Regulation in Eukaryoten teilweise noch sehr lückenhaft. Im Folgenden soll ein kurzer Abriss über das bisherige Modell zur Regulation der eukaryotischen Schadensantwort erfolgen:

Ein wichtiger Aspekt bei dem vermehrten Auftreten von DNA-Schäden in einer Zelle ist das Verlangsamen oder Aufhalten des Zellzyklus und der Synthese. Dies geschieht über den DNA-damage-checkpoint, welcher in drei Sub-checkpoints unterteilt wird: den G1-, den Sund den G2/M-checkpoint. Durch den G1-checkpoint wird die Initiation der Synthesephase aufgehalten, wodurch vorhandene Schäden durch NER etc. repariert werden können, bevor die Replikation beginnt und es zu einem Replikationsarrest kommen kann. Durch den S-checkpoint wird die Synthesephase verlängert, indem die Replikationsinitiation an spät induzierten ARS unterdrückt wird. Vermutlich dient dies dazu, das Zeitfenster für die Reparatur bzw. Umgehung von DNA-Schäden zu vergrößern. Durch den G2/M-checkpoint wiederum wird die Zellteilung verhindert, vermutlich damit zunächst verbleibende Replikationsarreste aufgehoben werden können und die DNA-Synthese vervollständigt wird, bevor die Teilung stattfindet (Budzowska \& Kanaar, 2009; Zegerman \& Diffley, 2009). Darüber hinaus wird durch den DNA-damage-checkpoint die Transkription von Genen sowie die Aktivität von Proteinen gesteuert, welche zur Reparatur oder Umgehung von DNA-Schäden notwendig sind (Bashkirov et al., 2000; Zegerman \& Diffley, 2009).

Initiiert wird der DNA-damage-checkpoint wahrscheinlich über die Bindung der 9-1-1-slidingclamp (Rad1, Rad9, Hus1 in Menschen, Budzowska \& Kanaar, 2009; Rad17, Mec3, Ddc1 in Bäckerhefe Majka \& Burgers, 2003) an Einzelstranglücken, wie sie bspw. hinter einem Replikationsarrest entstehen. Unterstützt wird dies unter anderem über den sliding-clamp-loader Rad17 (Rad24 in Bäckerhefe). Das Rad9 des 9-1-1-Komplexes bindet wiederum das Protein TopBP1, welches zusätzlich ATR binden kann. ATR ist eine ssDNA-bindende Protein-Kinase, und wird durch Bindung an RPA-besetztem Einzelstrang aktiviert. Die zusätzliche Bindung an TopBP1 verstärkt die Aktivität zusätzlich um ein Vielfaches. Aktiviertes ATR phosphoryliert Rad17, welches wiederum in phosphorylierter Form Capsin phosphoryliert, welches anschließend mit Chk1 interagieren kann. Die Kinase Chk1 wird durch diese Interaktion zu einem Substrat für ATR und ebenfalls phosphoryliert. Chk1 ist die 


\section{EINLEITUNG}

hauptsächliche Effektorkinase des DNA-Damage-Checkpoints und wird durch diese Phosphorylierung aktiviert (Budzowska \& Kanaar, 2009). Anschließend werden über eine Signalkaskade mehrere Proteine aktiviert, welche unter anderem den Zellzyklus anhalten können. Neben der ATR-abhängigen Transduktionskaskade ist noch eine Vielzahl weiterer Proteine an der schadensabhängigen Regulation des Zellzyklus beteiligt. Ein weiterer wichtiger Regulator ist Chk2 (Rad53 in Bäckerhefe Matsuoka et al., 1998), welches ebenfalls eine Effektor-Kinase ist und unter anderem Einfluss auf die Aktivität von Rad55 hat, welches an der homologen Rekombination beteiligt ist (s.o.; Bashkirov et al., 2000; Mendenhall \& Hodge, 1998).

\section{Regulation von Transläsionssynthese und fehlerfreier Schadens-Um- gehung}

Neben der Regulation des Zellzyklus muss, wie zuvor angemerkt, auch der Einsatz von Transläsionssynthese und homologer Rekombination reguliert werden. Zwar hat auch der DNA-Damage-Chekpoint vermutlich einen Einfluss auf die Aktivität der an diesen Prozessen beteiligten Proteine, wie die Regulation von Rad55 zeigt. Allerdings gibt es auch Evidenzen, dass die Regulation von TLS und HR direkt am Replikationsarrest stattfinden könnte, was vermutlich über Modifikation des proliferating cell nuclear antigen (PCNA) geschieht. PCNA ist das eukaryotische Homologe zur $\beta$-sliding-clamp in E. coli, welcher die Prozessivität der replikativen DNA-Polymerasen steigert (Kelman und O'Donnell, 1995). Es besteht aus drei identischen Untereinheiten, welche in Hefe durch das Gen POL30 codiert werden (Krishna et al., 1994). PCNA interagiert mit der Ubiquitinligase Rad18 (Hoege et al., 2002), welche neben der Interaktion mit PCNA auch eine ssDNA-Bindedomäne aufweist und Rad6 binden kann (Bailly et al., 1997). Vermutlich bindet Rad18 ssDNA, welche hinter einem Replikationsarrest entsteht, und vermittelt so die Bindung von Rad6 an PCNA. Rad6 ist ein ubiquitinkonjugierendes Enzym, welches die kovalente Verknüpfung eines einzelnen Ubiquitins an das Lysin 164 von PCNA katalysiert (Hoege et al., 2002). Zusätzlich zu ssDNA, PCNA und Rad6 kann Rad18 auch mit der Ubiquitinligase Rad5 interagieren. Rad5 interagiert selbst wiederum zusätzlich mit dem heterodimeren, ubiquitinkonjugierenden Enzym Mms2/Ubc13. Dieses Heterodimer ist in der Lage, an das durch Rad6/Rad18 angelagerte Ubiquitin am Lysin 164 weitere Ubiquitine kovalent $\mathrm{zu}$ binden und somit PCNA zu polyubiquitinieren. Im Gegensatz zu der Polyubiquitinierung von Proteinen als Signal für den Transport in das Proteosom, geschieht die Verknüpfung der Ubiquitine untereinander hierbei nicht über das interne Lysin 48, sondern über Lysin 63.

\section{Modifikation des PCNA reguliert die Postreplikative Reparatur}

Sowohl rad6- und rad18-Mutanten als auch mms2- und rad5-Mutanten weisen einen Defekt in der postreplikativen Reparatur (PRR) auf (Gangavarapu et al., 2007; Prakash, 1981; Torres-Ramos et al., 2002). Unter diesem Begriff wurden ursprünglich Prozesse zusammengefasst, welche für die Reparatur von niedermolekularen zu hochmolekularen DNAFragmenten nach UV-Strahlung notwendig sind: Exzisionsreparatur-defiziente Hefestämme weisen eine starke Varianz in der Größe von neu synthetisierter Einzelstrang-DNA auf. Dieses zeigt sich in einem alkalischen Sedimentationsgradienten als spezifische Vertei- 
lung von hoch- und niedermolekularen DNA-Fragmenten. Ca. 30 Min nach einer Bestrahlung der Zellen mit UV-Licht zeigt sich in einem solchen Gradienten eine Verschiebung der Fragmentgrößen in Richtung niedrigmolekularer Fragmente. Nach ca. sechs Stunden dagegen entspricht die Verteilung in etwa wieder der einer nicht bestrahlten Zelle. Vermutlich stellen die niedermolekularen Fragmente DNA-Stränge dar, welche aufgrund von UVSchäden in ihrer Synthese arretiert sind. Die Prozesse, welche für die „Reparatur“ der niedermolekularen Fragmente notwendig sind, ermöglichen vermutlich die Umgehung der Schäden und die Wiederaufnahme der Synthese und werden als postreplikative Reparatur (PRR) bezeichnet. Diese Prozesse umfassen sowohl Transläsionssynthese als auch die fehlerfreie Umgehung durch homologe Rekombination oder fork regression.

Neben dem benannten Defekt in der PRR weisen rad6-, rad18-, rad5-, mms2- und ubc13Mutanten eine deutliche Sensitivität gegenüber DNA-schädigenden Agenzien auf. Dabei sind sowohl rad6 als auch rad18 epistatisch zu mms2 und ubc13 (Broomfield et al., 1998). Darüber hinaus treten sowohl Poly- als auch Monoubiquitinierung in S. cerevisiae nach Inkubation mit DNA-schädigenden Agenzien wie MMS auf (Hoege et al., 2002). Dieses Agens ist in der Lage, unter anderem auch Replikationsarreste hervorzurufen (für Details hierzu siehe Ergebnisteil „MMS-induzierte Reversionsfrequenz in $m p h 1 \Delta "$, Seite 87 sowie Wyatt \& Pittman, 2006). Zusätzlich scheint die Ubiquitinierung auf bereits auf der DNA sitzendes PCNA beschränkt zu sein (Garg \& Burgers, 2005). Diese Tatsachen führten zu der Vermutung, dass durch Ubiquitinierung von PCNA Prozesse gesteuert werden, welche die Umgehung von replikationsarretierenden DNA-Schäden ermöglichen. Desweiteren wurden diese Prozesse in zwei unterschiedliche Wege unterteilt: die fehlerfreie und die fehlerbehaftete PRR (s.u). Die schematische Darstellung eines möglichen Modells hierzu ist in Abb. 5 dargestellt.

\section{Monoubiquitinierung ist vermutlich ein Signal zur Transläsionssynthese: fehlerbehaftete PRR}

Während rad6 eine Reduktion in der induzierten Mutagenese sowie einen spontanen Mutatorphänotyp aufweist, zeigt mms2 sowohl einen spontanen als auch einen induzierten Rev3abhägigen Mutatorphänotyp (Broomfield et al., 1998; Broomfield et al., 2001; CassierChauvat \& Fabre, 1991; Prakash, 1974). Daher kann man vermuten, dass Mms2/Ubc13 für einen fehlerfreien Prozess notwendig ist, wohingegen Rad6 und Rad18 sowohl fehlerfreie als auch fehlerbehaftete Prozesse beeinflussen. Weiter unterstützt wird diese Vermutung durch die Tatsache, dass rad6 epistatisch zu rev3 in Bezug auf die Sensitivität gegen UVBestrahlung ist, wohingegen mms2 und rev3 synergistisch sind (Broomfield et al., 1998; Xiao et al., 1999). Aus diesen Befunden entstand ein Modell, nach dem die Monoubiquitinierung von PCNA einen fehlerbehafteten Prozess (die fehlerbehaftete PRR) stimuliert, während polyubiquitiniertes PCNA ein Signal für die fehlerfreie Umgehung von DNA-Schäden darstellt (die fehlerfreie PRR; Broomfield et al., 2001). Der fehlerbehaftete Prozess scheint darüber hinaus Rev3-abhängige Transläsionssynthese darzustellen. Zusätzlich gestützt wird dies durch die Epistasis von rad18 zu rad30 und die in vitro gefundene Interaktion von Rad30 mit monoubiquitiniertem PCNA, welche die Aktivität von Rad30 stimuliert (McDonald et al., 1997; Stelter \& Ulrich, 2003; Watanabe et al., 2004). Diese Daten und die Tatsache, dass sich Rad6 und Rad18 aus humanen Zellen als Komplex mit Rev1 und 


\section{EINLEITUNG}

Rad30 aufreinigen lassen (Yuasa et al., 2006), lassen es sehr plausibel erscheinen, dass Transläsionssynthese in vivo durch Monoubiquitinierung von PCNA stimuliert wird. Dies könnte bspw. geschehen, indem Transläsionspolymerasen wie Rad30 eine höhere Affinität zu ubiquitiniertem PCNA aufweisen als die replikativen DNA-Polymerasen und somit an einen Repliationsarrest rekrutiert werden (Watanabe et al., 2004).

\section{Polyubiquitinierung ist das Signal für eine fehlerfreie Umgehung von DNA-Schäden: fehlerfreie} PRR

Während für eine Stimulation der Transläsionssynthese durch Monoubiquitinierung viele Evidenzen existieren, sind die Mechanismen des Mms2-abhängigen Prozesses noch unklar. Der Synergismus zwischen rev3 und mms2 sowie der Rev3-abhängige Mutatorphänotyp zeigen, dass es sich um einen fehlerfreien Mechanismus zu handeln scheint, weshalb dieser als fehlerfreie PRR bezeichnet wird. Gleichzeitig zeigen mms2- und rad52-Mutanten eine Additivität in Bezug auf die Sensitivität gegen UV-Bestrahlung (Torres-Ramos et al., 2002). Zusätzlich sind rad5 und rad52 synergistisch in Bezug auf die postreplikative Reparatur nach UV-Strahlung (Gangavarapu et al., 2007). Aus diesem Grund wurde lange Zeit angenommen, dass es sich bei dem Mms2-abhängigen Prozess nicht um homologe Rekombination handelt, sondern dieser vielmehr eine fehlerfreie Alternative zu HR darstellt. Ein weiteres Indiz hierfür ist die Aufhebung der HR-abhängigen rad6-Suppresion durch srs2: Srs2 ist eine Helikase mit 3'-5'-Aktivität, deren Ausfall die Sensitivität von rad6-Mutanten supprimiert (Lawrence \& Christensen, 1979). Durch den gleichzeitigen Ausfall der homologen Rekombination wird diese Suppression jedoch wieder aufgehoben. Daher wurde vermutet, dass die Suppression des rad6-Phänotyps auf einer Zunahme an homologer Rekombination beruht. Wird die homologe Rekombination ausgeschaltet, kann demnach auch keine Suppression mehr stattfinden. Besonders gestützt wird diese Vermutung durch die Tatsache, dass Srs2 in vitro in der Lage ist, Rad51-ssDNA-Filamente aufzulösen (Krejci et al., 2003; Veaute et al., 2003). Aus diesen Gründen wurden die Rad52-abhängigen Prozesse bisher in der Literatur häufig nicht zur PRR gezählt, sondern die postreplikative Reparatur als Synonym für Rad6-abhängige Prozesse benutzt, welche alternativ zur homologen Rekombination einsetzen können. Da die wahrscheinlichste fehlerfreie Alternative zur homologen Rekombination fork regression darstellt, wurde diese meist als Mechanismus der fehlerfreien PRR postuliert. Neueste Daten zeigen jedoch, dass Mms2 möglicherweise trotz der zuvor genannten Evidenzen einen Einfluss auf die homologe Rekombination hat: mms2-Mutanten sind epistatisch zu den Genen des Shu-Komplexes (psy3) in Bezug auf die Überlebensrate nach MMS-Inkubation. Die Gene des Shu-komplexes sind Teil der RAD52-EpistasisGruppe und werden damit der homologen Rekombination zugeordnet (Ball et al., 2009). Darüber hinaus konnte ich während meiner Diplomarbeit zeigen, dass Mms2 möglicherweise an Prozessen beteiligt ist, welche die Mechanismen der homologen Rekombination voraussetzen (Ede, 2006). 
PCNA kann SUMOyliert werden, was möglicherweise suppressiv auf homologe Rekombination wirkt

Neben der Ubiquitinierung von Lysin 164 kann es am PCNA auch zur SUMOylierung kommen. Dies geschieht über die Interaktion mit der SUMO-Ligase Siz1, welche mit dem SUMO-konjugierenden Enzym Ubc9 interagiert. Ubc9 wiederum SUMOyliert das Lysin 164 von PCNA (Takahashi et al., 2001), was zur Rekrutierung von Srs2 an die Replikationsgabel führt (Pfander et al., 2005). Wie oben beschrieben, wirkt Srs2 vermutlich reprimierend auf homologe Rekombination, indem es Rad51-ssDNA-Filamente auflöst (Krejci et al., 2003; Veaute et al., 2003). Allerdings zeigen srs2-Mutanten gleichzeitig eine Reduktion an induzierten Rekombinationsereignissen sowie eine Suppression des Hyperrekombinationsphänotyps von rad5- und rad18-Mutanten (Ede, 2006; Friedl et al., 2001). Demnach scheint die Funktion von Srs2 nicht ausschließlich auf eine Repression der homologen Rekombination beschränkt zu sein.

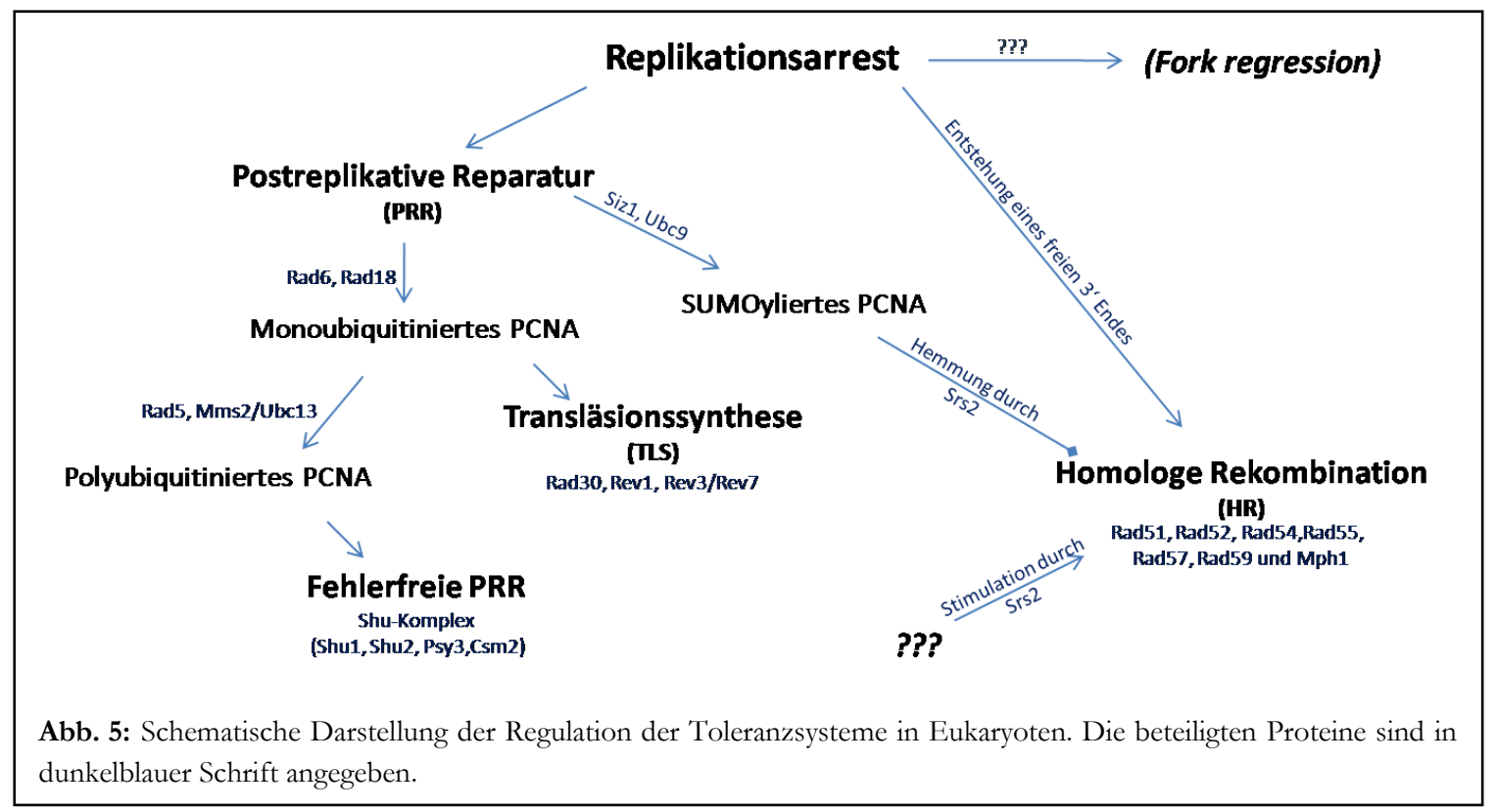

Generell erscheint es als wären die Mechanismen der fehlerfreien PRR komplexer als bisher angenommen und würden zumindest teilweise auch Prozesse der homologen Rekombination benötigen. Ein wesentlicher Aspekt der vorliegenden Arbeit war daher, tiefere Einblicke in die Funktionsweise der fehlerfreien PRR zu erhalten und vor allem die Rolle der homologen Rekombination bei diesen Prozessen anhand des Modellorganismus Saccharomyces cerevisiae zu untersuchen.

\section{Das Protein MPH1}

Ein weiterer Schwerpunkt dieser Arbeit war die Untersuchung der Funktion des Proteins Mph1 aus S. cerevisiae in Bezug auf dessen Beteiligung an der homologen Rekombination. Mph1 ist Mitglied der DEAH-Familie und weist in vitro eine $3^{6}-5^{6}$-Helikaseaktivität auf (Prakash et al., 2005; Scheller et al., 2000). mph1 wurde im Rahmen eines Großprojekts zur Untersuchung von 150 verschiedenen Deletionsmutanten identifiziert als eine Mutante mit erhöhter spontaner Mutationsrate im CAN1-Vorwärts- sowie im trp1-289-Reversions- 


\section{EINLEITUNG}

system (Entian et al., 1999). Der Mutatorphänotyp von mph1 ist Rev3-abhängig und mph1Mutanten sind zusätzlich sensitiv gegenüber DNA-schädigende Agenzien wie 4-NQO und MMS, was zu der Vermutung führte, Mph1 sei an der fehlerfreien Prozessierung von DNA-Schäden beteiligt. Durch genetische Interaktionsstudien ließ sich darüber hinaus feststellen, das $m p h 1$ höchstwahrscheinlich nicht Bestandteil der NER oder BER ist. Vielmehr konnte gezeigt werden, dass mph1 hypostatisch zu den Genen der rad52-Epistasisgruppe in Bezug sowohl auf die Sensitivität als auch in Bezug auf den Mutatorphänotyp ist (Scheller et al., 2000). Einzige Ausnahme hierbei bildet rad54, welches in Bezug auf den Mutatorphänotyp subadditiv mit mph1 ist. Aus diesem Grund wurde für Mph1 eine Beteiligung an der homologen Rekombination postuliert, welche möglicherweise am selben Punkt relevant wird wie Rad54 (Scheller et al., 2000; Schürer et al., 2004). Bei Messungen der Sensitivität von mph1 gegenüber ionisierender Strahlung sowie gegenüber Camptothecin zeigte sich kaum eine Veränderung im Vergleich zum Wildtyp. Da durch ionisierende Strahlung und Camptothecin vor allem Strangbrüche induziert werden (s.o. sowie Avemann et al., 1988; Ferguson \& Baguley, 1996), ist es sehr wahrscheinlich, dass Mph1 nicht maßgeblich für die Reparatur von Doppelstrangbrüchen oder von an Einzelstrangbrüchen kollabierten Replikationsgabeln notwendig ist. Vielmehr erscheint es plausibel, dass Mph1 hauptsächlich eine Funktion bei der Prozessierung von Replikationsarresten durch homologe Rekombination hat. Zusätzlich gestützt wird diese Vermutung dadurch, dass mph1-Mutanten keinen Defekt in der mitotischen Rekombination aufweisen, welche jedoch vermutlich durch Doppelstrangbrüche induziert wird (Scheller et al., 2000; Schürer et al., 2004). Dagegen weisen mph1-Mutanten eine Reduktion an 4-NQO-induzierten Rekombinationsereignissen auf, was die Vermutung unterstützt, dass Mph1 an der Umgehung von replikationsarretierenden DNA-Schäden beteiligt ist (Rudolph, 2003).

Einen tieferen Einblick in die mögliche Funktion von Mph1 zeigt die kürzlich veröffentlichte Arbeit von Prakash et al.. Die Autoren konnten zeigen, dass Mph1 in vitro in der Lage ist, D-Loops aufzulösen. Gleichzeitig ließ sich für mph1-Mutanten bei der Reparatur von Doppelstrangbrüchen eine Zunahme an cross over gegenüber Genkonversionen zeigen. Aufgrund dieser Daten erscheint es sehr plausibel, dass Mph1 speziell an der Auflösung von $D$ Loops beteiligt ist. Durch die Auflösung des D-Loops nach der Verlängerung am Schwesterchromatid würde Genkonversion gegenüber cross over bevorzugt stattfinden (Siehe Abb. 4 iii', iv'und v'). Allerdings kann dieses Modell nicht alle bisherigen Daten in Bezug auf Mph1 erklären, weshalb es sehr wahrscheinlich ist, dass Mph1 noch eine weitere Funktion aufweist.

Ein Ziel der vorliegenden Arbeit war es mehr Einblick in die Funktionsweise von Mph1 zu erhalten. Darüber hinaus sollte die genetische Interaktion zwischen homologer Rekombination und fehlerfreier Postreplikativer Reparatur genauer untersucht werden, um mehr Einsicht in die Regulation der Toleranzsysteme zu erhalten. 


\section{STÄMME}

\section{E.coli:}

DH5 $\alpha$ (F-, endA1, hsdR17, $\left(r_{k^{-}} m_{k}^{-}\right)$, supE44, thi1, recA1, gyrA (Nal,), relA1, (lacZYAargF), U169, Ф80dlacZA M15); (Hanahan, 1983).

\section{S. cerevisiae:}

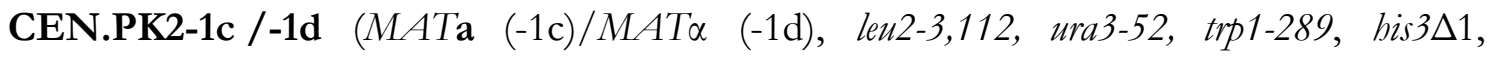
MAL2-8c, SUC2); (Entian et al., 1999). - In dieser Arbeit verwendete CEN.PK2 Stammderivate, die verwendeten Disruptionskassetten sowie die Quelle sind in Tab. 1 aufgelistet.

Tab. 1: Verwendete Derivate von CEN.PK2-1c/1d.

\begin{tabular}{|c|c|c|c|}
\hline Stamm & Disruptionskassette & Disruptionsart & Quelle \\
\hline$m m s 2 \Delta$ & mms2: :HisMX6 & PCR-basiert & Schürer, 2003 \\
\hline$m m s 2 \Delta m p h 1 \Delta$ & $\begin{array}{c}\text { mms2: }: \text { HisMX6; } \\
\text { mph1::HisG }\end{array}$ & PCR-basiert & Schürer, 2003 \\
\hline$m m s 2 \Delta$ rad $30 \Delta$ & \multicolumn{2}{|c|}{ Kreuzung $m m s 2 \Delta \times$ rad $30 \Delta$} & Diese Arbeit \\
\hline$m m s 2 \Delta \operatorname{rad} 51 \Delta$ & \multicolumn{2}{|c|}{ Kreuzung $m m s 2 \Delta \times$ rad51 $1 \Delta$} & Ede, 2006 \\
\hline$m m s 2 \Delta$ rad52 2 & \multicolumn{2}{|c|}{ Kreuzung $m m s 2 \Delta \times$ rad52 $\Delta$} & Ede, 2006 \\
\hline$m m s 2 \Delta \operatorname{rev} 3 \Delta$ & $\begin{array}{c}\text { mms2: :HisMX6; } \\
\text { rev3: :natMX4 }\end{array}$ & PCR-basiert & Unveröffentlicht \\
\hline$m m s 2 \Delta \operatorname{rev} 3 \Delta m p h 1 \Delta$ & \multicolumn{2}{|c|}{ durch Kreuzung erhalten } & Unveröffentlicht \\
\hline$m m s 2 \Delta$ rev $3 \Delta$ rad51 $1 \Delta$ & \multicolumn{2}{|c|}{ durch Kreuzung erhalten } & Unveröffentlicht \\
\hline mph1s & mph1::HisG & Plasmid-basiert & Schürer, 2003 \\
\hline$m p h 1 \Delta \operatorname{rad} 51 \Delta$ & $\begin{array}{l}\text { mph1::HisG; } \\
\operatorname{rad51::LEU2~}\end{array}$ & PCR-basiert & Schürer 2003 \\
\hline phr1s & phr1::HisMX6 & PCR-basiert & Diese Arbeit \\
\hline 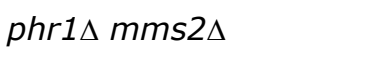 & \multicolumn{2}{|c|}{ Kreuzung $m m s 2 \Delta \times p h r 1 \Delta$} & Diese Arbeit \\
\hline 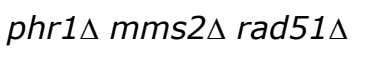 & \multicolumn{2}{|c|}{ Kreuzung phr1 $1 \mathrm{mms} 2 \Delta \times \mathrm{mms} 2 \Delta \operatorname{rad} 51 \Delta$} & Diese Arbeit \\
\hline 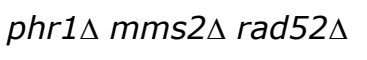 & \multicolumn{2}{|c|}{ Kreuzung phr1 $1 \mathrm{mms} 2 \Delta \times \mathrm{mms} 2 \Delta \operatorname{rad} 52 \Delta$} & Diese Arbeit \\
\hline phr1 $1 \Delta \operatorname{rad} 51 \Delta$ & \multicolumn{2}{|c|}{ Kreuzung $p h r 1 \Delta \times \operatorname{rad} 51 \Delta$} & Diese Arbeit \\
\hline 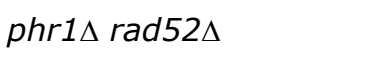 & \multicolumn{2}{|c|}{ Kreuzung $p h r 1 \Delta \times$ rad52 $\Delta$} & Diese Arbeit \\
\hline pol30s & pol30: :HisG & PCR-basiert & Diese Arbeit \\
\hline $\operatorname{rad} 30 \Delta$ & rad30: :HisMX6 & PCR-basiert & Diese Arbeit \\
\hline
\end{tabular}




\begin{tabular}{|c|c|c|c|}
\hline Stamm & Disruptionskassette & Disruptionsart & Quelle \\
\hline $\operatorname{rad} 51 \Delta$ & rad51::Leu2 & PCR-basiert & Schürer, 2003 \\
\hline $\operatorname{rad} 52 \Delta$ & rad52: :HisMX6 & PCR-basiert & Diese Arbeit \\
\hline $\operatorname{rev} 3 \Delta$ & rev3: :HisMX6 & PCR-basiert & Diese Arbeit \\
\hline $\operatorname{rev} 3 \Delta$ & rev3: :NatMX4 & PCR-basiert & Schürer, 2003 \\
\hline $\operatorname{rev} 3 \Delta \operatorname{rad} 51 \Delta$ & $\begin{array}{l}\text { rev3::natMX4; } \\
\text { rad51::LEU2 }\end{array}$ & PCR-basiert & Unveröffentlicht \\
\hline$u b c 13 \Delta$ & ubc13:: HisMX6 & PCR-basiert & Ede, 2006 \\
\hline$u b c 13 \Delta$ pol30 1 & $\begin{array}{c}\text { pol30::HisG; } \\
\text { ubc13::HisMX6 }\end{array}$ & PCR-basiert/pBL243 & Diese Arbeit \\
\hline$u b c 13 \Delta \operatorname{rad} 51 \Delta$ & \multicolumn{2}{|c|}{ Kreuzung $u b c 13 \Delta \times \operatorname{rad} 51 \Delta$} & Ede, 2006 \\
\hline$u b c 13 \Delta \operatorname{rad} 52 \Delta$ & \multicolumn{2}{|c|}{ Kreuzung $u b c 13 \Delta \times$ rad52 $\Delta$} & Ede, 2006 \\
\hline yen1s & yen 1::HisMX6 & PCR-basiert & Diese Arbeit \\
\hline
\end{tabular}

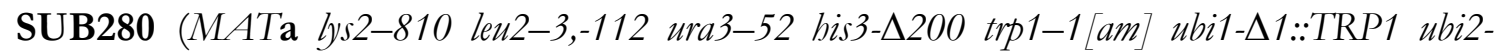
$\Delta 2::$ ura3 ubi3- $\Delta$ ub-2 ubi4- $\Delta 2:: L E U 2$ [pUB39] [pUB100]); (Finley et al., 1994).

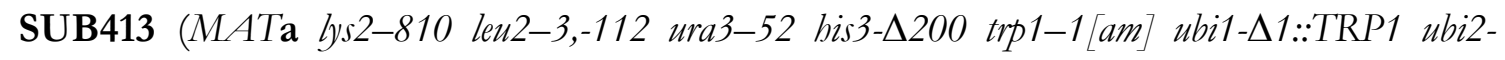

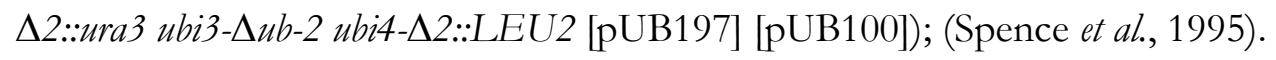

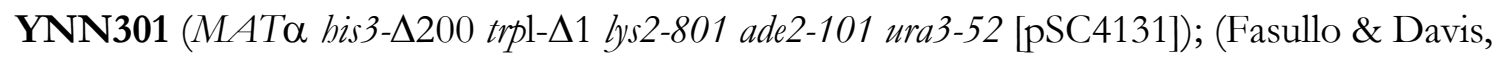
1987).

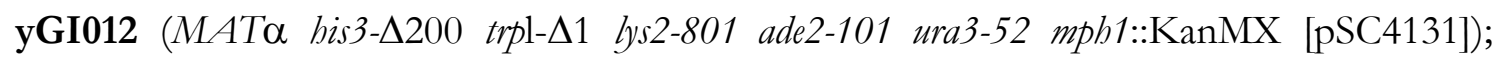
(Prakash et al., 2009). - mph1-Derivat von YNN301.

\section{Plasmide}

pJA6

Derivat von YCp50 mit einem funktionellen REV3-Gen; (Morrison et al., 1989). Details siehe Abb. 6.

\section{pRS316 KanKanMX4}

pRS316 Derivat mit dem KanKanMX4 Modul; (Rudolph, 2003). Details siehe Abb. 6.

\section{pBL243}

Vektor zur Deletion von POL30 durch eine HisG::URA3::HisG Disruptionskassette; (Ayyagari et al., 1995). 


\section{TOPO II Blunt PHR1}

Derivat von $\mathrm{pCR}{ }^{\circledR}$ Blunt II TOPO® (Invitrogen) mit dem PCR-amplifizierten Wildtyp PHR1-Fragment. Details siehe Abb. 8, sowie Seite 46.

\section{YIplac128}

Vektor zur chromosomalen Integration am LEU2-lokus von S. cerevisiae; (Gietz \& Sugino, 1988). Details siehe Abb. 7.

\section{YIplac128 KanKanMX4}

Derivat von YIplac128 mit dem KanKanMX4 Modul. Das Modul wurde via EcoRI/SalIVerdau aus YIplac211 KanKanMX4 in YIplac128 kloniert. Details siehe Abb. 7 sowie Seite 45 .

\section{YIplac128 REV3 flength}

Derivat von YIplac128 mit einem funktionellen REV3-Gen. Das REV3-Fragment wurde aus pJA6 via EcoRI/SalI-Verdau in YIplac128 kloniert. Details siehe Abb. 7 sowie Seite 46.

\section{YIplac211}

Vektor zur chromosomalen Integration am URA3-lokus von S. cerevisiae; (Gietz \& Sugino, 1988). Details siehe Abb. 8.

\section{YIplac211 KanKanMX4}

Derivat von YIplac211 mit dem KanKanMX4-Modul. Das Modul wurde via EcoRI/SalIVerdau von pRS316 KanKanMX4 in YIplac211 kloniert. Details siehe Abb. 8 sowie Seite 45 .

\section{YIplac211 PHR1 flength}

Wildtyp PHR1-tragendes Derivat von YIplac211. Das PHR1-Fragment wurde aus dem Vektor TOPO II Blunt PHR1 via BamHI/PstI Verdau umkloniert. Details siehe Abb. 8 sowie Seite 46.

\section{YIplac211-P13- UBC13 bzw. - ubc13C87S}

Derivat von YIplac211, welches ein funktionelles UBC13-Allel bzw. ein ubc13C87S-Allel hinter dem Ubc13-Promotor trägt; (Ulrich, 2003).

\section{YCp50}

E. coli/S. cerevisiae Shuttle-Vektor; (Rose et al., 1987). Details siehe Abb. 6. 

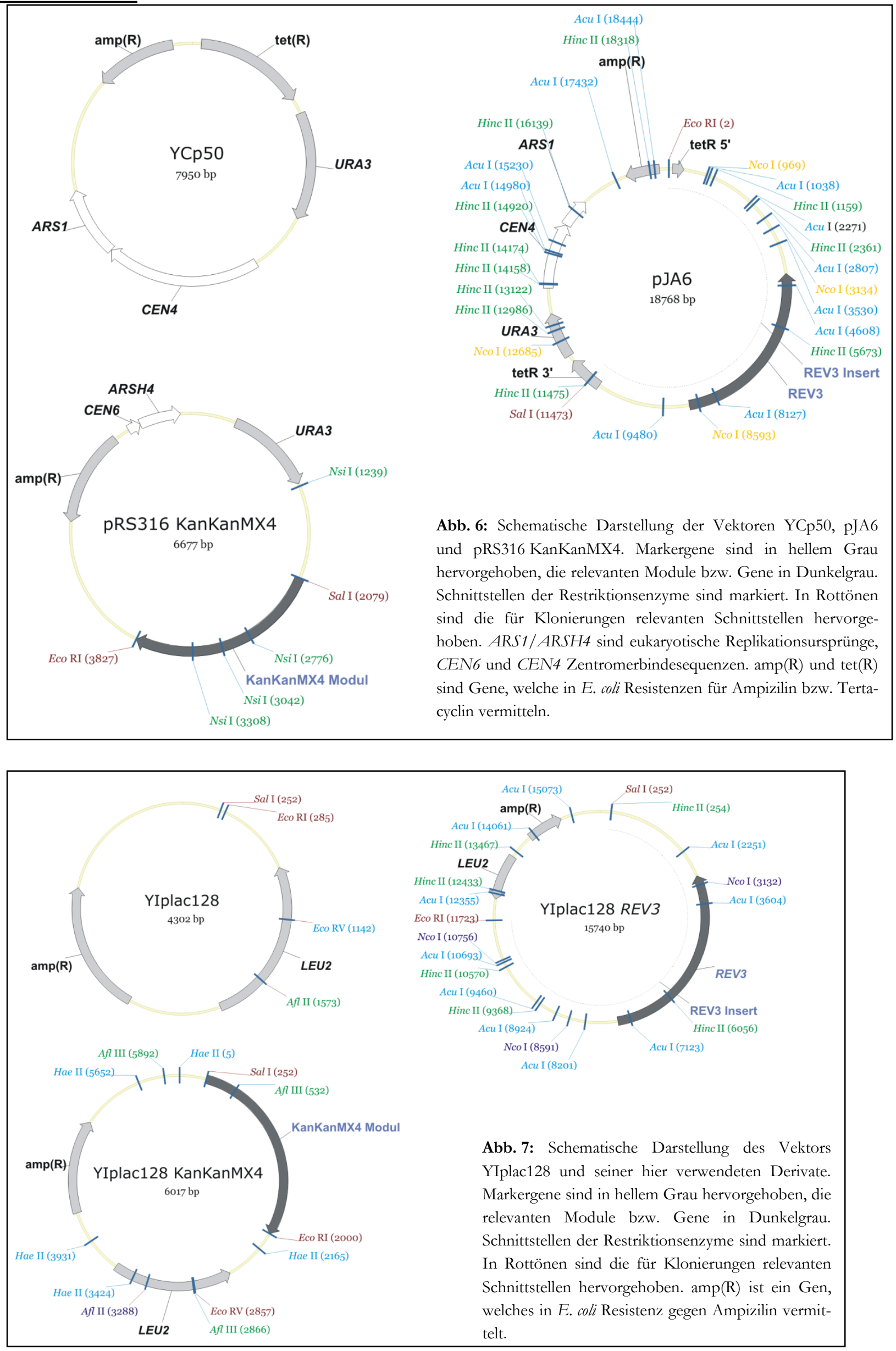

$30 \mid$ Seite 

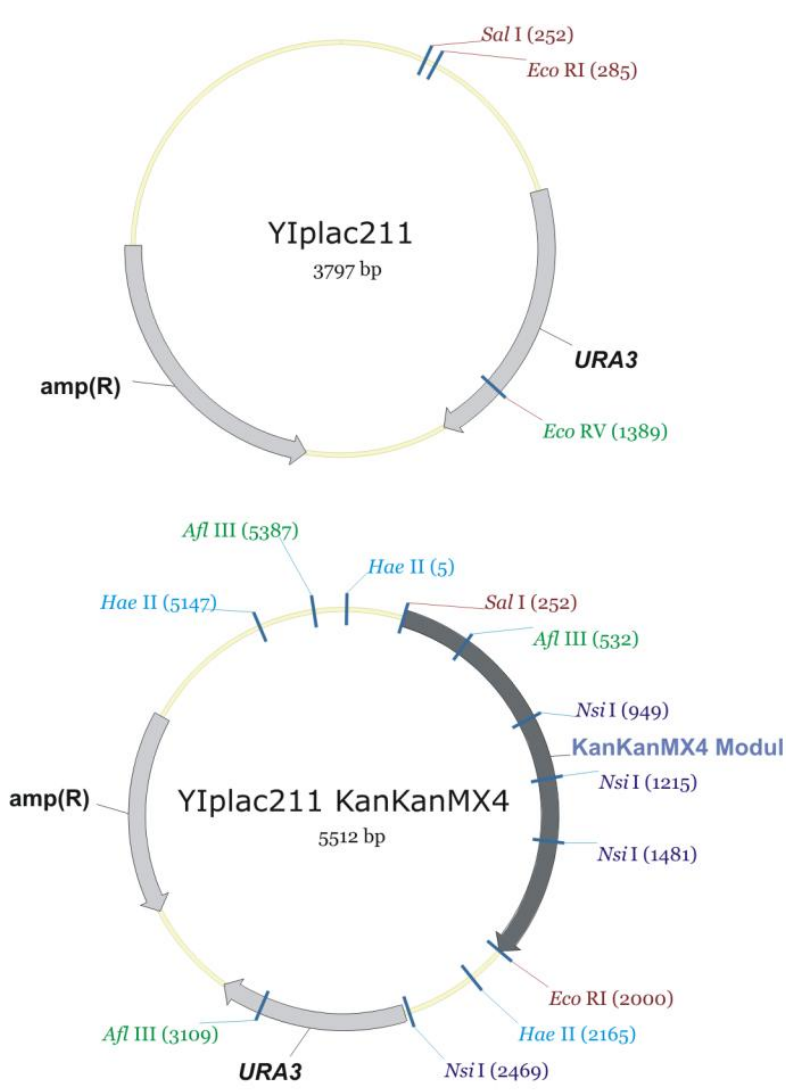
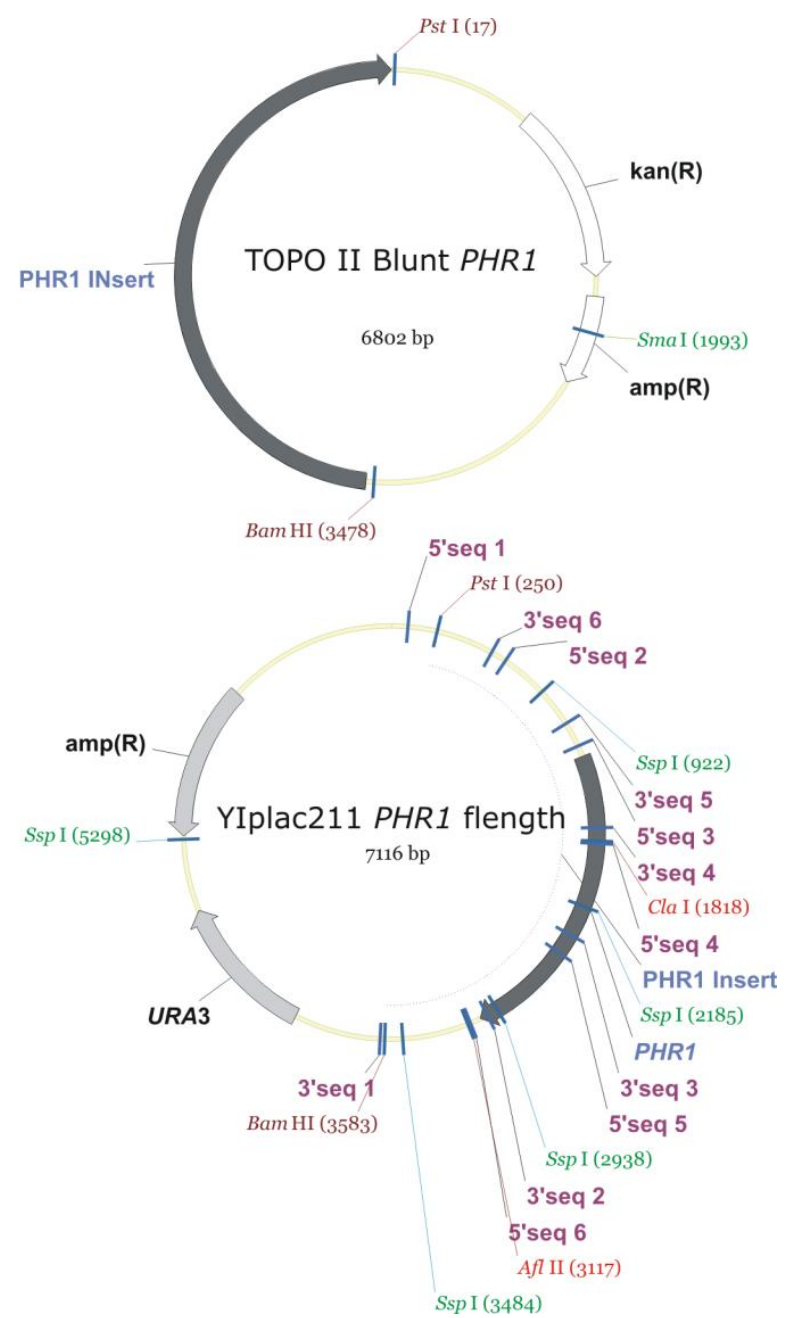

Abb. 8: Schematische Darstellung des Vektors YIplac211 und seiner Derivate sowie des Vektors TOPO II Blunt PHR1. Markergene sind in hellem Grau hervorgehoben, die relevanten Module bzw. Gene in Dunkelgrau. Schnittstellen der Restriktionsenzyme sind markiert. In Rottönen sind die für Klonierungen relevanten Schnittstellen hervorgehoben. amp(R) und kan(R) sind Gene, welche in E. coli Resistenzen für Ampizilin bzw. Kanamycin vermitteln.

\section{PRIMER FÜr DELETIONEN UND PCR-SCREENS}

Die Sequenzen aller nachfolgend aufgeführten primer sind in 5'-3'-Richtung angeben.

\section{Markerinterne primer}

his $G 1$

bis $G 2$

5'HisMX_int

3'HisMX_int

5' bis out

3' bis out

5'nat_out

3'nat_out
CCT TTC TGG TCG AGG TAG CGT TTG

GCT ATC TGC GAT TTG GTC TCT ACC

TCG CT'T TGG ACA AAG CTC CCT TAC

CGC ATG GCA ACA GCC AGA GAT TTA

GTA AAG TCG TAA GCT CCA GCC T

GAC GAA GCT CTT TCT AGA AGC G

AAG CCG TGT CGT CAA GAG TGG TAC

ATG CCC TGC CCC TAA TCA GTA CTG 
mms2A

5'Mms2_out (sc)

3'Mms2_out (sc)

5'Mms2_int

3'Mms2_int

\section{mph1}

5'Mph1_sc

3'Mph1_sc

5'Mph1_int

3'Mph1_int

5'Mph1_dis_MX

3'Mph1_dis_MX

phr1s

5'Phr1_sc

3'Phr1_sc

5'Phr1_int

3'Phr1_int

5'Phr1_dis

3'Phr1_dis

5'Phr1_flength

3'Phr1_flength

5'phr1_seq_1

5'phr1_seq_2

5'phr1_seq_3

5'phr1_seq_4

5'phr1_seq_5

5'phr1_seq_6

3'phr1_seq_1

3'phr1_seq_2

3'phr1_seq_3

3'phr1_seq_4

3'phr1_seq_5

3'phr1_seq_6
TGA ATG GTC CAC TCA ATG CAC TGA

GAT GAG GAC CGT TGC AAG GAT TGA

GCG ACG ATA TTA CCA TGA CCA

CGG TTG ACG CAA T'T'T CT'T GTT C

ATC TCC TCT AAC TCC TTA CTG GTG

CGA CAA AGC TAG AAC GCG AGT CAG

CGC TCT CTT AGT TCG TTC AGC TCC

TCT TGT CAT CGA TGA AGC TCA CAG

ATG GCT AGT GCA GAT GAT TAC TTT AGT GAT

TTC GAA GAT GCA GCT GAA GCT TCG TAC GCT GC

TCA AAA ATC AGA ATC TGA GCC CAG TAT GTC ATC TAA TTC TGC ATA GGC CAC TAG TGG ATC TG

AAG CTC CGT CAA TTG AAC CCA CCT

GGC ACA TCC TTC AGT AGC TAC TCA

TTG ATC ACT ACT GAC AGA GGC ACC

GGC CAG TTG CAC ATA CAA TGT CTG

ATG AAA AGA ACG GTA ATA TCT TCC TCG AAC GCA TAT GCT ACA GCT GAA GCT TCG TAC GCT GC

TCA CAT TGC GTC TT'T ATA AAC TT'T CAA AGC

ACG CTC CCT AGC ATA GGC CAC TAG TGG ATC TG

TAA CAC CGG CGC TAG TAC CAA CAT

T'TT CCA GCT GCA TAA TCT GTA GAC

GCA GTG AGC GCA ACG CAA TTA A

GGT CCA TTC TCA ACA TCA CCC T

CAG TGA TCA AGC AAA GCG GCA A

CCC ATT GAG GTA TAT GGC CAG T

CGT ACC TGT TCC TGA ACT TAC A

AGC ATA CTT TCA CCC CT'T AAG G

ACG TTG TAA AAC GAC GGC CAG T

CTT CCT CGA ACG CAT ATG CTA G

ACC ACG ACT CTT GCA TTG TTG C

GTG GTG TAC TGG TAA TAC AGG C

GTA GTG GAC CTA GAA AAC ACC G

CTG ATG GAC CTA GGA ACG ATC A 
pol30s

5'Pol30_sc

3'Pol30_sc

5'Pol30_int

3'Pol30_int

5'Leu2_rev

3'Leu2_rev

\section{$\operatorname{rad} 30 \Delta$}

5'Rad30_sc

3'Rad30_sc

5'Rad30_dis

3'Rad30_dis

\section{$\operatorname{rad51\Delta }$}

5'Rad51_sc

3'Rad51_sc

5'Rad51_int

3'Rad51_int

\section{$\operatorname{rad} 52 \Delta$}

5 'Rad52_out (sc)

3'Rad52_out (sc)

5'Rad52_int

3'Rad52_int

5'Rad52_dis

3'Rad52_dis
GGT GAA ATG AAA TAG CCG CCC ATA TCG AAT GCA GAG CTG TCC TAT ACG GGT CTC CT'T GGA AAT AGG TGT CGA CTG ATC CGA TAT CAC CGT CAG CTA GAC GAT CTT CTT AGG GGC AGA CAT TGG TTC CAA CAG TAC CAC CGA AGT

ACG CTA CCT AAT CCT GCC GAT TGAACAATCGCTGAGGTCAG ATG TCA AAA T'T'T ACT TGG AAG GAG T'TG AT'T CAG CTT GGT TGC TGA AGC TTC GTA CGC TGC TCA TTT TTT TCT TGT AAA AAA TGA TAA GAT GTT TTT GGA AAT AGG CCA CTA GTG GAT CTG

TCT CACCATATCCCA CGA CTA G GAG GAA GTA GTC ATC GGG AAG A CAG ATC CAA AGA AGC CTA TCG G GCT TAG TTC ACC ACG ACC AGA A

ATC GGG TCT TGC ACA CGT CGC TAA TTA ATA CGA CAC ATG GAG GAA AGA A TCC TAG AGC ATT ACC AAA CCC T GGG TAC CTC GAC TTA CTG TA CGA AAA ATA TAG CGG CGG GCG GGT TAC GCG ACC GGT ATC GAA TG GCT GAA GCT TCG TAC GCT G

TAA TAA ATA ATG ATG CAA AT'T TTTT TAT T'TG T'T'T CGG CCA GGA AGC GT'T TCA ATA GGC CAC TAG TAT CTG

$\operatorname{rev} 3 \Delta$

5'Rev3_sc

3'Rev3_sc

5'Rev3_int

3'Rev3_int

5'Rev3_dis
TGT CGC TCC TTT GTT CCA TTC CAC

TGC CTC GCA ACA AAA CCA CGT AGA

ACC ACG TTG GCT GGA ATC TGT T

CCG TAT CGC TCT GTA TTG TGT C

ATG TCG AGG GAG TCG AAC GAC ACA ATA CAG

AGC GAT ACG GCA GCT GAA GCT TCG TAC GC 


\section{AAT CAT TTA GAG ATA TTA ATG CTT CTT CCC TTT GAA CAG AGC ATA GGC CAC TAG TGG ATC TG}

\section{$u b c 13 \Delta$}

Für die Deletion von UBC13 in pol30 K164R wurden anstatt der „Ubc13_dis“-primer die „Ubc13_sc“-primer und chromosomale DNA einer existierenden ubc13::HisMX6-Mutante als template benutzt. Für den anschließenden screen der Mutante wurden die „Ubc13_sc_far"-primer benutzt, welche weiter außen (vom Gen aus betrachtet) als die „Ubc13_sc“-primer liegen.

\section{5'Ubc13_sc \\ 3'Ubc13_sc \\ 5'Ubc13_sc_far \\ 3'Ubc13_sc_far \\ 5'Ubc13_int \\ 3'Ubc13_int}

\section{yen14}

ATG CCG CAT CCG TAT TGT TAC C

AAT GCG CCT CTT TAG ATG ACC A

AAT GAT TAG ATT CTG CGG GAG CCG TGA TCC GGA ATT AAA CGT GGA CCC

CCG TCA CAC TCT ACA CTG TTT CCT

TGT AAT GCC AGG TAC TGG GTC A

$$
\begin{aligned}
& \text { 5'Yen1_sc } \\
& \text { 3'Yen1_sc } \\
& \text { 5'Yen1_int } \\
& \text { 3'Yen1_int } \\
& \text { 5'Yen1_dis }
\end{aligned}
$$

3'Yen1_dis

\author{
ATG TGA GTG CAG GCG GAA AGA TCA \\ TCT GTG TCA CCA CCA CAA ACT CTC \\ CCC TGA GTT CAT CAG TCT TGT ACG \\ AGG ATC TTC GCA TTG AGC CAA CTG \\ ATG GGT GTC TCA CAA ATA TGG GAA TTT TTG \\ AAG CCA TAT CCA GCT GAA GCT TCG TAC GCT \\ GC
}

\section{Chemikalien}

Adenin

Adenosin-5'-triphosphat (100mM)

Adenosin-5'-triphosphat Dinatriumsalz

Agar Bacterilogical

Ammonium Sulfat

Ampicillin Natriumsalz

$\alpha$-Faktor

Bacto-Pepton

Borsäure

Bromphenolblau
Carl Roth GMBH \& Co, Karlsruhe Fermentas GMBH, Burlington, Kanada

Boehringer, Mannheim

Oxoid $^{\text {TM }}$ CTD, Basingstoke, England

Carl Roth GMBH \& Co, Karlsruhe

Carl Roth GMBH \& Co, Karlsruhe

Instituts-intern produziert

Becton, Dickinson \& Company, Sparks

Scharlau Chemie S.A., Barcelona, Spanien

FLUKA AG, Buchs 
Camptothecin

L-Canavanin

Chill-Out 14, liquid Wax

Chloroform

Coomassie Brilliant Blue R250

Difco $^{\text {TM }}$ Skim Milk

Difco ${ }^{\text {TM }}$ Yeast Nitrogen Base

w/o ammino acids

\& ammoniumsulfate

Dimethylsulfoxid (DMSO)

1,4 Dithiothreitol (DTT)

dNTPs

Essigsäure

Ethylendiamintetraessigsäure

Dinatriumsalz (EDTA)

Ethanol

G418

Glucose

Glycerol (Plant)

Kanamycin Sulfat

Lachsspermien-DNA

Leucin

Lithiumacetat

Lysin

Melisepthol

Methanol

Methylmethansulfonat (MMS)

Mineralöl

Natriumchlorid

Natriumdodecyl Sulfat(SDS)

Natriumhydroxid

4-Nitrochinolin-1-oxid

Nourseothrecin (ClonNat)
Sigma-Aldrich Chemicals, Deisenhofen

Calbiochem, Schwalbach

MJ Research Inc, Waltham, USA

Scharlau Chemie S.A., Barcelona, Spanien

Applichem, Darmstadt

Becton, Dickinson \& Company, Sparks

Becton, Dickinson \& Company, Sparks

Fluka Chemie AG, Neu-Ulm

Applichem, Darmstadt

Invitek, Berlin

Carl Roth GmbH \& Co, Karlsruhe

Serva Electrophoresis GMBH, Heidelberg

Carl Roth GmbH \& Co, Karlsruhe

VWR International GmbH, Darmstadt

Calbiochem, Schwalbach

Carl Roth GmbH \& Co, Karlsruhe

SERVA Electrophoresis GmbH, Heidelberg

Applichem, Darmstadt

Sigma-Aldrich Chemicals, Deisenhofen Sigma-Aldrich Chemicals, Deisenhofen Sigma-Aldrich Chemicals, Deisenhofen Sigma-Aldrich Chemicals, Deisenhofen

B. Braun Melsungen AG, Melsungen VWR international GmbH, Darmstadt Sigma-Aldrich Chemicals, Deisenhofen Sigma-Aldrich Chemicals, Deisenhofen

Carl Roth GmbH \& Co, Karlsruhe Serve Electrophoresis GMBH, Heidelberg Carl Roth GmbH \& Co, Karlsruhe

Fluka Chemie AG, Neu-Ulm

Werner BioAgents, Jena 


\section{MATERIALIEN}

Phenol

Phenylalanin

PIPES

Polyethylenglykol 4.000

2-Propanol (Isopropanol)

Saccharose

Salzsäure

Sorbitol

Tris-Base

Triton X-100

Trypton

Tween 20

UltraPure Agarose

Uracil

Xylen Cyanol ff

Yeast Extract
Carl Roth GmbH \& Co, Karlsruhe

Fluka Chemie AG, Neu-Ulm

Sigma-Aldrich Chemicals, Deisenhofen

Fluka Chemie AG, Neu-Ulm

Carl Roth GmbH \& Co, Karlsruhe

Carl Roth GmbH \& Co, Karlsruhe

Carl Roth GmbH \& Co, Karlsruhe

Sigma-Aldrich Chemicals, Deisenhofen

AppliChem, Darmstadt

Sigma-Aldrich Chemicals, Deisenhofen

Oxoid, CTD, Basingstoke, England

Sigma-Aldrich Chemicals, Deisenhofen

Life Technologies Inc., Gaithersburg, USA

Fluka Chemie AG, Neu-Ulm

AppliChem, Darmstadt

Oxoid CTD, Basingstoke, England

Alle nicht explizit aufgeführten Chemikalien wurden von der Firma Merck KG, Darmstadt bezogen.

\section{ENZYME UND PROTEINE}

BSA

Phusion-Polymerase

Restriktionsendonukleasen

Taq-DNA-Polymerase

T4-Ligase

Yeast Lytic Ensyme
USB, Cleveland Ohio, USA

New England Biolabs, Bad Schwalbach

Fermentas GMBH, Burlington, Kanada

New England Biolabs, Bad Schwalbach

Invitrogen, Carlsbad, USA sowie Institutsintern hergestellt

Fermentas GMBH, Burlington, Kanada

MP Biomedicals, Eschwege 


\section{LÄNGENSTANDARDS}

\section{DNA-Marker:}

$\lambda$-DNA, Eco47I-geschnitten (Fermentas GmbH, Burlington, Kanada).

Fragmentgößen (in bp):

$8126,6555,6442,3676,2605,2555,2134,2005$, 1951, 1612, 1420, 1284, 985, 974, 597, 894, 597,

$513,511,433,398,345,310,308,272,242,215$, $151,88,73,67,45,42,32,28,23$

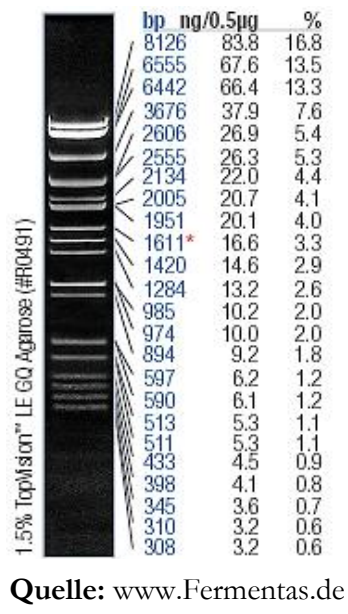

\section{KITS}

JetStar $2.0^{\mathrm{TM}}$

Wizard® SV Gel and PCR Clean-Up System

\section{GERÄTE UND VERBRAUCHSGÜTER}

\section{Verbrauchsgüter}

Dissektionsnadel

Einmalfiltrationseinheit Vacuflo $125 \mathrm{ml}$

Einmalpetrischalen

Filterpapier Filtropur S 0,2/0,45 $\mu \mathrm{m}$

Gefäße für Gefrierkulturen

Glaswaren

Glaswaren

Minisart NML Sterilfilter

Parafilm ${ }^{\circledR}$ "M"

PCR-Tube ultradünn, $0,2 \mathrm{ml}$

$\mathrm{pH}$ Indikator-Papier

Plastikröhrchen $13 \mathrm{ml}$

Plastikröhrchen $15 \mathrm{ml}$ und $50 \mathrm{ml}$

Quarzküvetten (2ml, 1cm Schichtdicke)

Reaktionsgefäße 1,5 $\mathrm{ml}$ und 2,0 ml

UV-transparente Plastikküvetten
Genomed, Bad Oeynhausen

Promega GMBH, Mannheim
Eigene Herstellung

Whatman International Ltd,

Maidstone, England

Sarstedt, Nürnbrecht

Sarstedt, Nürnbrecht

Nalgene, HEreford, England

Glasgerätebau Ochs GmbH, Bovenden

Schott, Mainz

Sartorius, Göttingen

Glasgerätebau Ochs $\mathrm{GmbH}$,

Bovenden

Biozym, Hessisch Oldendorf

Merck KG, Darmstadt

Greiner Bio-One GmbH,

Frickenhausen

Sarstedt, Nürnbrecht

Helma, Müllheim

Sarstedt, Nürnbrecht

Sarstedt, Nürnbrecht 


\section{MATERIALIEN}

\section{Geräte und Laborwerkzeug}

\section{Zentrifugen}

Kühlzentrifuge Rotanta/RPC

Tischzentrifuge (biofuge fresco)

Tischzentrifuge (biofuge pico)

Tischzentrifuge Mikrorapid K

Ultrazentrifuge Centrikon T-1055

(Rotortyp TFT 41.14)

Zentrifuge RC-5C

(Rotortypen SS34 und HB-4)

\section{Laborwerkzeug}

Chronometer

Dissektionsmikroskop, WILD M2O

Haematocytometer Neubauer improved

Heizplatten/Magnetrührer

Mikropipetten

Multipipette

Nikon Alphashot-2YS2, Mikroskop

Vortex ${ }^{\circledR}$ Genie 2

Heraeus Holding GmbH, Hanau

Heraeus Holding GmbH, Hanau

Heraeus Holding GmbH, Hanau

Hettich, Bäch, Schweiz

Kendo, Langenselbold

Sorvall, Bad Naulheim

Carl Roth GmbH \& Co, Karlsruhe

WILD Heerbrugg, Gais, Schweiz

Karl Hecht GmbH\&Co KG,

Sondheim/Rhön

$\mathrm{IKA}^{\circledR}$ Werke $\mathrm{GmbH} \&$ Co. KG,

Staufen

Gilson, USA

Eppendorf AG, Hamburg

Nikon Instruments Europe B.V.,

Amstelveen, Niederlande

Bender \& Hobein, Zürich,Schweiz

\section{Dokumentation/Analyse/Aufbereitung}

Feinwaagen (L 420 P, U4800 P)

pH-Meter (526, Multical ${ }^{\circledR}$ )

Photometer UV-1601

Ultrafree-20 Nanopore-Wasseranlage

(Filtereinheiten Millex FG13)

UV-System MW 312nm

(inkl. Kamera und Bearbeitungsprogramm)

UV-Transilluminator (UV2035 302nm)

Sartorius, Göttingen

WTW, Weilheim

Shimadzu Europa GmbH, Duisburg

Millipore, Eschenborn

INTAS, Göttingen

Herolab, Weisloch

\section{Elektrophorese}

Gelkammer für Agarosegele

Power Supply ECPS 3000/150

Institutsinterner Eigenbau

Pharmacia (heute Phadia), Uppsala,

Schweden

Power Supply LNGs 350-06

Heinzinger electronic $\mathrm{GmbH}$,

Rosenheim 


\section{Inkubation/Aufbewahrung}

Brutschrank

Freezer VIP Series $-80^{\circ} \mathrm{C}$

\section{PCR-Cycler}

Biometra UNO II

Thermocycler Primus 96 Plus

\section{Sonstiges}

Envirco Sterilbank

LaminAir HA2448 Sterilbank

UV-Lampe $254 \mathrm{~nm}$

\section{SOFTWARE}

Chem.Sketch 12.0

Corel DrawC Graphic Suite 12

Endnote 10.0

Programm zur Mutationsratenbestimmung

Sigma Plot 10.0

Vector NTI 11.0
Heraeus Holding GmbH, Hanau

SANYO Sales \& Marketing Europe

$\mathrm{GmbH}$, München

Biometra biomedizinische Analytik

GmbH, Göttingen

MWG-Biotech

CEAG Shirp Reinraumtechnick

Heraeus Holding GmbH, Hanau

Schütt Labortechnik, Göttingen

ACD Labs, Toronto, Kanada

Corel Corporation, Ottawa, Kanada

Thomson Reuters, London, England

Institutsintern programmiert von

Steffen Schmidt

Systat Software Inc., Chicago, USA

Invitrogen $\mathrm{GmbH}$, Karlsruhe

\section{PUFFER UND LÖSUNGEN}

Alle Lösungen und Puffer wurden mit Millipore-gereinigtem Wasser angesetzt. Soweit nicht anders vermerkt, sind alle Prozentangaben in w/v. Alle Konzentrationsangaben sind auf das Endvolumen der Stammlösungen bezogen.

\section{Stocklösungen}

\section{Ampicillin-Lösung}

$100 \mathrm{mg} / \mathrm{ml}$ Ampicillin-Natriumsalz in Wasser gelöst, Lagerung bei $-20^{\circ} \mathrm{C}$.

\section{APS}

$10 \%$ Ammoniumpersulfat in Wasser. Steril filtriert. Lagerung bei $-20^{\circ} \mathrm{C}$.

\section{$\alpha-F a k t o r$}

$2 \mathrm{mg} / \mathrm{ml} \alpha$-Faktor in Ethanol. Lagerung bei $4^{\circ} \mathrm{C}$. 


\section{MATERIALIEN}

Camptothecin Stammlösung

$5 \mathrm{mg} / \mathrm{ml}$ Camptothecin in DMSO. Lagerung bei $4^{\circ} \mathrm{C}$.

\section{L-Canavanin Lösung}

2\% L-Canavanin in Wasser. Steril filtriert. Lagerung bei $4^{\circ} \mathrm{C}$.

\section{Carrier DNA Lösung}

$2 \mathrm{mg} / \mathrm{ml}$ Lachsspermin DNA in Aktivkohle gereinigtem Wasser. Aufgekocht für 5 Min. bei ca. $100^{\circ} \mathrm{C}$, danach Lagerung bei $-20^{\circ} \mathrm{C}$.

\section{DT'T Stammlösung}

1 M 1,4 Dithiothreitol in Wasser. Steril filtriert. Lagerung bei $-20^{\circ} \mathrm{C}$.

\section{EDTA Stammlösung}

500 mM EDTA unter Zugabe von $\mathrm{NaOH}$ in Wasser gelöst.

\section{Ethidiumbromid-Lösung}

$10 \mu \mathrm{g} / \mathrm{ml}$ Ethidiumbromid in Wasser.

\section{Glukose-Stammlösung}

$2 \mathrm{M}$ Glukose in Wasser. Autoklaviert für $20 \mathrm{Min}$. bei $121^{\circ} \mathrm{C}$.

\section{Kaliumacetat Stammlösung}

$7 \mathrm{M}$ Kaliumacetat in Wasser. Autoklaviert für $20 \mathrm{Min}$. bei $121^{\circ} \mathrm{C}$.

\section{Lithiumacetat Stammlösung}

$1 \mathrm{M}$ Lithiumacetat in Aktivkohle gereinigtem Wasser. Autoklaviert für $20 \mathrm{Min}$. bei $121^{\circ} \mathrm{C}$.

\section{$\mathrm{MgCl}_{2}$ Stammlösung}

$1 \mathrm{M} \mathrm{MgCl}_{2}$ in Wasser. Autoklaviert für $20 \mathrm{Min}$. bei $121^{\circ} \mathrm{C}$.

\section{$\mathrm{MgSO}_{4}$ Stammlösung}

$1 \mathrm{M} \mathrm{MgSO}_{4}$ in Wasser. Autoklaviert für $20 \mathrm{Min}$. bei $121^{\circ} \mathrm{C}$. 


\section{MMS Stammlösung}

$10 \%$ oder 1\% (v/v) Methylmethansulfonat in Ethanol, direkt vor Benutzung angesetzt.

\section{Natriumthiosulfat Stammlösung}

$10 \%(\mathrm{v} / \mathrm{v})$ Natriumthiosulfat in Wasser, direkt vor Benutzung vermischt. Steril filtriert.

dNTP's

je $100 \mathrm{mM}$ in Wasser Steril filtriert. Lagerung bei $-20^{\circ} \mathrm{C}$.

\section{Nourseothricin-Lösung}

$100 \mathrm{mg} / \mathrm{ml}$ in Wasser. Steril filtriert. Lagerung bei $4^{\circ} \mathrm{C}$.

\section{4-NQO Stammlösung}

2,5 mg/ml, $25 \mathrm{mg} / \mathrm{ml}$ und $250 \mathrm{mg} / \mathrm{ml}$ 4-NQO in Ethanol. Lagerung bei $4^{\circ} \mathrm{C}$.

\section{Sorbitol Stammlösung}

1 M Sorbitol in Wasser. Steril filtriert.

\section{Yeast Lytic Enzyme Stocklösung}

$2 \mathrm{mg} / \mathrm{ml}$ Yeast Lytic Enayme in Wasser. Lagerung bei $4^{\circ} \mathrm{C}$.

\section{Puffer und Gele}

\section{X\%-Agarose für Geleelektrophorese}

$\mathrm{X} \%(\mathrm{w} / \mathrm{w})$ Agarose in $1 \mathrm{x}$ TBE-Puffer bei $300^{\circ} \mathrm{C}$ auf einer Heizplatte aufgekocht, bis eine klare Lösung entstanden ist. Lagerung bei $65^{\circ} \mathrm{C}$.

\section{Enzym Puffer}

Puffer für Restriktionsenzyme von NEB und Fermentas; HF-Puffer für Phusion-Polymerase von NEB; T4-Ligasepuffer von Fermentas.

\section{JetStar ${ }^{\mathrm{TM}}$ E1}

$50 \mathrm{mM}$ Tris- $\mathrm{HCl} \mathrm{pH}$ 8,0, $10 \mathrm{mM}$ EDTA.

\section{JetStar ${ }^{\text {TM }}$ E2}

$200 \mathrm{mM} \mathrm{NaOH}, 1 \%$ SDS. 


\section{MATERIALIEN}

JetStar $^{\text {TM }}$ E3

3,1 M Kaliumacetat pH 5,5.

JetStar ${ }^{\mathrm{TM}}$ E4

$600 \mathrm{mM} \mathrm{NaCl}, 1 \mathrm{mM}$ Natruimacetat, 0,15\% Triton X-100, pH 5,0.

JetStar ${ }^{\mathrm{TM}}$ E5

$800 \mathrm{mM} \mathrm{NaCl}, 100 \mathrm{mM}$ Natruimacetat, $\mathrm{pH}$ 5,0.

JetStar ${ }^{\mathrm{TM}}$ E6

1,25 M NaCl, 100 mM Tris-HCl pH 8,5.

\section{0x KGB-Puffer}

$1 \mathrm{M}$ Kaliumglutamat, $250 \mathrm{mM}$ Tris- $\mathrm{HCl} \mathrm{pH}$ 7,5, $100 \mathrm{mM}$ Magnesiumacetat, $5 \mathrm{mM}$ 2-Mercaptoethanol in Wasser.

\section{PEG 50\%}

$50 \%$ (v/v) Polyethylenglycol MW 4.000, 2,5 M NaCl in Aktivkohle gereinigtem Wasser. Autoklaviert für 20 Min bei $121^{\circ} \mathrm{C}$.

\section{Saccharosefarbmarker}

60\% Sucrose, 0,01\% Bromphenolblau, 0,01\% Xylen Cyanol ff in TBE-Puffer.

\section{Saccharosegradienten-Puffer}

$100 \mathrm{mM}$ Tris-HCL pH 8,0, $100 \mathrm{mM} \mathrm{NaCl}, 10 \mathrm{mM}$ EDTA in Wasser, zuzüglich 40, 30 bzw. 10\% Saccharose. Bei 30\%-igem Puffer zusätzlich 0,01\% Bromphenolblau hinzugegeben. Autoklaviert für $20 \mathrm{Min}$. bei $121^{\circ} \mathrm{C}$.

\section{SCE-Puffer}

1 M Sorbitol, $100 \mathrm{mM}$ tri-Natriumcitrat, $60 \mathrm{mM}$ EDTA in Wasser.

\section{0x Taq-Puffer}

$500 \mathrm{mM} \mathrm{KCl}, 100$ mM Tris- $\mathrm{HCl}$ pH 9,0, $15 \mathrm{mM} \mathrm{MgCl}_{2}, 1 \%$ Triton X-100 in Wasser. Steril filtriert.

\section{0x TBE-Puffer}

0,89 M Tris-Borat, $25 \mathrm{mM}$ EDTA in Wasser.

\section{TBS Tween}

1x TBS mit 0,05\% (v/v) Tween 20. 


\section{TE-Puffer}

$10 \mathrm{mM}$ Tris- $\mathrm{HCl} \mathrm{pH}$ 8,0, 0,5 mM EDTA in Wasser. Steril filtriert.

\section{TES-Puffer}

$50 \mathrm{mM}$ Tris- $\mathrm{HCl} \mathrm{pH}$ 8,0, $50 \mathrm{mM}$ EDTA, 1\% SDS in Wasser. Steril filtriert.

\section{Transformationspuffer (Hanahan)}

$10 \mathrm{mM}$ PIPES, $15 \mathrm{mM} \mathrm{CaCl}_{2}, 250 \mathrm{mM} \mathrm{KCl}$ in Wasser und auf $\mathrm{pH} \mathrm{6,7} \mathrm{eingestellt.} \mathrm{An-}$ schließend $\mathrm{MnCl}_{2}$ ad $55 \mathrm{mM}$ zugegeben.

\section{NÄHRMEDIEN}

Alle Medien wurden mit Millipore-gereinigtem Wasser angesetzt. Prozentangaben stellen w/v-Angaben dar. Die Medien wurden, soweit nicht anders angegeben, für $20 \mathrm{Min}$. bei $121^{\circ} \mathrm{C}$ autoklaviert. Antibiotika wurden nach dem Autoklavieren bei etwa $60-70^{\circ} \mathrm{C}$ zugegeben. Für Platten wurden jeweils 1,5\% (E. coli) bzw. 1,8\% (S. cerevisiae) Bactoagar dazugegeben.

\section{E. coli}

Bei folgenden Medien wurden im späteren Text die entsprechenden Medien mit $100 \mu \mathrm{g} / \mathrm{ml}$ Ampicilin bzw. $75 \mu \mathrm{g} / \mathrm{ml}$ Kanamycin mit amp ${ }^{100}$ bzw kan $^{75}$ gekennzeichnet.

\section{dYT}

1,6\% Trypton, $1 \%$ Yeast Extract in Wasser. Autoklaviert für $20 \mathrm{Min}$. bei $121^{\circ} \mathrm{C}$.

\section{LB}

1\% Trypton, $0,5 \%$ Yeast Extract, $1 \% \mathrm{NaCl}$ in Wasser.

\section{SOC}

$2 \%$ Trypton, 0,5\% Yeast Extract, $10 \mathrm{mM} \mathrm{NaCl}, 2,5 \mathrm{mM} \mathrm{KCl}$ in Wasser. Autoklaviert für 10 Min. bei $121^{\circ} \mathrm{C}$. Anschließend $\mathrm{MgCl}_{2}$ ad $10 \mathrm{mM}, \mathrm{MgSO}_{4}$ ad $10 \mathrm{mM}$ und Glukose ad $20 \mathrm{mM}$ aus autoklavierten Stammlösungen dazugeben.

\section{S. cerevisiae}

\section{CAN}

Wie SC $_{- \text {Arg }}$ zuzüglich $40 \mu \mathrm{g} / \mathrm{ml}$ L-Canavanin.

\section{DM}

2\% Glukose, 0,5\% Pepton, 1\% Yeast Extract, 0,3\% Beef Extract, 1x Amminosäuremixtur (siehe Tab. 2) in Wasser. Verwendung des Dissektionsmediums nur als Platten. Statt 1,8\% 


\section{MATERIALIEN}

wurde hierbei 2,5\% Bactoagar zugegeben. Für jede Platte wurden $37 \mathrm{ml}$ Medium möglichst heiß in eine Petrischale mit $85 \mathrm{~mm}$ Durchmesser gegossen.

\section{KAc}

2\% Kaliumacetat, 0,23\% Yeast Extract, 0,05\% Glukose, 1x Aminosäuremixtur (siehe Tab. 2) in Wasser.

\section{Pre5}

10\% Glukose, 0,3\% Pepton, 0,8\% Yeast Extract in Wasser.

\section{$\mathrm{SC}$}

2\% Glukose in Wasser und 0,17\% Yeast Nitrogen Base w/o Amminoacids and Ammonium Sulfate, $0,51 \%\left(\mathrm{NH}_{4}\right)_{2} \mathrm{SO}_{4}, 1 \mathrm{x}$ Aminosäuremixtur in Wasser jeweils getrennt autoklaviert und anschließend vereinigt. Der Agar wurde mit der Glukose zusammen autoklaviert. Flüssigmedium wurde steril filtriert. Die Zusammensetzung der Aminosäuremixtur ist in Tab. 2 festgehalten.

\section{SC-x (Drop-Out Medium)}

Wie SC, jedoch ohne die Komponente X in der Aminosäuremixtur, d.h. bei SC -Arg $_{\text {wrde }}$ eine Aminosäuremixtur ohne Arginin verwendet.

\section{YPD}

2\% Pepton, 2\% Glukose, 1\% Yeast Extract in Wasser.

\section{YPD G418}

Wie YPD zuzüglich $200 \mu \mathrm{g} / \mathrm{ml} \mathrm{G418.}$

\section{YPD nat}

Wie YPD zuzüglich $100 \mu \mathrm{g} / \mathrm{ml}$ Nourseothricin.

Tab. 2: Zusammensetzung der Aminosäuremixtur für synthetisches Komplettmedium (SC).

Angegeben ist die jeweilige Endkonzentration im Medium.

\begin{tabular}{lclr}
\hline Aminosäure/Base & Endkonz. & Aminosäure/Base & Endkonz. \\
\hline \hline Adenin & $40 \mathrm{mg} / 1$ & L-Phenylalanin & $50 \mathrm{mg} / 1$ \\
L-Arginin & $30 \mathrm{mg} / 1$ & L-Serin & $100 \mathrm{mg} / 1$ \\
L-Histidin & $20 \mathrm{mg} / 1$ & L-Threonin & $150 \mathrm{mg} / 1$ \\
L-Isoleucin & $30 \mathrm{mg} / 1$ & L-Tryptophan & $30 \mathrm{mg} / 1$ \\
L-Leucin & $30 \mathrm{mg} / 1$ & L-Tyrosin & $30 \mathrm{mg} / 1$ \\
L-Lysin-HCl & $30 \mathrm{mg} / 1$ & Uracil & $20 \mathrm{mg} / 1$ \\
L-Methionin & $20 \mathrm{mg} / 1$ & L-Valin & $100 \mathrm{mg} / 1$ \\
\hline
\end{tabular}




\section{MOLEKULARBIOLOGISCHE METHODEN}

\section{Allgemeine Methoden}

Folgende grundlegende molekularbiologische Methoden wurden im Rahmen dieser Arbeit angewandt. Die jeweilige Durchführung ist jedoch im Weiteren nicht explizit ausgeführt. Für einen Überblick über die Funktionsweise und für gängige Protokolle siehe Lottspeich \& Engels, 2006 oder Walker, 1984.

Agarosegelelektrophorese ${ }^{1}$

Denaturierende Polyacrylamidgelelektrophorese (SDS-PAGE)

Ethanolfällung von Nukleinsäuren

Extraktion von Plasmid-DNA aus E. coli via alkalischer Lyse ${ }^{2}$

Ligation geschnittener DNA-Fragmente ${ }^{4}$
Phenol-/Chloroformextraktion

Photometrische Konzentrationsbestimmung von Nukleinsäurelösungen

Polymerasekettenreaktion (PCR)

Restriktionsverdau von $\mathrm{DNA}^{3}$

Saccharosegradientenzentrifugation

\section{Klonierungen}

\section{YIplac211 KanKanMX4/YIplac128 KanKanMX4}

Zur Integration ins Chromosom von S. cerevisiae wurde das KanKanMX4-Modul in die Vektoren YIplac128 und YIplac211 (Gietz \& Sugino, 1988) kloniert. Dazu wurde das Modul als EcoRI/SalI-Fragment aus dem originalen Plasmid pRS316 KanKanMX4 herausgeschnitten und in den Vektor YIplac211 kloniert. Eine genauere Beschreibung der Klonierung ist in Rudolph, $2003 \mathrm{zu}$ finden. Für die Umklonierung in YIplac128 wurde das EcoRI/SalI-Fragment aus YIplac211 KanKanMX4 per gleichzeitigem Doppelverdau herausgeschnitten (Puffer $\mathrm{O}^{+}$, Fermentas). Der Zielvektor YIplac128 wurde entsprechend geschnitten. Sowohl Insert als auch Vektor wurden via Agarosegelelektrophorese aufgereinigt und das Vektorfragment anschließend per Saccharosegradientenzentrifugation zusätzlich gereinigt. Die gereinigten Fragmente wurden in einem ungefähren Mengenverhältnis 1:4 (Vektor zu Insert) mithilfe von T4-Ligase bei $4^{\circ} \mathrm{C}$ über Nacht ligiert. Mit dem Ligationsprodukt

\footnotetext{
${ }^{1}$ Für alle Gele wurden Agarosegele mit 0,7-1\% Agarose in TBE-Puffer benutzt.

${ }^{2}$ Für die Extraktion von Plasmid-DNA aus E. coli wurde das JetStar ${ }^{\circledR} 2.0$ Kit (Genomed) verwendet. Wurden nur geringe Mengen Plasmid gebraucht, wie bspw. bei der Analyse von Transformanten, so wurde die DNALösung nach Fällung der chromosomalen DNA und Proteine mit Phenol und Chloroform extrahiert anstatt über eine JetStar® Säule gereinigt zu werden.

${ }^{3}$ Verdaue mit Restriktionsenzymen wurden entsprechend der Herstellervorgaben durchgeführt.

${ }^{4}$ Zur Aufreinigung der Restriktionsfragmente bei Klonierungen wurden die elektrophoretisch aufgetrennten DNA-Fragmente aus dem Agarosegel mithilfe des Wizard® SV Gel und PCR Clean-Up System (Promega) extrahiert (präparative Gelelektrophorese).
} 


\section{METHODEN}

wurden anschließend chemisch kompetente E. coli-Zellen (DH5a, nach Hanahan, s.u.) transformiert und die Transformanten auf LB-amp ${ }^{100}$ selektiert. Die Plasmid-DNA ausgewählter Transformanten wurde durch alkalische Lyse der Zellen extrahiert. Analysiert wurden die extrahierten Plasmide per AflII-, AflIII- und HaeII-Spaltung. Die Spaltung mit AflII diente als Evidenz für die Anwesenheit des KanKanMX4-Moduls im Vektor und die Spaltungen mit AflIII und HaeII der Identifikation des Vektorgerüsts. Für einen Überblick über die Restriktionsschnittstellen siehe Vektorkarten Seite 30/31. Die Gelbilder der analytischen Spaltungen sind im Anhang Abb. A1 zu finden.

\section{YIplac128 REV3 flength}

Für die Klonierung des REV3-Wildtypfragments wurde der Vektor pJA6 (Morrisonet al., 1989) mit EcoRI und SalI geschnitten (Doppelverdau in Puffer $\mathrm{O}^{+}$, Fermentas). Das Fragment wurde über eine präparative Agarosegelelektrophorese aufgereinigt. Der Zielvektor YIplac128 wurde ebenfalls mit EcoRI und SalI gespalten und per präparatives Agarosegel und anschließender Saccharosegradientenzentrifugation aufgereinigt. Die gereinigten Fragmente wurden in einem ungefähren Mengenverhältnis 1:4 (Vektor zu Insert) gemischt. Ligiert wurde mithilfe der T4-Ligase bei $4^{\circ} \mathrm{C}$ über Nacht. Anschließend wurden chemisch kompetente E. coli-Zellen (DH5 $\alpha$, nach Hanahan s.u.) mit dem Ligationsprodukt transformiert und die Transformanten auf LB-amp ${ }^{100}$ selektiert. Zur Analyse wurde Plasmid-DNA per alkalische Lyse aus ausgewählten Transformanten extrahiert und mit Restriktionsenzymen gespalten. Dazu wurden die Enzyme NcoI, HincII und AcuI benutzt. Für einen Überblick über die Restriktionsschnittstellen siehe Vektorkarten Seite 30/31. Die Gelbilder der analytischen Spaltungen sind im Anhang Abb. A2 zu finden.

\section{YIplac211 PHR1 flength}

Für die Herstellung eines Vektors mit dem Wildtyp PHR1-Fragment wurde ein Sequenzabschnitt des PHR1 ausgewählt, der in etwa dem komplementierfähigen PvuII-Fragment aus Schildet al., 1984 entspricht. Dieses Fragment wurde mithilfe der Primer 5'PHR1_flength und 3'PHR1_flength amplifiziert und in den Vektor pCR® Blunt II TOPO® (Invitrogen) zwischenkloniert. Transformanten wurden auf LB-kan ${ }^{75}$ selektiert. Die Plasmid-DNA ausgewählter Transformanten wurde per alkalische Lyse extrahiert und die gesuchten Plasmide wurden durch Spaltung mit ClaI, SmaI und BamHI + PstI identifiziert. Anschließend wurde das Fragment durch Doppelverdau mit BamHI und PstI (KGB-Puffer) aus einem geeigneten Vektor herausgeschnitten und per präparative Agarosegelelektrophorese aufgereinigt. Da sich Vektorfragment und Insert nur um ca. 200 bp in der Größe unterscheiden, wurde der Ansatz zusätzlich mit SmaI gespalten, welches das Vektorfragment in ein 1.527 bp und ein 1.993 bp großes Fragment spaltet. Anschließend wurden die Fragmente elektrophoretisch in einem Agarosegel aufgetrennt und das $3.283 \mathrm{bp}$ große PHR1-Fragment aus dem Gel extrahiert. Der Zielvektor YIplac211 wurde ebenfalls mit BamHI und PstI geschnitten (Doppelverdau, KGB-Puffer) und per präparative Agarosegelelektrophorese aufgereinigt. Zusätzlich wurde der Vektor durch Saccharosegradientenzentrifugation weiter gereinigt. Ligiert wurde mit T4-Ligase in einem Mengenverhältnis von ca. 1:4 (Vektor zu Insert) bei $4^{\circ} \mathrm{C}$ über Nacht. Transformiert wurden chemisch kompetente 
E. coli-Zellen (DH5 $\alpha$, nach Hanahan, s.u.). Die Transformanten wurden auf LB-amp ${ }^{100}$ selektiert und die Plasmid-DNA ausgewählter Transformanten per alkalischer Lyse extrahiert. Eine Vorauswahl möglicher korrekter Plasmide wurde anhand von Spaltungen mit AflII, EcoRV und SspI getroffen. Eine als wahrscheinlich korrekt identifizierte Transformante wurde anschließend sequenziert ( $\mathrm{G}_{2} \mathrm{~L}$, Göttingen). Dazu wurden die Primer 5'phr1_seq_1 bis 5'phr1_seq_6 sowie 3'phr1_seq_1 bis 3'phr1_seq_6 benutzt. Da in dem sequenzierten Vektor zwei direkt aufeinander folgende $\mathrm{C}$ nach $\mathrm{T}$ Transitionen im PHR1 ORF vorlagen, wurde anschließend ein AflII/ClaI-Fragment des Klons durch Umklonieren eines entsprechenden zuvor sequenzierten Fragments aus einem anderen TOPOPHR1-Klon ersetzt. Kloniert wurde entsprechend der zuvor für BamHI/PstI dargestellten Durchführung. Das erhaltene Plasmid wurde sequenziert. Die Gelbilder zu der Klonierung sind im Anhang zu finden (Abb. A3). Für einen Überblick über die Restriktionsschnittstellen siehe Vektorkarten Seite 30/31.

\section{Extraktion chromosomaler DNA aus Saccharomyces cerevisiae als Matrize für PCR}

Je $2 \mathrm{ml}$ Übernachtkultur des benötigten Stammes wurden sedimentiert (Heareus Biofuge fresco, $13.000 \mathrm{rpm}$ für $2 \mathrm{Min}$.) und in $500 \mu \mathrm{l}$ SCE-Puffer mit $50 \mathrm{mM}$ DTT resuspendiert. Anschließend wurde die Suspension mit $200 \mu \mathrm{g} / \mathrm{ml}$ Yeast Lytic Ensyme $(150 \mathrm{kU} / \mathrm{g})$ versetzt und eine Stunde bei $37^{\circ} \mathrm{C}$ inkubiert. Yeast Lytic Enzyme ist ein aus Rhizoctonia solani bzw. Arthrobacter luteus gewonnenes Gemisch aus $\beta-1,3-G l u k a n a s e$, Protease, Hemizellulase, Pektinase und Amylase und wird benutzt, um Zellwände von Pilzen zu zersetzen. Durch die Zugabe von DTT wird dieser Vorgang unterstützt, da DTT Sulfidbrücken in der Zellwand reduziert (Cleland, 1964). Weil durch diese Behandlung die Zellmembran intakt bleibt und nur die Zellwand abgebaut wird, entstehen hierbei so genannte Spheroblasten. Durch das Sorbitol im SCE-Puffer bleiben diese Spheroblasten osmotisch stabil und konnten daher durch vorsichtiges Zentrifugieren (5 Min bei $3.000 \mathrm{rpm}$, Heareus Biofuge fresco) geerntet werden. Reste der Zellwand blieben dabei im Überstand und wurden mit diesem entfernt. Die Spheroblasten wurden anschließend in $500 \mu \mathrm{l}$ TES-Puffer resuspendiert und für 30 Min. bei $60^{\circ} \mathrm{C}$ lysiert. Das SDS im TES-Puffer fungiert als Detergens, welches Proteine denaturiert und die Zellmembran auflöst, was durch die erhöhte Temperatur unterstützt wird. Durch Zugabe von $170 \mu \mathrm{l}$ 7M Kaliumacetat wurde das SDS als Kaliumdodecylsulfat ausgefällt. Denaturierte Proteine fallen dabei mit aus. Unterstützt wurde die Fällung durch einstündige Inkubation auf Eis. Anschließend wurde das ausgefällte KaliumdodecylsulfatProteingemisch abzentrifugiert (13.000 rpm für 30 Min. bei $4{ }^{\circ} \mathrm{C}$, Haereus Biofuge fresco) und der Überstand abgenommen. Die DNA wurde aus dem Überstand mit dem 2-fachen Volumen Ethanol präzipitiert. Eine Zugabe von Ammoniumacetat war dabei nicht notwendig, da im Überstand bereits genügend Salze vorhanden sind, um die DNA ausfällen zu können. 


\section{METHODEN}

\section{MIKROBIOLOGISCHE METHODEN}

Für einen generellen Überblick über die Handhabung der Bäckerhefe Saccharomyces cerevisiae siehe Guthrie and Fink, 1991.

\section{Anzucht von Mikroorganismen}

\section{Escherichia coli}

Das Bakterium E. coli wurde im Rahmen dieser Arbeit für die Amplifikation von Plasmid-DNA benutzt. Aufgrund der hohen Wachstumsrate kann über Nacht eine große Menge Zellmaterial angezogen werden, aus der Plasmid-DNA extrahiert werden kann. Gezogen wurden die Zellen über Nacht bei $37^{\circ} \mathrm{C}$ in einem Inkubationsroller bzw. Schüttler (Flüssigmedium, je nach Volumen) oder Brutschrank (Platten). Für Wachstum in Flüssigmedium wurde dYT verwendet, für das Wachstum auf Platten LB-Medium mit 1,5\% (w/v) Bactoagar. Zur Selektion der Plasmid-tragenden Zellen wurde dem Medium das entsprechende Antibiotikum beigefügt. Gelagert wurden die Kulturen in der Regel als Plattenausstrich bei $4^{\circ} \mathrm{C}$. Zur langfristigen Lagerung wurden Übernachtkulturen mit 50\% Glycerin versetzt und bei $-20^{\circ} \mathrm{C}$ aufbewahrt.

\section{Saccharomyces cerevisiae}

Kulturen von S. cerevisiae wurden bei $30^{\circ} \mathrm{C}$ in synthetischem Selektivmedium (SC-X) oder YPD wachsen gelassen. Flüssigkulturen wurden je nach Volumen im Inkubationsroller oder im Schüttler angezogen. Für Wachstum auf Platten wurden entsprechende Medien mit 1,8\% Bactoagar verwendet. In der Regel wurden sowohl Flüssig- als auch Plattenausstriche über Nacht inkubiert. Für den Fall, dass ein Zelltiter durch Ausplattieren ermittelt werden sollte, waren je nach Stamm zwei bis vier Tage Inkubation notwendig, um sichtbare Kolonien zu erhalten. Als Plattenausstrich wurden Stämme bis zu einem Monat bei $4^{\circ} \mathrm{C}$ gelagert. Für langfristige Lagerung wurden $2 \mathrm{ml}$ Flüssigkulturen zu 7\% (v/v) mit DMSO versetzt und bei $-80^{\circ} \mathrm{C}$ eingefroren.

\section{Methoden zur genetischen Manipulation von Mikroorganismen}

\section{Transformation von chemisch kompetenten $E$. coli nach Hanahan}

Für die Transformation von E. coli wurden chemisch kompetente DH5 $\alpha$ benutzt. Diese wurden nach Hanahan, 1983 präpariert. Dazu wurden die Zellen bei möglichst guter Sauerstoffzufuhr und $18^{\circ} \mathrm{C}$ bis zu einer $\mathrm{OD}_{600 \mathrm{~nm}}$ von ca. 0,5 in SOC-Medium angezogen und anschließend geerntet (10 Min. bei $4.000 \mathrm{rpm}$ und $4^{\circ} \mathrm{C}$, Hettich Rotanta/RPC). Das Zellpellet wurde ab hier permanent auf Eis behandelt und zunächst vorsichtig in $15 \mathrm{ml}$ gekühltem Transformationspuffer resuspendiert. Anschließend wurden die Zellen erneut wie zuvor abzentrifugert und nach $15 \mathrm{Min}$. auf Eis wieder in $15 \mathrm{ml}$ Transformationspuffer resuspendiert. Zusätzlich wurden der Suspension $525 \mu$ DMSO zugesetzt und die Zellen erneut 5 Min. auf Eis inkubiert. Nach weiterer Zugabe von $525 \mu$ DMSO wurde die Sus- 
pension wiederum für 5 Min. auf Eis gehalten. Von der Zellsuspension wurden je $200 \mu \mathrm{l}$ Aliquots abgenommen und bei $-80^{\circ} \mathrm{C}$ eingefroren. Die so kompetent gemachten Zellen wurden bei Bedarf auf Eis aufgetaut und mit 0,5-1 $\mu$ g DNA vermischt. Nach 30-60 Min. Inkubation auf Eis wurden die Zellen für $60 \mathrm{Sek}$. auf $42^{\circ} \mathrm{C}$ erhitzt und danach weitere 23 Min. auf Eis gestellt. Damit sich die Antibiotikaresistenz ausprägen kann, wurden die transformierten Zellen abschließend noch für 60 Minuten bei $37^{\circ} \mathrm{C}$ in $1 \mathrm{ml} \mathrm{SOC-Medium}$ inkubiert. $100 \mu \mathrm{l}$ der Zellsuspension wurden auf Selektivmedium ausplattiert und die restlichen $900 \mu \mathrm{l}$ als Flüssigkultur über Nacht in $50 \mathrm{ml}$ dYT, versetzt mit dem entsprechenden Antibiotikum, angezogen. Die Platten dienten der Überprüfung des Transformationserfolges, die Flüssigkultur zur Präparation des Plasmids via alkalische Lyse.

\section{Transformation von $S$. cerevisiae nach Gietz \& Wodds, 2002}

Für die Transformation von S. cerevisiae wurden $50 \mathrm{ml}$ YPD mit 0,5-1 ml einer frischen Übernachtkultur angeimpft und für 3-5 Std. bei $30^{\circ} \mathrm{C}$ unter Schütteln wachsen gelassen. Anschließend wurden die Zellen geerntet ( 2 Min. bei $4.000 \mathrm{rpm}$ und $4^{\circ} \mathrm{C}$, Hettich Rotanta/RPC) und in $50 \mathrm{ml}$ sterilem Wasser resuspendiert. Danach wurden die Zellen erneut sedimentiert und zunächst in $25 \mathrm{ml}$ sterilem Wasser resuspendiert. Im Anschluss wurden die Zellen noch zweimal abzentrifugiert und jedesmal in $1 \mathrm{ml}$ sterilem Wasser resuspendiert. Von den so gewaschenen Zellen wurden pro Transformationsansatz je $100 \mu \mathrm{l} \mathrm{mit}$ $360 \mu \mathrm{l}$ Transformationsmix vermischt und intensiv gevortext. Die Zusammensetzung des Transformationsmixes ist in Tab. 3 festgehalten. Die Ansätze wurden für 40 Min. bei $42^{\circ} \mathrm{C}$ inkubiert und anschließend für 30 Sek. abzentrifugiert (13.000 rpm, Haereus Biofuge fresco). Der Überstand wurde verworfen und die Zellen wurden in $1 \mathrm{ml}$ sterilem Wasser resuspendiert. Die Suspension wurde auf Selektivmedien ausplattiert. Bei S. cerevisiae kommen neben Antibiotika wie Nourseothrecin und G418 vor allem Prototrophiemarker für die Selektion der Transformanten zum Einsatz. Da bei diesen Markern die nicht transformierten Zellen nur inaktiv sind und nicht sterben, wurden nach zwei bis drei Tagen Wachstum bei $30^{\circ} \mathrm{C}$ ausgewählte Kolonien auf Selektivmedium vereinzelt. Von jeder Vereinzelung wurde eine Kolonie ausgewählt und auf YPD ausgestrichen (bei nicht integrativen Plasmiden auf Selektivmedium). Von diesen Kulturen wurde dann jeweils eine Gefrierkultur angelegt.

Tab. 3: Transformationsmixtur für die Transformation von S. cerevisiae.

\begin{tabular}{lr}
\hline PEG 50\% & $240 \mu \mathrm{l}$ \\
Lithiumacetat $(1 \mathrm{M})$ & $36 \mu \mathrm{l}$ \\
Carrier-DNA $(2 \mathrm{mg} / \mathrm{ml}$ Lachssperma-DNA) & $50 \mu \mathrm{l}$ \\
DNA-Lösung & $34 \mu \mathrm{l}$ \\
(Plasmid oder PCR-Produkt, $0,1-10 \mu \mathrm{g}$ in sterilem Wasser) & $360 \mu \mathrm{l}$
\end{tabular}




\section{PCR-basierte Gendeletion}

Alle in dieser Arbeit benutzten Stämme wurden mithilfe einer PCR-basierten Methode nach Wach et al., 1994 hergestellt. Diese Methode nutzt die Mechanismen der homologen Rekombination für die gerichtete Disruption eines Zielgens. Eine schematische Darstellung dazu ist in Abb. 9 A zu sehen. Hierbei wurde zunächst per PCR das jeweilige Markergen amplifiziert. Als template diente dabei ein das Gen tragendes Plasmid (pFA6aHis3MX6 für Histidinprototrophie). Für die PCR wurde das jeweilige Plasmid zunächst gespalten. Kovalent geschlossene, zirkuläre Plasmide rehybridisieren beim annealings-Schritt sehr schnell und können somit das annealing der primer erschweren. Da die Deletionseffizienz mit steigender DNA-Menge zunimmt, wurde in der Regel das PCR-Produkt von jeweils acht parallel angefertigten PCR-Ansätzen vereinigt und mit Ethanol gefällt. Das gefällte Produkt wurde dann in $34 \mu \mathrm{l}$ sterilem Wasser gelöst und direkt für die Transformation von S. cerevisiae benutzt (siehe „Transformation von S. cerevisiae [...]"). Die zur Amplifikation benutzten primer wurden so definiert, dass jeweils die $40 \mathrm{nt}$ am 5'-Ende eine Sequenzidentität mit dem Zielgen aufweisen. Über diese homologe Sequenz kann das PCR-Produkt nach der Transformation mit dem Zielgen rekombinieren. Durch cross over mit reziprokem Austausch kann es infolgedessen zum Austausch des kompletten Fragments mit dem Zielgen kommen, wodurch letzteres durch das Markergen ausgetauscht wird. Um den Zellen ausreichend Zeit für die Integration des Markergens im Chromsom zu geben, wurden die Zellen nicht wie bei der Transformation mit Plasmid-DNA direkt nach dem Hitzeschock ausplattiert, sondern zunächst für 2-3 Std. bei $30^{\circ} \mathrm{C}$ in ca. $5 \mathrm{ml}$ YPD im Roller inkubiert. Nach der Vereinzelung der Transformanten wurde chromosomale DNA extrahiert, um den Erfolg der Deletion per PCR zu überprüfen (siehe „Extraktion chromosomaler DNA aus S. cerevisiae"). Dazu wurden Primerkombinationen genutzt, wie sie in Abb. 9 B dargestellt sind. Je ein primer, welcher in der chromosomalen Flanke des Zielgens bindet, wurde kombiniert mit einem primer, welcher im Markergen bindet. Bei dieser Kombination sollte nur ein PCR-Produkt der korrekten Länge entstehen, insofern das Zielgen wie gewünscht mit dem Markergen ausgetauscht wurde (Abb. 9 B ii, blaue und graue PCR-Produkte). Die Kombination der primer 5' Zielgen (Z.g.) int und 3' Z.g. int führt dagegen nur zu einem PCR-Produkt in Anwesenheit des Zielgens (Abb. 9 B i, rotes PCR-Produkt). Da das ausgetauschte Zielgen wiederum ebenfalls bspw. durch NHEJ an einer anderen Stelle im Chromosom integrieren kann, ist es notwendig anhand dieser primer zu testen, ob das Zielgen noch im Chromsom vorliegt. Nur wenn anhand dieser Tests Evidenzen für die korrekte Deletion des Gens gefunden wurden, wurden von den entsprechenden Kulturen Gefrierkulturen angelegt und die Stämme für Experimente verwendet.

\section{Verifikation von pol30 K164R-, pol30 K127R- und pol30 K127/164R-Mutanten}

Da die Deletion von POL30 letal ist, musste bei der Konstruktion der pol30 K164R-, pol30 K127R- und pol30 K127/164R-Mutanten vor der Deletion bereits das entsprechende Plasmid mit der jeweiligen Lysin-Substitution integriert werden. Da somit zwei Gen-loci für die Deletion in Frage kamen, musste per PCR überprüft werden, welches der vorliegenden Pol30-Allele deletiert wurde. Dazu wurden zusätzlich zu den zuvor beschriebenen primerKombinationen die primer HisG1 (5'Mar.out) bzw. HisG2 (3'Mar.out) und 3'pol30_screen 
bzw. 5'pol30_screen mit den primern 3'leu2_rev bzw. 5'leu2_rev kombiniert. Die leu2_revprimer binden im Leu2-locus. Bei einer Deletion des neu integrierten pol30-Allels, welches von einem LEU2-Gen und einem leu2-3,112-Gen flankiert ist (vergleiche Abb. 10), kann nur durch Kombination der leu2_rev-primer mit den HisG-primern ein PCR-Produkt entstehen. Bei der Deletion des chromosomalen POL30 ergibt nur die Kombination der leu2_rev-primer mit den pol30_screen-primern ein Produkt. Zusätzlich wurde die K127RSubstitution anhand einer AflII-Schnittstelle überprüft: Durch die Mutation im POL30Gen wurde eine AflII-Schnittstelle innerhalb des Gens generiert. Per PCR mit den POL30internen primern kann diese Region amplifiziert und durch Spaltung des so entstehenden PCR-Produktes die Substitution überprüft werden (ein Bild der Spaltung ist im Anhang zu finden).

A
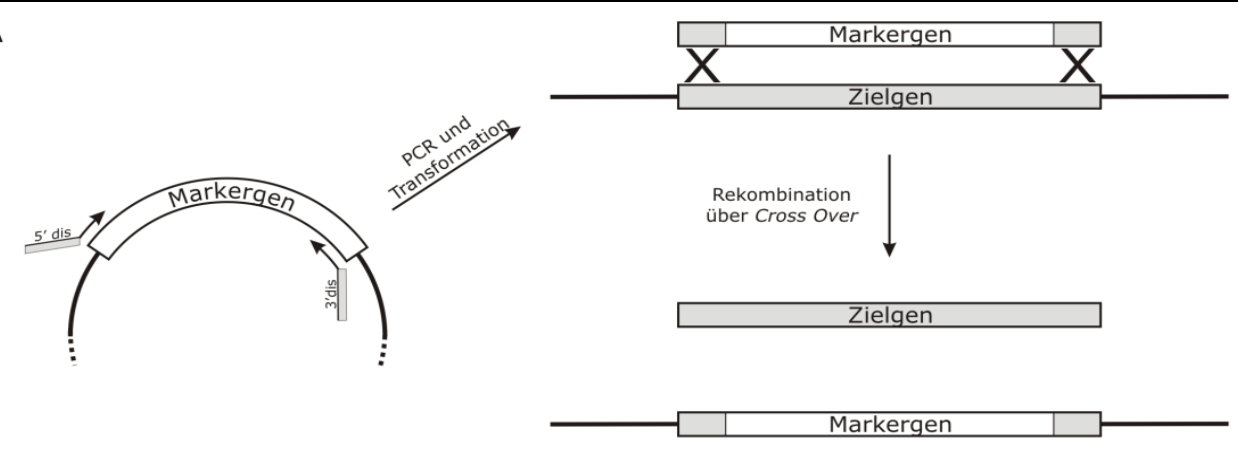

B

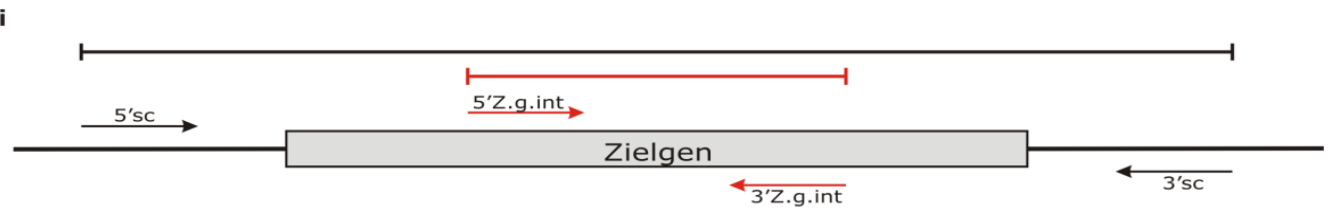

ii

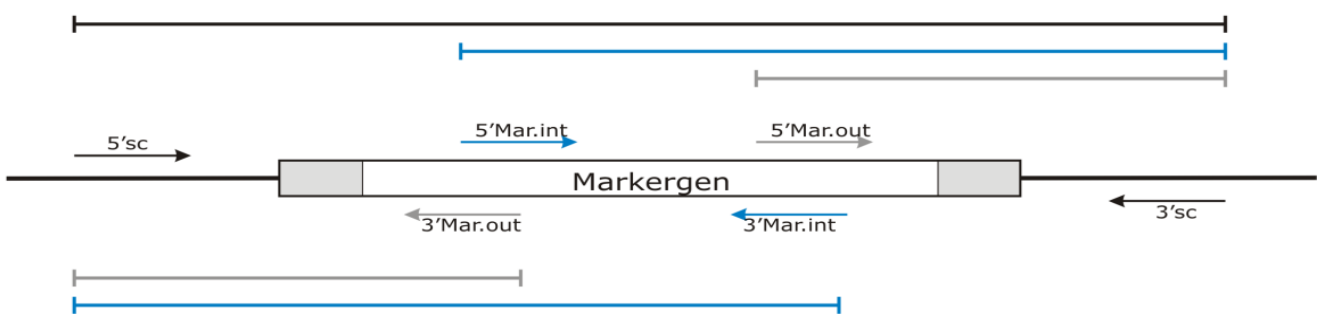

Abb. 9: A Schematische Darstellung der Deletion eines Zielgens durch homologe Rekombination mit einem Markergen. Die primer 5'dis und 3'dis sind im Bild als schwarze Pfeile angedeutet. Ein X kennzeichnet die Stelle der cross over. B Schematische Darstellung der möglichen primer-Kombinationen für einen PCR-screen. Primer sind als Pfeile dargestellt, die möglichen PCR-Produkte als schwarze, graue, blaue und rote Balken. i Anordnung im Wildtyp. ii Anordnung in der Deletionsmutante. 


\section{Chromosomale Integration von YIplac211 bzw. YIplac128}

Die chromosomale Integration der Plasmide YIplac211 und YIplac128 geschieht über homologe Rekombination des Plasmids mit dem chromosomalen leu2-3,112 (im Falle von YIplac128) bzw. ura3-52 (im Falle von YIplac211) im Rezipientenstamm. Eine schematische Darstellung dazu ist in Abb. $10 \mathrm{zu}$ finden. Die Plasmide enthalten das jeweilige Gen als Wildtypallel. Durch Rekombination des Wildtypallels mit dem jeweiligen chromosomalen Allel kann das gesamte Plasmid über zwei cross over in das Chromosom am leu2-3,112 bzw. ura3-52 integriert werden. Da das Plasmid selbst nicht über einen $A R S$ verfügt, kann es als Episom nicht repliziert werden. Erst nach Integration in das Chromosom wird es mitrepliziert. Für die Integration wurden zunächst 5-10 $\mu \mathrm{g}$ des Plasmids mit dem Restriktionsenzym AflII (YIplac128-Derivat) oder EcoRV (YIplac211-Derivat) in einem $40 \mu$ l-Ansatz gespalten. Die Enzyme schneiden im LEU2 bzw. URA3 und generieren somit Enden, welche die homologe Rekombination initiieren können. Der Erfolg der Spaltung wurde per Agarosegelelektrophorese überprüft und der restliche Spaltungsansatz direkt für die Transformation des gewünschten Hefestammes benutzt (siehe „Transforma-

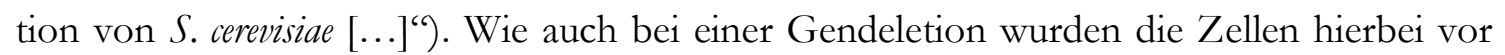
dem Plattieren für 2-3 Std. bei $30^{\circ} \mathrm{C}$ in 5-10 ml YPD gekurt. Da das funktionsfähige URA3 bzw. LEU2 zusammen mit dem Plasmid ins Chromosom integriert wird, lässt sich der Erfolg der Integration durch Selektion und nachfolgende Vereinzelung der Transformanten überprüfen. Die Vereinzelung ist dabei notwendig, da eine Zelle mit episomalen Plasmid ebenfalls das funktionsfähige Markgern besitzt und daher immer noch teilungsfähig ist. Zwar können die Tochterzellen nicht wachsen, da das episomale Plasmid nicht repliziert wird, dennoch können sich durch Vererbung der mRNA bzw. des Proteins kleine Kolonien bilden. Bei einer Vereinzelung solcher Kolonien entstehen jedoch keine weiteren Kolonien, da nur eine einzelne Zelle der Kultur das Plasmid trägt. Neben der Integration des kompletten Plasmids kann auch eine Genkonversion zwischen Plasmid und Chromosom stattfinden, wobei das intakte Wildtypgen ins Chromosom integriert wird. Daher wurde die Anwesenheit des vollständigen Plasmids im Chromosom nachfolgend in den ausgesuchten Einzelklonen überprüft. Im Falle von YIplac128- bzw. YIplac211-KanKanMX4 geschah

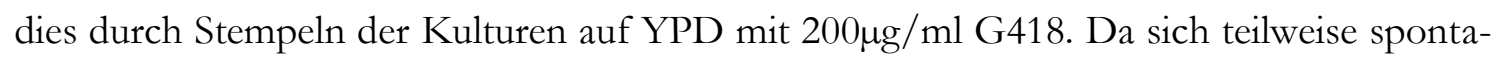
ne Revertanten des KanKanMX4 bilden, entstehen bei Anwesenheit des Moduls einzelne G418 resistente Kolonien, so genannte Papillen. Das Auftreten solcher Papillen ist daher ein hinreichendes Indiz für die Anwesenheit des KanKanMX4-Moduls. Gleichzeitig ließen sich so Transformanten identifizieren, welche bereits bei der Vereinzelung eine Reversion aufwiesen und somit vollständig resistente Kulturen bildeten. Bei den restlichen in dieser Arbeit benutzten integrativen Plasmiden wurde die Anwesenheit bzw. Funktionsfähigkeit phänotypisch in Bezug auf die Sensitivität gegen DNA-schädigende Agenzien überprüft, was in den entsprechenden Kapiteln des Ergebnisteils angesprochen wird. 


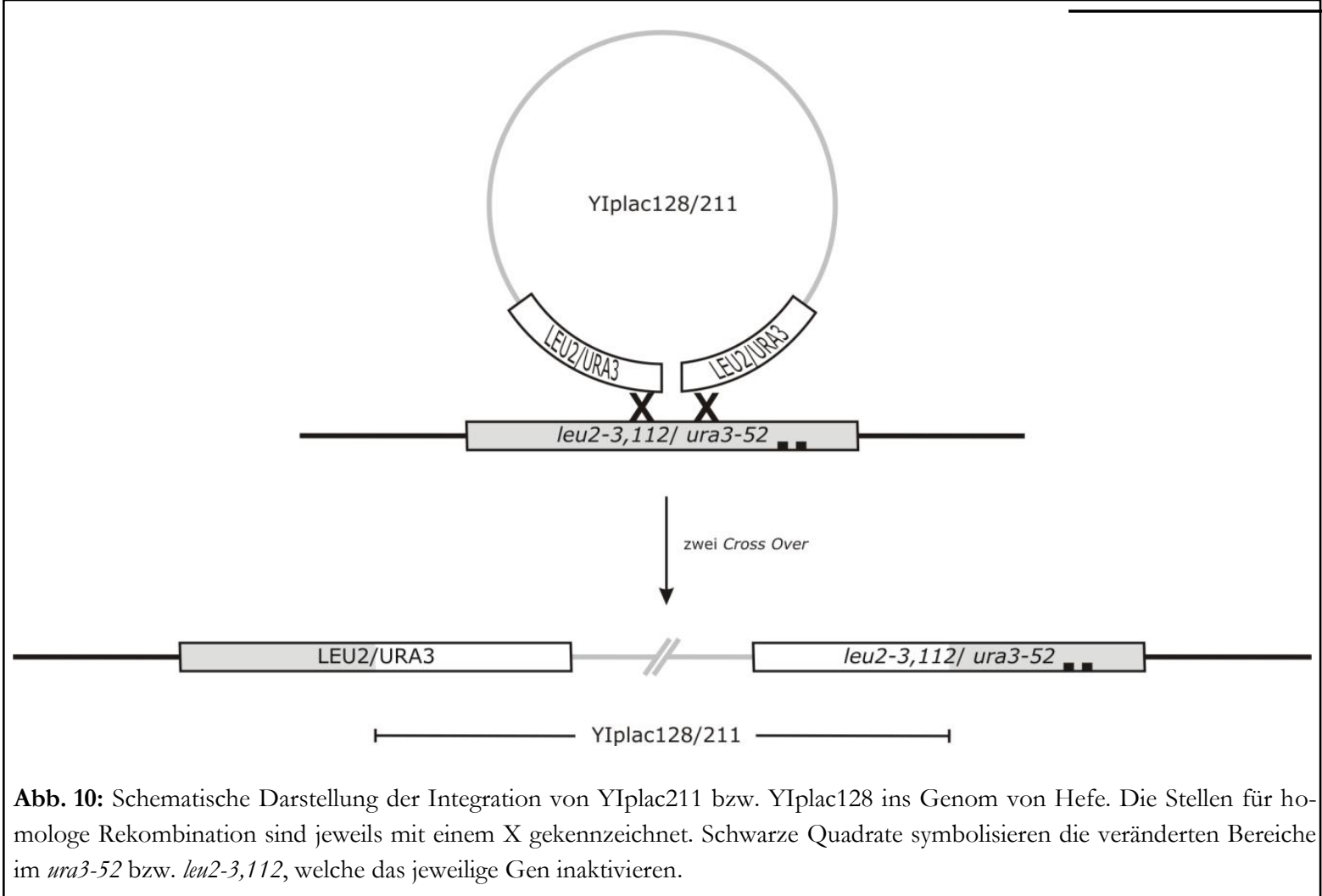

\section{Kreuzung von Hefestämmen}

Einige Doppel- bzw. Tripelmutanten konnten nicht durch PCR-basierte Deletion hergestellt werden, da sie defekt in der homologen Rekombination waren ( $\mathrm{rad51 \Delta}$ und $\mathrm{rad52 \Delta}$ ) und die korrekte Deletion eine Rekombination der homologen Bereiche voraussetzt (siehe „PCR-basierte Gendeletion“). In diesem Fall wurden durch Kreuzung bereits vorhandener Einzelmutanten und anschließende Sporulation der Zygoten neue haploide Doppel- bzw. Tripelmutanten hergestellt. Ebenfalls wurde auf Kreuzung zurückgegriffen, wenn in beiden Einzelmutanten das gleiche Markergen benutzt wurde (bspw. mms2 $\operatorname{rad} 30 \Delta$ ).

Da alle im Rahmen dieser Arbeit benutzten Stämme Haplonten sind, war es möglich, zwei Stämme mit unterschiedlichem mating-type ( $M A T \underline{\text { a }}$ und $M A T \alpha$ ) zu kreuzen, wobei diese eine diploide Zygote bilden. Dazu wurden Abstriche von frischen Plattenkulturen beider Stämme mit Hilfe eines sterilen Glasstabes auf einer YPD-Platte vermengt. Die Platte wurde für 3-4 Std. bei $30^{\circ} \mathrm{C}$ inkubiert. Anschließend wurden die gekreuzten Zellen von der Platte abgenommen und auf Medium ausplattiert, welches auf beide Marker selektiert. Da die Zygote durch Konjugation zweier Mutanten mit unterschiedlichen Markern entsteht, weist sie im Gegensatz zu den jeweiligen Einzelmutanten für beide Marker die entsprechende Resistenz bzw. Prototrophie auf. Auf einem Medium, welches auf beide Marker selektiert, können daher nur die diploiden Zygoten wachsen. Alternativ dazu bzw. bei der Kreuzung zweier Mutanten mit gleichem Markergen wurden die Zygoten mit Hilfe eines Mikromanipulators isoliert. Bei der Kreuzung verschmelzen Haplonten unterschiedlichen mating-types. Die erste aus der Zygote entstehende Tochterzelle wird am Verschmelzungspunkt der beiden Zellen gebildet, weshalb sich die Zygoten in diesem Stadium von den Haplonten morphologisch eindeutig unterscheiden lassen (Kleeblatt-artige Struktur) und 
mit dem Mikromanipulator isoliert werden können. Unabhängig davon, auf welche Art die Zygote selektiert wurde, wurden die Diplonten nach ein bis zwei Tagen Wachstum bei $30^{\circ} \mathrm{C}$ von Selektivmedium auf YPD transferiert. Nach einem weiteren Tag Wachstum wurden diese Platten auf Pre5-Medium gestempelt. Wachstum auf Pre5-Medium erhöht die Sporulationsrate der Zellen deutlich (Codonet al., 1995). Nach einem Tag Wachstum wurden die Kulturen dann auf KAc-Medium gestempelt und erneut für mindestens drei Tage bei $30^{\circ} \mathrm{C}$ inkubiert. Aufgrund des Mangels an Stickstoff kommt es bei gleichzeitiger Abwesenheit einer fermentierbaren C-Quelle auf diesem Medium zur Meiose und anschließender Ausbildung von Asci mit jeweils vier Sporen (Tetraden). Von den KAc-Platten wurde mit einem sterilen Zahnstocher eine ausreichende Menge an Zellmaterial abgenommen und in ca. $30 \mu \mathrm{l} 1 \mathrm{M}$ Sorbitol suspendiert. Anschließend wurde die Suspension mit ca. 0,15 U Yeast Lytic Ensyme versetzt und für $6 \mathrm{Min}$. bei $30^{\circ} \mathrm{C}$ inkubiert. Dabei wurden die Asci teilweise durch das Enzymgemisch verdaut, während die Sporenwände intakt blieben. Durch Zugabe von $800 \mu \mathrm{l}$ sterilem Wasser wurde der Verdau gestoppt. Anschließend wurden die Tetraden auf DM-Platten ausgestrichen und mit einem Mikromanipulator einzelne Tetraden isoliert und aufgebrochen. Die vier Sporen jeder Tetrade wurden jeweils auf vorgegebene Stellen der Platte abgesetzt. Pro Platte wurden so je vier Sporen von 2 x 8 Tetraden gitterförmig verteilt. Nach zwei Tagen Wachstum wurden die aus den Sporen entstandenen Kolonien auf Platten gestempelt, welche auf die Marker der gekreuzten Mutationen selektieren und so die gesuchten haploiden Doppel- bzw. Tripelmutanten identifiziert.

\section{Methoden zur phänotypischen Untersuchung von Hefestämmen}

In den folgenden Methoden war es u.a. notwendig, die Zelldichte von Zellsuspensionen zu bestimmen. Dafür wurde ein Haematocytometer benutzt („Neubauer improved“). Um den statistischen Fehler hierbei hinreichend klein zu halten, wurden jeweils Zellmengen von mindestens 200 Zellen gezählt bzw. mindestens fünf Zählfelder ausgezählt: Bei einem Stichprobenfehler mit $\sqrt{N}$, mit $\mathrm{N}$ als Stichprobengröße entspricht der Fehler bei 200 gezählten Zellen etwa 7\%, was hinreichend genau für die hier angewandten Methoden ist.

Bei allen phänotypischen Untersuchungen wurde in der Regel ein Wildtypstamm mitbehandelt, da die hier ermittelten Phänotypen durch den Vergleich zum Wildtyp definiert sind.

\section{Messung induzierter Reversionsfrequenzen}

Für die Messung induzierter Reversionsfrequenzen mit dem KanKanMX4-Modul wurden zunächst Übernachtkulturen der zu untersuchenden Mutanten in $5 \mathrm{ml} \mathrm{SC}_{\text {-Ura }}$ (für Zellen mit integriertem YIplac211 KanKanMX4) bzw. SC-Leu (mit integriertem YIpla128-KanKanMX4) angezogen. Anschließend wurde die Zelldichte der Kulturen bestimmt und für jeden Stamm eine 6 ml-Kultur mit $1 \times 10^{7}$ Zellen $/ \mathrm{ml}$ angesetzt (ebenfalls $\mathrm{SC}_{\text {-Leu }}$ bzw. SC ura). Die Kulturen wurden für 90 Min. bei $30^{\circ} \mathrm{C}$ im Roller wachsen gelassen. Nach Zugabe von $30 \mu \mathrm{l} \alpha$-Faktor $\left(2 \mathrm{mg} / \mathrm{ml}\right.$ ) wurden die Kulturen erneut $90 \mathrm{Min}$. bei $30^{\circ} \mathrm{C}$ gerollt. $\alpha$-Faktor ist ein Oligopeptid, welches von Zellen mit dem mating-type $\alpha$ sezerniert wird und bei a-Zellen Prozesse induziert, welche die Zelle auf eine möglicherweise bevorstehende 
Konjugation vorbereiten. U.a. führt dies zu einem Arrest des Zellzyklus im G1. Darüberhinaus bekommen a-Zellen teilweise kleine hyphenartige Auswüchse (so genannte shmoos), welche vermutlich dazu dienen, geringe Distanzen zwischen den Konjugationspartnern zu überbrücken. Das Auftreten dieser „Shmoos“ kann als Indiz für den G1-Arrest herangezogen werden. Nach den 90 Min. Inkubation wurden weitere $10 \mu \mathrm{l} \alpha$-Faktor dazugegeben. aZellen sezernieren die für den $\alpha$-Faktor spezifische Protease Bar1, durch die der $\alpha$-Faktor in der Kultur abgebaut wird. Im Anschluss wurden die Zellen weitere $60 \mathrm{Min}$. bei $30^{\circ} \mathrm{C}$ im Roller inkubiert. Die Inkubation unter Anwesenheit des $\alpha$-Faktors dient der Synchronisation der Zellen via Arrest in der G1-Phase. Diese Synchronisation wurde gewählt, um zu erreichen, dass die Zellen während der anschließenden Inkubation mit einem DNAschädigenden Agens genau eine S-Phase durchlaufen. Durch zweimaliges Waschen der Zellen mit jeweils $10 \mathrm{ml}$ sterilem Wasser wurde der $\alpha$-Faktor zur Aufhebung des Arrests entfernt. Die gewaschenen Zellen wurden in $6,5 \mathrm{ml} \mathrm{SC}_{\text {-Leu }}$ bzw. $\mathrm{SC}_{\text {-Ura }}$ resuspendiert, in jeweils sechs Ansätze á $1 \mathrm{ml}$ aufgeteilt und jeder Ansatz wurde mit je $1 \mathrm{ml} \mathrm{SC}_{\text {-leu }}$ bzw. SC-Ura vereint, welcher mit einem DNA-schädigenden Agens versetzt war. Jeder der sechs Ansätze wurde so mit einer unterschiedlichen Konzentration des Agens versetzt, wobei ein Ansatz ohne Giftstoff blieb. Die untersuchten Agenzien und deren Konzentrationen sind im Folgenden aufgeführt.

$$
\begin{array}{ll}
\text { 4-NQO (in } \mu \mathrm{g} / \mathrm{ml}) & 0 ; 0,02 ; 0,04 ; 0,08 ; 0,16 ; 0,24 \\
\text { MMS (in \%) } & 0 ; 0,0025 ; 0,005 ; 0,01 ; 0,02 ; 0,03 \\
\text { Camptothecin (in } \mu \mathrm{g} / \mathrm{ml}) & 0 ; 5 ; 7,5 ; 15 ; 30 ; 60
\end{array}
$$

Die Ansätze wurden für $105 \mathrm{Min}$. bei $30^{\circ} \mathrm{C}$ inkubiert. Anschließend wurde mikroskopisch überprüft, ob der größte Teil der Zellen (ca. 95\%) die G2-Phase erreicht hatte. Dies zeigt sich anhand der miteinander verbundenen, annähernd gleich großen Mutter- und Tochterzellen (dumbbells). Für den Fall, dass ein deutlicher Anteil der Zellen noch nicht in G2 war, wurde die Inkubation für alle Ansätze um ca. 30 Min. verlängert. Im Anschluss wurden die Zellen zweimal mit je $2 \mathrm{ml}$ sterilem Wasser gewaschen, je nach Größe des Zellpellets in 200-800 $\mu \mathrm{l} \mathrm{SC}_{\text {-Leu/Ura }}$ resuspendiert und auf Eis gehalten. Von jeder Suspensionen wurden jeweils Verdünnungen in sterilem Wasser hergestellt (in der Regel waren Verdünnungen von $1 / 5,1 / 25$ und $1 / 125$ ausreichend) und von jeder dieser Verdünnungen $100 \mu \mathrm{l}$ auf YPD-Platten mit $200 \mu \mathrm{g} / \mathrm{ml}$ G418 ausplattiert, um den Titer an KanKanMX4-Revertanten in der Suspension zu ermitteln. Darüber hinaus wurden Verdünnungen für die Ermittlung des jeweiligen Lebendtiters hergestellt und jeweils $100 \mu$ dieser Verdünnungen auf YPD ausplattiert (in der Regel waren hier eine 1/50.000- und eine 1/250.000-Verdünnung ausreichend). Nach drei Tagen Inkubation der Platten bei $30^{\circ} \mathrm{C}$ wurden die Kolonien gezählt. Anhand der Kolonien auf YPD-Platten wurde der Lebendtiter errechnet und anhand der Koloniezahl auf YPD mit G418 der Titer an KanKanMX4-Revertanten. Anhand der Titer wurde wiederum die Reversionsfrequenz errechnet. Die Frequenz des Ansatzes ohne DNA-schädigendes Agens diente der Bestimmung des spontanen Hintergrunds und wurde von den Reversionsfrequenzen der restlichen Ansätze subtrahiert, um die induzierten Re- 
versionsfrequenzen zu erhalten. Zusätzlich wurde jede der induzierten Reversionsfrequenzen auf die des Wildtyps normiert. Sowohl die induzierten als auch die normierten induzierten Reversionsfrequenzen wurden gegen die Konzentration des DNA-schädigenden Agens aufgetragen. Zum Vergleich der Mutanten wurden die normierten induzierten Reversionsfrequenzen gemittelt und als Balkendiagramm dargestellt.

\section{Messung spontaner Reversions- bzw. Mutationsraten}

Die spontanen Reversions- bzw. Mutationsraten wurde nach der Methode des Medians (Lea \& Coulson, 1948) gemessen. Dazu wurde die Zelldichte von Übernachtkulturen (5 ml YPD) ermittelt und je eine Suspension auf $1 \times 10^{3}$ Zellen $/ \mathrm{ml}$ eingestellt. Mit diesen Suspensionen wurden anschließend pro Stamm elf parallele Kulturen mit 20 Zellen/ $\mathrm{ml}$ in $7 \mathrm{ml}$ YPD angeimpft. Für die Messung spontaner Reversionsraten wurde hierbei autoklaviertes Medium, für die Messung spontaner Mutationsraten auf pH 5,8 eingestelltes, nicht autoklaviertes, steril filtriertes YPD verwendet. Nach zwei Tagen Wachstum ohne Bewegung im Brutschrank bei $30^{\circ} \mathrm{C}$ wurden die Kulturen in den Inkubationsroller transferiert und weitere drei bis vier Tage bei $30^{\circ} \mathrm{C}$ unter Rollen inkubiert. Anschließend wurden von jeder Kultur Aliquots ausplattiert (bei der Messung spontaner Mutationsraten je nach Mutante zwischen 50 und $200 \mu \mathrm{l}$ unverdünnter Suspension; bei der Messung spontaner Reversionsraten je nach Mutante $100 \mu \mathrm{l}$ einer $1 / 5^{-}, 1 / 10^{-}$oder einer $1 / 50^{-V e r d u ̈ n n u n g) . ~ F u ̈ r ~ d i e ~ M e s s u n g ~ d e r ~}$ Reversionsraten wurde auf YPD mit $200 \mu \mathrm{g} / \mathrm{ml}$ G418 plattiert. Zusätzlich wurden pro Stamm von je drei zufällig ausgewählten Kulturen geeignete Verdünnungen auf YPD plattiert, um den Lebendtiter zu bestimmen. Für die Messung der Mutationsraten wurde auf $\mathrm{SC}_{\text {-Arg }}$ mit $40 \mathrm{mg} / \mathrm{l} \mathrm{L-Canavanin} \mathrm{plattiert.} \mathrm{Für} \mathrm{die} \mathrm{Messung} \mathrm{des} \mathrm{Lebendtiters} \mathrm{wurde} \mathrm{auf}$ $\mathrm{SC}_{\text {-Arg }}$ plattiert. L-Canavanin ist ein Analogon von Arginin und kann anstatt diesem bei der Proteinsynthese eingebaut werden, was zu inaktiven Proteinen und damit zum Zelltod führt. Das Gen CAN1 in S. cerevisiae codiert für eine Argininpermease, welche auch LCanavanin in die Zelle transportiert. Mutationen in diesem Gen, welche das Genprodukt inaktivieren bzw. dessen Translation verhindern, führen zu einer Resistenz gegen LCanavanin (Larimeret al., 1978). Daher kann die spontane Mutationsrate einer Kultur anhand der Rate spontan auftretender L-Canavanin-Resistenz ermittelt werden. Da LCanavanin in Anwesenheit von Arginin jedoch nur sehr ineffizient in Proteine eingebaut wird, wurde hier $\mathrm{SC}_{-\mathrm{Arg}}$ anstelle von YPD benutzt. Nach drei Tagen Inkubation der Platten wurden die Kolonien gezählt und sowohl der Revertanten- bzw. Mutantentiter als auch der jeweilige Lebendtiter errechnet. Für die weitere Berechnung wurde bei jedem Stamm der Mittelwert der drei ermittelten Lebendtiter verwendet sowie der Mutanten- bzw. Revertantentiter der jeweiligen Mediankultur. Da die Mutationen bzw. Reversionen während des Wachstums der Kulturen sowohl zu einem frühen als auch zu einem späten Zeitpunkt auftreten können, kann der Gesamtanteil an Mutanten bzw. Revertanten in unterschiedlichen Kulturen stark variieren. Das Auftreten der Ereignisse in einer Vielzahl betrachteter Kulturen ist statistisch normalverteilt. D.h. der größte Teil der Kulturen weist eine der durchschnittlichen Mutations- bzw. Reversionsrate entsprechende Anzahl an Mutationen bzw. Reversionen auf. In einigen Kulturen ist jedoch bereits früh eine Mutation bzw. Reversion aufgetreten, weshalb hier die Anzahl an Mutanten bzw. Revertanten zu hoch ist. Einige 
weitere Kulturen dagegen weisen eine zu geringe Anzahl an Mutanten bzw. Revertanten auf, da die Mutationen bzw. Reversionen erst spät während des Wachstums auftreten. Daher gibt die Mutations- bzw. Reversionsfrequenz einer einzelnen betrachteten Kultur nicht die tatsächliche Rate der Mutations- bzw. Reversionsereignisse in der Kultur wieder. Die tatsächliche Rate der Ereignisse in einer Kultur des gegebenen Stammes sollte jedoch aufgrund der Normalverteilung in der Mediankultur aus einer Stichprobe mehrerer Kulturen abgebildet sein. Daher wurde für die Berechnung der Reversions- bzw. Mutationsrate die Mediankultur jeden Stammes herangezogen. Hierbei gilt: Je mehr Kulturen für die Ermittlung der Mediankultur herangezogen werden, desto genauer ist das Ergebnis. Bei den hier vorliegenden Auswertungen wurden je elf Kulturen benutzt. Die Mutationsrate bzw. Reversionsrate wurde wie folgt nach Lea \& Coulson, 1948 in Bezugnahme auf die Mediankultur ermittelt:

Die Anzahl an Mutationsereignissen (m), welche in der Mediankultur zu einer gegebenen Anzahl an Mutanten $r_{0}$ führt, kann durch folgende Formel näherungsweise bestimmt werden:

$$
r_{0}=1,24 m+m \ln m
$$

Durch Subtraktion von $r_{0}$ lässt sich $\mathrm{m}$ als Nullstelle einer streng monoton steigenden Funktion betrachten, bei der $r_{0}$ als Konstante angesehen werden kann. Die Bestimmung von $\mathrm{m}$ kann demnach durch eine Newtonsche Iteration erfolgen, da die resultierende Folge gegen m konvergiert:

$$
m_{i+1}=-\frac{m_{i}+m_{i} \ln m_{i}-r_{0}}{2,24+\ln m}
$$

Für die Iteration wurde $m_{1}=r_{0}$ gesetzt und der Algorithmus bis $m_{i+1}-m_{i} \leq 10^{-8}$ ausgeführt. Die Frequenz $\mathrm{m} / \mathrm{N}$ mit $\mathrm{N}$ als der Gesamtlebendzellzahl ergibt die Mutationsrate. Die Standardabweichung wurde anhand

$$
\frac{\sigma m^{2}}{m^{2}}=\frac{1}{N} \frac{12,7}{(2,24+\ln m)^{2}}
$$

berechnet.

\section{Messung der UV-Sensitivität per Strahlungsgradient}

Die semiquantitative Messung der UV-Sensitivität erfolgte über abgestufte Bestrahlung eines Zellausstrichs. Dazu wurde jeweils eine Übernachtkultur der zu untersuchenden Stämme (ca. $5 \mathrm{ml} \mathrm{YPD)} \mathrm{zunächst} 1 / 5$ in YPD verdünnt und für 3-5 Std. bei $30^{\circ} \mathrm{C}$ inkubiert. Anschließend wurde die Zelldichte bestimmt und die Suspensionen wurden auf jeweils $4 \times 10^{6}$ Zellen $/ \mathrm{ml}$ eingestellt. Von dieser Suspension wurden 25-50 $\mu$ l gleichförmig als etwa $0,5 \mathrm{~cm}$ breiter Strich über die Länge einer YPD-Platte (quadratisch, $120 \times 120 \mathrm{~mm}$ ) ausgestrichen (siehe Abb. 11). Anschließend wurde die Platte in einer Dunkelkammer stufenweise mit UV belichtet (bei $254 \mathrm{~nm}$ und $0, \overline{5} \mathrm{~J} \mathrm{Sek}^{-1} \mathrm{~m}^{-2}$ ). Dazu wurde die Platte zunächst lichtdicht abgedeckt und schrittweise sukzessiv geöffnet. Die Platten wurden für zwei bis drei Tage im Dunkeln (zur Vermeidung der Phtoreaktivierung) bei $30^{\circ} \mathrm{C}$ inkubiert und an- 
schließend die Sensitivität der Mutanten gegen UV-Bestrahlung verglichen. Zur Dokumentation wurden die Platten eingescannt bzw. photographiert.

\section{Messung der Überlebensrate nach UV-Strahlung}

Die quantitative Bestimmung der Sensitivität gegen UV-Bestrahlung wurde ähnlich wie in Torres-Ramoset al., 2002 dargestellt durchgeführt. Dazu wurden Übernachtkulturen $(5 \mathrm{ml}$ YPD) der zu untersuchenden Stämme zunächst $1 / 5$ in YPD verdünnt und 3-5 Std. bei $30^{\circ} \mathrm{C}$ inkubiert. Anschließend wurden die Zellen geerntet (2 Min bei 4.000 rpm, Hettich Rotanta/RPC) und zweimal mit sterilen Wassers gewaschen. Danach wurde die Zelldichte bestimmt und auf $2 \times 10^{8}$ Zellen/ml eingestellt. Anschließend wurden von geeigneten Verdünnungen je $100 \mu \mathrm{l}$ auf YPD ausplattiert und je eine bis zwei Platten gleichzeitig in einer Dunkelkammer mit UV-Licht bestrahlt (bei $254 \mathrm{~nm}$ und 0, $\overline{5} \mathrm{~J} \mathrm{Sek}^{-1} \mathrm{~m}^{-2}$ ). Um den Zeitraum zwischen Ausplattieren und Bestrahlung möglichst kurz zu halten, wurde immer ein Stamm komplett plattiert und dann bestrahlt, bevor der nächste Stamm plattiert wurde. Die noch nicht plattierten Stämme wurden deshalb nach dem Verdünnen zunächst bei $4^{\circ} \mathrm{C}$ aufbewahrt. Die Platten wurden für drei Tage im Dunkeln bei $30^{\circ} \mathrm{C}$ inkubiert. Die Kolonien wurden ausgezählt und die Lebendtiter bestimmt. Der Lebendtiter auf unbestrahlten Platten wurde als 100\% festgelegt und der prozentuale Anteil überlebender Zellen bei jeder Bestrahlungszeit errechnet. Das Ergebnis wurde halblogarithmisch gegen die Bestrahlungszeit aufgetragen. Diese Auftragung ermöglicht es, im Gegensatz zu einer linearen Auftragung, die genetische Interaktion zweier Mutationen zu ermittelten. Die prozentuale Überlebensrate ist eigentlich für einen Vergleich zweier Phänotypen nicht direkt geeignet. Zwar addiert sich bei Additivität zweier Mutantionen die mittlere Anzahl an letalen DNASchäden, jedoch wird ein Großteil der zusätzlich entstehenden Schäden in bereits letal getroffenen Zellen auftreten. Da diese jedoch bereits tödlich geschädigt sind, lässt sich dieser zusätzliche Schaden nicht registrieren. Der Vergleich der Überlebensrate kann daher eigentlich nicht dazu herangezogen werden, um Interaktionen wie eine Additivität zu identifizieren. Vielmehr muss für die Untersuchung genetischer Interaktionen die mittlere Anzahl an letalen Schäden ermittelt werden. Die mittlere Anzahl solcher tödlichen Ereignisse in einem betrachteten Genom entspricht einer Binomial-Verteilung mit selten eintreffenden Ereignissen und kann damit anhand der Poisson-Verteilung beschrieben werden. Die mittlere Anzahl letaler Schäden ist dabei $\lambda . p(k)$ ist die Wahrscheinlichkeit einer Zelle, „,““ letale Schäden erhalten zu haben:

$$
p(k)=\frac{\lambda^{k}}{k !} e^{-\lambda}
$$

Da überlebende Zellen keine letalen Schäden erhalten haben können, stellt die prozentuale Überlebensrate $y(x)$ bei der Menge „x“ an DNA-schädigendem Agens die Wahrscheinlichkeit dar, keinen letalen Schaden zu erhalten (also $k=0$ ):

$$
y(x)=p(0)
$$


Daraus folgt:

$$
y(x)=\frac{\lambda^{0}{ }_{x}}{0 !} e^{-\lambda_{x}}=\frac{1}{1} e^{-\lambda_{x}}
$$

Und:

$$
-\ln (y(x))=\lambda_{x}
$$

Demnach ist der negative logarithmus naturalis der Überlebensrate gleich der mittleren Anzahl letaler DNA-Schäden. Daher ist eine semilogarithmische Auftragung der Überlebensrate ein negatives Abbild der mittleren Anzahl an letalen DNA-Schäden und kann somit Aufschluss über die genetische Interaktion zweier Gene in Bezug auf die Sensitivität gegen DNA-schädigende Agenzien geben. Aus Gründen der Anschaulichkeit wurde jedoch eine Auftragung des dekadischen Logarithmus gewählt, da sich hierbei an den Relationen der Mutanten zueinander nichts ändert, aber das Ablesen der Überlebensrate vereinfacht wird.

\section{Bestimmung der Sensitivität durch einen drop-dilution-assay}

Zur Bestimmung der Sensitivität gegen 4-NQO, Camptothecin und MMS wurden zunächst Übernachtkulturen der zu untersuchenden Stämme in $5 \mathrm{ml}$ YPD angezogen. Diese Kulturen wurden $1 / 5$ in frischem YPD verdünnt und weitere 3-5 Std. wachsen gelassen. Anschließend wurde von jeder Kultur die Zelldichte bestimmt und eine Suspension mit $1 \times 10^{7}$ Zellen $/ \mathrm{ml}$ hergestellt. Jede dieser Suspensionen wurde anschließend sukzessiv dreimal $1 / 10$ verdünnt, so dass von jedem Stamm vier Suspensionen mit abnehmender Zelldichte vorlagen $\left(1 \times 10^{7}, 1 \times 10^{6}, 1 \times 10^{5}\right.$ und $1 \times 10^{4}$ Zellen/ml). Für jeden Stamm wurden je $7 \mu$ dieser Suspensionen nebeneinander auf mehrere YPD-Platten mit unterschiedlicher Konzentration an MMS, Camptothecin bzw. 4-NQO getropft (siehe Abb. 11). Diese Platten wurden vorbereitet, indem nach dem Autoklavieren das Agens in entsprechender Menge zugegeben wurde. Beim Autoklavieren kann je nach Verhältnis der Komponenten im YPD und je nach Dauer des Autoklaviervorgangs die Menge der im Medium durch Maillardreaktionen entstehenden Mutagene variieren (Kimet al., 1991). Daher wurde für jede Platte YPD aus demselben Ansatz verwendet, um eine gute Vergleichbarkeit der einzelnen Giftkonzentrationen untereinander zu ermöglichen. Darüber hinaus wurden die Platten jeweils an dem Tag gegossen, an dem sie benötigt wurden. Dies ist notwendig, da die Agenzien wie MMS und 4-NQO mit dem Medium reagieren können und daher die Konzentration des Agens in der Platte abnimmt. Nach dem auströpfeln der Suspensionen wurden die Platten für zwei Tage bei $30^{\circ} \mathrm{C}$ inkubiert. Anschließend wurde die Sensitivität der Stämme anhand des Wachstums bei den unterschiedlichen Konzentrationen an Giftstoffen untereinander verglichen. Bei schwer zu erkennenden Unterschieden wurden die Platten gegebenenfalls zusätzlich noch ein bis zwei weitere Tage bei $30^{\circ} \mathrm{C}$ inkubiert. Zur Dokumentation wurden die Platten eingescannt bzw. photographiert. Die im Rahmen dieser Arbeit untersuchten Konzentrationen variierten je nach untersuchten Mutanten. Im Folgenden sind alle relevanten Konzentrationen aufgeführt. Zusätzlich wurde jeder Stamm zur Kontrolle, ob die betreffenden Mutanten eine generell geringere Überlebens- bzw. 
Wachstumsrate aufweisen, auch auf eine YPD-Platte ohne DNA-schädigendes Agens ausgetropft.

MMS (in \%)

4-NQO (in $\mu \mathrm{g} / \mathrm{ml})$

Camptothecin (in $\mu \mathrm{g} / \mathrm{ml})$
0,$01 ; 0,0075 ; 0,005 ; 0,0025 ; 0,001 ; 0,00075 ; 0,0005$ 0,$0001 ; 0,000075 ; 0,00005$

0,$5 ; 0,25 ; 0,1 ; 0,075 ; 0,05 ; 0,025 ; 0,01 ; 0,005$

$100 ; 50 ; 20 ; 10 ; 7,5 ; 5 ; 2,5 ; 1$

Im Falle der Sensitivität gegen UV-Strahlung (siehe Ergebnisse mms $2 \Delta$ rev3 $\Delta$ rad51 $\Delta$ ) wurden die Suspensionen auf YPD-Platten ausgetropft und jede Platte einzeln bestrahlt. Bestrahlt wurde dabei für 10, 20, 30, 45, 60, 75, 90, 105 und 120 Sekunden (bei $254 \mathrm{~nm}$ und $0, \overline{5} \mathrm{~J} \mathrm{Sek}^{-1} \mathrm{~m}^{-2}$ ) in einer Dunkelkammer. Die Platten wurden hierbei anschließend im Dunkeln inkubiert, um Photoreaktivierung durch die Photolyase zu verhindern.

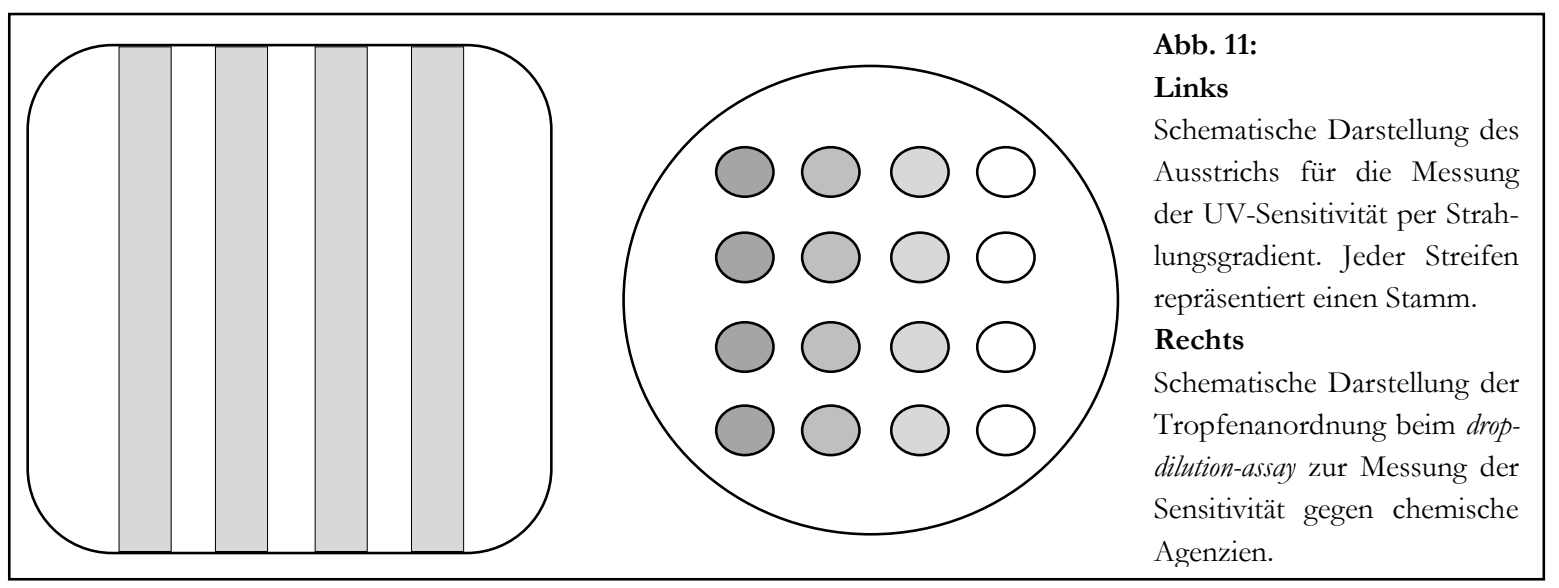

\section{Messung der Überlebensrate nach Inkubation mit DNA-schädigenden Agen- zien}

Die quantitative Messung der Sensitivität gegen DNA-schädigende Agenzien wurde entsprechend der Messung induzierter Reversionsfrequenzen durchgeführt (siehe „Messung induzierter Reversionsfrequenzen"). Jedoch wurden die Zellen hierbei nach Inkubation mit den Agenzien nicht gewaschen. Durch das Waschen kommt es zu deutlichen Schwankungen in der Zelldichte der einzelnen Ansätze eines Stammes. Daher wurde jeder Ansatz direkt verdünnt und ausplattiert, was gewährleistet, dass sich die Zelldichten der einzelnen Ansätze nicht voneinander unterscheiden. Plattiert wurde auf YPD, um die jeweiligen Lebendtiter zu ermitteln. Der Lebendtiter des jeweiligen Ansatzes ohne DNA-schädigendes Agens wurde als 100\% festgelegt und die prozentuale Anzahl Überlebender wurde für jeden Ansatz eines Stammes errechnet. Diese Werte wurden semilogarithmisch gegen die Konzentration des Agens aufgetragen (zur semilogarithmischen Auftragung siehe „Messung der Überlebensrate nach UV-Strahlung"). Bei der Messung der Überlebensrate nach MMS wurde zu den Kulturen vor dem Verdünnen 5\% Natriumthiosulfat hinzugegeben. Dies war notwendig, um das MMS durch Reaktion mit dem Thiosulfat zu ,inaktivieren“ 
und so eine definierte Reaktionszeit mit definierten Konzentrationen an MMS zu gewährleisten.

\section{Messung der Verdopplungszeit}

Zur Messung der Verdopplungszeiten wurde von den zu untersuchenden Stämmen zunächst eine Übernachtkultur in $5 \mathrm{ml}$ YPD angesetzt. Von dieser wurde die Zelldichte bestimmt und eine $50 \mathrm{ml}$-YPD-Kultur auf $5 \times 10^{5}$ Zellen/ml eingestellt. Die OD $_{600 \mathrm{~nm}}$ dieser Kulturen wurde anschließend bestimmt und die Kulturen bei $30^{\circ} \mathrm{C}$ unter Schütteln für acht bis zehn Stunden inkubiert. Etwa alle 30 Minuten wurde ein Aliquot der Zellsuspensionen abgenommen und die $\mathrm{OD}_{600 \mathrm{~nm}}$ gemessen. Der $\log \left(\mathrm{OD}_{600 \mathrm{~nm}}\right)$ wurde gegen die Zeit aufgetragen und für den linearen Bereich der Graphen wurde jeweils eine Regressionsgerade ermittelt. Die Verdopplungszeit der Zellen ließ sich dann anhand der Steigung dieser Geraden wie folgt berechnen:

Gleichung der Regressionsgeraden:

$$
\log y\left(t_{x}\right)=\log y\left(t_{0}\right)+a t_{x}
$$

Wobei $t_{x}$ die Zeit in Minuten zum Zeitpunkt $\mathrm{x}$ darstellt. Für die Berechnung der Verdopplungszeit $t_{d p}$ gilt:

$$
t_{d p}=t_{2}-t_{1} ; \text { bei } y\left(t_{2}\right)=2 y\left(t_{1}\right)
$$

und:

$$
t_{2}=\frac{\log 2 y\left(t_{1}\right)-\log y\left(t_{0}\right)}{a} ; \text { und } t_{1}=\frac{\log y\left(t_{1}\right)-\log y\left(t_{0}\right)}{a}
$$

Demnach gilt:

$$
\begin{gathered}
a t_{d p}=\log 2 y\left(t_{1}\right)-\log y\left(t_{0}\right)-\left(\log y\left(t_{1}\right)-\log y\left(t_{0}\right)\right) ; \\
a t_{d p}=\log 2 y\left(t_{1}\right)-\log y\left(t_{1}\right)=\left(y\left(t_{1}\right)-y\left(t_{1}\right)\right) \log 2=\log 2 ; \\
t_{d p}=\frac{\log 2}{a}
\end{gathered}
$$

Wobei a die Steigung der Regressionsgraden darstellt. 


\section{ERGEBNISSE}

\section{MESSUNG VON SCHWESTERCHROMATID-INTERAKTIONEN}

Täglich entstehen ca. 80.000 DNA-Schäden in einer einzelnen Säugerzelle allein durch spontane Vorgänge wie Hydrolyse, Oxidation oder Alkylierung. Dazu kommt eine Vielzahl exogener Einflüsse, welche zu einer Schädigung der DNA führen können (Friedberg et al., 2006). Bei dieser Menge an DNA-Schäden ist es unvermeidlich, dass auch während der Replikation Schäden in der DNA vorliegen und die Replikationsmaschinerie auf eine solche Läsion trifft. Da die Schäden in einem solchen Fall nicht mehr im Doppel-, sondern im Einzelstrang vorliegen, können Basen- und Nukleotidexzision hier nicht mehr eingesetzt werden. Somit ist eine Reparatur des Schadens nicht mehr oder nur in seltenen Fällen möglich. Läuft die DNA-Polymerase in einen Schaden auf dem template hinein, kann es zu einem Replikationsarrest kommen. Bleibt dieser bestehen, so führt dies wahrscheinlich zum Zelltod. Wie in der Einleitung dargelegt (siehe Seite 10 bis 20), gibt es unterschiedliche Modelle, die beschreiben können, nach welchen Mechanismen ein Replikationsarrest behoben werden kann: zum einen die Benutzung von Transläsionspolymerasen, welche eine höhere Toleranz gegenüber chemisch veränderten Basen besitzen, aber gleichzeitig eine erhöhte Fehlerrate aufweisen, zum anderen die Rekonstruktion der ursprünglichen Information über eine Interaktion mit dem Schwesterchromatid. In beiden Fällen wird der Arrest durch Umgehen der beschädigten Base aufgehoben. Während Transläsionssynthese Ereignisse generiert, welche anhand der erhöhten Anzahl an Mutationen nach DNASchädigung gemessen werden können, ist die Messung von Schwesterchromatid-Interaktionen nicht trivial, da Schwesterchromatiden genetisch identisch sind und die Messung eines Informationsaustausches nicht ohne weiteres möglich ist. Um einen solchen Austausch dennoch untersuchen zu können, müssen Mechanismen genutzt werden, die es ermöglichen, bei einem Informationsaustausch eine messbare Veränderung hervorzurufen. Das von Christian Rudolph entwickelte KanKanMX4-Modul stellt ein experimentelles System dar, welches solche Veränderungen ermöglicht und messbar macht (siehe Abb. 12; Rudolph, 2003). Es besteht aus dem KanMX4-Modul (Wach et al., 1994), welches eine direkte Sequenzduplikation von 266 bp beinhaltet. Das KanMX4 codiert für ein Protein, welches in Saccharomyces cerevisiae eine Resistenz gegen das Antibiotikum G418 vermittelt. Durch die Sequenzduplikation wird jedoch das Leseraster verschoben, wodurch diese Resistenz aufgehoben wird. Eine vollständige Deletion des Duplikats, wie sie unter anderem über eine Interaktion zwischen Schwesterchromatiden entstehen kann, führt zu einer Reversion der G418-Resistenz. Zur Integration des Moduls in das Genom der zu messenden Stämme von S. cerevisiae wurde das Modul in das Integrationsplasmid YIplac128 bzw. YIplac211 via SalIEcoRI-Verdau kloniert. 


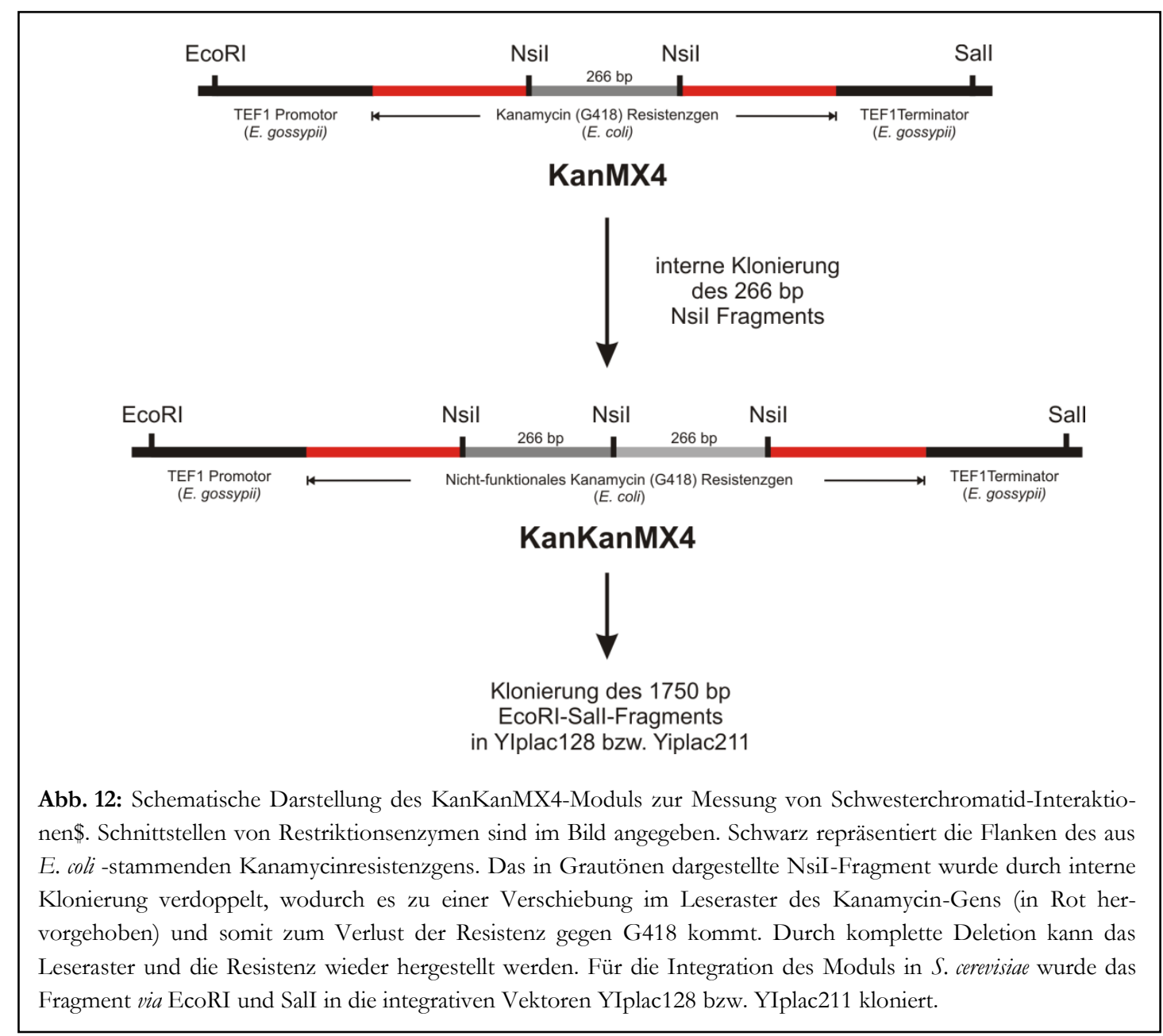

\section{Untersuchungen zur Entstehung von Reversionsereignissen im \\ KanKanMX4-Modul}

\section{Modelle zur Deletion von Sequenzduplikaten}

Die Deletion der direkten Sequenzwiederholung im KanKanMX4 kann nach aktuellem Wissensstand am wahrscheinlichsten über folgende fünf Mechanismen erfolgen:

i. Die Deletion durch Springen des primers auf dem template-Strang.

ii. Die Reparatur von Doppelstrangbrüchen über Single Strand Annealing (SSA).

iii. Die Reinitiation der Replikation durch homologe Rekombination nach run offSynthese oder einem enzymatisch forcierten Schnitt im template-Strang einer blockierten Replikationsgabel.

iv. Die Reparatur von Doppelstrangbrüchen durch homologe Rekombination.

v. Die Umgehung eines replikationsarretierenden DNA-Schadens durch Schwesterchromatid-Interaktion mit reinem Informationsaustausch (Sister Chromatid Interaction - SCI) oder materiellem Schwesterchromatidaustausch (Sister Chromatid Exchange SCE). 
Deletion durch Springen des primers auf dem template-Strang

Eine Deletion von Sequenzduplikationen kann durch eine Verschiebung bzw. ein Springen des primer-Endes auf dem template stattfinden. Die beiden wahrscheinlichsten und vermutlich auch häufigsten Formen einer solchen primer-template-Verschiebung sind die Bildung von Sekundärstrukturen zwischen palindromischen Sequenzen im template-Strang und primer template slippage (PTS). Da das KanKanMX4-Modul jedoch keine palindromische oder teilweise palindromische Sequenz aufweist, kommt von diesen beiden Möglichkeiten nur primer template slippage als möglicher Ursprung einer Reversion in Frage. Als primer template slippage wird die verschobene Rehybridisierung nach einem Lösen des primer-Endes von der Matrize bezeichnet. Eine schematische Darstellung hierzu ist in Abb. $13 \mathrm{~A}$ zu finden. Das primer-Ende kann während der Synthese den Kontakt zum template-Strang verlieren. Bei dem darauf folgenden Rehybridisieren des primer-Endes mit der Matrize ist es möglich, dass das Ende mit in der näheren Umgebung vorhandenen Sequenzduplikationen hybridisiert, anstatt mit dem ursprünglichem Sequenzabschnitt. Der Bereich zwischen diesen Abschnitten wird dabei übersprungen und somit bei anschließend fortschreitender Synthese deletiert (Abb. 13 A vi; Ripley, 1990).

\section{Deletion durch Single Strand Annealing}

Eine schematische Darstellung der Deletion durch SSA ist in Abb. 13 B zu sehen. Während der Reparatur von Doppelstrangbrüchen durch homologe Rekombination werden zunächst an den Bruchenden 3'-Überhänge generiert. Diese sind notwendig, um anschlieBend unter Bildung eines D-Loops an homologer Stelle in das Schwesterchromatid invadieren zu können (siehe Seite 7, Abb. 1). Liegt der Bruch jedoch direkt innerhalb einer Sequenzduplikation bzw. innerhalb eines Bereichs zwischen zwei sich wiederholenden Sequenzen, so können durch das Generieren der 3'-Überhänge komplementäre Einzelstrangbereiche entstehen (Abb. 13 B ii). Diese Überhänge können direkt miteinander hybridisieren. Die Konsequenz aus dieser direkten Hybridisierung ist der Verlust einer der beiden Sequenzduplikationen. In S. cerevisiae wird für SSA Rad52 benötigt, für das in vitro gezeigt werden konnte, dass es RPA von den Einzelstrangüberhängen verdrängt und die Bindung komplementärer Stränge fördert. Je nachdem, wie die Überhänge hybridisieren, sind zusätzlich möglicherweise noch eine flap-Endonuklease oder eine Polymerase notwendig, um eventuell vorhandene flaps zu entfernen bzw. Lücken aufzufüllen. Die verbleibenden Unterbrechungen der Einzelstränge werden anschließend durch eine DNA-Ligase geschlossen, sodass der Doppelstrangbruch repariert wird. Diese für Sequenzduplikationen spezifische Form der Doppelstrangbruchreparatur durch homologe Rekombination wird als Single Strand Annealing bezeichnet (Krogh \& Symington, 2004; Lin et al., 1984; Smith \& Rothstein, 1999). 


\section{ERGEBNISSE}

Deletion durch die Reparatur kollabierter Replikationsgabeln nach run off-Synthese

Eine schematische Darstellung des folgenden Modells ist in Abb. 13 C gezeigt. Trifft die DNA-Polymerase auf einen Bruch im template, so kann sie von der Matrize herunterfallen und ein unvollständiges Chromosom mit Doppelstrangende entstehen (Abb. 13 C i). Dieser Vorgang wird in der Literatur oft als Kollaps einer Replikationsgabel bezeichnet. Zur Vervollständigung des Chromosoms muss anschließend die Replikation reinitiiert werden, was über homologe Rekombination mit dem Schwesterchromatid erreicht werden kann (siehe Seite 9, Abb. 2). Dabei wird zunächst das Doppelstrangende des unvollständigen Chromosoms zurückgeschnitten und ein 3'-Überhang generiert. Anschließend kommt es zu einer Invasion des 3'-Endes in die homologe Region des Schwesterchromatids. Im Falle einer Sequenzduplikation existiert die homologe Sequenz jedoch zweimal, sodass es zu einer Invasion in der falschen Duplikation kommen kann (Abb. 13 C iii). Befand sich der Einzelstrangbruch in der ersten und invadiert das 3'-Ende in der zweiten Duplikation, so wird der Bereich zwischen den sich wiederholenden Sequenzen ausgelassen. Durch einen Schnitt in dem bei der Invasion entstehenden D-Loop kann anschließend eine Struktur ähnlich der Replikationsgabel entstehen, an der die Replikation reinitiiert werden kann. Da die Replikation somit in der zweiten Duplikation weiterläuft und der Bereich zwischen den Wiederholungen ausgelassen wurde, kommt es zu einer Deletion der Sequenzduplikation (Abb. 13 C iv; Krogh \& Symington, 2004).

\section{Deletion durch homologe Rekombination bei der Doppelstrangbruchreparatur}

Eine schematische Darstellung hierzu ist in Abb. 13 D zu finden. Die Reparatur von Doppelstrangbrüchen beinhaltet, wie bereits im Abschnitt über SSA angemerkt, eine Invasion in das Schwesterchromatid bzw., soweit vorhanden, in das homologe Chromosom (Abb. 13 D ii). Das Schwesterchromatid bzw. Homologe kann als template dienen und das invadierte 3'-Ende kann an dieser Matrize bis in den hinter dem Bruch liegenden Bereich verlängert werden (Abb. 13 D iii). Durch das anschließende Auflösen des D-Loops entstehen so komplementäre Überhänge, welche miteinander hybridisieren können (Abb. 13 D iv). Hierdurch werden die gebrochenen Enden wieder zusammengefügt. Anschließend werden die Einzelstränge durch eine DNA-Ligase geschlossen, wodurch der Doppelstrangbruch repariert wird. Wie beim SSA können auch hier zusätzlich eine FlapEndonuklease oder eine Polymerase notwendig sein. Bei der Interaktion mit dem Homologen bzw. Schwesterchromatid ist es möglich, durch eine Invasion in der falschen Duplikation, das erste Sequenzduplikat auszulassen, was zu einer Deletion der Sequenz und somit zur Reversion der G418-Resistenz führt. Anstelle einer direkten Auflösung des D-Loops ist es allerdings auch möglich, den verdrängten Strang unter Bildung einer Holliday-Junction mit dem beschädigten template-Strang zu hybridisieren. Auch kann es darüber hinaus zu einer Hybridisierung des Endbereichs des am Schwesterchromatid verlängerten Stranges mit der ursprünglichen Matrize kommen, wobei eine doppelte Holliday-Junction entsteht, wie es ana$\log$ in Abb. 13 E iii dargestellt ist. Diese junctions können anschließend durch eine Resolvase aufgelöst werden, wobei es zur Genkonversion oder zum cross over kommen kann. Auch hierbei kann das Sequenzduplikat im verlängerten Strang ausgelassen werden. 


\section{ERGEBNISSE}

Deletion durch Schwesterchromatid-Interaktion bzw. Schwesterchromatid-Austausch bei einem Replikationsarrest

Neben der Reparatur von Doppelstrangbrüchen und den bei run off-Synthese entstehenden Doppelstrangenden kann auch das Beheben eines Replikationsarrests an einer beschädigten Base zu der Deletion einer Sequenzduplikation führen. Eine schematische Darstellung hier$\mathrm{zu}$ ist in Abb. $13 \mathrm{E} \mathrm{zu}$ finden. Dazu ist die Bildung eines einzelsträngigen 3'-Endes durch Kontaktverlust des primer-Endes zum template notwendig, was bspw. mithilfe einer Helikase erreicht werden kann. Dieses 3'-Ende kann für eine Invasion in das Schwesterchromatid genutzt werden. Wie zuvor bereits dargelegt, kann es hierbei zu einer Invasion in der falschen Sequenzduplikation kommen (Abb. 13 E ii). Um den Replikationsarrest aufzuheben, muss die beschädigte Base, welche den Arrest hervorgerufen hat, umgangen werden. Dafür wird das Schwesterchromatid als alternatives, unbeschädigtes template genutzt und so das 3'Ende des invadierenden Stranges über den Schaden hinaus verlängert. Dabei kann die Verlängerung über die doppelt vorhandene Sequenz hinausgehen. Nach dem Auflösen des DLoops und der Rehybridisierung des am Schwesterchromatid verlängerten Strangs mit dem ursprünglichen template, kann der bei der Invasion ausgelassene DNA-Bereich als einzelsträngige Schleife aus dem Doppelstrang hinausragen (Abb. 13 E iv). Wird anschließend die Replikation fortgesetzt, führt dies zur Deletion der Sequenzduplikation im neu synthetisierten Strang. Alternativ kann der D-Loop durch Bildung von Holliday-Junctions und anschließende Genkonversion bzw. cross over aufgelöst werden, wie es in Abb. 13 E iii angedeutet ist. Anstatt der direkten Invasion des $3^{\prime}$ primer-Endes ins Schwesterchromatid ist es auch denkbar, dass es zu einem Schnitt in der hinter dem Arrest entstehenden Einzelstrangregion kommt, wodurch ein unvollständiges Chromosom mit 5'-Überhang entsteht. Auch kann es durch fork regression zu einem Chicken Foot kommen, welcher durch eine Resolvase geschnitten wird. In diesem Fall kommt es zu einem unvollständigen Chromosom mit 3'-Überhang. In beiden Fällen kann das resultierende unvollständige Chromosom entsprechend der Reparatur nach run off-Synthese prozessiert werden (Abb. 13 E i, angedeutet durch einen unterbrochenen Pfeil). Alternativ zu der für diese Modelle notwendigen Invasion des 3'-Endes, kann auch der hinter dem Arrest entstehende Einzelstrang im Schwesterchromatid invadieren, wobei jedoch bisher nicht klar ist, inwiefern dies in vivo in S. cerevisiae möglich ist bzw. ob Rad51 zwingend ein freies 3'-Ende benötigt. Auch hierbei ist eine Invasion in der falschen Duplikation möglich, jedoch muss für eine Umgehung des Schadens das in der Synthese arretierte 3'-Ende mit dem verdrängten Strang hybridisieren, um eine Umgehung des Schadens zu ermöglichen, so dass es per se zu einer Holliday-Junction als Intermediat kommt.

Bei jedem der benannten Modelle ist es möglich, dass es anstelle der Deletion einer Sequenzduplikation zu der Triplikation der entsprechenden Sequenz kommt. Dies geschieht, wenn es ausgehend von der zweiten Duplikation zu einer Invasion bzw. beim primer template slippage zur Rehybridisierung im ersten Duplikat des Schwesterchromatids kommt. Die Triplikation führt jedoch im Gegensatz zur Deletion nicht zu einer phänotypischen Veränderung und kann somit nicht mit dem KanKanMX4-System erfasst werden. 


\section{ERGEBNISSE}

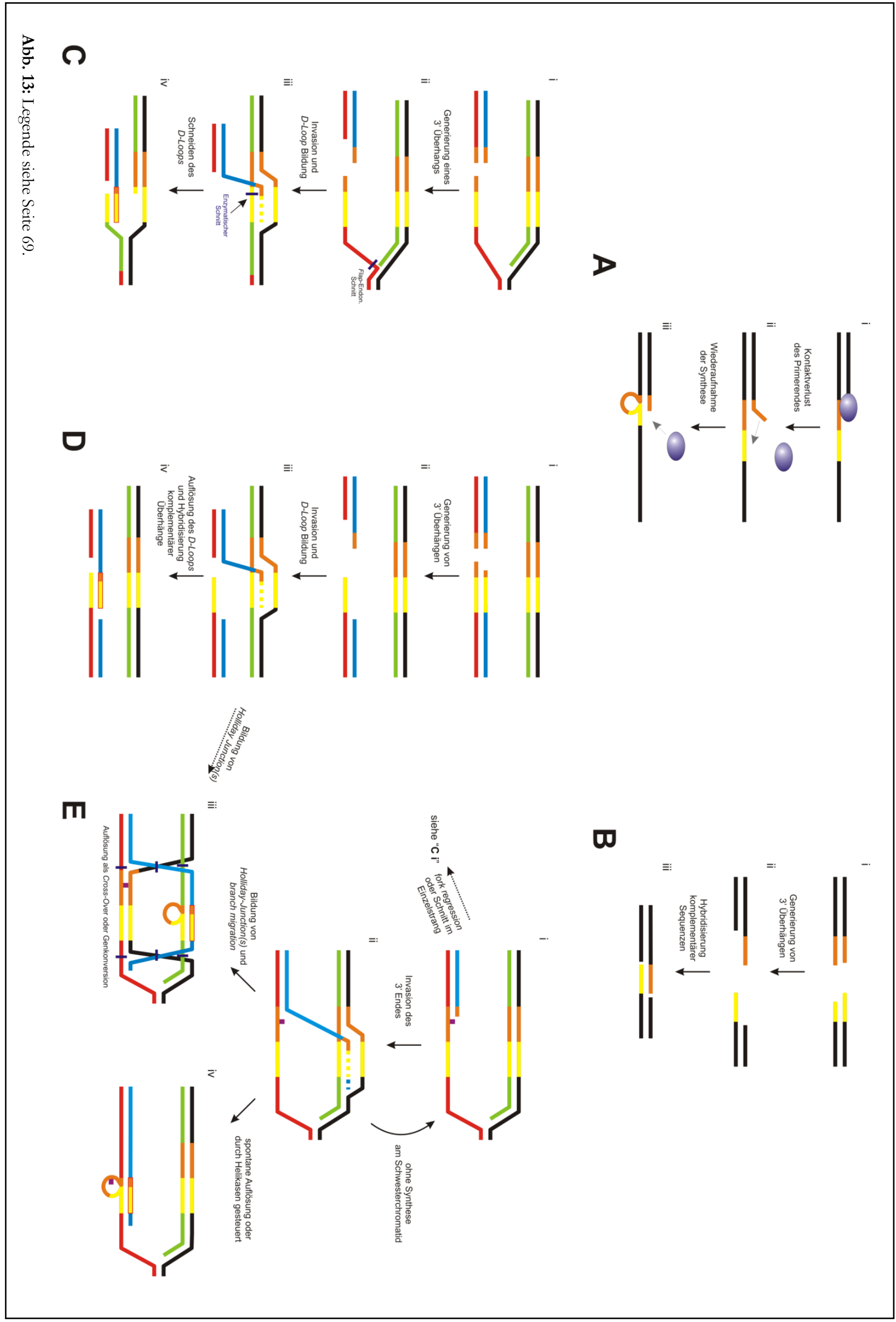

$68 \mid$ S eite 


\begin{abstract}
Abb. 13: Modelle zur Deletion von Sequenzduplikaten. Die duplizierten Sequenzen sind in Orange und Gelb dargestellt. A Deletion durch das Springen des primer-Endes (rechts). Die Polymerase ist als lila-farbene Elipse dargestellt. B Deletion durch single strand annealing. C Deletion durch fehlerhafte Invasion nach run offSynthese. Die unterschiedlichen DNA-Stränge sind durch Färbung in Schwarz, Rot, Grün und Blau voneinander differenziert. Stellen für enzymatische Schnitte in den Strängen sind mit einem dunkel blauem Strich angedeutet. Die singuläre Sequenz nach der Deletion ist durch einen roten Rahmen hervorgehoben. D Deletion über eine fehlerhafte Invasion beim Single Strand Annealing. Bedeutungen der Farbkodierung siehe (A). E Deletion nach fehlerhafter Invasion infolge eines Replikationsarrests. Bedeutungen der Farbkodierung siehe (A). (Modelle nach Krogh und Symington 2004 und Ripley 1990).
\end{abstract}

\title{
Untersuchungen zur Entstehung der Reversionsereignisse in vivo
}

\section{Messung spontaner Reversionsraten}

Damit anhand des KanKanMX4-Systems überhaupt eine Aussage über die damit untersuchten Mutanten gemacht werden kann, ist es zunächst notwendig, zu überprüfen, welche der zuvor dargestellten Modelle überhaupt in vivo zu einer Deletion der Sequenzduplikation im KanKanMX4 führen und welche weitestgehend keinen Einfluss auf die Reversionsereignisse haben. Am einfachsten von den anderen Modellen zu unterscheiden ist eine Deletion durch primer template slippage. Dieser Prozess ist der einzige, bei dem weder eine Invasion eines 3'-Endes in einen homologen Bereich des Schwesterchromatids, noch die Hybridisierung komplementärer Überhänge notwendig ist. Für die Invasion eines Einzelstrangs in homologe dsDNA werden in S. cerevisiae die Proteine Rad51 und Rad52 benötigt. Die Hybridisierung von komplementären Überhängen beim SSA ist dagegen nur Rad52abhängig (Krogh \& Symington, 2004). Die Messung spontaner Reversionsraten in einer

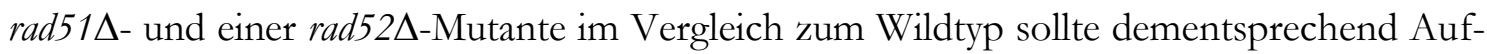
schluss über eine eventuelle Beteiligung von PTS an der Entstehung von Reversionsereignissen im KanKanMX4-Modul geben. Daher wurde für diese Mutanten die spontane Reversionsrate mit Hilfe der Methode des Medians ermittelt (Tab. 4; Lea \& Coulson, 1948). Hierzu wurden von jedem Stamm elf parallele Kulturen mit sehr geringer Zelldichte angeimpft und vier bis sechs Tage wachsen gelassen. Für jede der elf Kulturen wurde der Revertantentiter und darauf aufbauend die Mediankultur ermittelt. Diese Kultur wurde dann für die Berechnung der Reversionsrate herangezogen.

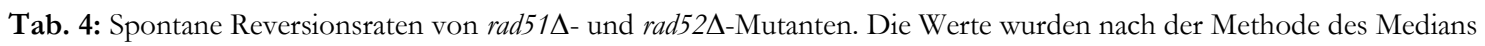
ermittelt (Lea \& Coulson, 1948). Im Falle der rad52 $\Delta$-Mutante bildeten sich keine Kolonien während des Tests. Die angegebenen Maximalwerte entsprechen der Berechnung anhand einer einzelnen hypothetischen Kolonie.

\begin{tabular}{lcr}
\hline Stamm & Spontane Reversionsrate & Faktor Mut. / WT \\
\hline \hline Wildtyp & $9,36 \times 10^{-6} \pm 9,82 \times 10^{-7}$ & 1 \\
& $9,54 \times 10^{-6} \pm 9,83 \times 10^{-7}$ & 1 \\
rad51 & $3,35 \times 10^{-5} \pm 3,3 \times 10^{-6}$ & 3,6 \\
& $4,77 \times 10^{-5} \pm 4,56 \times 10^{-6}$ & 5,6 \\
rad52 & $<5,5 \times 10^{-7}$ & $<0,06$ \\
& $<3,1 \times 10^{-8}$ & $<0,003$ \\
\hline
\end{tabular}




\section{ERGEBNISSE}

Bei beiden Versuchen konnten für die rad52 $\Delta$-Mutante keine Revertanten gefunden werden. Demnach scheinen die Ereignisse, welche in vivo zu einer Reversion führen, im Wesentlichen Rad52-abhängig zu sein. Da für primer template slippage keine Invasion im Schwesterchromatid notwendig ist und dieser Mechanismus dementsprechend nicht von Rad52 abhängig sein sollte, ist PTS höchstwahrscheinlich nicht die Ursache der in vivo entstehenden Reversionen. Interessanterweise ist die spontane Reversionsrate in rad51 $\Delta$ im Gegensatz zum Wildtyp erhöht. Es scheint demnach ein Teil der Reversionen über einen Prozess zu entstehen, welcher in Abwesenheit von Rad51 zu einem Anstieg der Reversionsfrequenz führt. In Abwesenheit von Rad51 könnten Doppelstrangbrüche anstatt durch eine Invasion in das Schwesterchromatid über Rad51, Rad52 und anschließende Generierung komplementärer Überhänge (SDSA), direkt über Rad52-vermitteltes SSA repariert werden. Um über SDSA eine Reversion zu erzeugen, ist die Invasion in der zweiten Sequenzduplikation im Schwesterchromatid, ausgehend von der ersten Duplikation, notwendig. Entsteht der Schaden in der zweiten Duplikation und folgt eine Invasion in der ersten Wiederholung im Schwesterchromatid, so entsteht eine Triplikation der Sequenz. Durch Invasion in der zweiten Duplikation des Schwesterchromatids, ausgehend von einem Schaden in der zweiten Sequenzwiederholung, bleiben beide Sequenzen erhalten. Dasselbe gilt für eine Invasion in der ersten Duplikation des Schwesterchromatids, ausgehend von der ersten Wiederholung. Drei von vier möglichen Invasionsszenarien stellen demnach phänotypisch keine Veränderung dar. Dagegen führt jede Ausgangssituation bei SSA zu einer Deletion der Duplikation und damit zu einer phänotypischen Änderung. Dementsprechend könnte bei einer Zunahme an SSA gegenüber SDSA auch die Frequenz an Reversionsereignissen steigen und die erhöhte spontane Reversionsrate in rad51 $\Delta$ auf diese Zunahme zurückzuführen sein. Eine weitere Erklärung könnte die Entstehung von Doppelstrangbrüchen als Sekundärschaden sein. Bei Abwesenheit von Rad51 wäre es möglich, dass DNA-Schäden anderweitig prozessiert werden, was unter anderem zu einer Anhäufung von Doppelstrangbrüchen führt, welche wiederum über SSA prozessiert werden. Jedoch wäre auch in diesem Fall die erhöhte spontane Reversionsrate wahrscheinlich auf eine Zunahme an SSA zurückzuführen.

Zusammengefasst machen es die Beobachtungen für rad52 $\Delta$ und rad51 $\Delta$ eher unwahrscheinlich, dass primer template slippage der Ursprung der in vivo spontan entstehenden Reversion darstellen. Vielmehr sind die Daten konsistent mit der Vermutung, dass die Reversionen im Wesentlichen durch Prozesse entstehen, welche von der homologen Rekombination abhängig sind.

\section{Messung schadensinduzierter Reversionsfrequenzen im Wildtyp}

Den Beobachtungen bei der spontanen Reversionsrate zufolge entstehen die Reversionen höchstwahrscheinlich über eines der zuvor benannten vier Modelle, welche eine Invasion im Schwesterchromatid benötigen. Jedes dieser Modelle setzt voraus, dass der Prozess durch einen Schaden in der DNA induziert wird. Demnach sollte die gemessene Reversionsfrequenz mit der Schadensdichte in den Zellen korrelieren. Um zu untersuchen, inwiefern die gemessenen Reversionen abhängig von DNA-Schäden sind, wurde daher die schadensinduzierte Reversionsfrequenz im Wildtyp bestimmt. Dazu wurden die Zellen mit dem Agens 4-Nitrochinolin-1-Oxid (4-NQO) behandelt. 4-NQO kann metabolisch aktiviert 
werden und bildet in aktivierter Form sperrige Addukte mit den Basen der DNA (Abb. 15; Galiegue-Zouitina et al., 1986; Turesky, 1994). Solche Addukte von Aromaten mit den Basen sind wahrscheinlich in der Lage, Replikationsarreste hervorzurufen. Gezeigt werden konnte dies bspw. bereits für 2-Acetylaminofluorene (Pages et al., 2005). Darüber hinaus kann es durch 4-NQO-Inkubation zu oxidativen Schäden wie der Bildung von 8-OxoGuanin oder Strangbrüchen kommen (Galiegue-Zouitina et al., 1985; Kohda et al., 1986; Ramotar et al., 1998; Yamamoto et al., 1993). Wie zuvor bereits erwähnt, stellen sowohl Strangbrüche als auch Replikationsarreste eine Möglichkeit dar, die Invasion im Schwesterchromatid zu induzieren und damit eine Reversion hervorzurufen. Die Behandlung der Zellen mit 4-NQO sollte demnach zeigen, ob Reversionen durch Erzeugung von DNASchäden entstehen können. Um die 4-NQO-induzierte Reversionsfrequenz zu ermitteln, wurden die Zellen zunächst in der G1-Phase durch Zugabe von $\alpha$-Faktor arretiert. Anschließend wurden die Zellen um den Arrest aufzuheben gewaschen und danach in Anwesenheit von 4-NQO bis zum Erreichen der G2-Phase wachsen gelassen. Damit wurde weitgehend sichergestellt, dass die Zellen genau für die Dauer einer S-Phase dem Agens ausgesetzt waren, da bspw. Replikationsarreste nur in dieser Phase auftreten können. Untersucht wurden die 4-NQO-Konzentrationen 0,02; 0,04; 0,08; 0,16 und 0,24 $\mu \mathrm{g} / \mathrm{ml}$. Dazu wurde die synchronisierte Zellsuspension entsprechend der Anzahl an untersuchten Konzentrationen in sechs Ansätze aufgeteilt. Fünf dieser Ansätze wurden jeweils mit einer der benannten 4-NQO-Konzentration inkubiert. Der sechste Ansatz diente zur Messung des spontanen Hintergrunds und wurde ohne 4-NQO weiterverwendet. Im Anschluss wurden die Zellen gewaschen, um das 4-NQO zu entfernen. Geeignete Verdünnungen wurden auf YPD-Platten mit und ohne G418 ausplattiert. Die ermittelte Koloniezahl auf YPD diente zur Berechnung des Lebendtiters, diejenige auf G418 zur Berechnung des Revertantentiters. Anhand der Titer wurde anschließend die Reversionsfrequenz errechnet und jeweils der spontane Hintergrund subtrahiert, um die induzierte Reversionsfrequenz zu erhalten. Die Auftragung der induzierten Frequenz gegen die 4-NQO-Konzentration ist in Abb. 14 zu sehen.

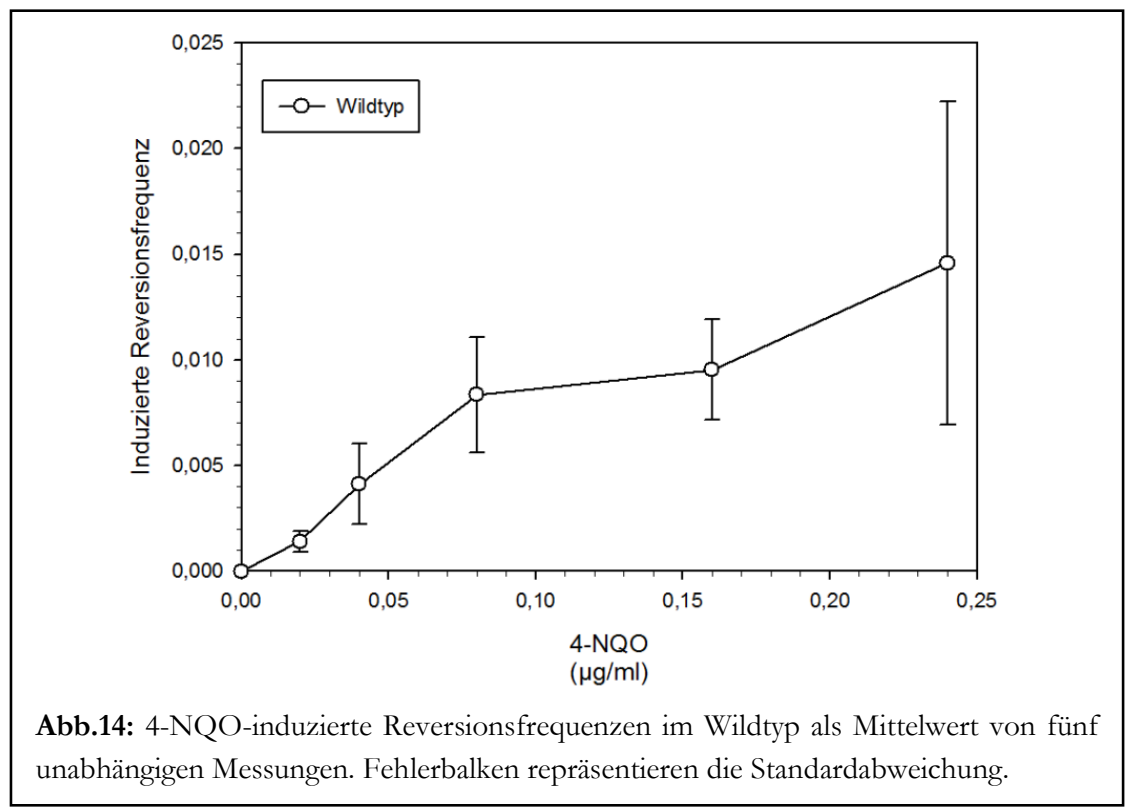




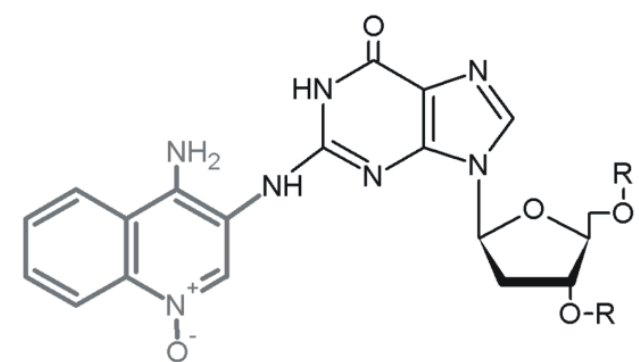

A

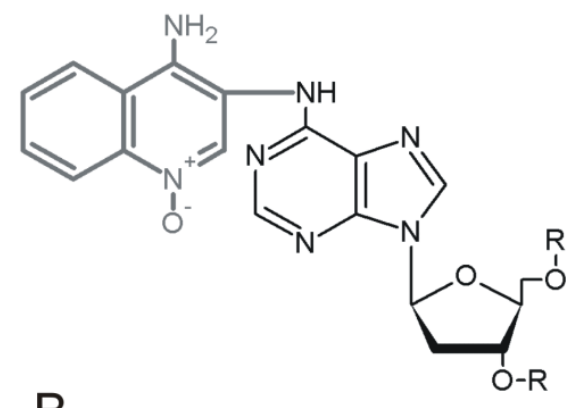

B<smiles></smiles>

Abb. 15: Darstellung der hauptsächlich durch 4-NQO gebildeten DNA-Addukte nach Galiegue-Zouitina et al., 1985 und Galiegue-Zouitina et al., 1986. A 3-(Desoxyguanosin-N2-yl)-4-aminochinolin-1-oxid. B 3-(Desoxyadenosin-N6-yl)-4-aminochinolin-1-oxid. C N-(Desoxyguanosin-C8-yl)-4-aminochinlin-1-oxid.

Tatsächlich lässt sich ein Dosis-abhängiger Anstieg der induzierten Reversionsfrequenz im Wildtyp feststellen. In erster Näherung sollte primer template slippage nicht von der Konzentration an 4-NQO im Medium abhängig sein. Es scheinen demnach andere Mechanismen zu einer Reversion zu führen, welche durch 4-NQO induzierbar sind.

Ein wichtiger Aspekt bei der Interpretation der induzierten Reversionsfrequenzen ist die Frage nach der Aussagekraft der ermittelten Daten. Die induzierten Reversionsfrequenzen werden durch Abziehen der spontanen Reversionsfrequenz erhalten. Diese ist jedoch generell einer gewissen statistischen Schwankung unterworfen. Ist die spontane Frequenz dabei deutlich höher als die induzierte, so kann letztere durch die statistischen Schwankungen überlagert werden. Da die induzierten Reversionsfrequenzen im Wildtyp jedoch je nach 4-NQO-Konzentration 2- bis 14-fach über dem spontanen Hintergrund liegt (Daten nicht gezeigt), ist es eher unwahrscheinlich, dass statistische Schwankungen die Ergebnisse der Messungen beeinflussen. 


\section{ERGEBNISSE}

\section{Messung schadensinduzierter Reversionsfrequenzen in rekombinationsdefekten Mutanten}

Wie die Messung spontaner Reversionsraten zeigt, sind die spontanen Reversionsereignisse in vivo wahrscheinlich vollständig von Rad52 abhängig. Um zu überprüfen, ob auch die durch 4-NQO induzierten Reversionsereignisse Rad52-abhängig sind, wurden auch die 4-NQO-induzierten Reversionsfrequenzen von rad52A gemessen. Das Ergebnis ist in Abb. 16 ii und iv zu sehen. Auch hierbei lassen sich für rad52 $\Delta$ annähernd keine Reversionen in den drei Messungen feststellen. Durch die Inkubation mit 4-NQO lassen sich demnach nahezu ausschließlich Rad52-abhängigen Reversionsereignisse induzieren.

Neben der induzierten Reversionsfrequenz von $\operatorname{rad} 52 \Delta$ wurde auch die induzierte Frequenz von rad51 gemessen. Das Ergebnis ist in Abb. 16 i anhand eines repräsentativen Experiments zu sehen. Die induzierten Reversionsfrequenzen in rad51 $\Delta$ sind deutlich verringert gegenüber dem Wildtyp. Um einen besseren Eindruck darüber zu bekommen, wie stark die induzierte Reversionsfrequenz im Vergleich zum Wildtyp erniedrigt ist und vor allem um einen Wert zu erhalten, welcher es später ermöglicht, unterschiedliche Mutanten miteinander zu vergleichen, wurden die jeweiligen Werte einer Messung auf die Werte des Wildtyps normiert und ebenfalls gegen die 4-NQO-Konzentration aufgetragen. Durch diese in Abb. 16 iii dargestellte Art der Auftragung zeigt sich, dass die induzierten Reversionsfrequenzen in rad51D unabhängig von der Konzentration an 4-NQO im Vergleich zum Wildtyp innerhalb einer Messung immer um etwa den gleichen Faktor erniedrigt sind. Somit kann der Mittelwert der normierten induzierten Reversionsfrequenzen berechnet werden, was den späteren Vergleich mit anderen Mutanten erleichtert. Allerdings wurden für die Berechnung des Mittelwerts die jeweiligen auf den Wildtyp normierten induzierten Reversionsfrequenzen für die Konzentration $0,02 \mu \mathrm{g} / \mathrm{ml}$ nicht hinzugezogen. In einer der Messungen für rad51 $\Delta$ schien der berechnete Faktor bei dieser Konzentration nicht dem ansonsten mehr oder weniger konstanten Wert zu entsprechen. Auch bei späteren Messungen anderer Mutanten konnte solch eine teilweise auftretende Abweichung gefunden wer-

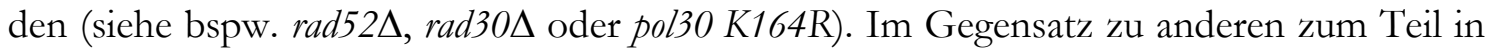
den Messungen auftretenden Schwankungen des ansonsten wahrscheinlich konstanten Faktors scheint eine deutliche Schwankung bei $0,02 \mu \mathrm{g} / \mathrm{ml}$ in einer gewissen Regelmäßigkeit aufzutreten. Eine mögliche Erklärung für diese Abweichung ist eine Schwankung der induzierten Reversionsfrequenz in beiden betrachteten Stämmen: Alle betrachteten Werte unterliegen einer gewissen Schwankung, wie in Abb. 14 anhand der Standardabweichung $\mathrm{zu}$ erkennen ist. Bei den vergleichsweise geringen induzierten Reversionsfrequenzen für 0,02 $\mu \mathrm{g} / \mathrm{ml}$ 4-NQO können sich solche Schwankungen wesentlich stärker auf den Quotienten von Mutante und Wildtyp auswirken, sodass eine leichte Schwankung bereits eine deutliche Veränderung im Quotienten hervorruft. Zwar ist es auch möglich, dass diese Schwankungen spezifische Phänomene einzelner Mutanten darstellen, jedoch erscheint es wahrscheinlicher, dass es sich hierbei um ein experimentelles Artefakt handelt. Unabhängig davon sind diese Schwankungen wahrscheinlich nicht von Interesse für die Betrachtung des eigentlichen Phänotyps, da die qualitative Aussage der Ergebnisse durch diese Schwankung nur minimal beeinflusst wird. Für eine bessere Vergleichbarkeit der Mutanten wurden dennoch für alle (auch im Folgenden berechneten) Mittelwerte der normierten induzierten Reversionsfrequenzen grundsätzlich die Werte für $0,02 \mu \mathrm{g} / \mathrm{ml}$ ausgelassen. 


\section{ERGEBNISSE}

Die Auftragung des Mittelwerts aller für rad51 $1 \Delta$ ermittelten, auf den Wildtyp normierten

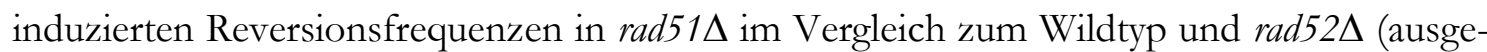
nommen $0,02 \mu \mathrm{g} / \mathrm{ml} 4-\mathrm{NQO})$ ist in Abb. 17 iii zu finden. Dabei lässt sich feststellen, dass rad51 $\Delta$ im Mittel eine im Vergleich zum Wildtyp um den Faktor 20 erniedrigte induzierte Reversionsfrequenz aufweist. Wie zuvor ausgeführt, wurde vermutet, dass die in einer rad51D-Mutante gemessene Erhöhung der spontanen Reversionsrate auf eine Zunahme an SSA-Ereignissen zurückzuführen ist. Daneben lässt sich für die 4-NQO-induzierten Reversionsfrequenzen vermuten, dass es sich bei den gemessenen induzierten Reversionen im Wesentlichen um Ereignisse während der Reparatur von kollabierten bzw. der Umgehung von arretierten Replikationsgabeln handelt. Die Reparatur von Doppelstrangbrüchen durch SDSA oder SSA ist dagegen wahrscheinlich nicht die hauptsächliche Ursache für die Entstehung der 4-NQO-induzierten Reversionen, da Doppelstrangbrüche vermutlich nur einen geringeren Anteil der durch 4-NQO induzierten Schäden ausmachen. Für diese Vermutung spricht unter anderem die deutliche Sensitivität von NER-defekten Mutanten gegenüber 4-NQO. Da Strangbrüche nicht durch NER repariert werden können, scheint somit ein wesentlicher Teil der Schäden anderer Natur zu sein. Demnach sollte der größte Teil an durch 4-NQO induzierten DNA-Schäden nicht in Abwesenheit von Rad51 durch Rad52-abhängiges SSA repariert werden können und somit auch nicht zu einer erhöhten Frequenz an Reversionen führen, wie es möglicherweise bei spontanen Schäden der Fall ist. Die schadensabhängigen Ereignisse in vivo sind daher vermutlich in einem wesentlichen Maße abhängig von einer Rad51-vermittelten Invasion ins Schwesterchromatid. Die Tatsache, dass die induzierten Reversionsfrequenzen nicht vollständig durch die Deletion von RAD51 ausgelöscht sind, könnte auf die Anwesenheit von Rad52 zurückzuführen sein. Rad52 ist in vitro auch in Abwesenheit von Rad51 in der Lage, selbst in begrenztem Maße eine Stranginvasion in eine homologe Sequenz zu initiieren. (Kagawa et al., 2001; Malkova et al., 1996; Rattray \& Symington, 1994). Es wäre daher möglich, dass in einer rad51-Mutante die induzierten Reversionen zum Teil durch Rad52-vermittelte Invasion ins Schwesterchromatid entstehen. Alternativ wäre es auch denkbar, dass die induzierten Reversionen in rad51 $\Delta$ Folge der Rad52-abhängige Reparatur von Strangbrüchen sind, welche möglicherweise doch in geringem Maße durch Inkubation mit 4-NQO entstehen. Beide Vermutungen sind gleichzeitig konsistent mit der Tatsache, dass die Reversionsereignisse vollständig in einer rad52 $\Delta$-Mutante ausgelöscht zu sein scheinen.

Nach diesen Daten ist es anzunehmen, dass die durch 4-NQO induzierten Reversionen durch Rad51-abhängige homologe Rekombination entstehen. Darüber hinaus sind nach diesen Ergebnissen vermutlich auch spontane Reversionen von Rad51 abhängig, werden jedoch wie zuvor dargelegt alternativ durch SSA repariert, weshalb es zu einer Zunahme an Reversionsereignissen kommt. Bei den induzierten Schäden kann SSA dagegen nicht als Alternative dienen und es kommt zur Reduktion der Reversionsfrequenz. Gleichzeitig ist es damit eher unwahrscheinlich, dass es sich bei den spontanen Reversionsereignissen um die Reparatur von Doppelstrangbrüchen handelt, welche als sekundärer Schaden in einer rad51 $\Delta$-Mutante entstehen, da solche Sekundärschäden wahrscheinlich auch in Abhängigkeit von 4-NQO entstehen sollten. 


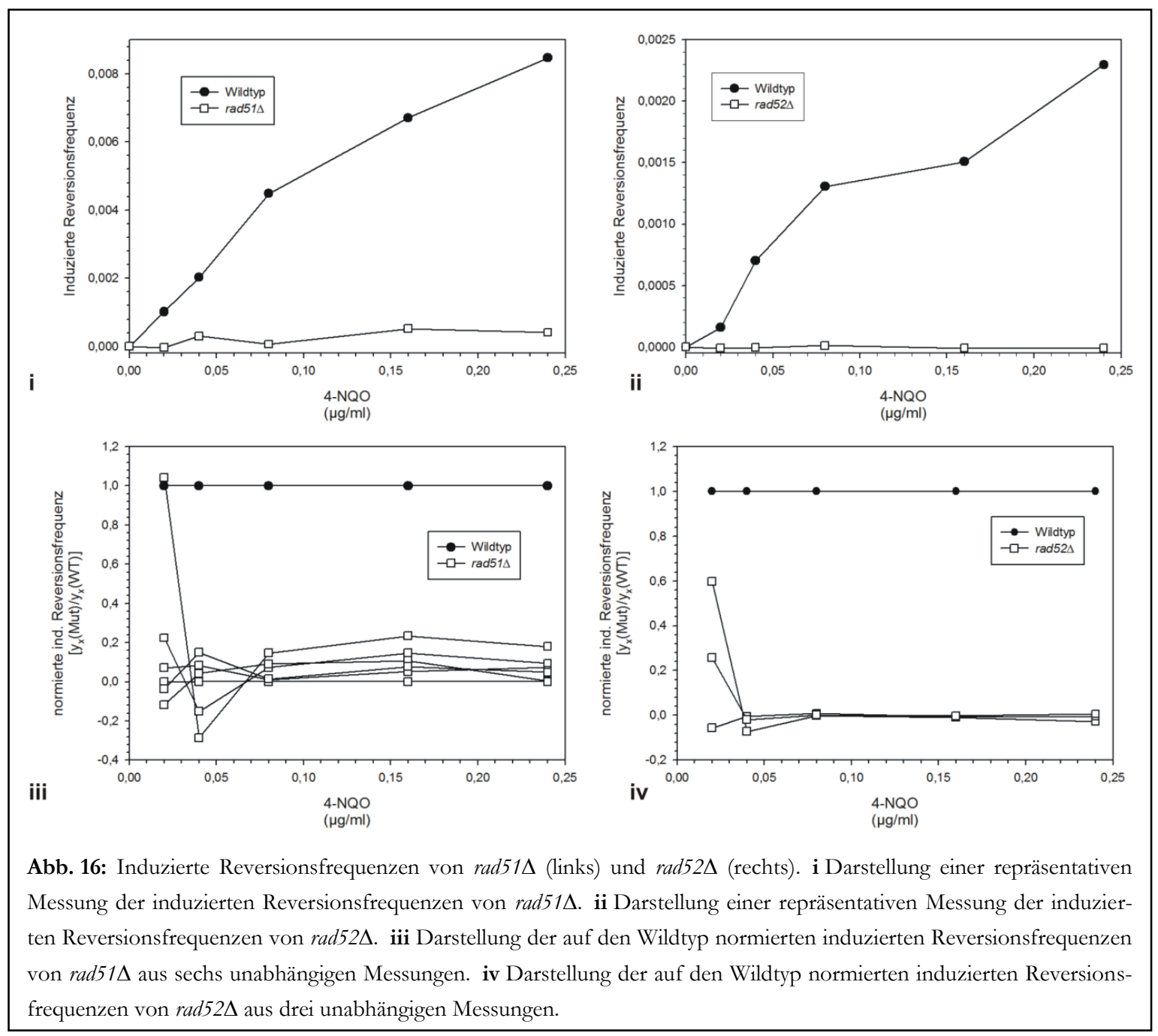

\section{Messung schadensinduzierter Reversionsfrequenzen in yen $1 \Delta$-Mutanten}

Wie in der Einleitung, Abb. 4 i-iv dargestellt (Seite 19), kann bei einem Replikationsarrest die Information des Schwesterchromatids auch durch fork regression genutzt werden. Der dabei entstehende Chicken Foot entspricht strukturell einer Holliday-Junction und kann daher durch eine Resolvase geschnitten werden wobei ein vollständiges und ein unvollständiges Chromosom entstehen. An dem unvollständigen Chromosom kann anschließend ein 3'Überhang gebildet werden, welcher über homologe Rekombination in das vollständige Schwesterchromatid invadiert. Anschließend kann die Replikationsgabel wieder hergestellt und die Replikation reinitiiert werden (siehe Seite 19, Abb. 4 iv-vi). Durch die Invasion kann es auch in diesem Fall zu einer Reversion der Sequenzduplikation kommen (siehe Abb. 13 C). Nach diesem Modell wären die Reversionsfrequenzen abhängig von der Auflösung des Chicken Foots durch eine Resolvase. Um dies nachzuprüfen, wurde die induzierte Reversionsfrequenz in einer yen1 $\Delta$-Mutante gemessen. YEN1 codiert für die einzige derzeit bekannte Resolvase, welche in S. cerevisiae im Zellkern zu finden ist (Ip et al., 2008). Die 4-

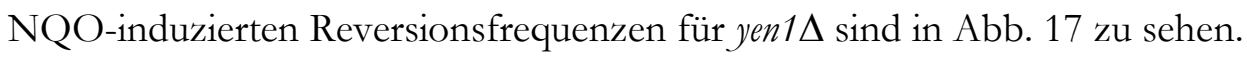




\section{ERGEBNISSE}

yen $1 \Delta$ weist im Vergleich zum Wildtyp nur eine sehr schwach verringerte induzierte Reversionsfrequenz auf (ca. $10 \%$ verringert), weshalb die beobachteten Ereignisse vermutlich nicht über einen Chicken Foot als Intermediat, sondern direkt über eine Rad51-vermittelte Invasion ins Schwesterchromatid mit D-Loop Bildung initiiert zu werden scheinen.

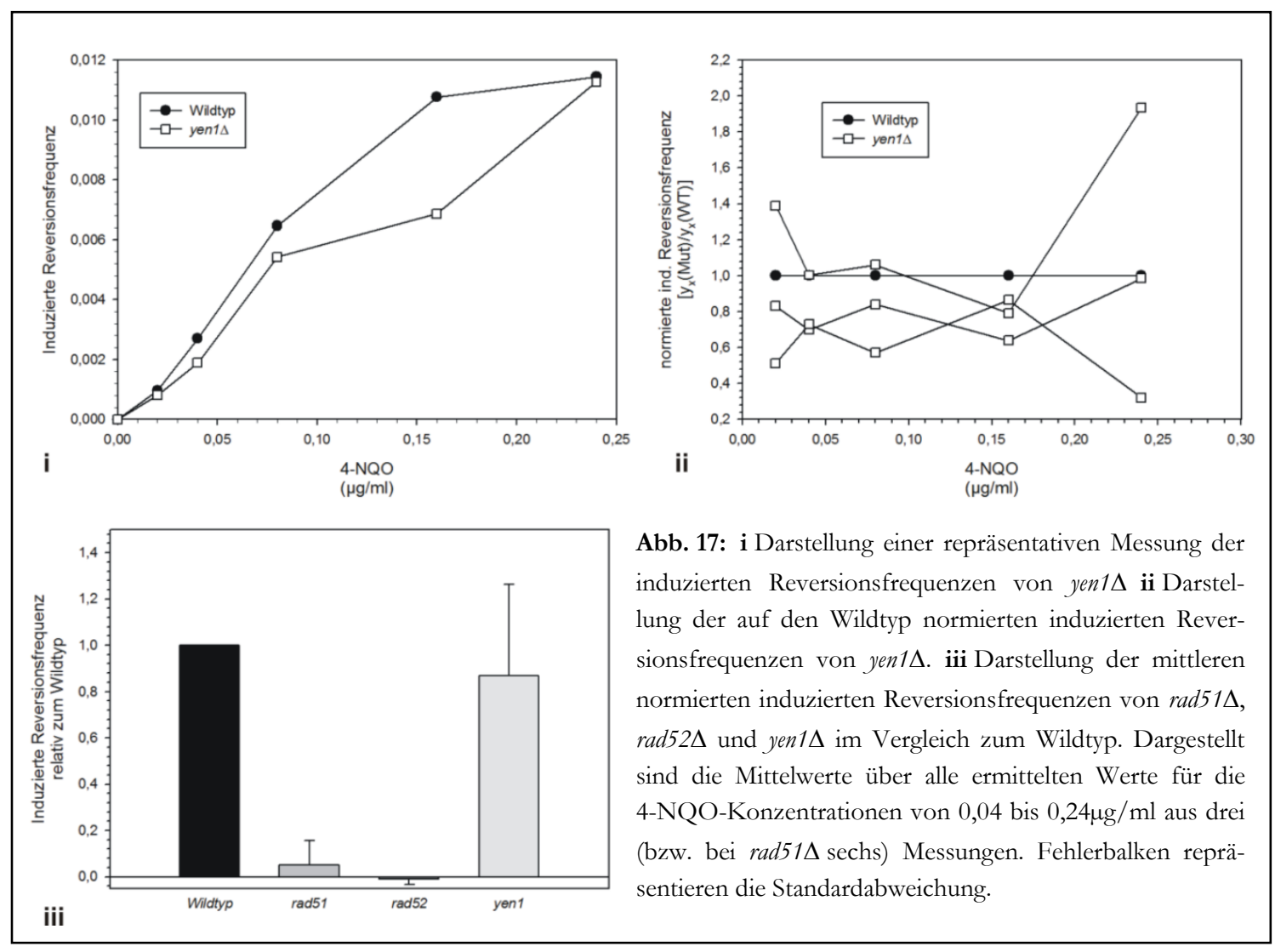

\section{Messung Schadens--induzierter Reversionsfrequenz, in $\operatorname{rad} 30 \Delta$-Mutanten}

Nach dem Modell der fehlerfreien Umgehung eines replikationsarretierenden Schadens durch homologe Rekombination wird für die Umgehung eine Verlängerung des DNAStrangs mit Hilfe des Schwesterchromatids benötigt. Darüber hinaus setzt die Interaktion mit dem Schwesterchromatid durch homologe Rekombination nach diesem Modell die Bildung eines D-Loops voraus. Um anschließend den invadierten Strang über die im originalen template beschädigte Stelle hinaus zu verlängern, wird demnach eine Polymerase benötigt, welche fähig ist, die Synthese an einem D-Loop zu initiieren. RAD30 codiert für die Transläsionspolymerase $\eta$, welche cis-syn-Cyclobutanpyrimidindimere fehlerfrei überlesen kann (Abdulovic \& Jinks-Robertson, 2006; Yagi et al., 2005). Darüber hinaus kann sie ein breites Spektrum weiterer DNA-Schäden überlesen (Waters et al., 2009). Für humane Pol $\eta$ wurde anhand von biochemischen Daten gezeigt, dass sie im Gegensatz zu Pol $\delta$ und Pol 1 das primer-Ende in einem D-Loop verlängern kann (McIlwraith et al., 2005). Demnach ist es plausibel, dass Pol $\eta$ auch in Hefe diese Funktion bei der homologen Rekombination ausüben kann, weshalb die induzierten Reversionsfrequenzen in rad30د-Mutanten gemessen wurde. Das Ergebnis ist in Abb. 18 gezeigt. 
Die Frequenz in einer rad30 $\Delta$-Mutante ist im Vergleich zum Wildtyp verringert, wobei die

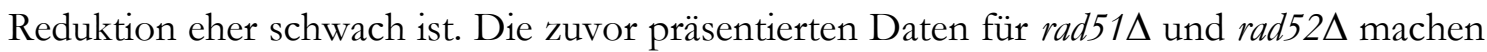
es wahrscheinlich, dass die induzierten Reversionsfrequenzen vornehmlich ein Resultat der fehlerfreien Umgehung von replikationsarretierenden DNA-Schäden sind. Demnach könnte diese leichte Reduktion in rad30 $\Delta$ tatsächlich ein Hinweis auf eine Beteiligung von Rad30 bei der Umgehung von DNA-Schäden durch homologe Rekombination sein. Die geringe Reduktion könnte dabei darauf hinweisen, dass Rad30 jedoch nicht die einzige bzw. wichtigste Polymerase hierfür ist, sondern möglicherweise durch andere DNA-Polymerasen ersetzt werden kann. Allerdings wäre es ebenfalls möglich, dass der Wegfall von Pol $\eta$ aufgrund ihrer Funktion als Transläsionspolymerase gleichzeitig zu einem Anstieg an Reversionen führt: Bei dem Ausfall der fehlerfreien Mechanismen lässt sich ein Anstieg der spontanen Mutationsrate feststellen, welche von Transläsionssynthese abhängig ist (Schürer et al., 2004). Umgekehrt könnte daher der Ausfall einer Transläsionspolymerase wie Rad30 zu einer Zunahme an fehlerfreier Umgehung und damit zu einer Erhöhung der Reversionsfrequenz führen. Da gleichzeitig jedoch die homologe Rekombination ebenfalls verringert wird, könnten sich diese Phänotypen gegenseitig teilweise aufheben, weshalb die Reduktion nur schwach ausfällt. In jedem Fall erscheint die Reduktion der induzierten Reversionsfrequenzen deutlich genug, um eine Beteiligung von Rad30 an jenen Prozessen, welche zu einer Reversion führen, zumindest wahrscheinlich zu machen.

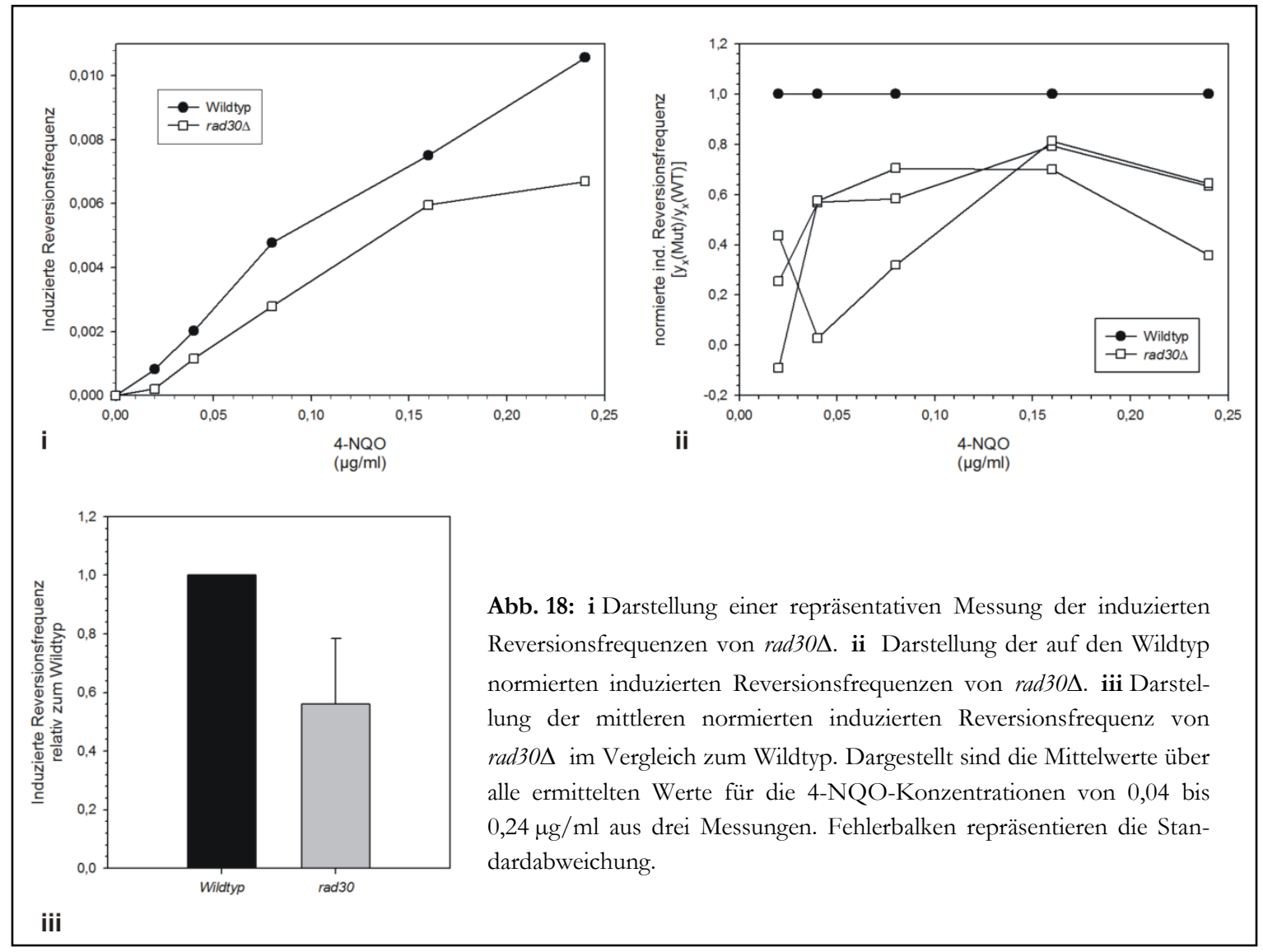




\section{ERGEBNISSE}

Messung Schadens-induzierter Reversionsfrequenzen in rev3 $\Delta$-Mutanten

Wie bereits in Bezug auf Rad30 erwähnt, können alternativ zur fehlerfreien Umgehung durch homologe Rekombination auch Transläsionspolymerasen eingesetzt werden, um einen DNA-Schaden zu umgehen. Dies zeigt sich bspw. daran, dass sich bei einem Ausfall von Genen der rad52-Epistasisgruppe ein deutlicher Anstieg der spontanen Mutationsrate im CAN1-Vorwärtsmutationssystem feststellen lässt (Schürer et al., 2004). Gleichzeitig lässt sich so vermuten, dass es in Abwesenheit der fehlerfreien Umgehung zu einer verstärkten Umgehung durch Transläsionssynthese kommt. Um zu überprüfen, ob umgekehrt ein Ausfall der Transläsionssynthese zu einer Erhöhung der induzierten Reversionsfrequenz führt, wurden die induzierten Reversionsfrequenzen in einer TLS-defekten Mutante ermittelt. Ein rad30 $\Delta$-Stamm ist jedoch wie zuvor dargelegt zur Klärung dieser Hypothese nur begrenzt von Nutzen, da Pol $\eta$ vermutlich zusätzlich an der homologen Rekombination beteiligt ist. Daher wurde hier eine rev3 $\Delta$-Mutante untersucht. Rev3 ist die katalytische Untereinheit der DNA-Polymerase $\zeta$. Diese Polymerase ist zwar keine Transläsionspolymerase im eigentlichen Sinne, sondern gehört wie die replikativen DNA-Polymerasen zur B-Familie. Dennoch ist Rev3 für die Entstehung spontaner Mutationen im CAN1 in S. cerevisiae notwendig (Lawrence, 2004; Nelson et al., 1996). Vermutlich dient Pol $\zeta$ dazu, nach dem Einbau einer Base gegenüber einem DNA-Schaden, die Transläsionspolymerase zu ersetzen und die Verlängerung des fehlgepaarten primer-Endes zu katalysieren. Transläsionspolymerasen wie Pol $\eta$ sind zu dieser Verlängerung wahrscheinlich nicht fähig, weshalb Rev3 für die Entstehung spontaner Mutationen notwendig ist (Waters et al., 2009).

Die gemessenen induzierten Reversionsfrequenzen sind in Abb. 19 gezeigt. Für rev3 3 lässt sich eine deutlich erniedrigte Reversionsfrequenz feststellen. Demnach scheint sich durch Ausschalten der Transläsionssynthese die Frequenz induzierter Reversionsereignisse nicht zu erhöhen. Allerdings zeigen frühere Daten bezüglich einer rev3 $\Delta$-Mutante, welche mit einem episomalen KanKanMX4-Modul durchgeführt wurden, eine leicht erhöhte induzierte Frequenz (Rudolph, 2003). Um herauszufinden, woran die Diskrepanz dieser voneinander unabhängigen Messungen liegen könnte, wurden zunächst neue rev3 $\Delta$-Mutanten untersucht. Hierzu wurde zum einen eine rev3::HisMX4-Mutante (PCR-basiert nach Wach et al., 1997) ausgehend von einem bestehenden CEN.PK2-1c YIplac211KanKanMX4 hergestellt (Isolat I). Zum anderen wurde in einen bereits existierenden rev3::natMX4 das Plasmid YIplac211KanKanMX4 integriert (Isolate II-V). Die induzierten Reversionsfrequenzen der neuen Isolate sind in Abb. 19 ii zu sehen. Von diesen fünf Mutanten wiesen drei, ähnlich wie bei Christian Rudolph, eine erhöhte und zwei eine, wie hier zuvor festgestellte, erniedrigte induzierte Reversionsfrequenz auf. Eine Erklärungsmöglichkeit für diese Unterschiede wäre eine Hintergrundmutation in einigen der Isolate, welche den rev3 $\Delta$-Phänotyp überlagert oder verändert. Um nachzuprüfen, ob einer der beiden Phänotypen möglicherweise auf einer Hintergrundmutation und nicht auf der rev3 $\Delta$-Deletion beruht, wurde daher versucht, rev3 $\Delta$ in je einem Isolat mit erhöhter (Isolat I) und einem mit erniedrigter induzierter Reversionsfrequenz (Isolat II) in Bezug auf die induzierte Reversionsfrequenz durch REV3 zu komplementieren. Dazu wurde zunächst das Wildtyp REV3-Fragment mit EcoRI und SalI aus dem Vektor pJA6 (Morrison et al., 1989) ausgeschnitten und in den Vektor YIp- 
lac128 kloniert. Anschließend wurde der so erhaltene Vektor „YIplac128 REV3 flength“ (siehe „Materialien“) in die beiden rev3 $\Delta$-Isolate integriert und je ein ausgesuchter Einzelklon wurde in Bezug auf die induzierte Reversionsfrequenz untersucht. Daraufhin wurde zunächst die Fähigkeit des Plasmids zur Komplementation von rev3s in Bezug auf die Sensitivität gegen 4-NQO überprüft. Dazu wurde die Überlebensrate der beiden Isolate jeweils mit und ohne Plasmid nach Inkubation mit 4-NQO verglichen. Die Daten hierzu entstammen den Messungen der induzierten Reversionsfrequenzen aus Abb. 20 i (errechnet anhand der Lebendtiter). Das Ergebnis ist in Abb. 20 ii zu sehen. Sowohl Isolat I, als auch Isolat II werden dabei in Bezug auf die Überlebensrate durch das Plasmid komplementiert. Wie in Abb. $20 \mathrm{i}$ zu erkennen ist, konnte rev3 3 in Bezug auf die induzierten Reversionsfrequenzen jedoch nur in dem Isolat mit erhöhten induzierten Frequenzen teilweise komplementiert werden. Die Mutante mit erniedrigten induzierten Reversionsfrequenzen wies weiterhin eine deutliche Reduktion der induzierten Frequenzen auf. Dies steht im Einklang mit der Hypothese, dass der Phänotyp von Isolat I auf eine Hintergrundmutation zurückzuführen ist und nicht auf die Deletion von REV3. Zur Validierung der Daten wurde anschließend noch zweimal die induzierte Reversionsfrequenz des komplementierbaren rev3 3 -Isolats gemessen. Die Darstellung der auf den Wildtyp normierten induzierten Reversionsfrequenzen der beiden Messungen sowie der vorhergehenden Messung sind in Abb. $21 \mathrm{zu}$ sehen. rev3 $\Delta$ scheint gegenüber dem Wildtyp etwa um den Faktor zwei bis drei erhöht zu sein. Jedoch zeigt sich für rev3 $\Delta$ in einer der drei Messungen eine deutlich stärkere Erhöhung der induzierten Frequenzen als in den anderen beiden Messungen. Vermutlich liegt dies allerdings an dem im Vergleich zu den anderen beiden Messungen eher geringen Anstieg der induzierten Reversionsfrequenz im Wildtyp. Während bei beiden Messungen mit weniger erhöhter Frequenz die induzierten Reversionsfrequenzen von rev3 $\Delta$ in etwa dieselben Werte aufweisen, wie in der dritten Messung, sind die Werte der dritten Messung im Wildtyp verglichen mit den Werten aus den beiden anderen Messungen erniedrigt (Abb. 21 iii). Dies führt dazu, dass der Quotient höher ist als bei den anderen beiden Messungen, obwohl die Mutante in etwa die gleichen induzierten Reversionsfrequenzen aufweist (vergleiche dazu Abb. 21 i und iii). Daher ist es wahrscheinlich, dass die induzierte Reversionsfrequenz in rev3 $\Delta$ eigentlich nur in etwa um den Faktor 1,3 im Vergleich zum Wildtyp erhöht ist. Es ist daher schwer zu entscheiden, inwiefern der Ausfall der Transläsionssynthese einen tatsächlichen Einfluss auf die Reversionsereignisse hat. Es könnte sein, dass die Anzahl an Reversionen steigt, da der Wegfall von Pol $\zeta$ zu einer erhöhten Frequenz an fehlerfreier Umgehung führt. Jedoch wäre es ebenfalls möglich, dass die sehr schwache Erhöhung in rev3 $\Delta$ nur eine leichte statistische Schwankung darstellt und im Rahmen der Genauigkeit des Versuchs gar keine qualitative Aussage zu treffen ist. Daher müssten weitere Messungen erfolgen, um einen statistischen Fehler weitgehend ausschlieBen zu können. 


\section{ERGEBNISSE}

Die Tatsache, dass von sechs untersuchten rev3 3 -Isolaten jeweils drei einen anderen Phänotyp in Bezug auf die 4-NQO-induzierte Reversionsfrequenz aufweisen als die anderen drei Isolate mag auf das zufällige Auswählen dreier Mutanten mit dem entsprechenden Phänotyp aus einer Vielzahl an Isolaten ohne den Phänotyp zurückzuführen sein. Allerdings konnte auch bei fünf weiteren unabhängigen Isolaten von rev3 $\Delta$ eine erniedrigte induzierte Reversionsfrequenz anstatt einer erhöhten beobachtet werden (Daten nicht gezeigt). Da die Komplementierungsversuche es jedoch wahrscheinlich machen, dass es sich bei der erniedrigten induzierten Frequenz um einen REV3-unabhängigen Phänotyp handelt, deutet dies auf eine möglicherweise gehäuft in $\operatorname{rev} 3 \Delta$ selektierte Hintergrundmutation hin, was bei späteren Untersuchungen von rev3 $\Delta$ bedacht werden sollte.
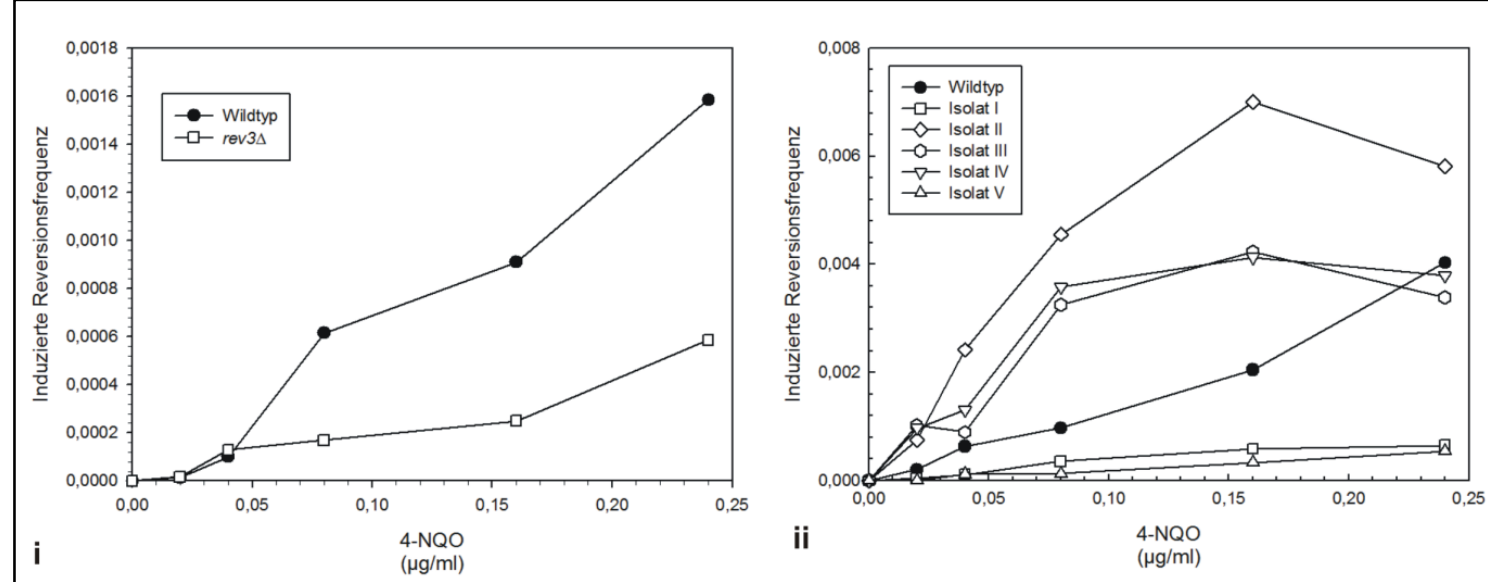

Abb. 19: i Induzierte Reversionsfrequenzen einer rev3 $\Delta$-Mutante, dargestellt anhand einer repräsentativen Messung. ii Induzierte Reversionsfrequenzen von fünf unabhängigen rev3 3 -Isolaten dargestellt anhand einer repräsentativen Messung.
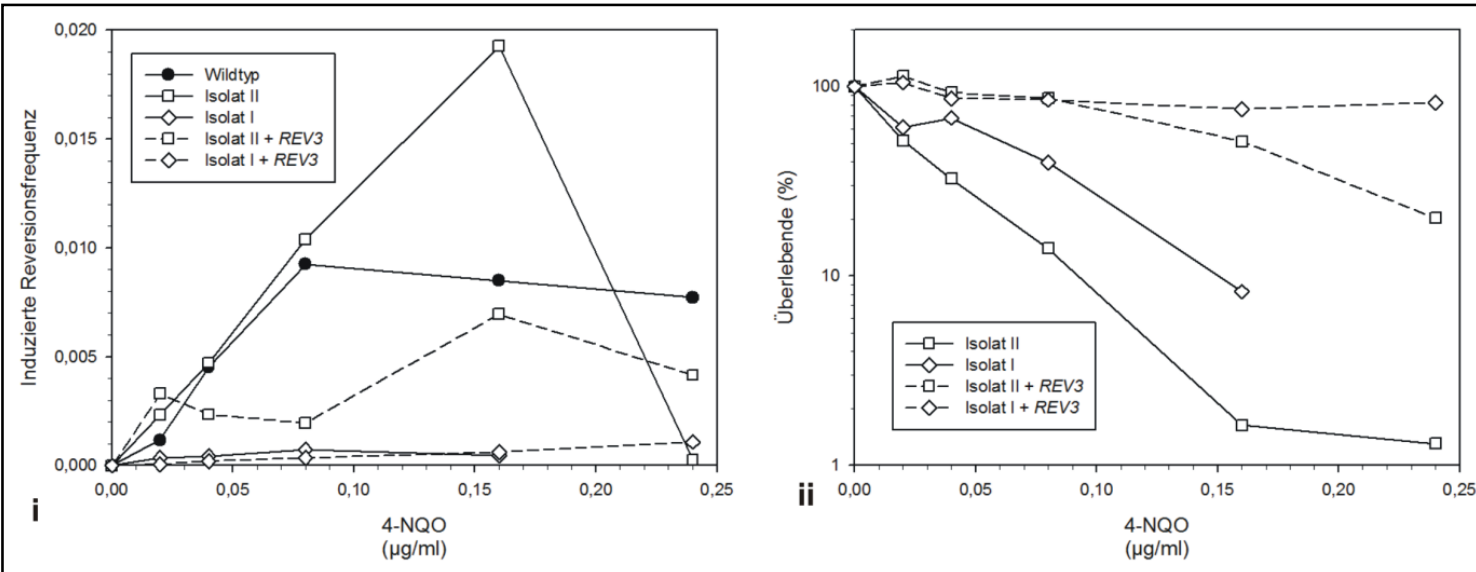

Abb. 20: i Komplementation der induzierten Reversionsfrequenzen in zwei rev3 $\Delta$-Isolaten unterschiedlichen Phänotyps. Komplementiert wurde mit YIplac128 REV3. ii Prozentuale Überlebensraten der rev3 $\Delta$-Isolate, ermittelt anhand der Lebendtiter des Experiments in (i). 


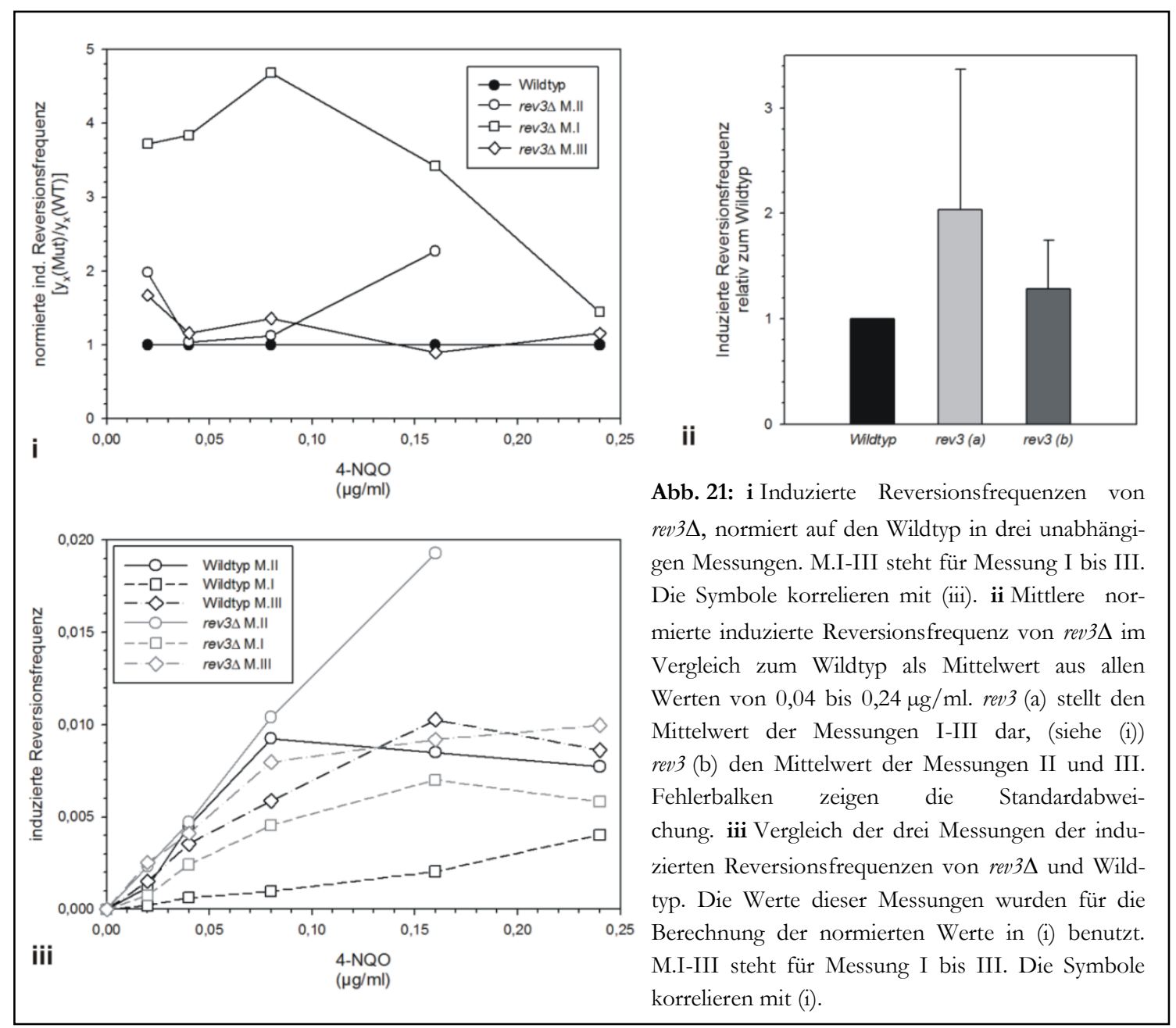

\section{Messung spontaner Reversionsraten von $\operatorname{rad} 30 \Delta$ - und $\operatorname{rev} 3 \Delta$-Mutanten}

Neben den 4-NQO induzierten Reversionsfrequenzen wurden auch die spontanen Reversionsraten für rad30 $\Delta$ und rev3 $\Delta$ ermittelt. Die Ergebnisse sind in Tabelle 5 zu sehen. Hierbei zeigt sich für rad30 $\Delta$ eine Erhöhung, wie sie in etwa auch bei rad51 $\Delta$ messbar ist (siehe Seite 69, Tabelle 4). Wie zuvor dargestellt, ist es durchaus möglich, dass Rad30 an der homologen Rekombination beteiligt ist, indem es im D-Loop das invadierte 3'-Ende verlängert. Diese Verlängerung ist sowohl bei der fehlerfreien Umgehung von DNA-Schäden als auch bei der Reparatur von Doppelstrangbrüchen via SDSA notwendig. Letztere kann jedoch wie bereits in Bezug auf rad51 d dargelegt (siehe Seite 69/70) möglicherweise alternativ durch Rad52-abhängiges SSA ersetzt werden. Demnach könnte die Erhöhung der spontanen Reversionsrate in rad30 $\Delta$ darauf zurückzuführen sein, dass SDSA nur noch eingeschränkt oder gar nicht mehr funktioniert und die entsprechenden Reversionen alternativ durch SSA entstünden. 


\section{ERGEBNISSE}

Im Gegensatz zu rad30 $\Delta$ weist rev3 $\Delta$ eine schwache Reduktion in der spontanen Reversionsrate auf. Allerdings ist in der betreffenden Messung der Wildtyp im Vergleich zu anderen im Rahmen dieser Arbeit durchgeführten Messungen leicht erhöht (vergleiche Messungen von $\mathrm{rad} 51 \Delta / \mathrm{rad} 52 \Delta$ - Seite 69 - und $m m s 2 \Delta / m m s 2 \Delta \operatorname{rev} 3 \Delta$ - Seite 107). Es wäre daher auch möglich, dass der Wert eher dem Wildtyp entspricht bzw. etwas darüber liegt. In beiden Fällen scheint jedoch weder eine deutliche Reduktion, noch ein deutlicher Anstieg der Reversionsrate im Vergleich zum Wildtyp vorzuliegen. Es scheint daher, als wäre der Ausfall der Transläsionssynthese kaum relevant für die Frequenz der gemessenen spontanen Reversionen.

Tab. 5: Spontane Reversionsraten von rad30 $\Delta$ und rev3 3 im Vergleich zum Wildtyp, ermittelt nach Lea \& Coulson, 1948. Die Indices geben an, welcher Wert des Wildtyps zu rad30 $\Delta$ - bzw. rev3 $\Delta$-Wert gehört.

\begin{tabular}{lcr}
\hline Stamm & Spontane Reversionsrate & Faktor Mut. / WT \\
\hline \hline Wildtyp & $7,99 \times 10^{-6} \pm 8,34 \times 10^{-7} 1$ & 1 \\
& $3,01 \times 10^{-5} \pm 2,07 \times 10^{-62}$ & 1 \\
rad30 & $3,67 \times 10^{-5} \pm 3,4 \times 10^{-6} 1$ & 4,6 \\
rev3 & $2,31 \times 10^{-5} \pm 2,1 \times 10^{-62}$ & 0,77 \\
\hline
\end{tabular}

Zusammengefasst zeigen die hier präsentierten Daten für rad30 $\Delta$ und rev3 $\Delta$ zum einen, dass Rad30 möglicherweise an der homologen Rekombination beteiligt ist, wie es bereits für humane Pol $\eta$ postuliert wurde (McIlwraith et al., 2005). Zum anderen lassen die Daten vermuten, dass Transläsionssynthese in Bäckerhefe scheinbar nur zu einem geringen Teil für die Umgehung von DNA-Schäden (zumindest in Bezug auf 4-NQO-induzierte Schäden) notwendig ist, wie die sehr geringe Erhöhung der induzierten Reversionsfrequenzen zeigt. Darüber hinaus ist es nach diesen Daten plausibel, dass tatsächlich ein wesentlicher Anteil der spontanen Reversionen über Reparatur von Doppelstrangbrüchen entsteht, da diese zwar eine Verlängerung am D-Loop und damit vermutlich Rad30 benötigen, jedoch nicht alternativ über Transläsionssynthese prozessiert werden können und somit eine rev3 $\Delta$-Deletion kaum einen Einfluss auf die Anzahl an Reversionen hat.

Insgesamt zeigen die hier präsentierten Daten, dass die homologe Rekombination für die Reversion des KanKanMX4-Moduls notwendig ist. Darüber hinaus lassen die Daten vermuten, dass die spontanen Reversionen durch eine Kombination an SDSA, SSA sowie der fehlerfreien Umgehung von DNA-Schäden über homologe Rekombination entstehen. Durch Inkubation mit 4-NQO lassen sich die gemessenen Ereignisse zum großen Teil auf Reversionsereignisse durch Rad51-abhängige Umgehung von DNA-Schäden eingrenzen. 


\section{Untersuchungen zur Beteiligung von Mph1 an der fehlerfreien Umgeh- ung von DNA-Schäden}

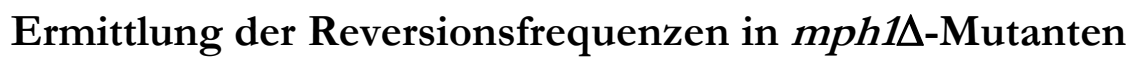

\section{4-NQO-induzierte Reversionsfrequenz in mph1 $1 \Delta$-Mutanten}

mph1-Mutanten weisen einen spontanen Mutatorphänotyp sowie Sensitivität gegenüber diversen DNA-schädigenden Agenzien wie 4-NQO und MMS auf. Des Weiteren konnte anhand von Epistasisanalysen gezeigt werden, dass Mph1 an einem Rad52/Rad51abhängigen Weg beteiligt ist. Die Sensitivität gegen DNA-schädigende Agenzien, der spontane Mutatorphänotyp und eine kaum vorhandene Sensitivität gegen ionisierende Strahlung in mph1 $\Delta$ machen es wahrscheinlich, dass Mph1 nicht oder nur in geringem Maße an der Reparatur von Doppelstrangbrüchen beteiligt ist, sondern vielmehr an der fehlerfreien Umgehung von replikationsarretierenden DNA-Schäden über homologe Rekombination. Zusätzlich wird diese Annahme dadurch gestützt, dass mph1 $\Delta$ weder einen Defekt in der spontanen mitotischen noch in der meiotischen Rekombination aufweist (Scheller et al., 2000; Schürer et al., 2004). Aus diesem Grund wurde von Christian Rudolph die induzierte Reversionsfrequenz in einer mph1 $\Delta$-Mutante ermittelt (Rudolph, 2003). Er konnte zeigen, dass $m p h 1 \Delta$ eine verringerte induzierte Reversionsfrequenz aufweist, was die Annahme unterstützt, dass Mph1 an der fehlerfreien Umgehung von DNA-Schäden beteiligt ist. Diese bereits vorliegenden Daten sollten im Rahmen dieser Arbeit validiert und durch Daten für MMS- und Camptothecin-induzierte Reversionen erweitert werden. Die hierbei ermittelten 4-NQO-induzierten Reversionsfrequenzen sind in Abb. 22 und Abb. 24 gezeigt. Wie auch bei Rudolph 2003 lässt sich für mph1s eine deutliche Verringerung der induzierten Frequenzen im Vergleich zum Wildtyp feststellen. Die zuvor dargestellten Daten für

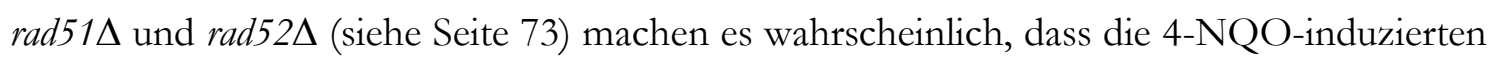
Reversionsfrequenzen zu einem großen Teil durch die Umgehung replikationsarretierender DNA-Schäden durch homologe Rekombination entstehen. Demnach wird die Annahme, dass Mph1 an dieser Umgehung durch HR beteiligt ist, durch die gemessene Reduktion in mph1s weiter gestützt. Darüber hinaus lässt sich anhand dieser Daten die Funktion von Mph1 bei diesem Prozess näher eingrenzen. Da mph1-Mutanten eine Reduktion der Reversionsfrequenzen aufweisen, ist es notwendig, dass Mph1 an einem Prozess vor oder während der Verlängerung am D-Loop beteiligt ist. Für die erfolgreiche Reversion des KanKanMX4-Moduls muss der invadierte Strang am Schwesterchromatid im D-Loop verlängert werden (siehe Abb. 68 C bis E). Geschieht dies nicht, so kann eine Deletion nicht stattfinden. Eine Reduktion der induzierten Reversionsfrequenzen wäre demnach nur zu erwarten, insofern ohne Mph1 die Verlängerung nicht mehr oder weniger effizient möglich wäre. Allerdings ist es dennoch plausibel, dass Mph1, zusätzlich zu einer Funktion vor der Verlängerung, eine Funktion nach der Synthese am Schwesterchromatid hat. Da solch eine Funktion wahrscheinlich auf die Messung der induzierten Reversionsfrequenzen keinerlei Einfluss hat, wäre der zusätzliche Ausfall dieser Funktion nicht anhand der Messung indu- 


\section{ERGEBNISSE}

zierter Reversionsfrequenzen zu detektieren. Ebenfalls ist es denkbar, dass Mph1 gar nicht an einem Prozess wie SDSA beteiligt ist, sondern vor allem für die Reinitiation der Replikationsgabel nach run-off-Synthese und auf diese Weise für die Reversion der Sequenzduplikation relevant ist. Jedoch erscheint dies eher unwahrscheinlich in Hinblick darauf, dass 4NQO vermutlich hauptsächlich Basenaddukte und damit Replikationsarreste hervorruft.

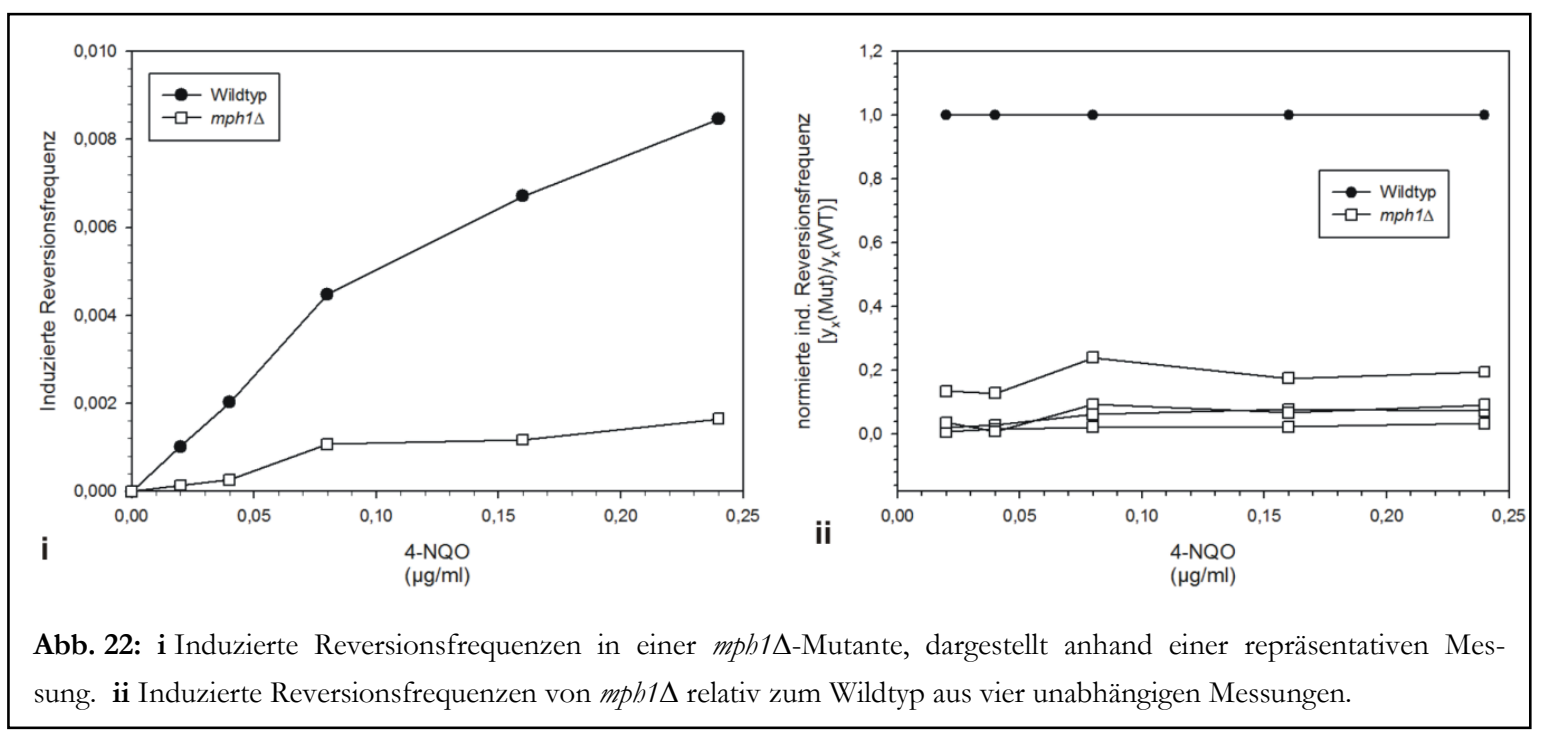

\section{Messung der induzierten Reversionsfrequenzen von mph1 $\Delta$ mit dem his3- $\Delta$ 5'/ his3- $\Delta$ 3'-Modul'}

In der Literatur etablierte Verfahren zur Messung von Schwesterchromatid-Rekombination basieren im Wesentlichen auf derselben Grundidee wie das KanKanMX4-Modul. Durch die fehlerhafte Invasion in einem doppelt vorhandenen Sequenzabschnitt wird die Reversion eines Selektionsmarkers hervorgerufen, welche messbar ist. Ein gängiges System für solche Untersuchungen ist das von Michael T. Fasullo und Ronald W. Davis 1987 vorgestellte his3- $\Delta 5$ ' / his3- $\Delta 3$ '-System. In diesem System wurde ein 5'-verkürztes HIS3 direkt hinter ein 3'-verkürztes HIS3 kloniert. Durch eine Invasion in einem der verkürzten Fragmente, ausgehend vom jeweils anderen, kann es zu einem cross over oder einer Genkonversion kommen, wodurch der Marker revertiert wird (Fasullo \& Davis, 1987). Eine schematische Darstellung des Moduls ist in Abb. $23 \mathrm{~A}$ zu sehen. Das his3- $\Delta 5$ ' / his3- $\Delta 3^{\prime}-$-Modul weist einige für die Messungen relevante Unterschiede zum KanKanMX4 auf. Der wesentlichste ist dabei die Lage der Sequenzduplikationen zueinander, was zu unterschiedlichen Möglichkeiten bei der Entstehung einer Reversion führt. Die wichtigsten dieser Unterschiede sind im Folgenden aufgeführt. Eine schematische Darstellung dazu ist in Abb. 23 zu finden:

1. SSA führt im his3- $\Delta 5^{\prime} / h_{i s} 3-\Delta 3^{\prime}$-Modul zu keiner Histidinprototrophie, da bei der Generierung der 3'-Überhänge bzw. durch eine Flap-Endonuklease Teile des HIS3Gens entfernt werden und somit kein funktionsfähiges HIS3 entsteht. Im KanKanMX4-Modul dagegen führt SSA, wie zuvor ausgeführt, immer zu einer Reversion (vergleiche Abb. 23 A i, B i und Abb. 13). Demnach lässt sich SSA mit dem 
his3- $\Delta 5$ ' / his3- $\Delta$ 3'-Modul nicht messen, wohingegen das KanKanMX4-System SSAEreignisse ebenfalls erfasst.

2. Genkonversion ist im his 3- $\Delta 5^{\prime} /$ his 3- $\Delta 3^{\prime}$-Modul theoretisch zwar messbar, jedoch ist die Frequenz gemessener Genkonversionsereignisse wahrscheinlich sehr gering. Für eine Genkonversion ist eine Verlängerung über den duplizierten Bereich hinaus bis hinter das his3- $\Delta 5^{\prime}$ (bzw. je nachdem ob leading- oder lagging-strand hinter das his3$\Delta 3$ ) notwendig (vergleiche Abb. $13 \mathrm{D}$ und $\mathrm{E}$ und Abb. $23 \mathrm{~A}$ ). Andernfalls wäre eine Rehybridisierung mit dem ursprünglichen template Strang (bei einem Replikationsarrest, siehe Abb. 13 E) bzw. dem komplementären Überhang (bei der Doppelstrangbruchreparatur via SDSA, siehe Abb. 13 D) nicht möglich und es käme zu keiner Deletion. Während im KanKanMX4 hierfür bereits eine Verlängerung von nicht mehr als $300 \mathrm{nt}$ ausreichend sein dürfte, ist im his3- $\Delta 5^{\prime} /$ his3- $\Delta 3^{\prime}$-Modul eine Verlängerung über das komplette Konstrukt hinaus notwendig, was eine Synthese am Schwesterchromatid über mindestens $1,8 \mathrm{~kb}$ bedeutet (vergleiche Abb. $23 \mathrm{~A} \mathrm{i}$ und $\mathrm{B}$ i). Daher sind die mit dem his3- $\Delta 5$ '/his3- $\Delta 3$ '-Modul erfassten Ereignisse vermutlich nur zu einem geringen Anteil auf Genkonversion zurückzuführen.

3. Sowohl im KanKanMX4- als auch im his3- $\Delta 5^{\prime} /$ his3- $\Delta 3^{\prime}$-Modul kann auch ein cross over zu einer G418-Resistenz bzw. Histidin-Prototrophie führen (Abb. 23 A ii und $B$ ii). Während bei einer Genkonversion jedoch die Verlängerung in den komplementären Bereich notwendig ist, kann durch die Bildung von Hollliday-Junctions und deren anschließende Auflösung durch Resolvasen via einfaches cross over direkt ein funktionsfähiges HIS3 entstehen, ohne dass eine Synthese über das gesamte Konstrukt hinaus notwendig ist (Abb. $23 \mathrm{~A}$ ii rechts). Durch den reziproken Austausch kommt es dabei in einem der Schwesterchromatiden zu einer Deletion der nicht duplizierten HIS3-Region. Da bei der Entstehung von cross over während der Doppelstrangbruchreparatur die Bildung einer doppelten Holliday-Junction vermutet wird (Krogh \& Symington, 2004), kann es in Abhängigkeit der Schnittrichtung der Resolvasen auch zu einem doppelten cross over kommen (Abb. 23 A ii links). In einem solchen Fall entsteht wiederum kein funktionsfähiges HIS3, es sei denn, das dabei ausgetauschte Fragment beinhaltet das komplette Konstrukt, was wie bei einer Genkonversion eine Synthese von mindestens $1,8 \mathrm{~kb}$ voraussetzt (vergleiche Abb. $23 \mathrm{~A}$ i und A ii). Dagegen ist eine Reversion durch doppelten cross over im KanKanMx4-Modul vermutlich wie bei der Genkonversion aufgrund des kürzeren am Schwesterchromatid zu synthetisierenden Bereichs wahrscheinlicher als im bis3$\Delta 5^{\prime} /$ his3- $\Delta 3^{\prime}$-Modul.

Zusammengefasst kann man sagen, dass mit dem his3- $\Delta 5$ '/ his3- $\Delta 3$ '-Modul in einem Haplonten vorwiegend cross over, also Schwesterchromatid-Austausche detektiert werden. Im KanKanMX4-Modul werden dagegen vermutlich sowohl cross over, Genkonversion als auch SSA detektiert. 


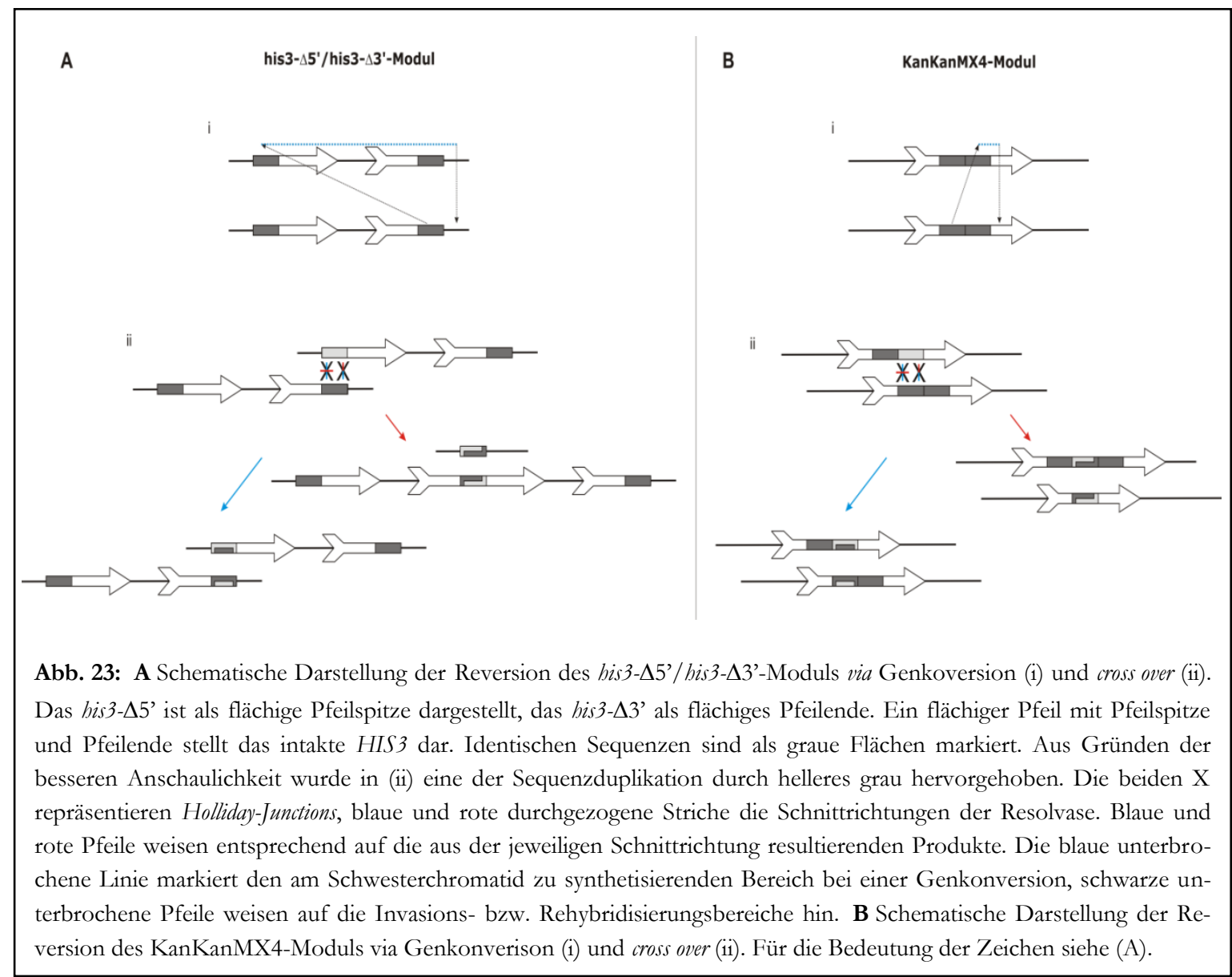

Um zu untersuchen, ob auch mit diesem Modul eine Erhöhung der Reversionsfrequenz mit steigender 4-NQO-Konzentration messbar ist, wurden die 4-NQO-induzierten Reversionsfrequenzen von dem Wildtypstamm YNN301 (Fasullo \& Davis, 1987) gemessen. Zusätzlich wurde zum Vergleich auch die induzierte Reversionsfrequenz in einer mph1 $\Delta$ Mutante des gleichen Stammhintergrunds gemessen (yGI012; Prakash et al., 2009). Die Ergebnisse sind in Abb. 24 dargestellt.

Tatsächlich lässt sich auch mit diesem System ein Anstieg der induzierten Reversionsfrequenz feststellen. Allerdings liegen die mit diesem System ermittelten Werte in etwa um den Faktor 100 niedriger als bei dem KanKanMX4-Modul. Eine mögliche Erklärung für diesen Unterschied ist, dass durch 4-NQO im Wesentlichen Schäden generiert werden, welche nicht oder nur ineffizient unter Bildung einer Holliday-Junction und anschließender Auflösung durch cross over umgangen bzw. repariert werden können. Ebenfalls ist es möglich, dass generell die Frequenz an cross over im Vergleich zu Genkonversionen um ein vielfaches geringer ist und deshalb mit dem his3- $\Delta 5$ ' / his3- $\Delta 3$ '-Modul generell weniger Ereignisse erfasst werden. Ein Indiz dafür könnte sein, dass die nicht induzierte Reversionsfrequenz in allen drei Messungen im Bereich von $1 \times 10^{-5}$ bis $1 \times 10^{-4}$ liegt, wohingegen auch die nicht induzierte Frequenz im KanKanMX4-Modul in etwa um den Faktor 100 höher liegt (Daten nicht gezeigt). 
Darüber hinaus lässt sich, wie in Abb. 24 ii dargestellt, für die mph1D-Mutante zwar in einem Fall eine leichte Erniedrigung der Reversionsfrequenzen gegenüber dem Wildtyp feststellen, allerdings zeigt die zweite Messung eine leichte Erhöhung. Die dritte wiederum zeigt ebenfalls eine leichte Reduktion, wobei jedoch ein einzelner Wert oberhalb des Wildtyps liegt. Eine deutlich erkennbare Reduktion wie bei der Messung mit dem KanKanMX4Modul ist jedoch in keiner Messung feststellbar. Es scheint daher wahrscheinlich, dass Mph1 nicht oder nur geringfügig an einem Prozess beteiligt ist, welcher die Entstehung von cross over fördert. Vielmehr sind die Daten konsistent mit der Annahme, dass Mph1 Genkonversion erleichtert.

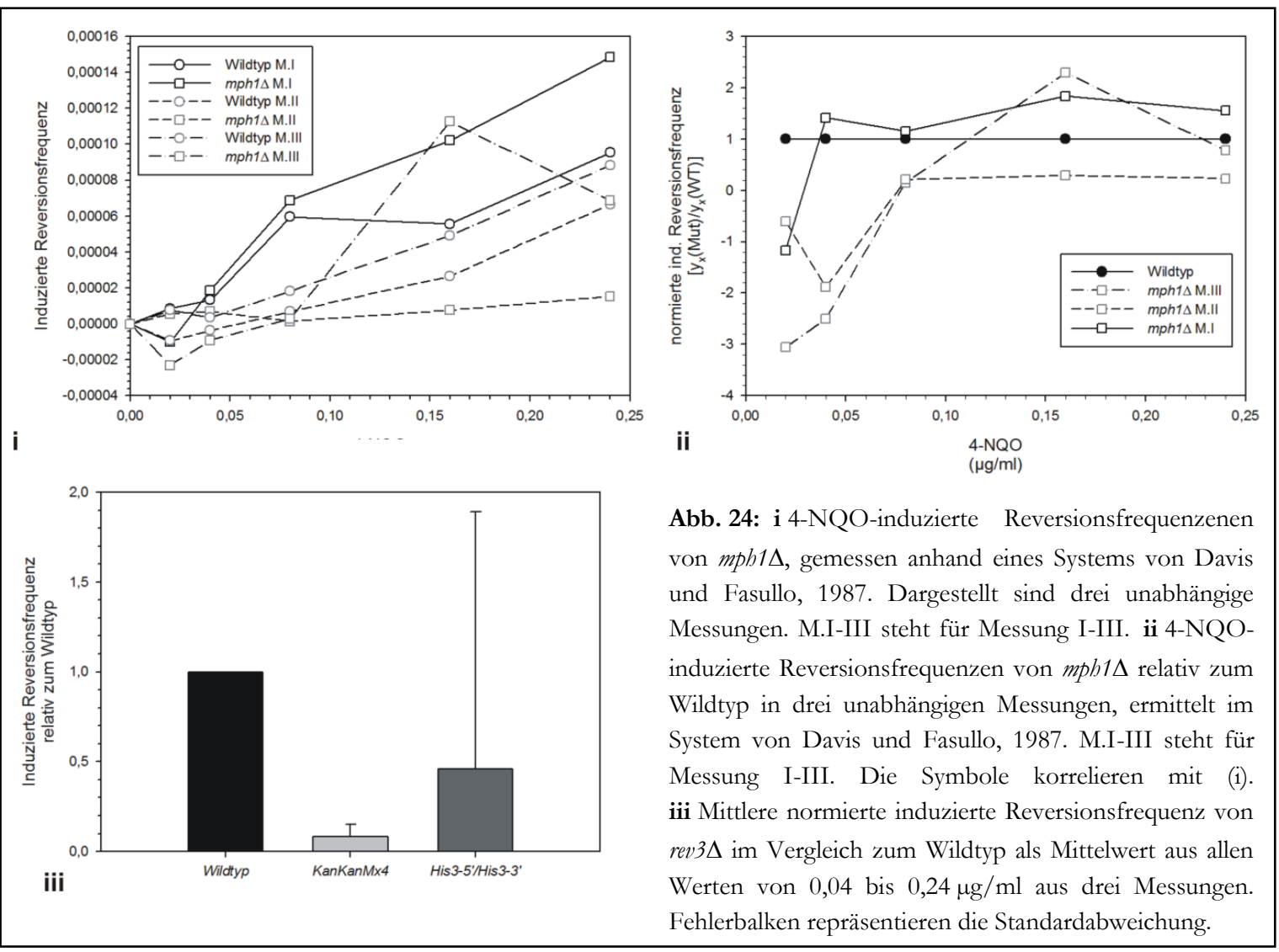

\section{MMS-induzierte Reversionsfrequenz in mph1}

Um den Einfluss anderer DNA-Schäden als der durch 4-NQO induzierten Läsionen auf die Reversionsfrequenz zu untersuchen, wurde im Folgenden die Induktion der Reversionsfrequenzen durch MMS untersucht. MMS (Methylmethansulfonat) ist ein methylierendes Agens, welches eine Methylgruppe auf Basen in der DNA übertragen kann. Es methyliert dabei vor allem N7 von Guanin (N7-Methylguanin) sowie N3 von Adenin (N3Methyladenin), wobei N7-Methylguanin mit ca. 80\% der Produkte das am häufigsten auftretende Addukt darstellt (Abb. 25; Beranek, 1990; Pegg, 1984; Wyatt \& Pittman, 2006). Sowohl die Methylierung des N7 von Guanin als auch die Methylierung des N3 von Adenin führen dazu, dass die glykosidische Bindung der jeweiligen Base leichter hydrolysiert werden kann, was zu einem gehäuften Verlust der Base führt. Die so entstehende AP-Site 


\section{ERGEBNISSE}

(A-Purinic/A-Pyrimidic site $=$ abasische Stelle) kann wiederum zu einem Replikationsarrest führen (Randall et al., 1987; Sagher \& Strauss, 1983). Allerdings ist die Halbwertszeit von N3-Methyladenin mit ca. 30 Stunden zehnmal höher als die von N7-Methylguanin mit ca. drei Stunden, weshalb vermutlich vor allem N7-Methylguanin als Quelle von AP-sites relevant ist. N3-Methyladenin kann dagegen direkt Replikationsarreste hervorrufen (Larson et al., 1985). Die N3 des Purins des zuletzt eingebauten Basenpaars bildet wahrscheinlich Wasserstoffbrücken zu der Handflächendomäne der DNA-Polymerase. Ohne diese Brücken kommt es verstärkt zum Ausschneiden des zuletzt eingebauten Nukleotids durch die proof reading-Exonuklease (Doublie et al., 1998). Durch die Methylierung am N3 von Adenin ist die Wasserstoffbrücke nicht mehr möglich und es kann zu einem Arrest durch wiederholtes proof reading kommen. In vitro kann allerdings auch N7-Methylguanin in der offenen Ringform (7-Methyl-Formamidoguanin; Abb. 25 C) direkt einen Replikationsarrest hervorrufen, wobei dies jedoch in vivo vermutlich nicht oder zumindest kaum relevant ist (Boiteux \& Laval, 1983). Gemessen wurden die MMS-induzierten Reversionsfrequenzen im Wildtyp und $m p h 1 \Delta$. Die Ergebnisse sind in Abb. 26 und Abb. 28 iii zu sehen.

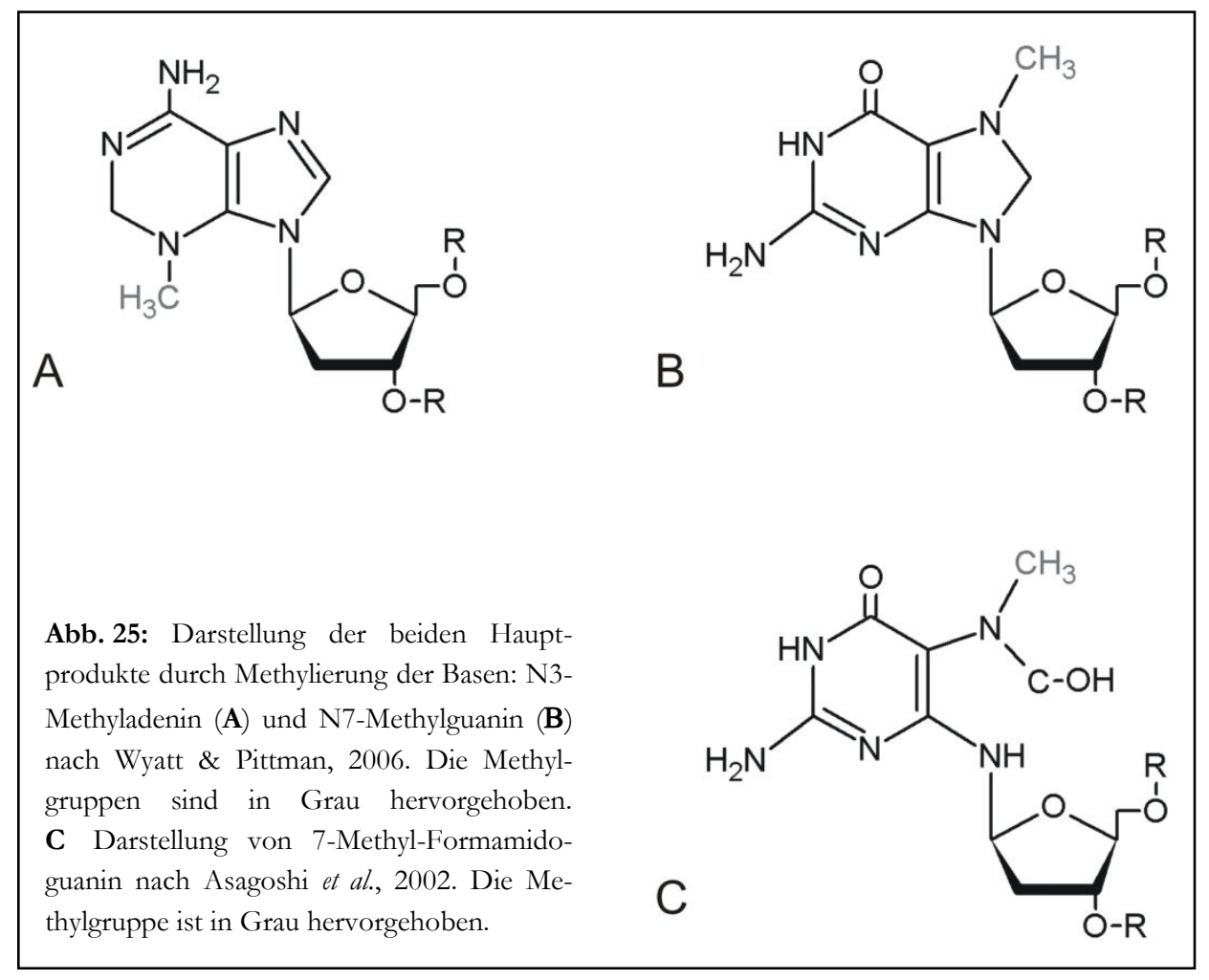

Wie auch bei 4-NQO, steigt im Wildtyp mit zunehmender MMS-Konzentration die induzierte Reversionsfrequenz deutlich. Während allerdings die Sterblichkeit sowohl bei MMS als auch bei 4-NQO in etwa in der gleichen Größenordnung liegt (ca. 50\% Überlebende bei höchster Konzentration, Daten nicht gezeigt), was es sehr wahrscheinlich macht, dass sich die Schadensdichte kaum voneinander unterscheidet (insofern nicht eine der beiden Agenzien eine höhere Letalität bei gleicher Schadensdichte aufweist), liegen die MMSinduzierten Reversionsfrequenzen durchweg ca. um den Faktor 10 geringer als bei der Inkubation mit 4-NQO. 


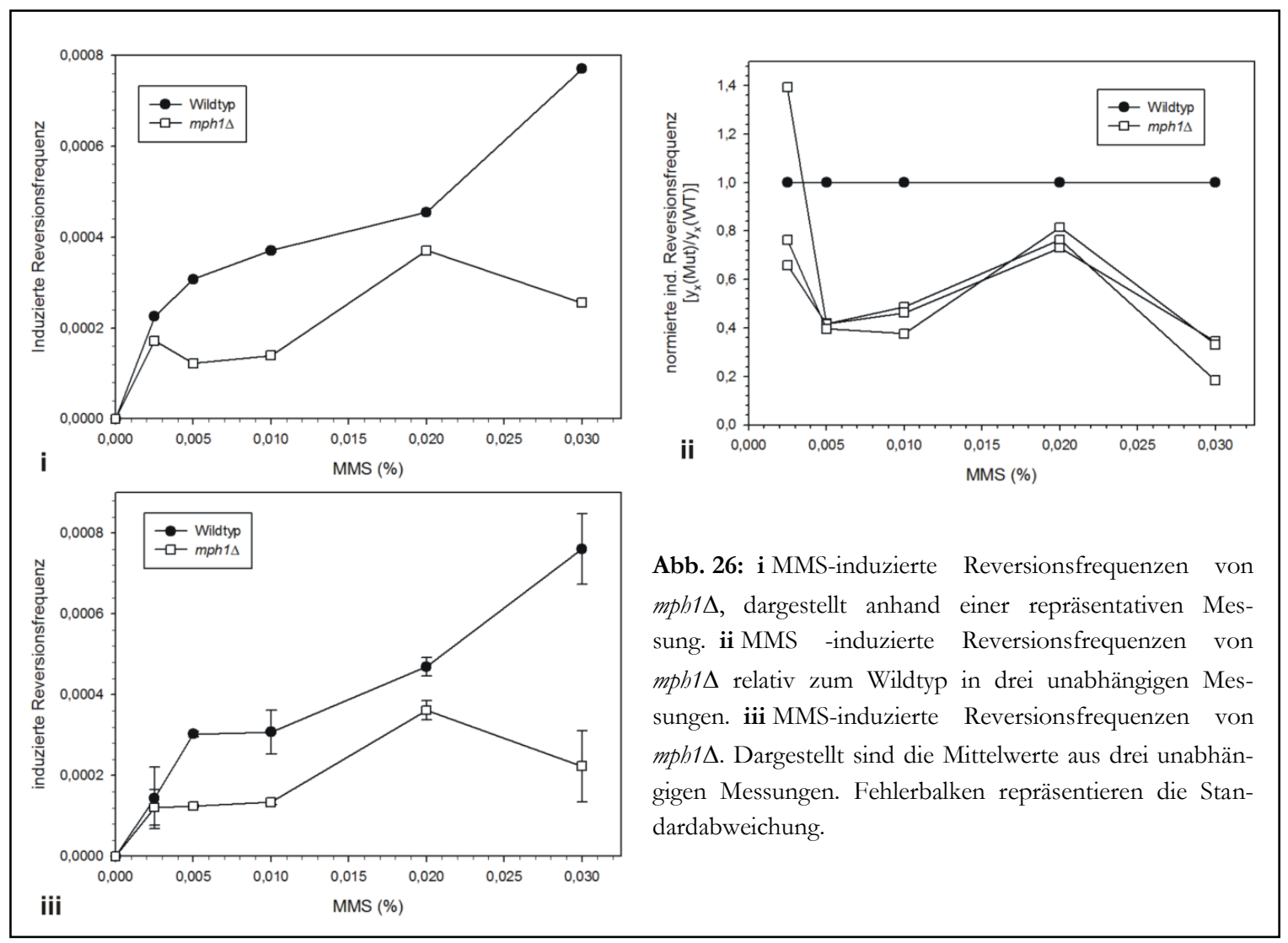

Unabhängig davon zeigt die mph1 1 -Mutante auch bei MMS eine dem Wildytp gegenüber verringerte induzierte Reversionsfrequenz. Jedoch ist diese Reduktion verglichen mit der Reduktion bei 4-NQO deutlich geringer, wie der Vergleich der normierten induzierten Reversionsfrequenzen zeigt (siehe Abb. 28). Interessanterweise zeigt sich dabei in allen drei durchgeführten Messungen für 0,02\% MMS eine etwas geringere Reduktion von mph1 $\Delta$ im Vergleich zum Wildtyp als bei den anderen Konzentrationen (Abb. 26 ii). Eine mögliche Erklärung hierfür könnte die Tatsache sein, dass für 0,02\% und 0,03\% MMS eine Stocklösung mit höherer Konzentration benutzt wurde, als für die geringeren Konzentrationen. Jedoch wurde die Stocklösung für jeden Versuch unabhängig angefertigt und die geringer konzentrierte Lösung durch Verdünnung aus der höher konzentrierten hergestellt. Dies macht einen Pipetierfehler unwahrscheinlich, sodass es am plausibelsten erscheint, dass es bei einer Konzentration von 0,02\% MMS zu einem Effekt kommt, der einen leichten Anstieg der induzierten Reversionsfrequenz in mph1 $\Delta$ hervorruft. Daher ist aufgrund dieser Schwankung eine Mittelung der normierten Werte, wie in Abb. 28 gezeigt, eigentlich nicht ohne Einwände zulässig, da die Reduktion in mph1s anscheinend nicht völlig unabhängig von der Konzentration ist. Dennoch wurde dieser Mittelwert für einen qualitativen Vergleich der Reduktion in mph1 $1 \Delta$ bei MMS, 4-NQO und Camptothecin (s.u.) benutzt, da die Schwankung bei MMS anhand der Standardabweichung in der Darstellung erfasst und damit auch in der qualitativen Aussage des Ergebnisses einbezogen ist. Die wahrscheinlichste Erklärung für die Tatsache, dass die Reduktion in diesen Messungen schwächer ausfällt als bei Messungen mit 4-NQO ist, dass MMS weniger DNA-Schäden hervorruft, welche durch einen Mph1-abhängigen Weg prozessiert werden, als 4-NQO. 


\section{ERGEBNISSE}

Camptothecin-indurierte Reversionsfrequen z in mph1s

Camptothecin ist ein Chemotherapeutikum, dessen Wirkung auf der Inhibition der Topoisomerase I beruht. Topo I kann strukturelle Spannungen in der DNA auflösen, indem sie die Anzahl der Verknüpfungen (linkage number) eines DNA-Doppelstrangs erhöht oder erniedrigt. Dazu wird zunächst einer der Stränge geschnitten, wobei das so entstehende 3'-Ende kovalent an die Topoisomerase gebunden ist, während das freie 5'-Ende rotieren kann. Durch diese Rotation wird die linkage number um 1 verändert. Anschließend wird der Schnitt durch Topo I religiert (Berger, 1998). Durch Camptothecin wird das kovalent am 3'-Ende gebundene Intermediat stabilisiert, weshalb die Ligation nicht erfolgt (Abb. 27). Wird die Topoisomerase vom DNA-Strang entfernt, verbleibt ein Einzelstrangbruch in der DNA (Avemann et al., 1988; Ferguson \& Baguley, 1996; Pommier, 2006; Pommier et al., 1998), durch den es bei der Replikation zu einer run off-Sysnthese kommen kann. Die Reinitiation der Replikation kann anschließend durch Rekombination mit dem Schwesterchromatid erreicht werden. Demnach sollte auch Camptothecin zu einer Dosis-abhängigen Erhöhung der Reversionsfrequenz führen. Daher wurden die induzierteen Reversionsfrequenzen nach Inkubation mit Camptothecin im Wildtyp und einer mph1 $1 \Delta$-Mutante gemessen. Die Ergebnisse sind in Abb. 28 dargestellt.

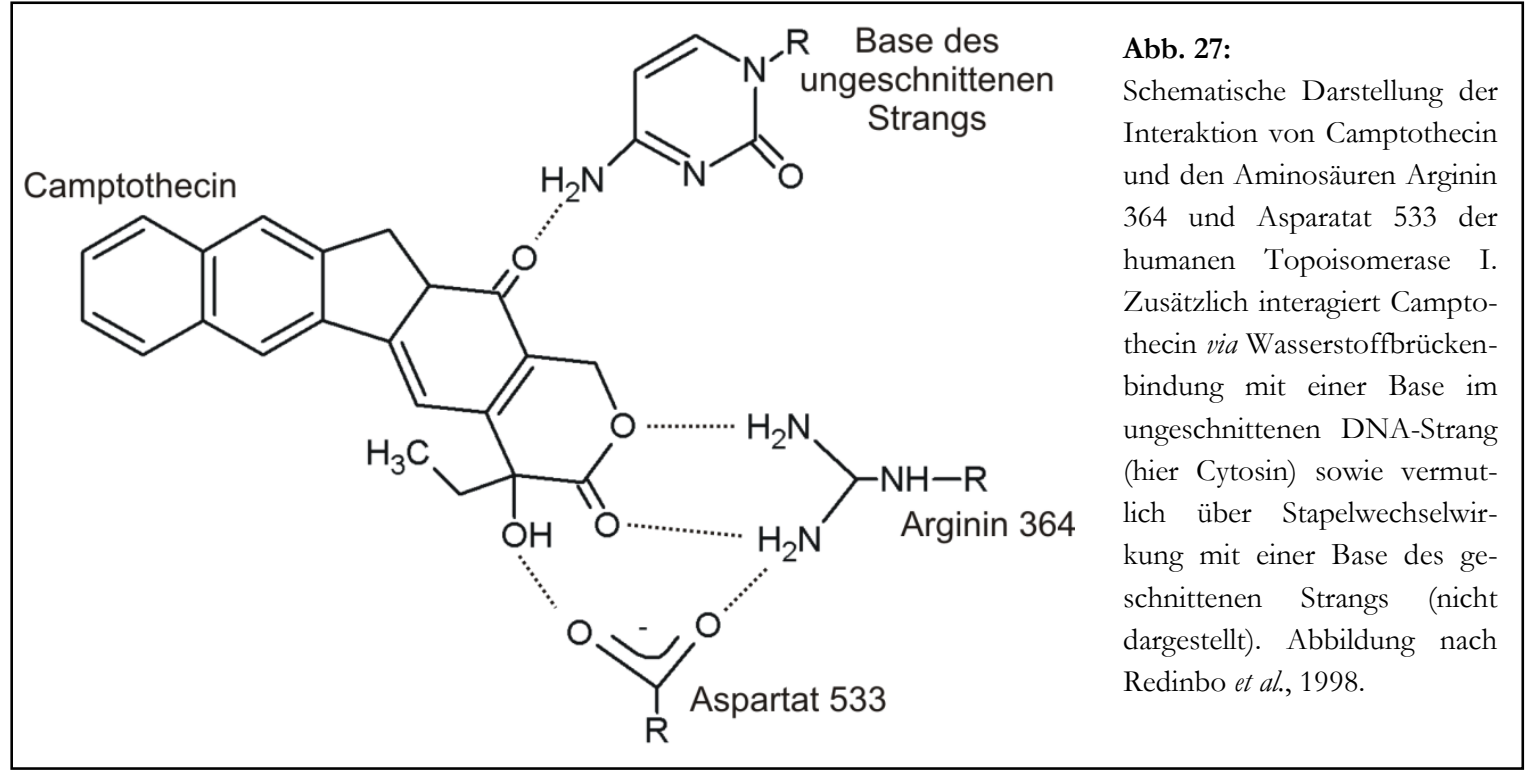

Auch nach Inkubation mit Camptothecin lässt sich eine deutliche Erhöhung der Reversionsfrequenzen in Abhängigkeit der Camptothecinkonzentration feststellen. Im Gegensatz zu MMS liegen die ermittelten Werte für Camptothecin in etwa in derselben Größenordnung wie bei der Inkubation mit 4-NQO. Allerdings ist die Überlebensrate bei der Inkubation mit Camptothecin kaum durch die Konzentration an Camptothecin beeinflusst, wohingegen bei 4-NQO eine deutliche Abnahme der Anzahl Überlebender mit steigender Konzentration festzustellen ist (Daten nicht gezeigt). Es könnte demnach sein, dass die Schadensdichte bei Camptothecin um ein vielfaches geringer ist als bei 4-NQO. Unabhängig davon steigen die Werte für Camptothecin bereits bei geringen Konzentrationen auf ein hohes Niveau an, auf dem sich die Werte relativ unabhängig von der Konzentration an 
Camptothecin konstant halten. Dagegen erscheint der Anstieg bei 4-NQO eher graduell (vergleiche Abb. 14 und Abb. 28 i). Ein solcher Unterschied von 4-NQO zu Camptothecin konnte auch bereits von Christian Rudolph bei Messungen mit dem episomalen KanKanMX4 festgestellt werden (Rudolph, 2003). Die durch Camptothecin hervorgerufenen Schäden können im Gegensatz zu 4-NQO-Basenaddukten ausschließlich über Rekombination repariert werden. 4-NQO-induzierte Schäden können dagegen auch über Nukleotidexzisionsreparatur entfernt werden, bevor sie einen Replikationsarrest auslösen (Sancar, 1996). Zusätzlich muss 4-NQO im Gegensatz zu Camptothecin erst metabolisch aktiviert werden (Singer \& Grunberger, 1983). Demnach beruht der steile Anstieg der induzierten Reversionsfrequenz bei Camptothecin höchstwahrscheinlich auf der Tatsache, dass Camptothecin bereits bei geringen Konzentrationen in hohem Maße Schäden hervorruft, welche zu einer Reversion führen. Dass sich bei Camptothecin die induzierten Reversionsfrequenzen gleichzeitig auf einem mehr oder weniger konstanten Maximalwert einzupegeln scheinen, ließe sich gleichzeitig durch eine schnelle Sättigung der im Zellkern aktiven Topoisomerase I erklären. Da die Wirkung von Camptothecin auf der Inhibition dieses Enzyms beruht, könnte es ab einer gewissen Konzentration keine weitere Zunahme an DNASchäden mehr geben, wenn jegliches aktives Protein bereits inhibiert ist. Eine weitere Möglichkeit ist, dass durch die geringe Löslichkeit des Agens im Medium die damit einhergehende „Verfügbarkeit“ sehr begrenzt ist (O'Leary \& Muggia, 1998). Beide oder eine der benannten Möglichkeiten könnten der Grund für diese Plateau-Bildung sein.

Für die mph1 1 -Mutante lässt sich wie zuvor bei 4-NQO und MMS eine deutliche Verringerung der induzierten Reversionsfrequenz im Vergleich zum Wildtyp feststellen. Allerdings ist die Reduktion bei Camptothecin, wie auch schon bei MMS, geringer als bei 4-NQO (Abb. 28 iii). Wie bereits bei der Messung der induzierten Reversionsfrequenzen nach Inkubation mit 4-NQO erwähnt, ist Mph1 wahrscheinlich an einem Prozess vor der Synthese am Schwesterchromatid beteiligt. Camptothecin führt jedoch zu Einzelstrangbrüchen und damit zur run-off-Synthese. Das resultierende unvollständige Chromosomenfragment wird ebenfalls über eine Invasion im Schwesterchromatid repariert. Jedoch wird hier durch den Schnitt im D-Loop direkt eine der Replikationsgabel ähnelnde Struktur hergestellt, ohne dass eine Rehybridisierung mit dem ursprünglichen template-Strang notwendig ist (siehe Abb. 13 C, Seite 68). Die Verlängerung vor der Auflösung des D-Loops, wie sie bei der Umgehung eines replikationsarretierenden Schadens notwendig ist, ist demnach bei der Reparatur von Camptothecin-induzierten Schäden nicht nötig, um eine Reversion zu erhalten (vergleiche Abb. $13 \mathrm{C}$ und E). Ebenfalls benötigt die Reparatur dieser Schäden nicht das Ablösen des 3'-Endes vom template-Strang, da nach einer run off-Synthese das 3'-Ende für die Invasion im Schwesterchromatid durch Zurückschneiden des Doppelstrangendes entsteht (siehe Abb. $13 \mathrm{C}$ i und ii). Demnach macht es die hier präsentierte Reduktion der Camptothecin-induzierten Reversionsfrequenz eher unwahrscheinlich, dass die einzige Funktion von Mph1 das Ablösen des 3'-Endes vom template-Strang ist. Ebenfalls scheint Mph1 nicht oder nur teilweise für die Verlängerung im D-Loop relevant zu sein. Konsistenter mit den Daten für die Camptothecin- und die 4-NQO-induzierten Reversionsfrequenzen ist daher die Vermutung, dass Mph1 in irgendeiner Form an der Prozessierung eines D- 


\section{ERGEBNISSE}

Loops beteiligt ist, welche die Bildung und/oder die Synthese am Schwesterchromatid erleichtert.

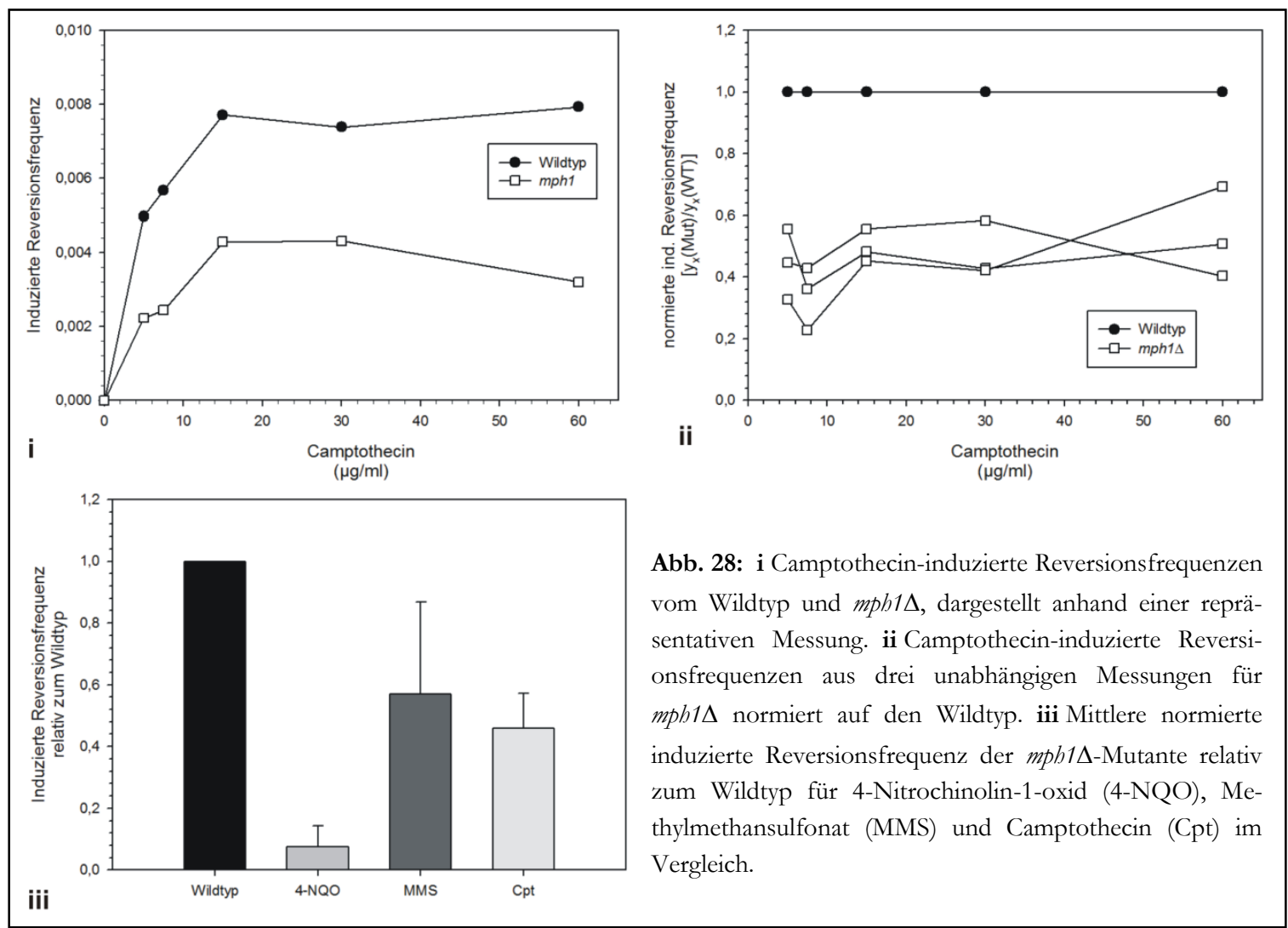

\section{Spontane Reversion in mph1s}

Alle hier bisher gezeigten Daten, sowie der Rev3-abhänige Mutatorphänotyp von mph1 $\Delta$

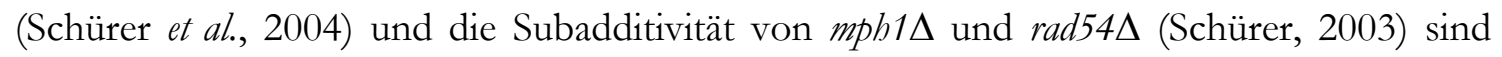
konsistent mit dem Modell, dass Mph1 unter anderem an der Interaktion von Schwester-

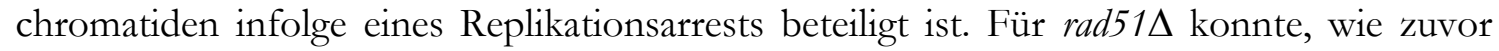
gezeigt, eine Erhöhung der spontanen Reversionsrate festgestellt werden, welche möglicherweise an einer Zunahme an SSA liegt. Da auch Mph1 anscheinend an der Entstehung der Reversionen der Sequenzduplikation im KanKanMX4-Modul beteiligt ist, wurde neben

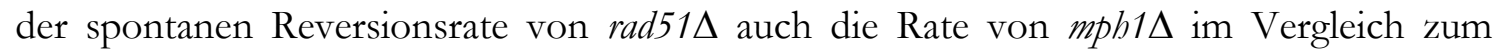
Wildtyp gemessen. Wie in Tab. 6 zu sehen ist, hat auch mph1 $\Delta$ eine leicht erhöhte spontane Reversionsrate im Vergleich zum Wildtyp. Allerdings ist die Zunahme der spontanen Re-

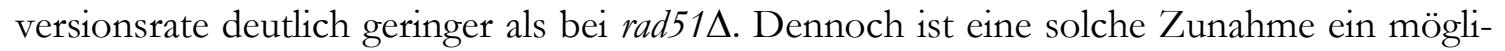
ches Indiz dafür, dass Mph1 an einem Rad51-abhängigen Prozess beteiligt ist, bei dessen Ausfall es zu einer erhöhten Frequenz an SSA kommt. 
Tab. 6: Spontane Reversionsraten von rad51 $\Delta$ - und rad52 $\Delta$-Mutanten. Die Werte wurden nach der Methode des Medians ermittelt (Lea \& Coulson, 1948).

\begin{tabular}{lcr}
\hline Stamm & Spontane Reversionsrate & Faktor Mut. / WT \\
\hline \hline Wildtyp & $9,36 \times 10^{-6} \pm 9,82 \times 10^{-7}$ & 1 \\
& $9,54 \times 10^{-6} \pm 9,83 \times 10^{-7}$ & 1 \\
rad51 & $3,35 \times 10^{-5} \pm 3,3 \times 10^{-6}$ & 3,6 \\
& $4,77 \times 10^{-5} \pm 4,56 \times 10^{-6}$ & 5,6 \\
mph1 & $1,50 \times 10^{-5} \pm 1,58 \times 10^{-6}$ & 1,6 \\
& $1,69 \times 10^{-5} \pm 1,71 \times 10^{-6}$ & 1,72 \\
\hline
\end{tabular}

Interaktion von mph1 $1 \Delta$ und $\operatorname{rad} 51 \Delta$ bei der 4-NQO-indurierten Reversionsfrequen:

Die bisherigen Ergebnisse machen es sehr plausibel, dass Mph1 an einem Rad51-abhängigen Weg beteiligt ist. Neben den hier präsentierten Daten spricht vor allem die Epistasis von rad51 $1 \Delta$ gegenüber mph1 $1 \Delta$, sowohl bei der Sensitivität gegen DNA-schädigende Agenzien als auch bei der spontanen Mutationsrate für eine solche Beteiligung von Mph1 (Schürer et al., 2004). Um zu prüfen, ob solch eine Epistasis auch bei der induzierten Reversionsfrequenz zu beobachten ist, wurde die 4-NQO-induzierte Reversionsfrequenz von $m p h 1 \Delta$

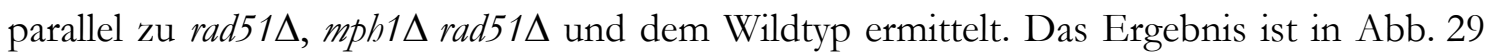
dargestellt.

Interessanterweise ließ sich anstelle einer Epistasis eine Verstärkung des Phänotyps durch gleichzeitiges Deletieren von rad51 $\Delta$ und mph1 $\Delta$ feststellen. Demnach scheint Mph1 auch in Abwesenheit von Rad51 noch einen positiven Einfluss auf die Interaktion von Schwesterchromatiden zu haben. Diese Beobachtung ist konsistent mit der bisherigen Vermutung, dass Mph1 unter anderem eine unterstützende Funktion bei der Bildung bzw. Prozessierung eines D-Loops hat. Ein D-Loop kann - zumindest in vitro - in Abwesenheit von Rad51 immer noch durch Rad52-vermittelte Invasion im Schwesterchromatid gebildet werden. Unterstützt Mph1 die Bildung eines D-Loops, so wird die Bildung desselben durch die Deletion von Rad51 bereits stark erschwert, da die Bildung eines D-Loops durch Rad52 weniger effizient ist als durch Rad51 (Kagawa et al., 2001). Durch das zusätzliche Deletieren von Mph1 würde die Entstehung oder Prozessierung des D-Loops darüberhinaus noch weiter erschwert. Demnach lässt sich diese Verstärkung des rad51 plausibelsten erklären, indem für Mph1 eine Funktion bei der Prozessierung oder Bildung des $D$-Loops angenommen wird. 

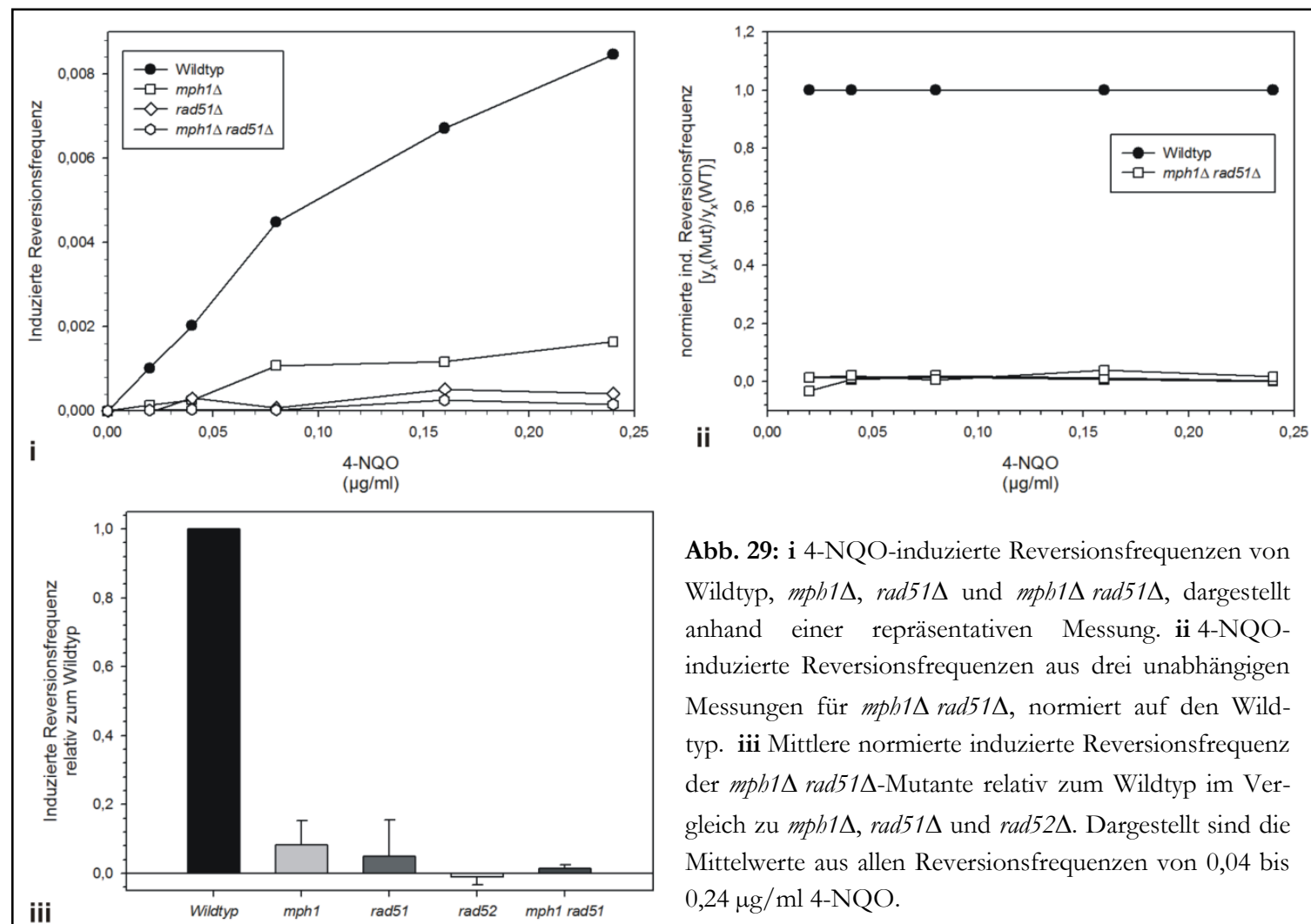

Abb. 29: i 4-NQO-induzierte Reversionsfrequenzen von

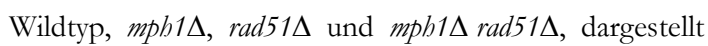
anhand einer repräsentativen Messung. ii 4-NQOinduzierte Reversionsfrequenzen aus drei unabhängigen Messungen für $m p h 1 \Delta \operatorname{rad} 51 \Delta$, normiert auf den Wildtyp. iii Mittlere normierte induzierte Reversionsfrequenz der $m p h 1 \Delta$ rad51 $\Delta$-Mutante relativ zum Wildtyp im Vergleich zu $m p h 1 \Delta$, rad51 $\Delta$ und $r a d 52 \Delta$. Dargestellt sind die Mittelwerte aus allen Reversionsfrequenzen von 0,04 bis $0,24 \mu \mathrm{g} / \mathrm{ml} 4-\mathrm{NQO}$.

Zusammengefasst sind die hier präsentierten Daten am ehesten konsistent mit der Hypothese, dass Mph1 in irgendeiner Form an der Prozessierung oder Stabilisierung eines DLoops beteiligt ist. 


\section{UNTERSUCHUNGEN ZUM MECHANISMUS DER FEHLERFREIEN POSTREPLIKATIVEN REPARATUR}

Gängige Modelle zur Umgehung von replikationsarretierenden Schäden benennen im Allgemeinen drei grundlegende Mechanismen, durch die eine solche Umgehung möglich ist:

i. Die Umgehung durch Transläsionssynthese.

ii. Die Umgehung durch Schwesterchromatid-Interaktion in Form von fork regression.

iii. Die Umgehung durch Schwesterchromatid-Interaktion anhand homologer Rekombination.

Wie zuvor bereits dargelegt ist es vermutlich notwendig diese Prozesse zu regulieren, da zumindest die unkontrollierte Nutzung von Transläsionssynthese und homologe Rekombination durchaus negative Folgen haben kann (siehe Seite 20). Genetische Evidenzen machen es dabei sehr wahrscheinlich, dass ein zentrales Protein bei der Regulation dieser Prozesse das proliferating cell nuclear antigen (PCNA) ist. Für einen detaillierteren Überblick über die im Folgenden angesprochenen Prozesse und die dazugehörigen genetischen und biochemischen Evidenzen siehe Seite 22.

PCNA kann auf unterschiedliche Art modifiziert werden: Das Lysin 164 kann sowohl mono- als auch polyubiquitiniert oder SUMOyliert werden. Für die Monoubiquitinierung werden in S. cerevisiae die Ubiquitinligase Rad18 und das Ubiquitin-konjugierende Enzym Rad6 benötigt. Vermutlich wird die Monoubiquitinierung durch das Auftreten persistierender Einzelstrangbereiche hinter dem replikationsarrtierenden Schaden initiiert, welche durch Rad18 gebunden werden können (Andersen et al., 2008). Die Polyubiquitinierung des Lysin 164 benötigt neben Rad6 und Rad18 noch die Ubiquitinligase Rad5 und das heterodimere Ubiquitin-konjugierende Protein Mms2/Ubc13. Vermutlich wird die Ubiquitinligase Rad5, gestützt durch die Bindung an Rad18, an PCNA rekrutiert. Rad5 wiederum vermittelt die Rekrutierung von Mms2/Ubc13 an PCNA. Mms2/Ubc13 katalysiert darauf folgend die Polyubiquitinierung des bereits monoubiquitinierten PCNA (Andersen et al., 2008). Die SUMOylierung des Lysin 164 benötigt dagegen statt den zuvor benannten Genen die SUMO-Ligase Siz1 sowie das SUMO-konjugierende Enzym Ubc9.

Sowohl rev3- als auch rad30-Mutanten sind hypostatisch zu rad6 und rad18 in Bezug auf die Sensitivität gegen DNA-schädigende Agenzien. mms2- und ubc13-Mutanten sind dagegen zwar ebenfalls hypostatisch zu rad6 und rad18, weisen aber gleichzeitig sowohl einen induzierbaren als auch einen spontanen Rev3-abhängigen Mutatorphänotyp auf. Aus diesem Grund lässt sich vermuten, dass durch Monoubiquitinierung ein fehlerbehafteter Prozess in Form von Transläsionssynthese induziert wird, wohingegen Polyubiquitinierung anscheinend das Signal für einen fehlerfreien Prozess darstellt (Andersen et al., 2008). Da gleichzeitig u.a. mms2 und rad52 additiv in Bezug auf UV-Sensitivität sind, wurde angenommen, dass es sich bei dieser fehlerfreien Umgehung um einen zur homologen Rekombination alternativen Mechanismus handelt (Torres-Ramos et al., 2002). Zusätzlich gestützt wird diese Vermutung durch die Tatsache, dass SUMOylierung von PCNA zur Rekrutie- 


\section{ERGEBNISSE}

rung von Srs2 an PCNA führt. Srs2 ist in vitro in der Lage, Rad51-ssDNA-Filamente aufzulösen und srs2-Mutationen führen zur Suppression der rad6-Sensitivität, was jedoch abhängig von Genen der homologen Rekombination ist (Andersen et al., 2008). Daher erscheint es plausibel zu vermuten, dass durch die Rekrutierung von Srs2 HR unterdrückt wird und somit bevorzugt ein alternativer fehlerfreier Weg stattfinden kann, welcher Rad6-abhängig ist. Da die Mutanten der rad6-Epistasisgruppe Defekte in der PRR aufweisen, wird die Transläsionsynthese auch als fehlerbehaftete PRR und der fehlerfreie Weg als fehlerfreie PRR bezeichnet. Da die plausibelste Alternative zur HR fork regression ist, wurde bisher vermutet wurde, dass die fehlerfreie PRR fork regression darstellt.

Zusammengefasst scheint es demnach in Eukaryoten drei Mechanismen zu geben, welche einen schadensinduzierten Replikationsarrest umgehen können und miteinander konkurrieren. Welcher der Mechanismen eintritt, entscheidet sich dabei vermutlich anhand der Modifikation von PCNA: Monoubiquitinierung führt zu Transläsionssynthese und Polyubiquitinierung zur fehlerfreien PRR, während SUMOylierung den Einsatz der homologen Rekombination reprimieren kann, was möglicherweise notwendig ist, um bspw. Transläsionssynthese oder fehelrfreie PRR zuzulassen.

\section{Untersuchung der fehlerfreien Postreplikativen Reparatur anhand von mms $2 \Delta$ und $u b c 13 \Delta$}

\section{Rückblick: $u b c 13 \Delta$ und $m m s 2 \Delta$ weisen verringerte 4-NQO-induzierte Rever- sionsfrequenzen auf.}

Der Ausfall der homologen Rekombination kann zu einer Zunahme an Transläsionssynthese führen, was der Mutatorphänotyp von rad51 und rad52 zeigt (siehe Seiten 78 und 117 Tab. 9). Da allem Anschein nach die fehlerfreie PRR eine Alternative zur fehlerfreien Umgehung durch homologe Rekombination darstellt, wurde getestet, ob eine mms $2 \Delta$ - bzw. ubc13 3 -Deletion einen Einfluss auf die Anzahl an Reversionen des KanKanMX4-Moduls hat. Dazu wurden bereits im Rahmen meiner Diplomarbeit die 4-NQO-induzierten Reversionen für beide Mutanten ermittelt (Ede, 2006). Eine Darstellung dieser Daten findet sich in Abb. 30. Sowohl für mms $2 \Delta$ als auch für $u b c 13 \Delta$ zeigte sich eine deutliche Erniedrigung der induzierten Reversionsfrequenz, die ähnlich stark ausfällt wie bei rad51 $\Delta$. Ein solches Ergebnis ist erstaunlich, da rad52 und mms2 additiv bei der Sensitivität gegenüber UVStrahlung sind (Torres-Ramos et al., 2002). Die mit dem KanKanMX4-System gemessenen Ereignisse sind jedoch vollständig von Rad52 und damit auch von der homologen Rekombination abhängig. Damit wird die Annahme, die fehlerfreie PRR verliefe über fork regression, sehr unwahrscheinlich. Es kommt vielmehr die Vermutung auf, dass es sich bei der PRR tatsächlich um einen zumindest teilweise von der homologen Rekombination abhängigen Prozess handelt. 

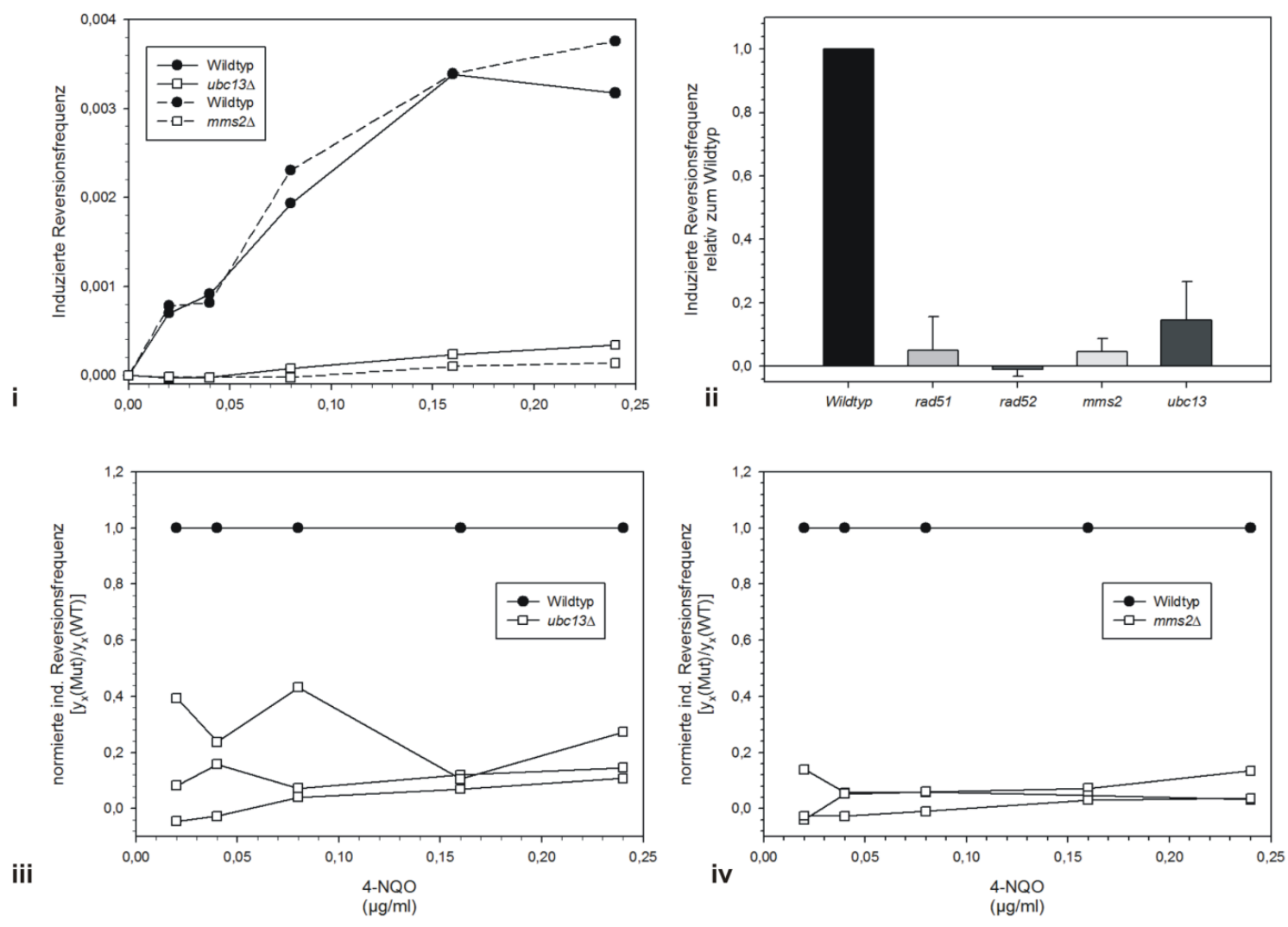

Abb. 30: i 4-NQO-induzierte Reversionsfrequenzen von ubc13 $\Delta$ und mms $2 \Delta$ im Vergleich zur jeweiligen Wildtypreferenz. Dargestellt sind zwei repräsentative Messungen. ii Mittlere normierte 4-NQO-induzierte Reversionsfrequenz von mms $2 \Delta$ und $u b c 13 \Delta$ im Vergleich zu rad51 $\Delta$, rad52 $\Delta$ und Wildtyp. Dargestellt ist der jeweilige Mittelwert aller Reversionsfrequenzen für 0,04 bis $0,24 \mu \mathrm{g} / \mathrm{ml}$ 4-NQO. Fehlerbalken repräsentieren die Standardabweichung. iii und iv Darstellung der induzierten Reversionsfrequenzen von $u b c 13 \Delta$ (iii) und mms $2 \Delta$ (iv) aus je drei unabhängigen Messungen relativ zum Wildtyp. Die hier verwendeten Daten wurden aus der Diplomarbeit C. Ede, 2006 entnommen.

Um zu überprüfen, ob die fehlerfreie PRR zumindest teilweise von der HR abhängig ist, wurden diverse Untersuchungen durchgeführt, welche zur Aufklärung des Phänomens beitragen können. Das Ergebnis dieser Untersuchungen wird im Folgenden präsentiert.

\section{Untersuchungen zur Funktion von mms2 $\Delta$ und ubc13 $\Delta$ anhand des Kan- KanMX4-Moduls}

\section{Messung 4-NQO-induzierter Reversionsfrequenzen einer ubc13 C87S-Mutante}

Der beobachtete Phänotyp von mms2 bzw. ubc13 muss nicht zwingend auf dem Verlust der Polyubiquitinierung von PCNA beruhen. Die Deletion von MMS2 bzw. UBC13 kann auch aufgrund einer strukturellen Funktion des codierten Proteins zu dem beobachteten Phänotyp führen. Bspw. könnten Mms2 und Ubc13 eine Funktion als Bindeglied in einem Multiproteinkomplex haben, welcher u.a. auch Proteine der homologen Rekombination beinhaltet. Durch Wegfall von Mms2 bzw. Ubc13 kann dieser Komplex nicht mehr stabil gebildet werden, was indirekt die Funktion der anderen Proteine im Komplex beeinträchtigt. Ebenfals ist es möglich, dass der beobachtete Phänotyp auf eine Hintergrundmutation zurückzu- 


\section{ERGEBNISSE}

führen ist. Um diese beiden Möglichkeiten zu überprüfen, wurde die induzierte Reversionsfrequenz einer ubc13 C87S-Mutante und einer mit dem Wildtyp-Allel komplementierten ubc13 $\Delta$-Mutante ermittelt. Die ubc13 C87S-Mutante weist eine stark verringerte katalytische Effizienz in der Bildung von Polyubiquitinketten auf (Eddins et al., 2006). Sie sollte jedoch weiterhin in der Lage sein, in einem Proteinkomplex als Bindeglied zu fungieren. Die Komplementation durch das Wildtypallel zeigt dagegen, ob eine Hintergrundmutation für den Phänotyp verantwortlich ist, da sich andernfalls ubc13 $\Delta$ nicht in Bezug auf den Phänotyp komplementieren ließe. Für die Messung der Mutante wurde zunächst je ein CEN.PK2-1c ubc13 YIplac128 KanKanMX4-Stamm mit dem Plasmid YIplac211-P13UBC13 bzw. dem Plasmid YIplac211-P13-ubc13C87S (Ulrich, 2003) transformiert. YIplac211-P13-UBC13 diente der Komplementation und gleichzeitig als Wildtyp-Kontrolle. Von jeder Transformation wurde je ein Einzelklon ausgesucht und zunächst die Komplementationsfähigkeit von YIplac211-P13-UBC13 in Bezug auf die Sensitivität gegen 4-NQO überprüft (Daten nicht gezeigt). Anschließend wurde die 4-NQO-induzierte Reversionsfrequenz ermittelt. Das Ergebnis ist in Abb. 31 zu sehen. ubc13A YIplac211-P13-UBC13 zeigt einen Konzentrations-abhängigen Anstieg der induzierten Reversionsfrequenz ähnlich wie im Wildtyp. Dass der Phänotyp auf eine Hintergrundmutation zurückzuführen ist, ist daher sehr unwahrscheinlich. Interessanterweise gleicht die Auftragung der auf den Wildtyp normierten induzierten Reversionsfrequenzen in $u b c 13$ C87S eher einer ansteigenden Kurve als einer Geraden, wie es bspw. bei ubc13 $\Delta$ bzw. mms $2 \Delta$ der Fall zu sein scheint (siehe Abb. 30). Allerdings liegt dieser Eindruck vermutlich vor allem an der sehr hohen induzierten Reversionsfrequenz bei $0,02 \mu \mathrm{g} / \mathrm{ml}$ 4-NQO im UBC13-Stamm. Unabhängig davon zeigt ubc13 C87S eine deutlich verringerte Frequenz an induzierten Reversionsereignissen im Vergleich zum Wildtyp UBC13. Allerdings ist die Verringerung um einiges schwächer als in der $u b c 13 \Delta$-Mutante. In $u b c 13$ C87S sollte sich eine Verringerung der induzierten Reversionsfrequenz messen lassen, sofern der Effekt in $u b c 13 \Delta$ auf der katalytischen Funktion von Ubc13 beruht. Da es sich bei ubc13 C87S allerdings um eine ineffiziente und nicht vollständig funktionslose Mutante handelt, sollte diese Verringerung geringer ausfallen als in einer Deletionsmutante. Da beides der Fall ist, ist es sehr wahrscheinlich, dass der beobachtete Phänotyp tatsächlich auf der enzymatischen Aktivität des Mms2/Ubc13 Heterodimers beruht. 


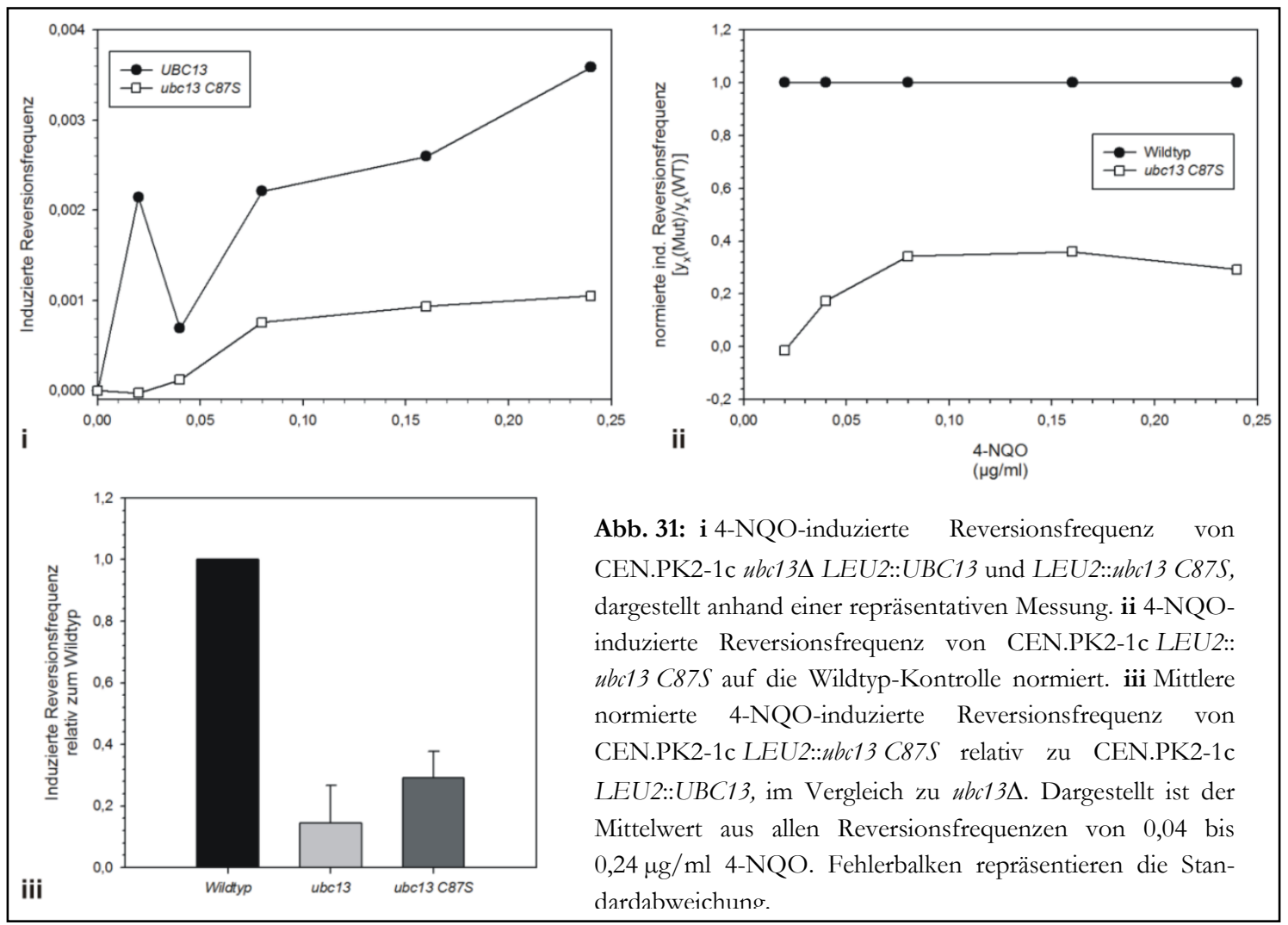

\section{Messung 4-NQO-induzierter Reversionsfrequenzen einer ubiK63R-Mutante}

Mms2/Ubc13 ist notwendig, um die Polyubiquitinierung von PCNA am Lysin 164 zu katalysieren (s.o.). Die dabei gebildeten Polyubiquitinketten entstehen durch Verknüpfung am Ubiquitin-internen Lysin 63. Verhindert man die Bildung dieser Ketten durch die Substitution von Lysin zu Arginin, so ist die Polyubiquitinierung von PCNA nicht mehr möglich. Um zu überprüfen, welchen Phänotyp eine ubi K63R-Mutante in Bezug auf die induzierte Reversionsfrequenz aufweist, wurden daher die Stämme SUB280 (UBI) und SUB413 (ubi K63R; Spence et al., 1995) mit dem Vektor YIplac128 KanKanMX4 transformiert und anschließend die 4-NQO-induzierte Reversionsfrequenz gemessen. Das Ergebnis ist in Abb. 32 dargestellt.

Die induzierte Reversionsfrequenz in der ubi K63R-Mutante entspricht in etwa der von $m m s 2 \Delta$ und $u b c 13 \Delta$. Der beobachtete Phänotyp von mms $2 \Delta$ und $u b c 13 \Delta$ scheint demnach abhängig von der über Lysin 63 verknüpften Polymerisierung von Ubiquitin zu sein. Wäre der Phänotyp von Mms2/Ubc13 auf eine strukturelle Funktion zurückzuführen, wäre in

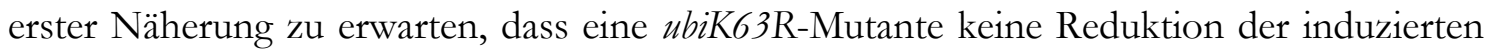
Reversionsfrequenz aufweist. Allerdings ist das Heterodimer Mms2/Ubc13 nicht das einzige Enzym, welches die Bildung Lysin 63 verknüpfter Polyubiquitinketten katalysiert. Es wäre also auch möglich, dass der hier beobachtete Phänotyp nicht von Mms2/Ubc13 abhängig ist. Allerdings erscheint dies in Bezug auf den zuvor für ubc13 C87S festgestellten Phänotyp eher unwahrscheinlich. 


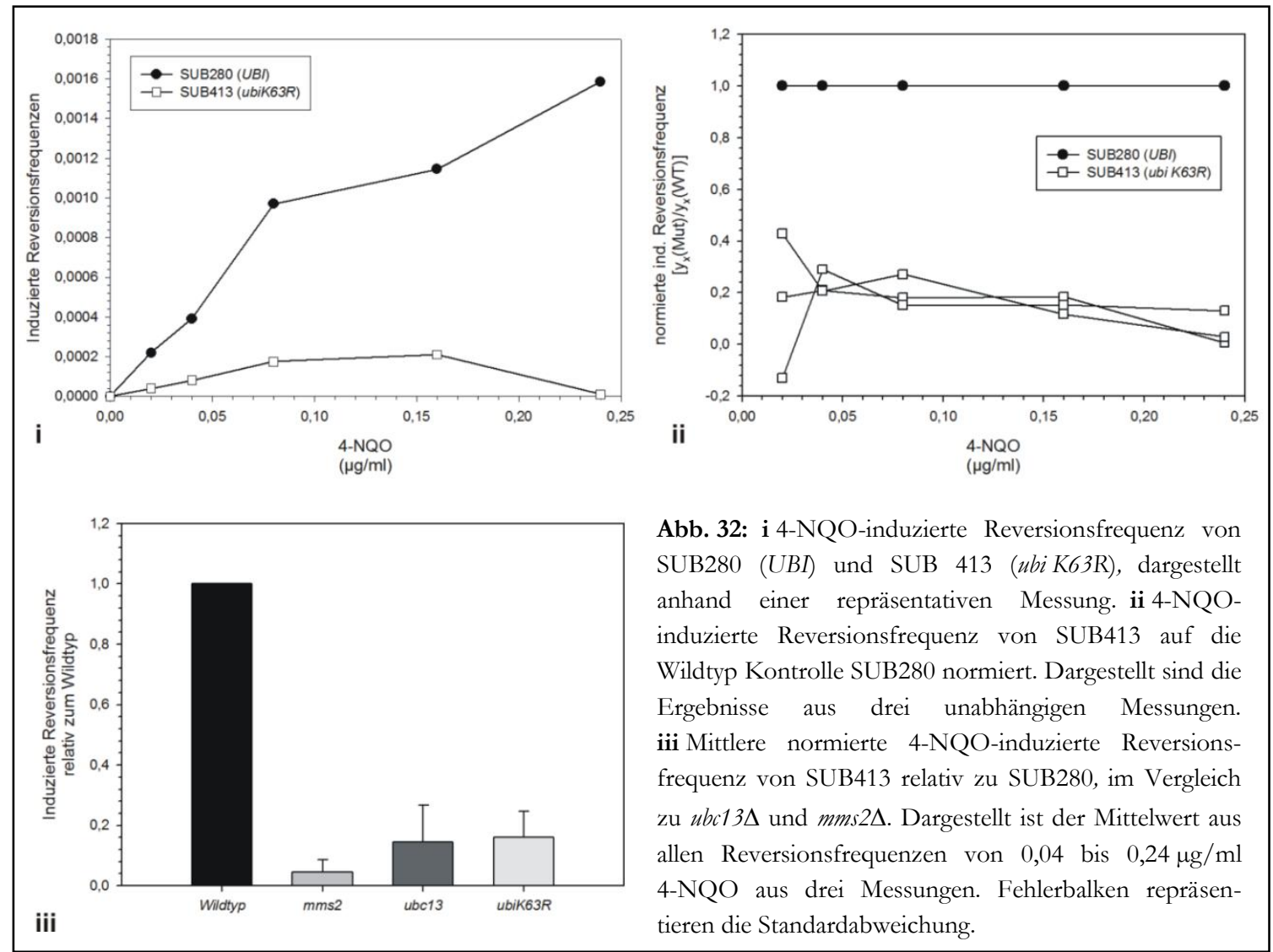

Messung 4-NQO-induzierter Reversionsfrequenzen von Modifikations-defirienten PCNAMutanten

Sowohl die Daten für ubc13 C87S als auch die für ubi K63R machen es sehr wahrscheinlich, dass die Phänotypen von mms $2 \Delta$ und $u b c 13 \Delta$ auf die katalytische Funktion des Heterodimers als ubiquitinkonjugierendes Enzym zurückzuführen sind. Die Ubiquitinierung am Lysin 164 von PCNA gilt aber als Signal für einen von der homologen Rekombination unabhängigen Prozess. Demnach gibt es zwei Möglichkeiten, dieses Phänomen zu erklären: 1. PCNA ist nicht das einzige Substrat für Mms2/Ubc13, oder 2. der Prozess, welcher durch die Polyubiquitinierung initiiert wird, ist kein unabhängiger, sondern ein zumindest teilweise von homologer Rekombination abhängiger Vorgang. Um nachzuprüfen, ob die Modifikation von PCNA relevant ist für den beobachteten Phänotyp, wurde daher die 4NQO-induzierte Reversionsfrequenz in einer pol30 K164R-Mutante untersucht. POL30 codiert in S. cerevisiae für die Untereinheit, welche als Homotrimer PCNA bildet (Bauer \& Burgers, 1990). Da PCNA auch am Lysin 127 modifiziert werden kann, wurde der Vollständigkeit halber auch eine pol30 K127R- sowie eine pol30 K164/127R-Mutante gemessen, obwohl die Polyubiquitinierung durch Mms2/Ubc13 wahrscheinlich nur am Lysin 164 geschieht (siehe Seite 22 sowie Andersen et al., 2008). Als Wildtyp-Referenz wurde ein CEN.PK2-1c pol30::HisG LEU2::POL30 genommen. Hergestellt wurden die Stämme durch Transformation von CEN.PK2-1c YIplac211 KanKanMX4 mit YIplac128 POL30 (bzw. pol30 K164R, K127R und K127/164R; Windecker \& Ulrich, 2008) und anschlieBende Deletion von POL30 durch den Vektor pBL243 (Ayyagari et al., 1995). Da pol30Mutantionen letal sind, musste die Deletion hier nach der Integration der am Lysin mutier$\mathbf{1 0 0 | \text { S eite }}$ 
ten Allele erfolgen. Da somit für die Deletion zwei mögliche Gen-loci vorlagen, musste die korrekte Lage der Deletion gesondert anhand von primern, welche im LEU2-locus binden, überprüft werden. Zusätzlich wurde die Substitution von Lysin $127 \mathrm{zu}$ Arginin mithilfe einer Spaltung des POL30-internen PCR-Produkts durch AflII verifiziert (für Details siehe Seite 50). Die induzierte Reversionsfrequenz der pol30 K164R ist in Abb. 33, die von pol30 K127R in Abb. 34 und pol30 K127/164R in Abb. 35 zu sehen.

In pol30 K164R ist die induzierte Reversionsfrequenz erniedrigt, wobei die Reduktion in der mms2 2 -Mutante jedoch deutlich stärker ist (Abb. 33 und Abb. 35). Durch den Aminosäurenaustausch von Lysin $164 \mathrm{zu}$ Arginin wird jedoch nicht nur die fehlerfreie PRR sondern auch Transläsionssynthese negativ beeinflusst. Wie der Mutatorphänotyp von mms zeigt, scheint bei einem Ausfall der Polyubiquitinierung von PCNA vermehrt Transläsionssynthese stattzufinden. Durch gleichzeitigen Verlust der Transläsionssynthese könnte ein gröBerer Teil an DNA-Schäden wieder über den fehlerfreien Weg erfolgen, was die geringe Reduktion der induzierten Reversionsfrequenz erklären könnte. Unabhängig davon ist die hier präsentierte Reduktion der induzierten Reversionsfrequenzen in pol30 K164R konsistent mit der Annahme, dass der Ausfall der Polyubiquitinierung von PCNA am Lysin 164 der Ursprung des in mms $2 \Delta$ bzw. $u b c 13 \Delta$ beobachteten Phänotyps ist.

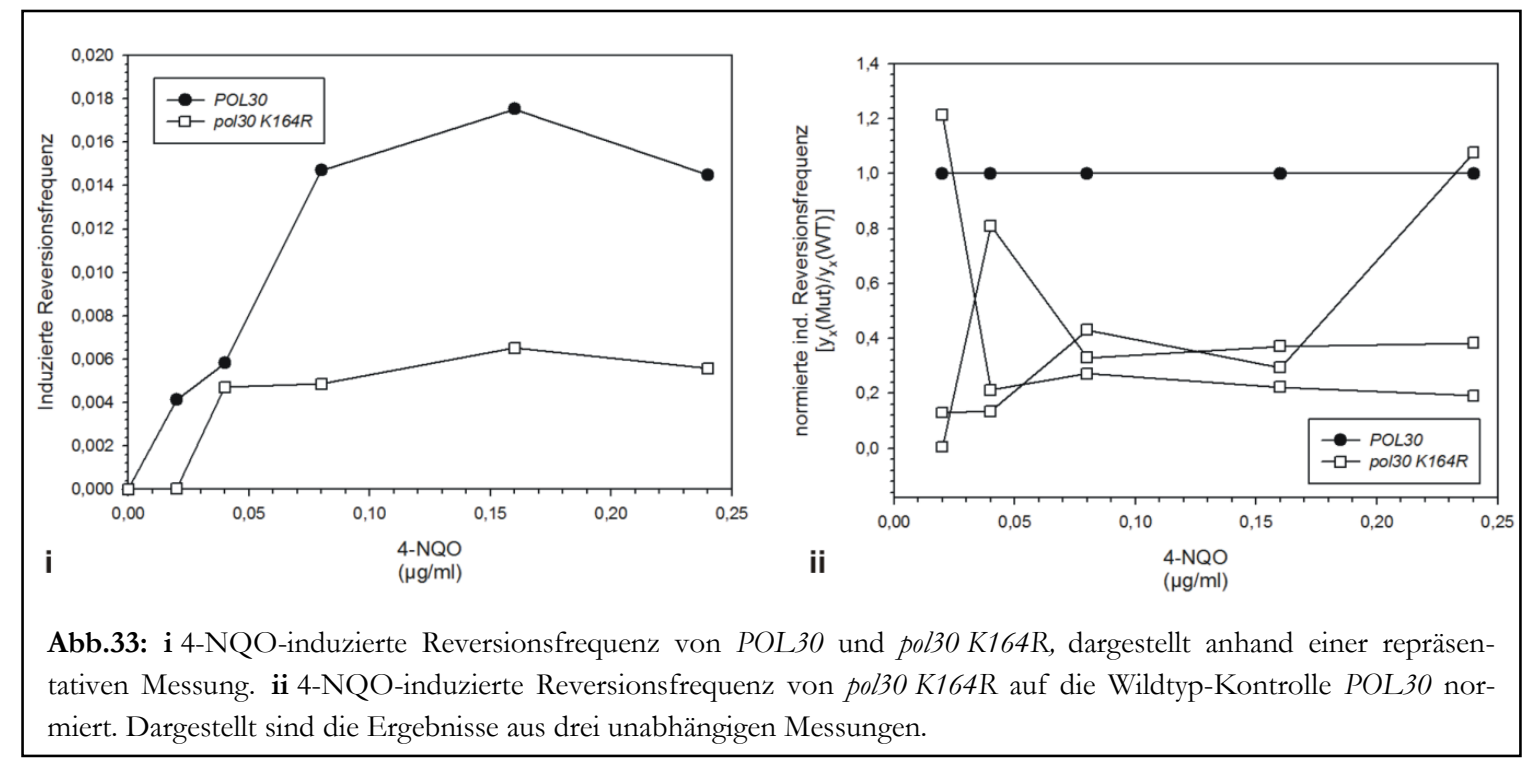

Erstaunlicherweise lässt sich nicht nur für die pol30 K64R-Mutante eine Reduktion der induzierten Reversionsfrequenz zeigen, sondern auch für pol30 K127R, welche sogar stärker ausfällt (Abb. 34 und Abb. 35). Allerdings ist zu vermuten, dass dieser Phänotyp nicht von Mms2/Ubc13 abhängig ist, da bisher keine Ubiquitinierung für das Lysin 127 in Hefe nachgewiesen wurde. Dagegen konnte für die SUMOylierung am Lysin 127 eine Funktion bei der Kontrolle von Schwesterchromatid Kohäsion nachgewiesen werden (Moldovan et al., 2006). Moldovan et al. postulieren, dass die SUMOlyierung von PCNA am Lysin 127 die Bindung von Eco1 an PCNA erschwert, welches für die Schwesterchromatid-Kohäsion notwendig ist. Die Autoren vermuten weiter, dass die Suppression dieser Bindung in vivo bestimmte DNA-Regionen von Kohäsinen freihält, um sie für Proteine zugänglich zu halten. So etwas könnte bspw. bei stark transkribierten Bereichen relevant sein, aber auch bei 


\section{ERGEBNISSE}

der Umgehung von Replikationsarresten. In letzterem Fall könnte der hier beobachtete Phänotyp auf einer Unzugänglichkeit der zu umgehenden Stelle aufgrund von Kohäsinbindung beruhen.
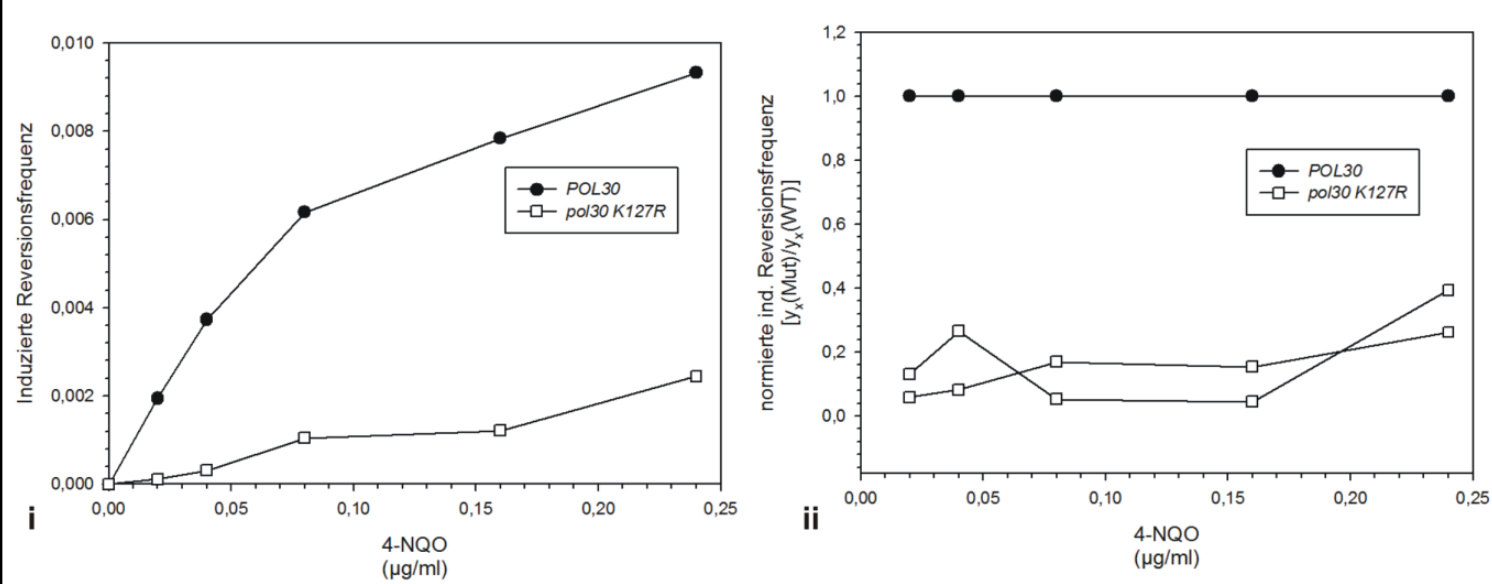

Abb. 34: i 4-NQO-induzierte Reversionsfrequenz von POL30 und pol30 K127R, dargestellt anhand einer repräsentativen Messung. ii 4-NQO-induzierte Reversionsfrequenz von pol30 K127R auf die Wildtyp-Kontrolle POL30 normiert. Dargestellt sind die Ergebnisse aus zwei unabhängigen Messungen.

Die K164/127R-Mutante zeigt den gleichen Phänotyp wie die pol30 K127R-Mutante (Abb. 35), was konsistent mit der Vermutung ist, dass die Bindung der Kohäsine die zu umgehende Stelle möglicherweise unzugänglich für andere Proteine macht. In so einem Fall wäre es irrelevant, ob ein Protein bspw. schlechter an nicht ubiquitiniertes PCNA binden kann, da es ohnehin durch die Kohäsine an der Bindung gehindert wird.

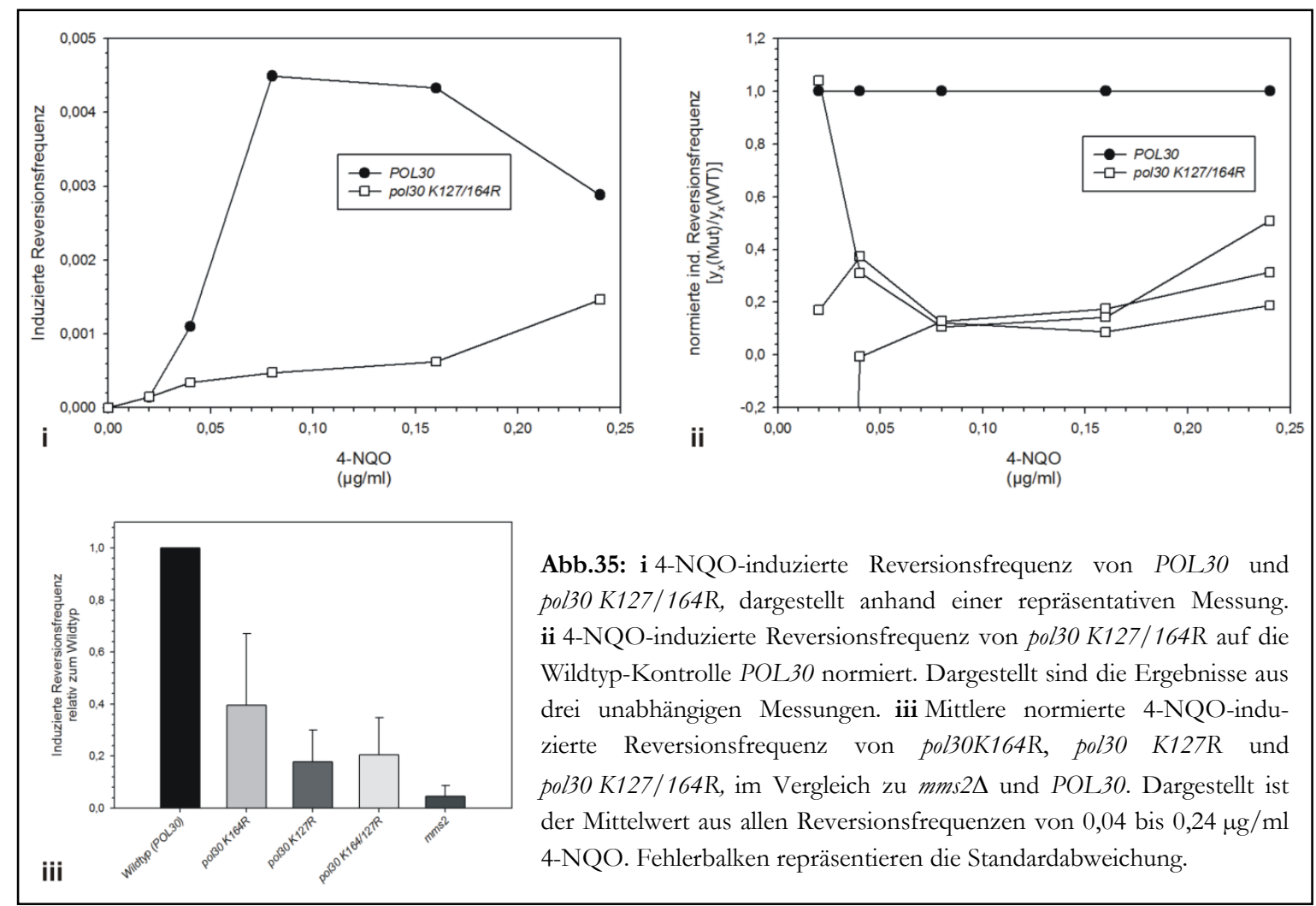




\section{Messung der Sensitivität einer ubc13 1 pol30 K164R-Mutante}

Die induzierten Reversionsfrequenzen in pol30 K164R machen es wahrscheinlich, dass der Verlust der Polyubiquitinierung am PCNA der Auslöser für die beobachteten Phänotypen ist. Um diese Hypothese weiter zu untersuchen, wurde zusätzlich die Sensitivität einer ubc13 $\Delta$ pol30 K164R-Mutante gegen 4-NQO anhand eines drop dilution-assays ermittelt. Dazu wurden Übernachtkulturen zunächst in frisches Medium transferiert und für einige Stunden wachsen gelassen, damit möglichst ein großer Teil der Zellen teilungsaktiv ist. Die Zellkulturen wurden dann in je vier Suspensionen mit abnehmender Zelldichte eingestellt. Für jeden Stamm wurden je $7 \mu$ l einer jeden Suspension auf YPD-Platten mit unterschiedlicher Konzentration an DNA-schädigenden Agenzien ausgetropft. Nach zwei Tagen im Brutschrank bei $30^{\circ}$ wurde dann das Wachstum der Stämme verglichen. Das Ergebnis ist in Abb. 36 zu sehen.

Für $u b c 13 \Delta$ zeigt sich dabei eine geringere Sensitivität gegen 4-NQO als für pol30 K164R. $\mathrm{Da}$ in pol30 K164R-Mutanten sowohl fehlerfreie als auch fehlerbehaftete PRR ausfallen, während in $u b c 13 \Delta$ nur die fehlerfreie PRR entfällt, ist eine solche höhere Sensitivität von pol30 K164R auch zu erwarten. Gleichzeitig ist die Doppelmutante ubc13s pol30 K164R genauso sensitiv wie die pol30 K164R-Mutante. Dies macht es sehr unwahrscheinlich, dass Mms2/Ubc13 neben PCNA ein weiteres Substrat aufweist, welches für die in mms2 $\Delta$ bzw. ubc13 $\Delta$ beobachtete Reduktion der induzierten Reversionsfrequenzen verantwortlich ist. Wäre dies der Fall, so sollte sich die Sensitivität in der Doppelmutante verstärken, da zusätzlich zu dem Wegfall der Ubiquitinierung von PCNA auch noch die Ubiquitinierung des alternativen Substrates wegfiele, was sich wahrscheinlich in der Sensitivität gegen 4-NQO zeigen würde.

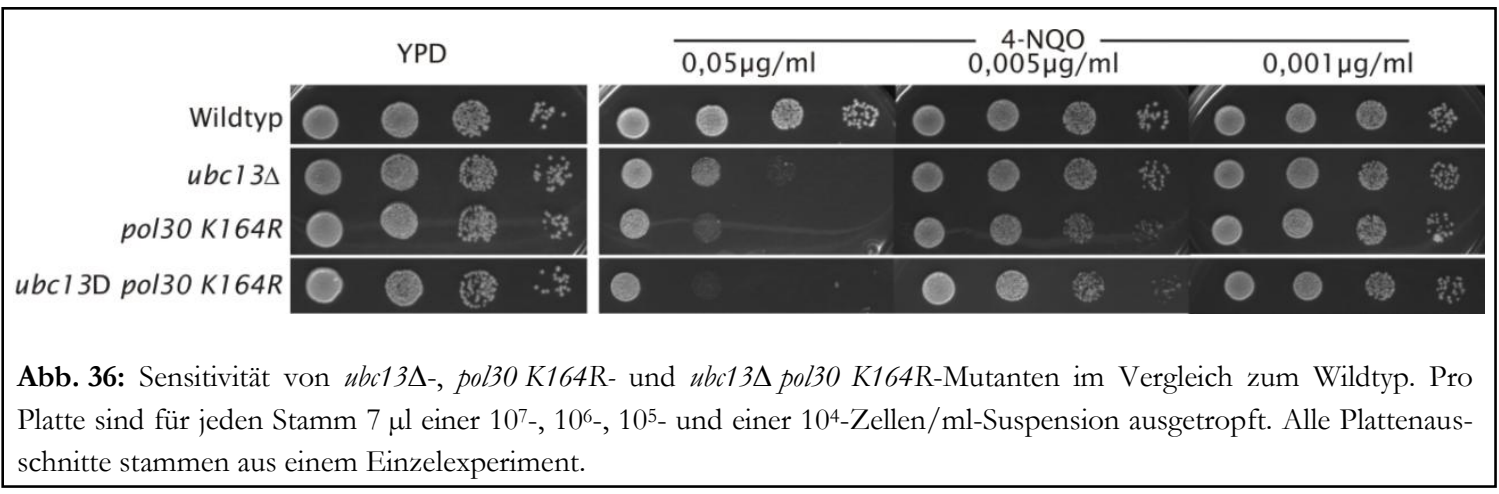

Insgesamt lassen die hier präsentierten Daten vermuten, dass die Polyubiquitinierung von PCNA durch Mms2/Ubc13 in irgendeiner Form einen Einfluss auf die Umgehung von DNA-Schäden durch homologe Rekombination hat. Dies könnte bspw. eine Repression konkurrierender Mechanismen wie Transläsionssynthese oder die Stimulation einzelner oder mehrerer Komponenten der homologen Rekombination sein. 


\section{ERGEBNISSE}

\section{Untersuchung zur Funktion von Mms2 anhand der Analyse genetischer Interaktionen}

\section{Untersuchungen zur Interaktion von $m m s 2 \Delta$ mit der Transläsionssynthese}

Messung 4-NQO-induzierter Reversionsfrequenzen von $\mathrm{mms} 2 \Delta \operatorname{rev} 3 \Delta$ - und $\operatorname{mms} 2 \Delta \operatorname{rad} 30 \Delta$ Mutanten

Ein mögliches Modell für die Funktion von Mms2/Ubc13, welches die zuvor gezeigten Phänotypen erklären kann, ist die Unterdrückung von Transläsionssynthese zugunsten der Umgehung durch homologe Rekombination. Monoubiquitinierung am PCNA gilt als induzierendes Signal für Transläsionssynthese durch pol $\eta$ (s.o. sowie Andersen et al., 2008; Waters et al., 2009). Eine darüber hinaus gehende Polyubiquitinierung könnte den Einsatz der Transläsionspolymerasen verhindern bzw. hinauszögern, damit andere fehlerfreie Mechanismen zunächst greifen können, ohne in Konkurrenz mit der Transläsionssynthese zu gelangen. In einem solchen Fall wäre der erniedrigte Phänotyp einer mms2 $\Delta$-Mutante bei der induzierten Reversionsfrequenz auf das vermehrte Einsetzen der Transläsionssynthese anstelle der fehlerfreien Mechanismen zurückzuführen. Der Schaden wird bereits fehlerbehaftet überlesen, bevor eine fehlerfreie Umgehung durchgeführt werden kann. Um zu überprüfen, ob die Deletion einer Transläsionspolymerase wie Rad30 oder Rev3 einen Einfluss auf die 4-NQO-induzierte Reversionsfrequenz in mms $2 \Delta$ hat, wurden die induzierten Frequenzen in $m m s 2 \Delta \operatorname{rev} 3 \Delta$ und $m m s 2 \Delta \operatorname{rad} 30 \Delta$ ermittelt. Dafür wurde zunächst die

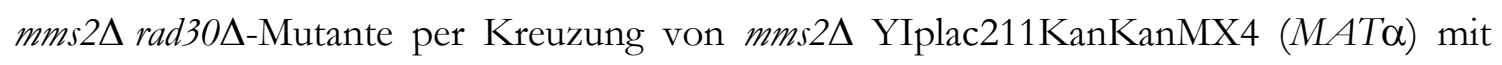
$\operatorname{rad} 30 \Delta$ (MAT $\underline{\mathrm{a}})$ hergestellt. Die Zygoten wurden mithilfe eines Mikromanipulators isoliert, die so erhaltenen Diplonten anschließend zur Sporulation gebracht und mit dem Mikromanipulator dissektiert. Anschließend wurden die induzierten Reversionsfrequenzen einer zufällig ausgewählten Segregate sowie einer vorhandenen $m m s 2 \Delta$ rev3 $\Delta$-Mutante gemessen. Die Ergebnisse für mms $2 \Delta$ rev $3 \Delta$ sind in Abb. 37 und die für mms $2 \Delta$ rad $30 \Delta$ in Abb. $38 \mathrm{zu}$ sehen.

Die induzierten Reversionsfrequenzen von $m m s 2 \Delta$ rev3 $\Delta$ scheinen wieder im Vergleich zu mms $2 \Delta$ deutlich erhöht, wobei sie im Mittel dem Wildtyp ähneln. Allerdings sind die Werte für die Doppelmutante von Messung zu Messung teilweise sehr unterschiedlich. Vor allem im Bereich zwischen 0,02 und 0,08 $\mu \mathrm{g} / \mathrm{ml}$ variieren die induzierten Reversionsfrequenzen stark. Während zwei Messungen eine deutlich erhöhte Frequenz aufweisen, ist in den anderen beiden Messungen eine leichte Reduktion festzustellen. Dagegen scheinen sich die Werte für die Konzentrationen 0,16 und $0,24 \mu \mathrm{g} / \mathrm{ml}$ tendenziell dem Wildtypniveau anzupassen. Eine klare Aussage lässt sich daher nicht formulieren, allerdings erscheint es plausibel zu vermuten, dass sich mms $2 \Delta$ rev3 $\Delta$ nicht wesentlich vom Wildtyp in Bezug auf die Frequenz induzierter Reversionen unterscheidet. Als sicher erscheint jedoch, dass die Doppelmutante nicht den erniedrigten Phänotyp von mms $2 \Delta$ aufweist. Eine Mutation wie rev3 $\Delta$ oder rad30 $\Delta$, welche TLS verhindert bzw. einschränkt, sollte nach der vorhergehend angeführten Hypothese den Phänotyp von mms $2 \Delta$ supprimieren können, da eine fehlerfreie 
Umgehung bei Ausfall der Transläsionssynthese wieder einsetzen könnte. Da die induzierte Reversionsfrequenz von mms $2 \Delta$ rev $3 \Delta$ zumindest nicht mehr die in mms $2 \Delta$ festgestellte Reduktion aufweist, mag eine solche Suppression tatsächlich auch vorliegen. Interessant ist auch die Tatsache, dass der Phänotyp von $m m s 2 \Delta \operatorname{rev} 3 \Delta$ wieder eher dem Wildtyp ähnelt, wohingegen pol30 K164R einen erniedrigten Phänotyp aufweist (vergleiche Abb. 33 und Abb. 37). Allerdings ist in der pol30-Mutante TLS nicht völlig ausgeschaltet, sondern wird nur nicht mehr stimuliert durch die Monoubiquitinierung. In mms $2 \Delta$ rev $3 \Delta$ dagegen ist TLS vermutlich vollständig inaktiv. Daher mag es sein, dass TLS in pol30 K164R durchaus noch teilweise mit homologer Rekombination konkurrieren könnte. Um zu überprüfen, ob die hier präsentierten Daten auf eine Hintergrundmutation zurückzuführen sind und somit nicht auf die genetische Interaktion von $m m s 2 \Delta$ und rev3 $\Delta$, wurde zusätzlich versucht, mms $2 \Delta$ rev3 $\Delta$ mit dem Plasmid pJA6 zu komplementieren. Als Kontrolle wurde $m m s 2 \Delta$ rev3 3 auch mit dem Leervektor YCp50 transformiert. Die induzierten Reversionsfrequenzen sind in Abb. 37 ii $\mathrm{zu}$ sehen. Tatsächlich ist die Reversionsfrequenz in der komplementierten Mutante wieder geringer als im Wildtyp, wenn auch der mms $2 \Delta$ Phänotyp nicht annähernd rekonstruiert wird. Dies mag jedoch bspw. darauf zurückzuführen zu sein, dass das Expressionsniveau des auf dem Plasmid vorliegenden REV3-Gens nicht dem der chromosomal lokalisierten Kopie entspricht.

Zusammengefasst scheint die induzierte Reversionsfrequenz in mms $2 \Delta$ durch zusätzliche Deletion von REV3 zumindest teilweise wieder angehoben zu werden.
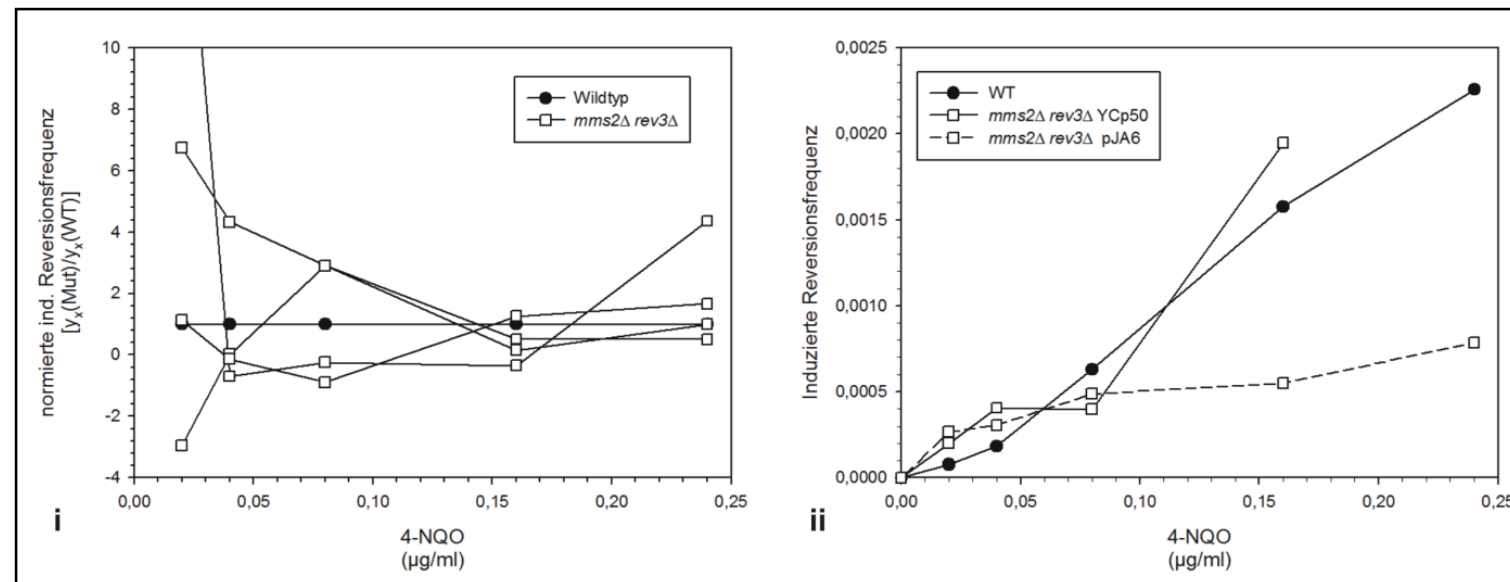

Abb. 37: i 4-NQO-induzierte Reversionsfrequenz von mms $2 \Delta$ rev3 $3 \Delta$ auf den Wildtyp normiert. Dargestellt sind die Ergebnisse aus vier unabhängigen Messungen. ii 4-NQO-induzierte Reversionsfrequenz von mms $2 \Delta$ rev3 $\Delta$ komplementiert mit pJA6 im Vergleich zum Wildtyp und mms2 2 rev3 $\Delta$, transformiert mit dem Leervektor YCp50.

Interessanterweise zeigt mms $2 \Delta$ rad30 $\Delta$ nicht den gleichen Phänotyp wie mms $2 \Delta$ rev3 $\Delta$, son-

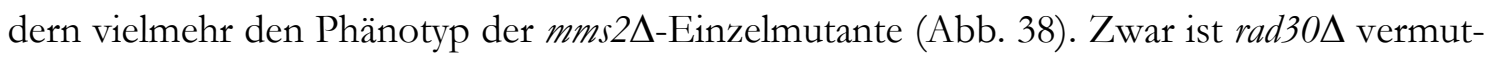
lich die einzige echte Transläsionspolymerase in Hefe und zumindest humane Pol $\eta$ ist in vitro in der Lage Benzpyren-Addukte zu überlesen (Zhang et al., 2000), jedoch ist es dennoch möglich, dass Rad30 in Hefe keine oder nur eine geringe Rolle bei der Umgehung von 4-NQO-induzierten Addukten spielt. Allerdings wäre in dem Fall auch kein Einfluss von rev3 3 auf die induzierten Reversionsfrequenzen von mms $2 \Delta$-Mutanten zu erwarten, da 


\section{ERGEBNISSE}

keine andere DNA-Polymerase in Hefe bekannt ist, welche in der Lage wäre, solche Addukte effizient zu überlesen. Wie zuvor gezeigt, kann jedoch die rev3 $\Delta$-Deletion vermutlich den Phänotyp von mms $2 \Delta$ supprimieren. Eine alternative und wesentlich plausiblere Erklärung ist vermutlich die Beteiligung von Rad30 an der homologen Rekombination. Da, wie

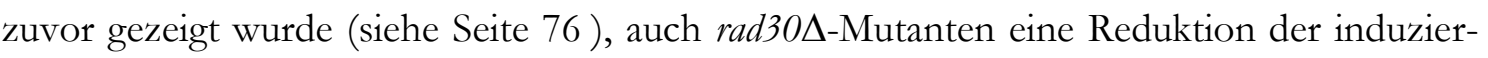
ten Reversionsfrequenzen aufweisen, ist es sehr wahrscheinlich, dass sich die zusätzliche Deletion von $\mathrm{R} A D 30$ nicht weiter auf die bereits stark erniedrigten Frequenzen in mms $2 \Delta$ Mutanten auswirkt.
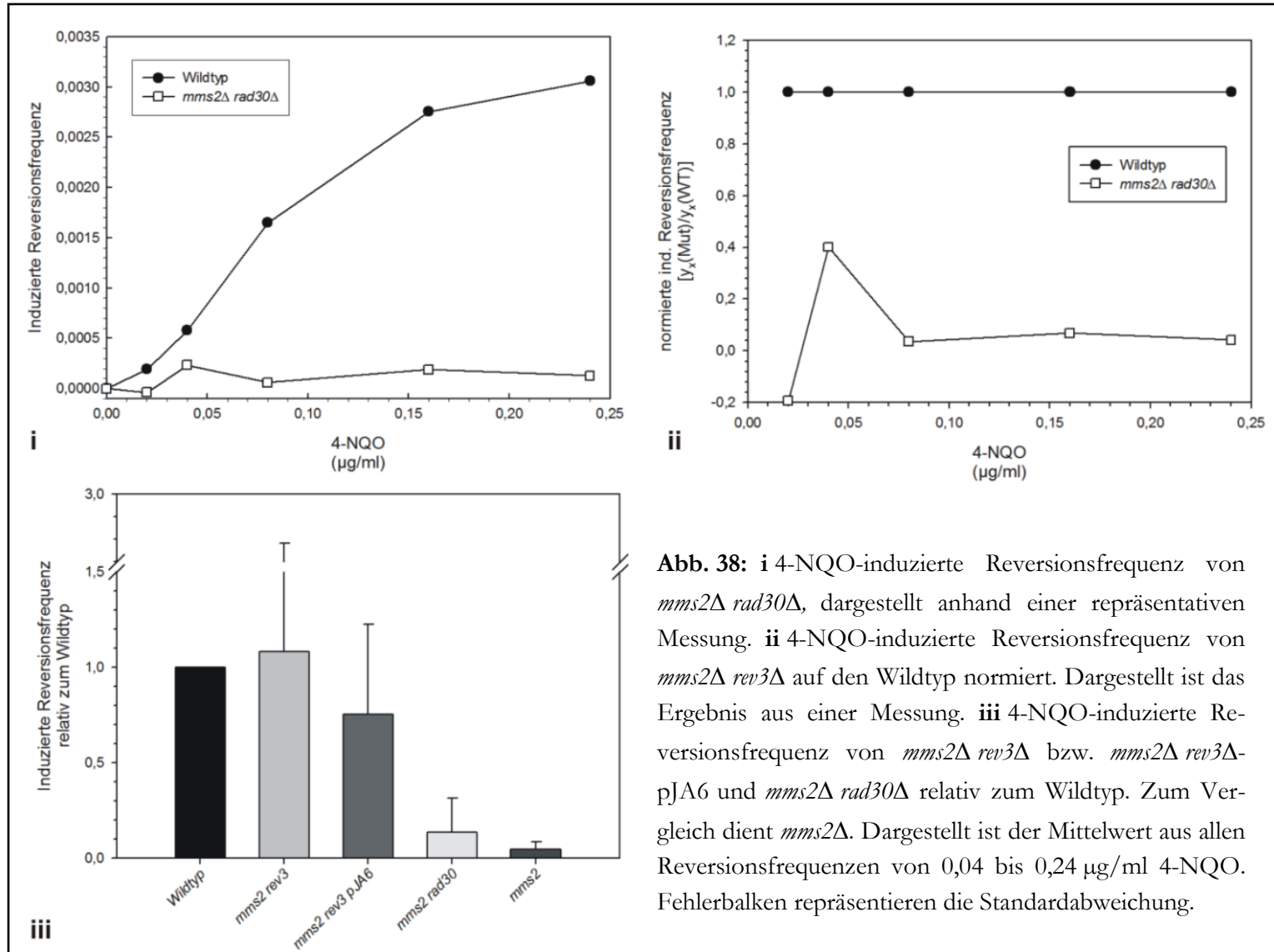

Abb. 38: i 4-NQO-induzierte Reversionsfrequenz von $m m s 2 \Delta \mathrm{rad} 30 \Delta$, dargestellt anhand einer repräsentativen Messung. ii 4-NQO-induzierte Reversionsfrequenz von $m m s 2 \Delta$ rev $3 \Delta$ auf den Wildtyp normiert. Dargestellt ist das Ergebnis aus einer Messung. iii 4-NQO-induzierte Reversionsfrequenz von mms $2 \Delta$ rev $3 \Delta$ bzw. $m m s 2 \Delta$ rev $3 \Delta$ pJA6 und mms $2 \Delta$ rad30 $\Delta$ relativ zum Wildtyp. Zum Vergleich dient mms $2 \Delta$. Dargestellt ist der Mittelwert aus allen Reversionsfrequenzen von 0,04 bis $0,24 \mu \mathrm{g} / \mathrm{ml} 4-\mathrm{NQO}$. Fehlerbalken repräsentieren die Standardabweichung.

$\mathrm{Da}$ während der Messungen der induzierten Reversionsfrequenzen in mms $2 \Delta \operatorname{rev} 3 \Delta$-Mutanten jeweils ein erstaunlich hoher spontaner Hintergrund festgestellt wurde, wurde zusätzlich die spontane Reversionsrate bestimmt. Die so ermittelten Daten sind in Tab. 7 zu sehen. Tatsächlich ist der Wert in etwa 20-40-fach höher als im Wildtyp, während er in mms $2 \Delta$-Mutanten leicht erniedrigt ist und rev3 $\Delta$-Mutanten vermutlich einen dem Wildtyp vergleichbaren Wert aufweisen (Seite 81). Um zu überprüfen, ob die gemessene Erhöhung durch Rad51-abhängige Prozesse entsteht, wurde auch die spontane Reversionsfrequenz einer mms $2 \Delta$ rev $3 \Delta$ rad51 $1 \Delta$-Mutante gemessen. In Tab. 7 sind auch die Raten dieser Mutante zu finden. In beiden Messungen zeigte sich, dass die zusätzliche rad51 $\Delta$-Mutation die Erhöhung der spontanen Reversionsrate deutlich supprimieren kann, wobei der Wert immer noch deutlich über dem Wert des Wildtyps liegt. Es scheint daher, dass zumindest ein gro- 
Ber Teil der in mms $2 \Delta$ rev3 3 -Mutanten auftretenden Reversionen über Rad51-vermittelte Prozesse entstehen.

Während der Mutatorphänotyp und die Reduktion der induzierten Reversionsfrequenz in $m m s 2 \Delta$ durch das zuvor angesprochene Modell zu erklären sind, kann es die Erhöhung der spontanen Reversionsfrequenz jedoch nicht ohne Weiteres erklären. Nach dem Modell sollte die Deletion von REV3 und damit der Verlust von TLS wieder zu einer Umgehung der DNA-Schäden über homologe Rekombination führen. Der Phänotyp der Doppelmutante sollte sich demnach nicht wesentlich von einer rev3 $\Delta$-Einzelmutante unterscheiden. Dies ist jedoch nicht der Fall. Allerdings lässt sich eine in sich schlüssige Interpretation dieses Phänomens anhand der bisher präsentierten Daten nicht formulieren. Es ist aber anzumerken, dass der beobachtete Anstieg der spontanen Reversionsfrequenz auch auf eine hohe Sensitivität der Doppelmutante gegen 4-NQO zurückzuführen sein könnte (näheres zur Sensitivität von mms $2 \Delta$ rev3 $\Delta$ ist auf Seite $107 \mathrm{zu}$ finden). Insofern Zellen, welche Schäden über homologe Rekombination umgehen oder reparieren, im Vergleich zu anderen Zellen eine höhere Überlebensrate aufweisen, wäre eine erhöhte Frequenz an Reversionen zu erwarten. In diesem Fall wäre der Phänotyp wiederum mit dem Modell zu vereinbaren.

Tab. 7: Spontane Reversionsraten von $m m s 2 \Delta-$, rev3 3 - und mms $2 \Delta$ rev3 $\Delta$-Mutanten im Vergleich zum Wildtyp. Die Werte wurden nach der Methode des Medians ermittelt (Lea \& Coulson, 1948). WT steht für Wildtyp, Mut. für Mutante. Die zusammengehörigen Werte aus jeweils einer Messung sind durch Indices (1-3) markiert.

\begin{tabular}{lcr}
\hline Stamm & Spontane Reversionsrate & Faktor Mut. / WT \\
\hline \hline Wildtyp & $1,2 \times 10^{-5} \pm 1,2 \times 10^{-6}$ & $1^{1}$ \\
& $3,6 \times 10^{-5} \pm 3,0 \times 10^{-6}$ & $1^{2}$ \\
& $3,0 \times 10^{-5} \pm 2,6 \times 10^{-6}$ & $1^{3}$ \\
mms2 & $7,5 \times 10^{-6} \pm 8,0 \times 10^{-7}$ & $0,6^{1}$ \\
mms2 rev3 & $2,8 \times 10^{-4} \pm 2,3 \times 10^{-5}$ & $23,1^{1}$ \\
& $6,2 \times 10^{-4} \pm 4,4 \times 10^{-5}$ & $17,3^{2}$ \\
mms2 rev3 rad51 & $1,3 \times 10^{-3} \pm 8,8 \times 10^{-5}$ & $43,2^{3}$ \\
& $1,5 \times 10^{-4} \pm 2,3 \times 10^{-5}$ & $4,3^{2}$ \\
& $6,7 \times 10^{-4} \pm 5,3 \times 10^{-5}$ & $22,16^{3}$ \\
\hline
\end{tabular}

Messung der Sensitivität von mms $2 \Delta \operatorname{rad} 30 \Delta, \operatorname{mms} 2 \Delta \operatorname{rev} 3 \Delta$ und pol30 K164R

Die Vermutung, Mms2 sei notwendig für einen fehlerfreien Zweig der Postreplikativen Reparatur, welcher eine Alternative zur Transläsionssynthese darstellt, beruht auf der Feststellung, dass mms2 einen Rev3-abhängigen Mutatorphänotyp und einen Synergismus mit rev3 in Bezug auf die Überlebensrate gegen MMS, UV- und $\gamma$-Strahlung zeigt (Broomfield $e t$ al., 1998; Xiao et al., 1999). Um die Interaktion von MMS2 mit den Genen der Transläsionssynthese genauer zu untersuchen, wurde die Sensitivität einer $m m s 2 \Delta \operatorname{rev} 3 \Delta$-und einer mms $2 \Delta$ rad30 -Mutante im Vergleich zu den entsprechenden Einzelmutanten, sowie einer pol30 K164R-Mutante ermittelt. Für die Messung der Sensitivität wurden logarithmisch 


\section{ERGEBNISSE}

wachsende Kulturen von jedem Stamm auf vier Suspensionen mit abnehmender Zelldichte eingestellt und von jeder Suspension ein Aliquot auf YPD-Platten mit unterschiedlicher Konzentration an DNA-schädigenden Agenzien ausgetropft. Untersucht wurde dabei die Sensitivität gegen 4-NQO, MMS und Cpt. Eine Darstellung der Daten ist in Abb. $39 \mathrm{zu}$ finden. Zusätzlich wurde die Sensitivität gegen UV-Strahlung für mms $2 \Delta$ rad30 $\Delta$ gemessen, da diese wie bereits angemerkt vor allem für das Überlesen von UV-Schäden wichtig zu sein scheint (s.o). Hierfür wurden die Zellsuspensionen nach Erreichen der logarithmischen Phase auf $4 \times 10^{6}$ Zellen/ml eingestellt und je Stamm $50 \mu$ gleichmäßig als Bahn auf einer YPD-Platte verteilt. Anschließend wurden Teile der Platte nach und nach mit UV bestrahlt, sodass man einen Stufengradient der Strahlungsintensität erhält. Die UV-Sensitivität von mms $2 \Delta \mathrm{rad} 30 \Delta$ ist in Abb. $40 \mathrm{zu}$ sehen. Wie auch in den erwähnten Arbeiten von Broomfield et al. und Xiao et al. lässt sich bei der Sensitivität gegen MMS ein Synergismus zwischen $\operatorname{rev} 3 \Delta$ und mms $2 \Delta$ beobachten, wobei die rev3 3 -Einzelmutante selbst nicht auffällig sensitiv gegen MMS ist. mms $2 \Delta$ dagegen weist eine moderate Sensitivität gegen MMS auf. Für 4-NQO lässt sich ebenfalls ein Synergismus zwischen mms $2 \Delta$ und rev3 $\Delta$ feststellen, wobei auch mms $2 \Delta$ eine deutliche Sensitivität gegenüber 4-NQO aufweist. Für rev3 $\Delta$ lässt sich auch bei 4-NQO keine gegenüber dem Wildtyp erhöhte Sensitivität feststellen. Bei Camptothecin weist dagegen keine der betrachteten Mutanten eine erkennbare Sensitivität auf. Rev3 ist für Transläsionssynthese notwendig, welche eine Alternative zu der fehlerfreien Umgehung von DNA-Schäden darstellt. Für eine Mutante mit Defekt in einem fehlerfreien Prozess wäre daher zu erwarten, dass sich die Sensitivität durch gleichzeitiges Ausschalten von Rev3 verstärken sollte. Der hier präsentierte Synergismus von mms $2 \Delta$ und rev3 $\Delta$ unterstützt demnach die ursprüngliche Hypothese, Polyubiquitinierung von PCNA führe zu einer fehlerfreien Umgehung von DNA-Schäden. Gleichzeitig lassen diese Daten das zuvor angeführte Modell als eher unwahrscheinlich erscheinen: Beruht die Reduktion der induzierten Reversionsfrequenz in mms $2 \Delta$ einzig auf dem verstärkten Einsatz der nun nicht mehr reprimierten Transläsionssynthese, müsste die Sensitivität der mms $2 \Delta$-Mutante im Wesentlichen auf dem mutagenen Effekt der Transläsionssynthese beruhen. Dies ist zum einen per se recht unwahrscheinlich, da eine Mutation durch Transläsionssynthese in den meisten Fällen wohl nicht letal ist und teilweise - je nach Art des Schadens - fehlerfrei erfolgen kann (siehe Seite 12). Zum anderen sollte ein zusätzliches Deletieren von REV3 diesen Effekt aufheben, da die Schäden wieder verstärkt über homologe Rekombination umgangen werden. Da mms $2 \Delta$ und rev3 3 jedoch synergistisch sind, kann die Polyubiquitinierung nicht ausschließlich eine Repression der Transläsionssynthese darstellen. Dennoch ist es möglich, dass solch eine Repression eine von mehreren möglichen Folgen der PCNA-Modifikation darstellt. Darüber hinaus zeigt die nicht vorhandene Sensitivität gegenüber Camptothecin, dass Mms2 keinen Einfluss auf die Reparatur von Strangbrüchen nach run off-Synthese zu haben scheint. Letzteres ist jedoch auch plausibel, da bei der run off-Synthese möglicherweise nicht nur die DNA-Polymerase, sondern auch PCNA von der DNA herunterläuft und somit die Ubiquitinierung des PCNA erst gar nicht stattfinden kann. Allerdings setzt dies voraus, dass die PCNA-Modifikation bei auf der DNA sitzendem PCNA stattfindet. Unabhängig davon scheint die Funktion von Mms2 jedoch nicht 
relevant für die Reparatur von Camptothecin-induzierten Schäden zu sein. Wenn Mms2 einen Einfluss auf homologe Rekombination hat, so scheint dieser demnach auf Prozesse beschränkt zu sein, welche bei der Umgehung von DNA-Schäden notwendig sind, aber nicht bei der Replikationsreinitiation nach run off-Synthese.

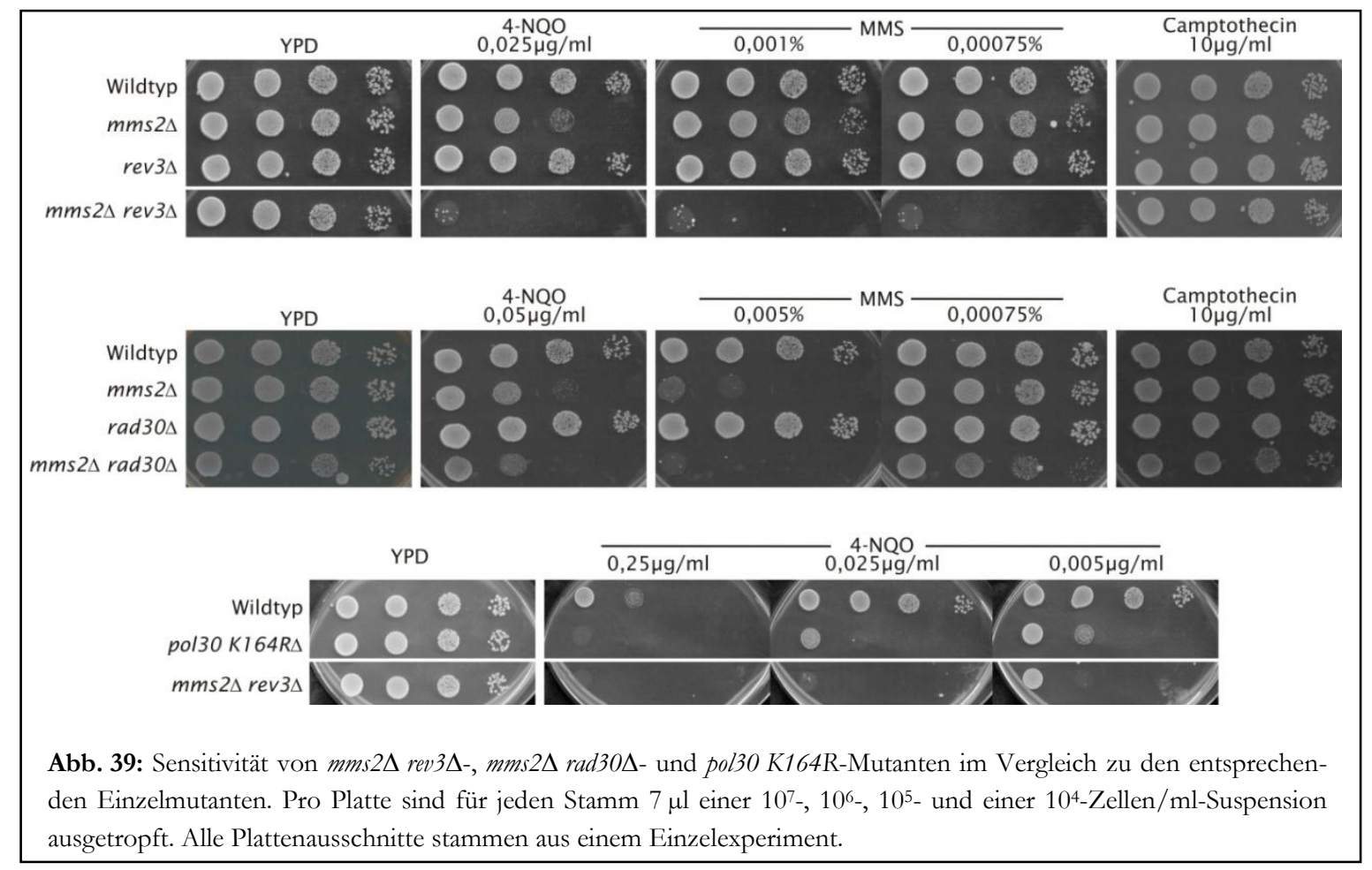

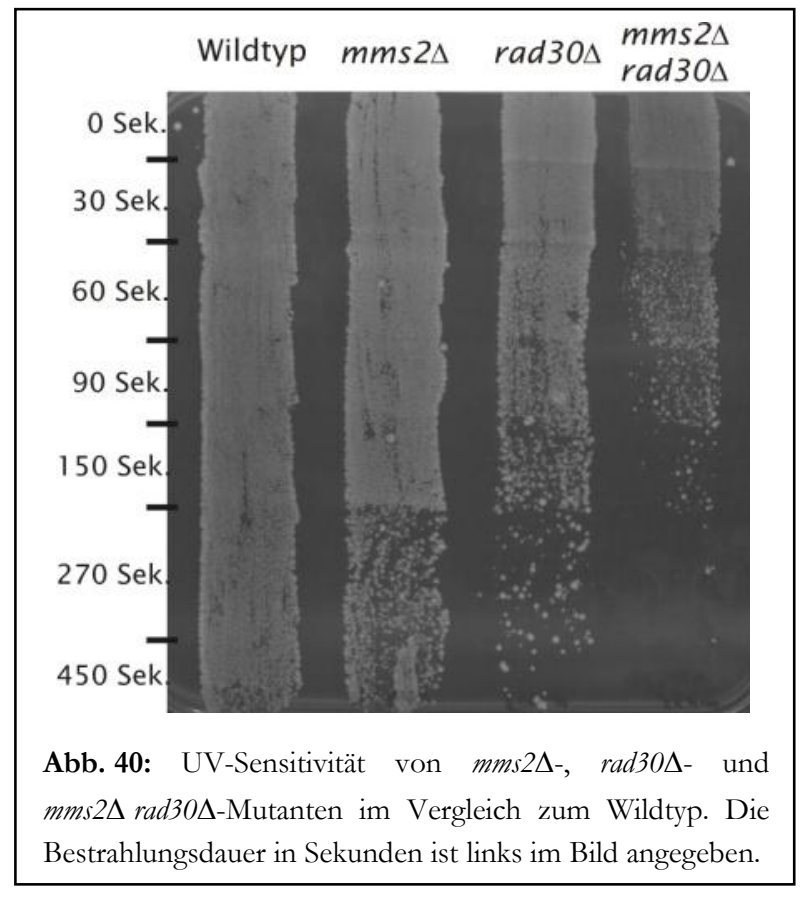

Für mms $2 \Delta \operatorname{rad} 30 \Delta$ stellt sich annähernd dasselbe Bild dar wie für mms $2 \Delta \operatorname{rev} 3 \Delta$. Auch hier weist die rad30 $\Delta$-Einzelmutante gegenüber MMS und 4-NQO keine erkennbare Sensitivität auf. Die Doppelmutante zeigt dagegen eine verstärkte Sensitivität im Vergleich zu mms $2 \Delta$. Allerdings ist diese Verstärkung nicht derart ausgeprägt wie in mms $2 \Delta$ rev $3 \Delta$. Dies lässt sich 


\section{ERGEBNISSE}

insofern erklären, als Rev3 vermutlich eine für die TLS wichtigere Funktion hat als Rad30. Rev3 ist im Gegensatz zu anderen DNA-Polymerasen in der Lage ein fehlgepaartes primerEnde zu verlängern. Wie bereits erwähnt erfordert die effiziente Transläsionssynthese jedoch auch bei dem Einsatz einer Transläsionspolymerase wie Rad30 zusätzlich die Funktion von Rev3. Bei der Bestrahlung mit UV zeigt rad30 eine deutliche Sensitivität, welche stärker ausfällt als die Sensitivität von mms $2 \Delta$ und in etwa der Sensitivität einer rad51 $1 \Delta$ Mutante entspricht (vergleiche Abb. 40 und Abb. 42). Dies lässt vermuten, dass die Funktion von Rad30 beim Überlesen von UV-induzierten DNA-Schäden möglicherweise eine wichtigere Rolle spielt, als bspw. bei der Umgehung von 4-NQO-induzierten Schäden. Ebenfalls lässt sich hier die Sensitivität der Einzelmutanten durch die gleichzeitige Deletion beider Gene verstärken.

Fasst man alle bisher hier präsentierten Ergebnisse zusammen, so erscheint es als sehr wahrscheinlich, dass die Polyubiquitinierung von PCNA durch Mms2/Ubc13 einen Prozess fördert oder initiiert, welcher eine fehlerfreie Umgehung von DNA-Schäden ermöglicht und eine Alternative zur Transläsionssynthese darstellt. Darüber hinaus scheint dieser Prozess zumindest teilweise von homologer Rekombination abhängig zu sein.

\section{Untersuchungen zur Interaktion von Mms2 mit der homologen Rekom- bination}

\section{Messungen der UV-Sensitivität in mms $2 \Delta \operatorname{rad} 52 \Delta$}

Da die hier präsentierten Messungen der induzierten Reversionsfrequenzen darauf hinweisen, dass Mms2 in irgendeiner Form die Umgehung von DNA-Schäden durch homologe Rekombination beeinflusst, sollte im Folgenden die genetische Interaktion zwischen MMS2 und den zentralen Genen der homologen Rekombination (RAD52 und RAD51) genauer untersucht werden. Bereits während meiner Diplomarbeit wurden Sensitivitätsmessungen

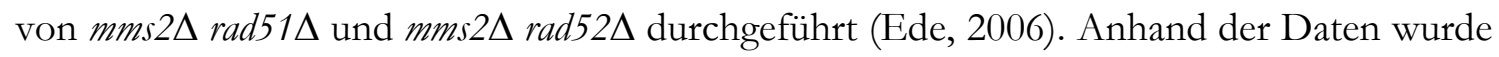
vermutet, dass bei der Sensitivität gegen 4-NQO eine Epistasis von rad51 $\Delta$ und eine Subadditivität mit rad52 $\Delta$ vorliegen. Dagegen konnte für MMS eine Additivität sowohl mit rad51 $\Delta$ als auch mit rad52 $\Delta$ festgestellt werden. Vorherige Untersuchungen bezüglich der Interaktion von MMS2 und der homologen Rekombination sind auf die Überlebensrate nach UV-Bestrahlung bei mms2 rad52 beschränkt (Torres-Ramos et al., 2002; Ulrich, 2001). Daher sollten weitere Interkationsstudien bezüglich anderer Schadensarten erfolgen. Dazu

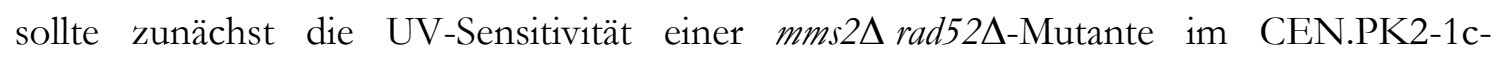
Stammhintergund ermittelt werden, da die bisherigen Messungen von Torres-Ramos et al. hierzu in einem anderen Stammhintergund erfolgten. Das Ergebnis ist in Abb. 41 zu sehen. Wie zu erwarten, ist eine Additivität bzw. eventuell ein schwacher Synergismus von mms $2 \Delta$ und $\operatorname{rad} 52 \Delta$ festzustellen, wie es auch bei Torres-Ramos et al. beobachtet wurde. 


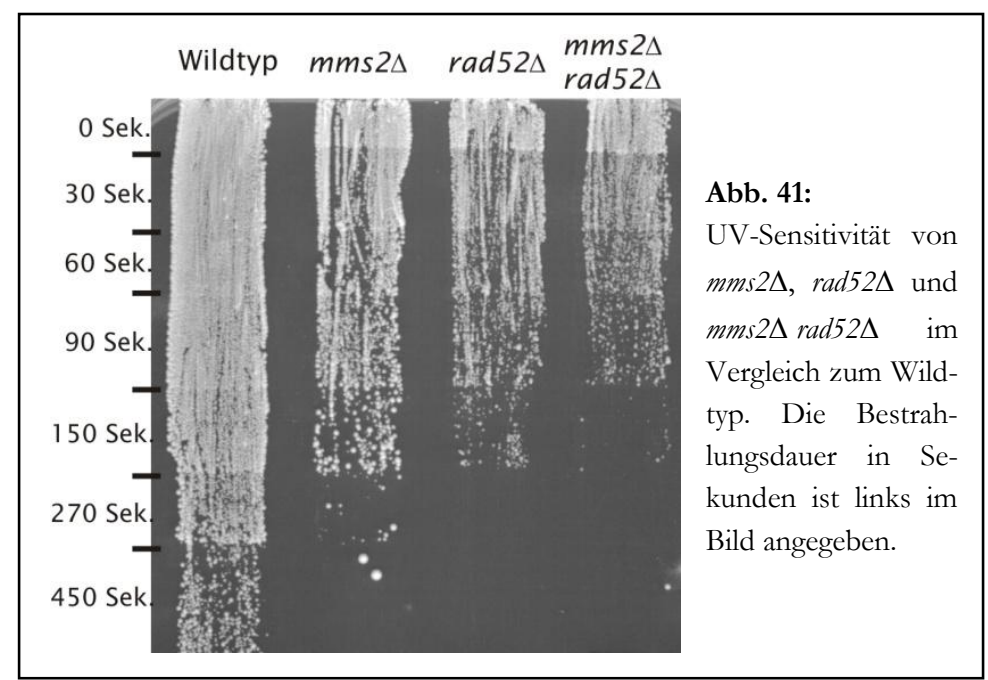

Messung der Sensitivität und Überlebensrate nach UV-Bestrablung von $\mathrm{mms} 2 \Delta \operatorname{rad} 51 \Delta$

$\mathrm{Da}$ sich die bisherigen Messungen wie bereits erwähnt auf die Untersuchung von mms 2 rad52 beschränken, wurden hier zusätzlich die Sensitivität und die Überlebensrate von mms $2 \Delta$ rad51 $\Delta$ nach der Bestrahlung mit UV ermittelt. Für die Überlebensrate wurden logarithmisch wachsende Zellen zunächst auf eine Zelldichte von $2 \times 10^{8}$ Zellen $/ \mathrm{ml}$ eingestellt und geeignete Verdünnungen auf YPD ausplattiert. Anschließend wurden die Platten mit UV-Licht bestrahlt und nach dreitägigem Wachstum die Anzahl Überlebender ermittelt. Die Ergebnisse sind in Abb. 42 dargestellt. Wie auch bei rad52A, zeigt sich hier eine moderate Sensitivität der Einzelmutanten sowie eine Additivität bzw. ein schwacher Synergismus von rad51 $\Delta$ und mms $2 \Delta$ (die bei $2,5 \mu \mathrm{g} / \mathrm{ml}$ 4-NQO auftretende höhere Sensitivität des Wildtyps im Vergleich zu mms $2 \Delta$ ist vermutlich ein Artefakt der Messung, da sie nicht reproduzierbar war). Dieses Ergebnis wirkt überraschend, da gleichzeitig rad51 $\Delta$ gegenüber mms $2 \Delta$ epistatisch bei der Sensitivität gegen 4-NQO zu sein scheint. Allerdings ist nicht auszuschließen, dass sich die Umgehung der durch 4-NQO-induzierten DNA-Schäden von der Umgehung UV-induzierter Schäden unterscheidet. Bspw. können UV-Schäden im Wesentlichen fehlerfrei durch Rad30 umgangen werden, was auch unter anderem an der Sensitivität von rad30 $\Delta$ gegen UV-Strahlung erkennbar ist (Johnson et al., 1999 und s.o.). Dagegen zeigt rad30 $\Delta$ keine erkennbare Sensitivität gegen 4-NQO, was die Vermutung zulässt, dass 4-NQO-induzierte Schäden anscheinend in vivo bevorzugt über einen anderen Prozess bzw. über andere Proteine als UV-Schäden prozessiert werden. Weiter scheint Mms2 sowohl auf Prozesse einen Einfluss zu haben, welche bei der Umgehung von UV-Schäden als auch bei der Umgehung von 4-NQO-induzierten Schäden eine Rolle spielen. 

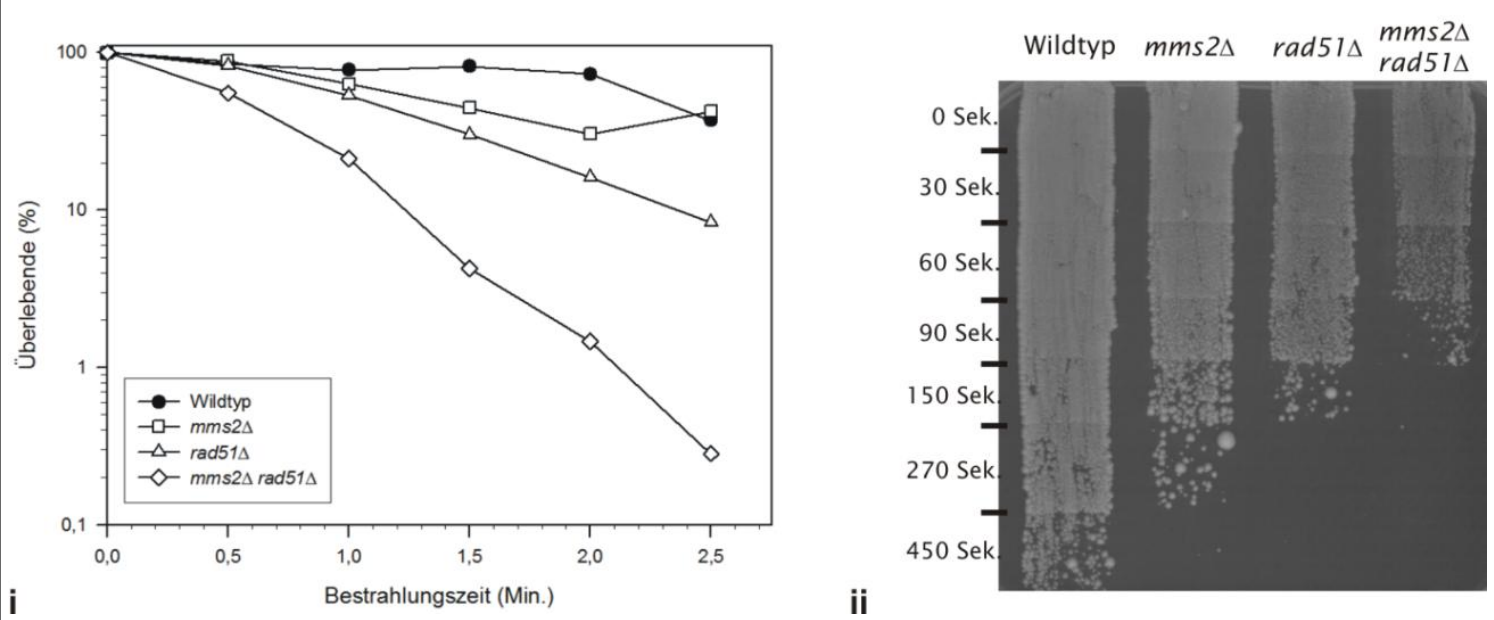

Abb. 42: i Überlebensrate nach UV-Bestrahlung von $m m s 2 \Delta, \operatorname{rad} 51 \Delta$ und $m m s 2 \Delta \operatorname{rad} 51 \Delta$ im Vergleich zum Wildtyp. ii Sensitivität gegen UV-Bestrahlung von $m m s 2 \Delta$, rad51 $\Delta$ und $m m s 2 \Delta$ rad51 $\Delta$ im Vergleich zum Wildtyp. Die Bestrahlungsdauer in Sekunden ist links im Bild angegeben.

Messung der Überlebensrate von $\mathrm{mms} 2 \Delta \operatorname{rad} 51 \Delta$ und $\mathrm{mms} 2 \Delta \operatorname{rad} 52 \Delta$ nach Inkubation mit 4-NQO

Die Messung der Sensitivität per Drop-Dilution-Assay ist ein semiquantitativer Test, welcher den Einfluss der Anwesenheit von DNA-schädigenden Agenzien auf das Wachstum von Zellen abschätzbar macht. Bei der Messung der Überlebensrate wird dagegen quantitativ die Anzahl der überlebenden Zellen nach einer zeitlich definierten Inkubation mit DNAschädigenden Agenzien ermittelt. Da die Interaktion von mms $2 \Delta$ und rad51 $\Delta$ bei der Inkubation mit 4-NQO bisher nur durch einen semiquantitativen Test ermittelt wurde und nicht auszuschließen ist, dass sich die Ergebnisse von einem rein quantitativen Test unterscheiden, wurde sowohl für mms $2 \Delta \mathrm{rad} 51 \Delta$ als auch für $m m s 2 \Delta \mathrm{rad} 52 \Delta$ die Überlebensrate nach Inkubation mit 4-NQO ermittelt. Darüber hinaus wird bei diesem Test nicht das Wachstum der Zellen in Anwesenheit von 4-NQO ermittelt, sondern direkt die Anzahl überlebender Zellen nach einer 4-NQO-Inkubation während der S-Phase. Dazu wurden die Zellen zunächst mithilfe von $\alpha$-Faktor im G1 synchronisiert. Nach Entfernen des $\alpha$ Faktors wurden die Zellen aufgeteilt und in Ansätzen mit unterschiedlichen 4-NQO Konzentrationen während der S-Phase inkubiert. Anschließend wurden von jedem Ansatz zwei bis fünf Verdünnungen hergestellt und je ein Aliquot auf Vollmedium plattiert. Nach drei Tagen Inkubation im Brutschrank wurde der Lebendtiter für jede 4-NQO-Konzentration ermittelt und die prozentuale Überlebensrate errechnet. Der Lebendtiter eines Ansatzes ohne 4-NQO während der Inkubation in der S-Phase diente als Grundwert und wurde als 100\% gesetzt. Eine Auftragung der prozentualen Überlebensrate gegen die 4-NQOKonzentration ist in Abb. 43 dargestellt.

Sowohl mms $2 \Delta$ als auch rad51 zeigen eine moderat verringerte Überlebensrate nach Inkubation mit 4-NQO, wobei rad51 $\Delta$ etwas sensitiver ist als mms $2 \Delta$. Für mms $2 \Delta \operatorname{rad51\Delta }$ lässt sich eine Epistasis von rad51 $1 \Delta$ feststellen, wie es auch schon anhand der Sensitivitätsmessungen während meiner Diplomarbeit vermutet wurde (Ede, 2006). Demnach erscheint es als sehr wahrscheinlich, dass Mms2 einen Prozess beeinflusst, welcher abhängig von homo- 
loger Rekombination und speziell von Rad51 ist. Auch die zuvor beobachtete Subadditivität von mms $2 \Delta$ und rad52 $\Delta$ lässt sich anhand der quantitativen Messung zumindest teilweise bestätigen. Wie in „Methoden“, Seite 58, beschrieben, ist zur Ermittlung einer Additivität der Mutanten die Berechnung der entsprechenden $\lambda$-Werte notwendig. Die daraus berechnete hypothetische Kurve bei einer Additivität von mms $2 \Delta$ und rad52 $\Delta$ ist in Abb. 43 iii zu sehen (zur besseren Vergleichbarkeit wurden die negativen $\lambda$-Werte aufgetragen). Dabei zeigt sich, dass mms $2 \Delta$ und $\mathrm{rad} 52 \Delta$ bis $0,5 \mu \mathrm{g} / \mathrm{ml} 4-\mathrm{NQO}$ anscheinend additiv sind. $\mathrm{Ab}$ $1,9 \mu \mathrm{g} / \mathrm{ml}$ dagegen ist die Sensitivität deutlich geringer, als sie bei einer Additivität sein müsste. Auch eine Subadditivität wie sie hier vorliegen könnte ist konsistent mit der Vermutung, dass Mms2 an der homologen Rekombination und speziell an einem Rad51abhängigen Prozess beteiligt ist. Die partielle Additivität könnte dabei auf rein Rad52abhängige Prozesse wie SSA zurückzuführen sein.
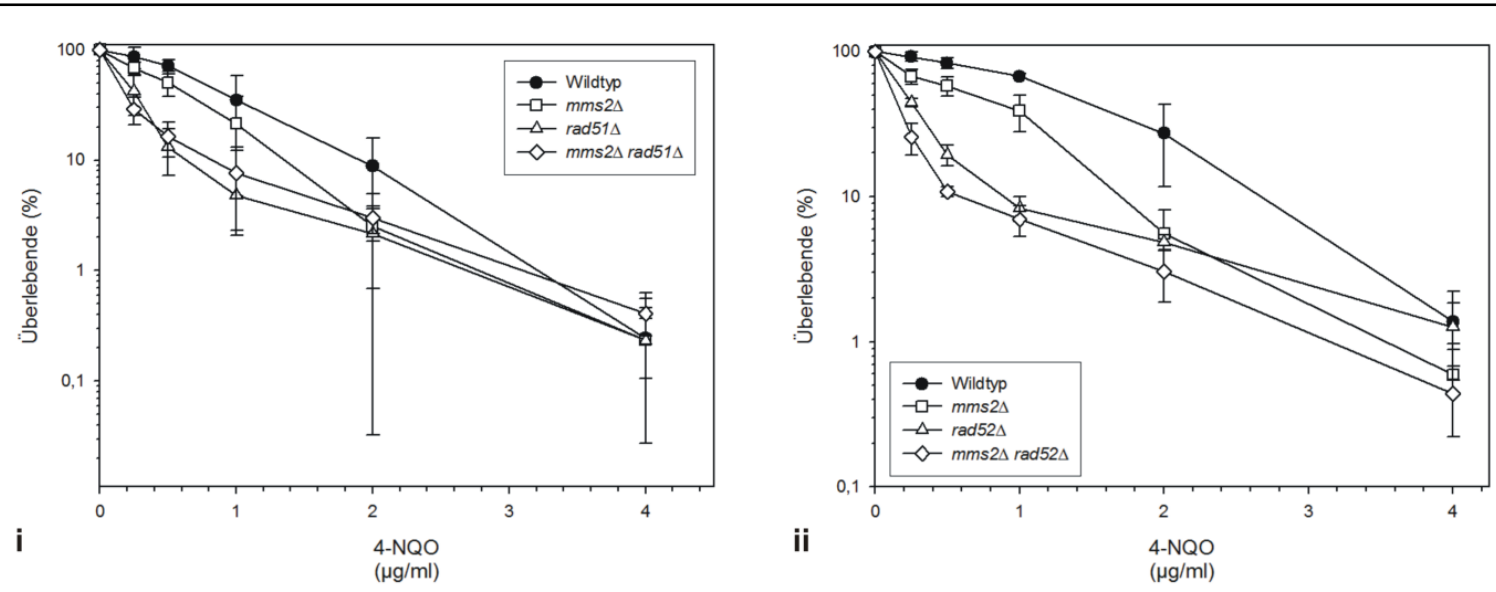

Abb. 43: $\mathbf{i}$ Überlebensrate nach Inkubation mit 4-NQO von

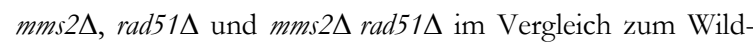
typ. Dargestellt ist der Mittelwert inklusive Standardabweichung aus drei unabhängigen Messungen. ii Überlebensrate nach Inkubation mit 4-NQO von mms $2 \Delta$, rad52 $\Delta$ und mms $2 \Delta$ rad52 $2 \Delta$ im Vergleich zum Wildtyp. Dargestellt ist der Mittelwert inklusive Standardabweichung aus drei unabhängigen Messungen. iii Vergleich einer hypothetischen Addition von mms $2 \Delta$ und $\operatorname{rad} 52 \Delta$ und der tatsächlichen Sensitivität von mms $2 \Delta$ rad52 2 . Die dargestellten $\lambda$-Werte wurden anhand der in (ii) dargestellten Mittelwerte berechnet. $\lambda_{\mathrm{x}}=-\ln$ (Überlebensrate $\mathrm{x}_{\mathrm{x}}$. Zur besseren Vergleichbar-

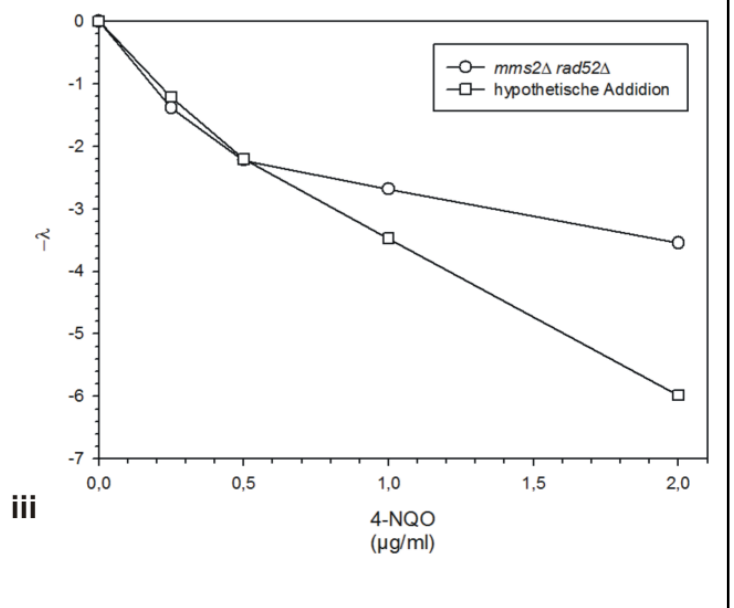

keit mit (ii) wurden die negativen $\lambda$-Werte aufgetragen.

\section{Messung der Überlebensrate von mms2 $\operatorname{rad} 51 \Delta$ nach Inkubation mit MMS}

Die wahrscheinlichste Erklärung für die unterschiedlichen Phänotypen bei andersartiger Schadensinduktion ist die bereits zuvor angesprochene Möglichkeit einer unterschiedlichen Umgehung von UV-Schäden und 4-NQO-Addukten. Diese Schadenstypen sind nur ein Teil des möglichen Schadensspektrums, dem eine Zelle ausgesetzt ist. Ein weiteres Beispiel für häufig auftretende Schäden ist die bereits im vorherigen Kapitel erwähnte Alkylierung

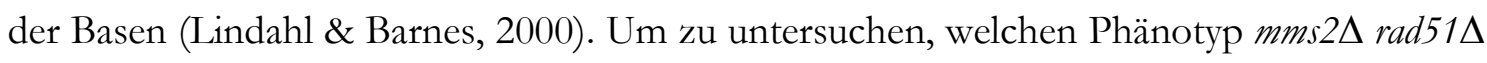




\section{ERGEBNISSE}

bei der Prozessierung von Alkylierungsschäden aufweist, wurde auch die Überlebensrate von mms $2 \Delta$ rad51 1 nach Inkubation mit MMS ermittelt. Dazu wurden die Zellen wie zuvor für die Inkubation mit 4-NQO beschrieben behandelt, wobei sie jedoch während der SPhase in entsprechenden Konzentrationen an MMS inkubiert wurden. Anschließend wurde das MMS durch Zugabe von Natriumthiosulfat ,inaktiviert“ und es wurden je zwei bis fünf unterschiedliche Verdünnungen ausplattiert. Das Ergebnis ist in Abb. 44 zu sehen.

Wie bereits während meiner Diplomarbeit, ist auch bei der Überlebensrate nach Inkubation

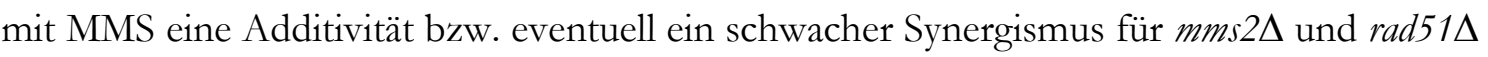
zu erkennen. Es scheint demnach zum einen tatsächlich so, dass die Umgehung von diversen DNA-Schäden in unterschiedlicher Form stattfindet. Zum anderen scheint Mms2 an mehr als einem Prozess beteiligt zu sein, da sich in Abhängigkeit von der Art der DNA-

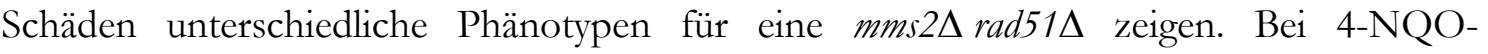
induzierten Schäden scheinen nur Rad51-abhängige Prozesse einzusetzen, an denen Mms2 beteiligt ist, was sich anhand der Epistasis zeigt. Dagegen scheinen bei MMS und UV Prozesse relevant zu sein, an denen Mms2 beteiligt ist, nicht aber Rad51, was sich in der Additivität zeigt.

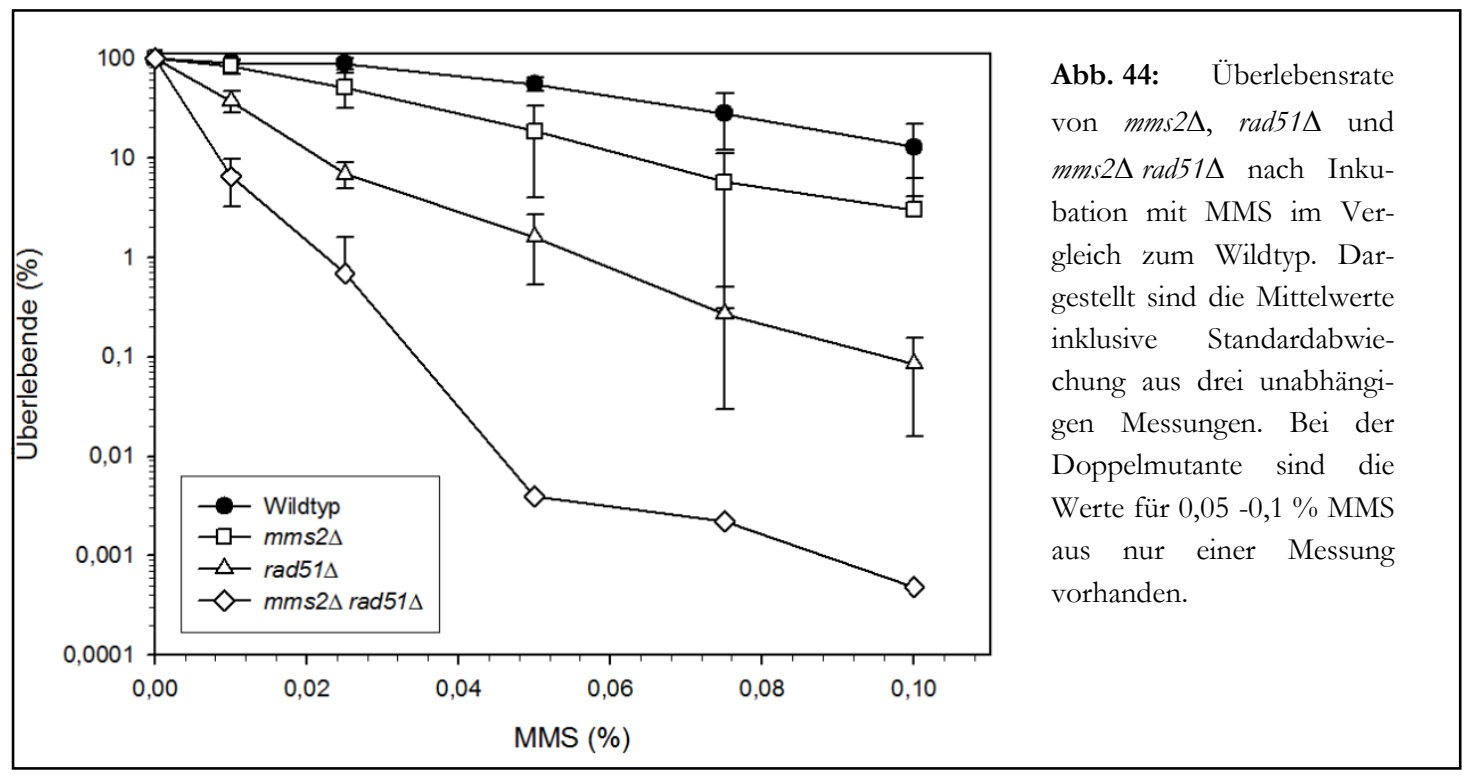

\section{Genetische Interaktion von $\mathrm{mph} 1 \Delta$ und $\mathrm{mms} 2 \Delta$}

Nach den bisherigen Daten scheint Mms2 zumindest in Bezug auf 4-NQO-induzierte DNA-Schäden an einem Prozess beteiligt zu sein, der Rad51-abhängig ist. Ein ebenfalls an diesem Prozess beteiligtes Protein ist Mph1, wie die im vorhergehenden Kapitel dargestellten Ergebnisse darlegen. Daher wurde als nächstes auch die Interaktion zwischen mph1 $\Delta$ und mms $2 \Delta$ anhand der Sensitivität gegen 4-NQO untersucht. Dazu wurde anhand eines drop-dilution-assays das Wachstum der Mutanten auf YPD-Platten mit unterschiedlichen Konzentrationen DNA-schädigender Agenzien verglichen. Eine Darstellung des Tests ist in Abb. $45 \mathrm{zu}$ finden. $m p h 1 \Delta$ zeigt hierbei in etwa die gleiche Sensitivität wie $m m s 2 \Delta$. Dagegen ist die Doppelmutante nicht wie rad51 $\Delta$ epistatisch, vielmehr liegt eine Additivität vor. Mph1 hat höchstwahrscheinlich eine Funktion bei der Prozessierung von D-Loops (siehe 114 | S e ite 
Ergebnisse, Seite $83 \mathrm{ff}$ ). Somit ist es sehr wahrscheinlich, dass Mms2 nicht an der Mph1abhängigen Prozessierung eines D-Loops beteiligt ist, sondern vielmehr einen alternativen oder zusätzlichen Einfluss auf die Prozessierung von DNA-Schäden via homologe Rekombination hat.

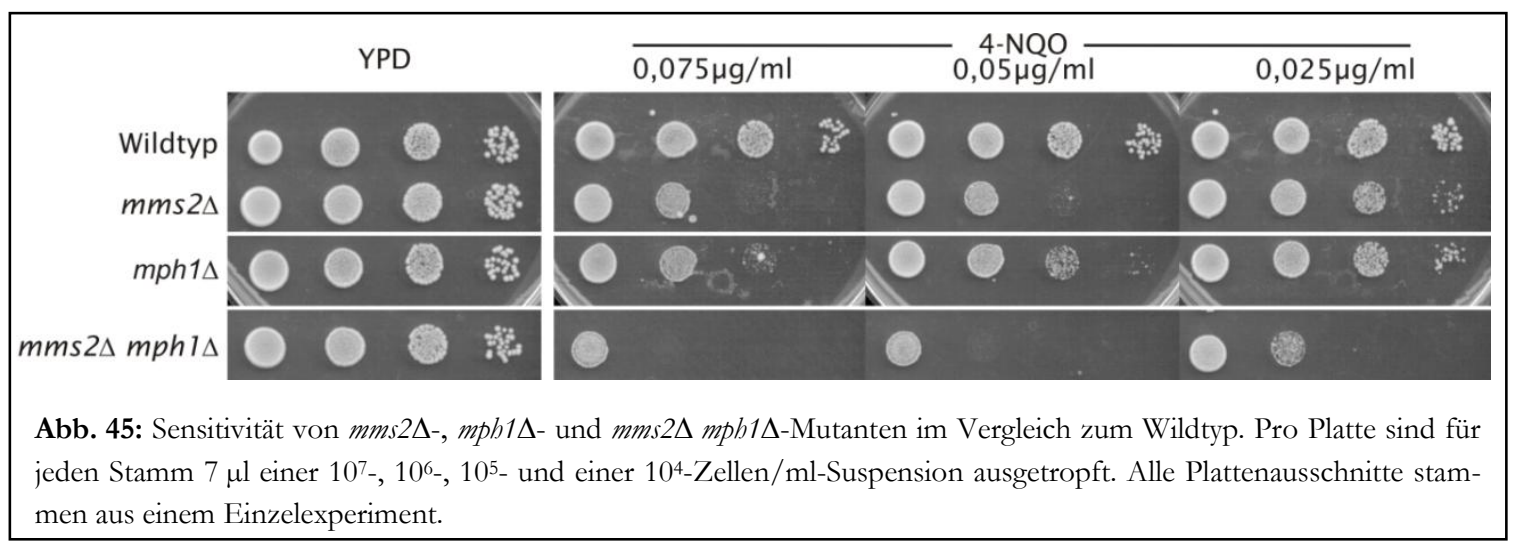

Messung der Verdopplungszeit von $\mathrm{mms} 2 \Delta \operatorname{rad} 51 \Delta$

Zusätzlich zur Messung der Sensitivität gegen DNA-schädigende Agenzien und der Messung der Überlebensrate nach Schadensinduktion sollte die Interaktion von mms $2 \Delta$ und rad51 $\Delta$ unter nicht induzierten Bedingungen untersucht werden. Dies geschah anhand der Messung der Verdopplungszeit der entsprechenden Mutanten im Vollmedium. Dazu wur-

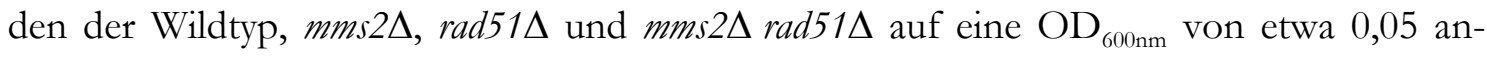
geimpft und über mehrere Stunden das Wachstum anhand der $\mathrm{OD}_{600 \mathrm{~nm}}$ festgehalten. Anhand der OD-Zunahme wurde anschließend die Verdopplungszeit der Stämme während der logarithmischen Phase errechnet. Die Wachstumskurven sowie die Regressionsgeraden zur Berechnung der Verdopplungszeiten eines Experiments sind in Abb. 46 zu sehen. Die Verdopplungszeiten sind in Tab. 8 angegeben. Bei allen drei Messungen lässt sich für mms $2 \Delta$ keine erkennbare Verlängerung der Verdopplungszeiten im Vergleich zum Wildtyp feststellen. rad51 $\Delta$ dagegen ist in zwei von drei Messungen deutlich langsamer bei der Verdopplung als der Wildtyp. In der dritten Messung unterscheidet sich rad51 $\Delta$ jedoch nicht wesentlich vom Wildtyp. Allerdings zeigt sich in dieser Messung für den Wildtyp eine 1,6bis 1,7-fache Verdopplungszeit verglichen mit den beiden vorhergehenden Messungen. Möglicherweise ist diese Varianz auf eine experimentelle Abweichung zurückzuführen (bspw. auf eine verringerte Temperatur) oder auf einen experimentellen Fehler (bspw. auf ein Vertauschen der Stämme). In beiden Fällen erscheint die dritte Messung jedoch sehr fragwürdig. In den ersten beiden Messungen zeigt sich für mms $2 \Delta$ rad51 $\Delta$ keine Veränderung gegenüber der rad51 $\Delta$-Einzelmutante. Da mms $2 \Delta$ aber keine Verlangsamung im Wachstum aufweist, lässt sich hierbei keine Aussage über eine Epistasis machen. Es lässt sich so nur feststellen, dass ein Defekt im MMS2 weder eine Auswirkungen auf die Verdopplungszeit einer rad51 $\Delta$-Mutante noch auf die Verdopplungszeit des Wildtyps zu haben scheint. 


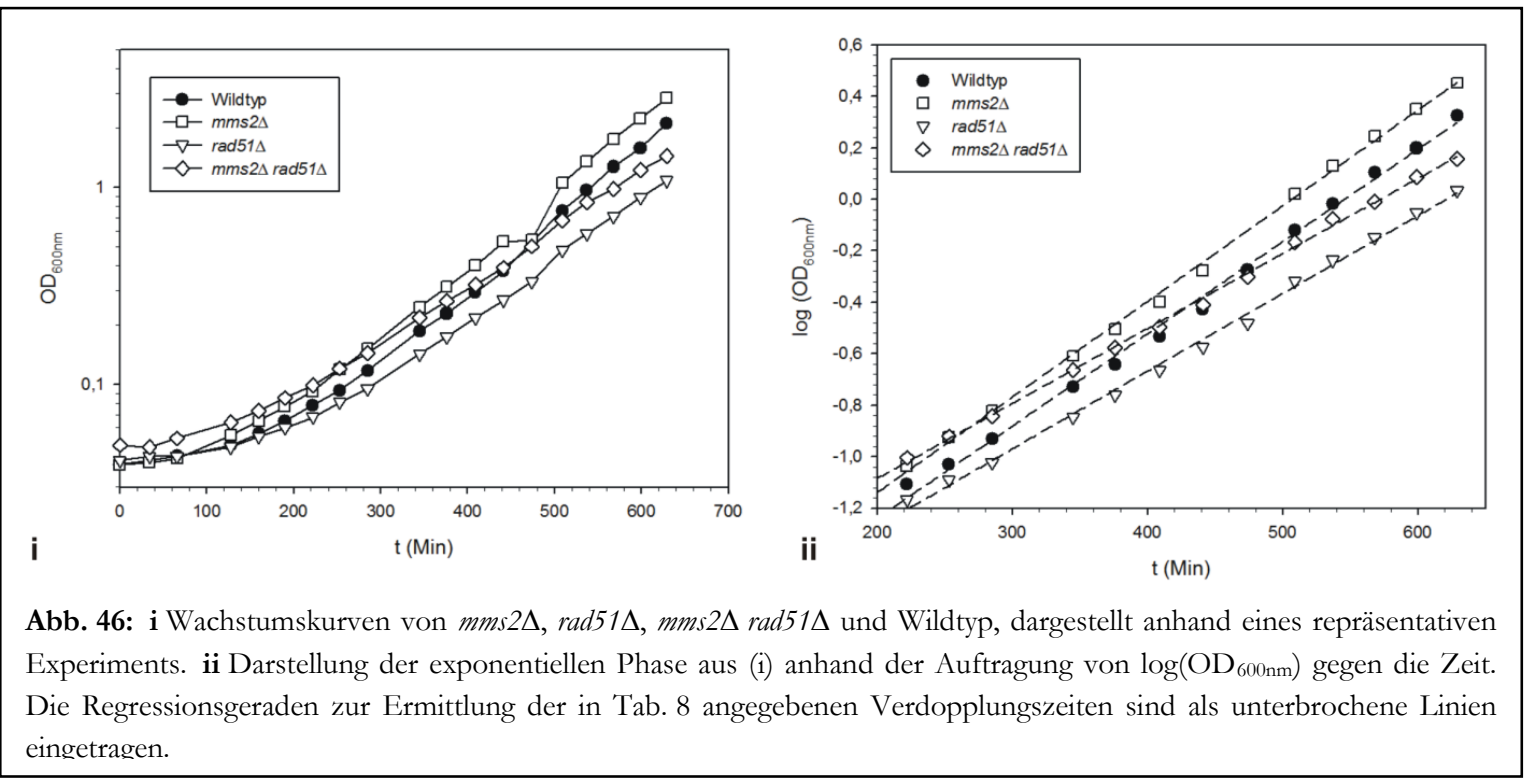

Tab. 8: Verdopplungszeiten von $m m s 2 \Delta$, rad51 $\Delta$ und mms $2 \Delta$ rad51 $\Delta$ im Vergleich zum Wildtyp.

\begin{tabular}{lcr}
\hline Stamm & $\begin{array}{c}\text { Steigung (a) der Regres- } \\
\text { sion }\end{array}$ & Verdopplungszeit (log2/a) \\
\hline \hline \multirow{2}{*}{ Wildtyp } & $3,58 \times 10^{-3} /$ Min. & 84 Min. \\
& $4,02 \times 10^{-3} /$ Min. & 75 Min. \\
& $2,29 \times 10^{-3} /$ Min. & 132 Min. \\
mms2 & $3,72 \times 10^{-3} /$ Min. & 81 Min. \\
& $3,83 \times 10^{-3} /$ Min. & 79 Min. \\
& $2,30 \times 10^{-3} /$ Min. & 131 Min. \\
rad51 & $3,02 \times 10^{-3} /$ Min. & 100 Min. \\
& $3,26 \times 10^{-3} /$ Min. & 92 Min. \\
& $2,28 \times 10^{-3} /$ Min. & 132 Min. \\
mms2 rad51 & $2,92 \times 10^{-3} /$ Min. & 103 Min. \\
& $3,07 \times 10^{-3} /$ Min. & 98 Min. \\
& $1,95 \times 10^{-3} /$ Min. & 154 Min. \\
\hline
\end{tabular}

Messung spontaner Mutationsraten von $\mathrm{mms} 2 \Delta \operatorname{rad} 51 \Delta$ und $\mathrm{mms} 2 \Delta \operatorname{rad} 52 \Delta$

Der spontane und induzierte Mutatorphänotyp einer mms2-Mutante, sowie deren Synergismus mit rev3 in Bezug auf die Sensitivität gegenüber DNA-schädigenden Agenzien machen es sehr wahrscheinlich, dass Mms2 in einem fehlerfreien Weg involviert ist. Darüber hinaus scheint nach den hier präsentierten Daten diese Funktion in einen HR-abhängigen sowie in einen HR-unabhängigen Prozess aufgeteilt zu sein. Um die genetische Interaktion zwischen HR und mms 2 genauer $\mathrm{zu}$ untersuchen, wurde die spontane Mutationsrate für mms $2 \Delta \operatorname{rad51\Delta }$ sowie mms $2 \Delta \operatorname{rad52\Delta }$ im CAN1-Vorwärtsmutationssystem gemessen. Zusätzlich wurde die Abhängigkeit der Phänotypen von Rev3 anhand einer mms $2 \Delta$ rev3 $\Delta$ - und

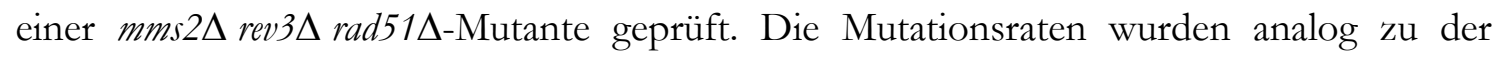
spontanen Reversionsrate mithilfe der Methode des Medians (Lea \& Coulson, 1948) erfasst. Die Anzahl an Mutanten wurde dabei durch Selektion auf L-Canavanin-Platten ermittelt. Für die hier präsentierten Daten wurde auf steril filtriertes und $\mathrm{pH}$-eingestelltes Me- 
dium zurückgegriffen, da durch Erhitzen des Mediums eine weite Bandbreite an potentiell mutagenen Stoffen entsteht (Kim et al., 1991). Durch filtrieren des Mediums kann die Entstehung dieser Substanzen umgangen werden. Die ermittelten Raten sind in Tab. 9 aufgeführt.

Tab. 9: Spontane Mutationsraten im CAN1-Vorwärtsmutationssystem, ermittelt nach Lea und Coulson, 1984. Die Nummer des jeweiligen Experiments wurde als hochgestellter Index angegeben. WT steht für Wildtyp, Mut. für Mutante.

\begin{tabular}{|c|c|c|c|c|c|}
\hline Stamm & Mutationsrate & Mut. / wT & Stamm & Mutationsrate & Mut. / wT \\
\hline Wildtyp & $\begin{array}{l}3,8 \times 10^{-7} \pm 5,3 \times 10^{-8} 1 \\
3,3 \times 10^{-7} \pm 5,0 \times 10^{-8} 2 \\
7,5 \times 10^{-7} \pm 1,1 \times 10^{-7} 3 \\
5,1 \times 10^{-7} \pm 7,3 \times 10^{-8} 4 \\
2,7 \times 10^{-7} \pm 3,8 \times 10^{-8} 5\end{array}$ & 1 & mms2 rev3 & $3,9 \times 10^{-7} \pm 5,7 \times 10^{-8}$ & $0,8^{1}$ \\
\hline$m m s 2$ & $\begin{array}{l}2,4 \times 10^{-6} \pm 2,8 \times 10^{-6} \\
2,3 \times 10^{-6} \pm 2,9 \times 10^{-7} \\
1,8 \times 10^{-6} \pm 2,2 \times 10^{-7} \\
2,1 \times 10^{-6} \pm 2,5 \times 10^{-7} \\
1,7 \times 10^{-6} \pm 1,9 \times 10^{-7}\end{array}$ & $\begin{array}{l}6,4^{1} \\
7,0^{2} \\
2,4^{3} \\
4,1^{4} \\
6,3^{5}\end{array}$ & $\begin{array}{l}\text { mms2 rev3 } \\
\text { rad51 }\end{array}$ & $7,4 \times 10^{-7} \pm 1,4 \times 10^{-7}$ & $1,5^{1}$ \\
\hline $\operatorname{rad51}$ & $\begin{array}{l}3,6 \times 10^{-6} \pm 4,1 \times 10^{-7} \\
2,9 \times 10^{-6} \pm 3,4 \times 10^{-7} \\
3,0 \times 10^{-6} \pm 3,6 \times 10^{-7} \\
3,0 \times 10^{-6} \pm 3,6 \times 10^{-7}\end{array}$ & $\begin{array}{l}9,5^{1} \\
8,7^{2} \\
4,0^{3} \\
5,9^{4}\end{array}$ & rad52 & $\begin{array}{l}2,9 \times 10^{-6} \pm 3,5 \times 10^{-7} \\
2,3 \times 10^{-6} \pm 2,9 \times 10^{-7} \\
3,3 \times 10^{-6} \pm 3,9 \times 10^{-7}\end{array}$ & $\begin{array}{c}7,6^{1} \\
4,5^{4} \\
12,3^{5}\end{array}$ \\
\hline mms2 rad51 & $\begin{array}{l}3,6 \times 10^{-6} \pm 4,3 \times 10^{-7} \\
2,9 \times 10^{-6} \pm 3,7 \times 10^{-7} \\
2,4 \times 10^{-6} \pm 3,1 \times 10^{-7} \\
3,1 \times 10^{-6} \pm 3,9 \times 10^{-7}\end{array}$ & $\begin{array}{l}9,5^{1} \\
8,9^{2} \\
3,2^{3} \\
6,1^{4}\end{array}$ & mms 2 rad52 & $\begin{array}{l}3,1 \times 10^{-6} \pm 3,8 \times 10^{-7} \\
2,5 \times 10^{-6} \pm 3,2 \times 10^{-7} \\
2,1 \times 10^{-6} \pm 2,6 \times 10^{-7}\end{array}$ & $\begin{array}{l}8,3^{1} \\
4,9^{4} \\
7,9^{5}\end{array}$ \\
\hline
\end{tabular}

Auffällig ist hierbei zunächst, dass die Raten für den Wildtyp in den Messungen 1, 2 und 5 sehr ähnliche Werte aufweisen, während in der dritten und in der vierten Messung höhere Werte auftreten (etwa zweimal so hoch). Dagegen weisen die betrachteten Mutanten eine solche deutliche Abweichung nicht auf, sondern zeigen in jeder der Messungen in etwa dieselbe Rate an spontanen Mutationen. Aus diesem Grund sind die berechneten Faktoren (Mutante/Wildtyp) in den Messungen 3 und 4 durchweg niedriger als in den Messungen 1,2 und 5. Auf die Auswertung der genetischen Interaktion zwischen den Mutanten hat dies jedoch vermutlich keinen Einfluss, da die Abweichung alle gemessenen Mutanten gleichermaßen betrifft.

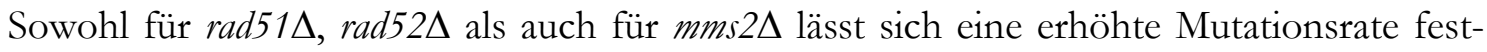
stellen, wobei durchgehend mms $2 \Delta$ ein geringerer Mutator zu sein scheint als rad51 $\Delta$ und rad52 $\Delta$. Durch zusätzliche Deletion von REV3 wird der Mutatorphänotyp jedoch wieder komplett aufgehoben, wie die mms $2 \Delta$ rev3 $\Delta$-Doppelmutante zeigt. Ohne Rev3 kann vermutlich keine Transläsionssynthese mehr stattfinden (siehe Seite 13). Demnach scheinen die in mms $2 \Delta$ vermehrt auftretenden spontanen Mutationen im Wesentlichen durch Transläsionssynthese zu entstehen. Zusätzlich zeigt rad51 $1 \Delta$ eine Epistasis gegenüber mms $2 \Delta$, wie es auch für die Sensitivität gegen 4-NQO festzustellen ist. Der Ausfall von Rad51 oder Rad52 führt vermutlich zu einer gehäuften Umgehung von DNA-Schäden durch Rev3abhängige Transläsionssynthese, was den Mutatorphänotyp in rad51 und rad52 erklären 


\section{ERGEBNISSE}

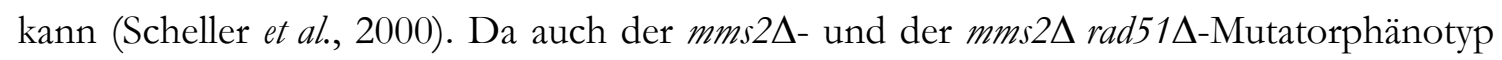
von Rev3 abhängig sind und gleichzeitig rad51 $\Delta$ epistatisch zu mms $2 \Delta$ ist, erscheint es plausibel, dass die gemessenen spontanen Mutationen in mms $2 \Delta$ durch den Ausfall von Rad51abhängigen Prozessen und somit durch den Ausfall der HR entstehen. Wäre der Ausfall anderer, nicht Rad51-abhängiger Prozesse der Grund für die Erhöhung der spontanen Mutationsrate, so wäre für den Mutatorphänotyp eine Subadditivität, eine Additivität oder ein Synergismus zu erwarten, jedoch keine Epistasis. Mms2 scheint demnach in einem Rad51abhängigen, fehlerfreien Prozess involviert zu sein. Gleichzeitig ist wie zuvor gezeigt rad51 $\Delta$ epistatisch zu mms $2 \Delta$ in Bezug auf die Sensitiviät gegen 4-NQO, während bei der Sensitivität gegen MMS und UV-Licht eine Additivität vorliegt. Dies macht es sehr wahrscheinlich, dass Mms2 in mehr als einem Prozess involviert ist und dass nur einer dieser Prozesse von Rad51 abhängig ist. In Bezug auf die Epistasis von rad51 zu mms2 $\Delta$ bei der spontanen Mutationsrate wäre es somit plausibel zu vermuten, dass es sich bei dem nicht Rad51-abhängigen Prozess möglicherweise um einen Mechanismus handelt, welcher nicht alternativ durch Transläsionssynthese ersetzt werden kann. Allerdings ist es ebenso plausibel, dass die spontanen Ereignisse, welche die Mutationen hervorrufen, ausschließlich Schäden darstellen, welche per se Rad51-abhängig prozessiert werden, wie es für 4-NQOinduzierte Schäden der Fall zu sein scheint. Um diese Frage zu klären, wäre die Messung MMS- oder UV-induzierter Mutationsfrequenzen notwendig, wurde jedoch im Rahmen dieser Arbeit nicht durchgeführt.

Auch für rad52 $\Delta$ deutet sich in zwei Messungen eine mögliche Epistasis von rad52 $\Delta$ an, in der dritten Messung dagegen zeigt sich eher eine Suppression des rad52 $\Delta$-Phänotyps durch $m m s 2 \Delta$. Dies unterstützt ebenfalls die Vermutung, dass die spontan entstehenden Mutationen in $m m s 2 \Delta$ auf den Ausfall der homologen Rekombination zurückzuführen sind.

Zusammengefasst machen die hier präsentierten Messungen zur Sensitivität von

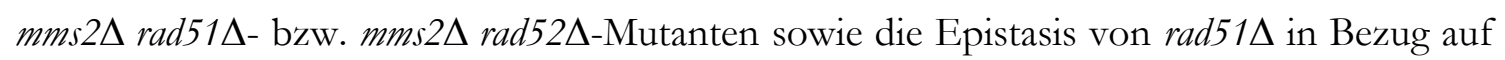
die spontane Mutationsrate es sehr wahrscheinlich, dass zumindest ein Teil der fehlerfreien PRR über homologe Rekombination abläuft. Gleichzeitig scheinen jedoch noch ein oder mehrere Prozesse involviert zu sein, welche nicht Rad51-abhängig sind und je nach Schadensart mehr oder weniger stark relevant zu sein scheinen.

\section{Untersuchungen zur Beteiligung der Photolyase (Phr1) an der fehlerfreien PRR}

Neben der Umgehung eines DNA-Schadens über homologen Rekombination oder fork regression kommt für die Aufhebung eines Replikationsarrests auch eine direkte Reversion des Schadens in Frage. Da hierfür weder ein alternatives template noch ein Gegenstrang notwendig sind, kann eine solche Schadensreversion prinzipiell auch in den Einzelsträngen während der Replikation stattfinden. Durch die Reversion wird der Schaden aus dem template entfernt und ein Replikationsarrest somit aufgehoben. Da mms $2 \Delta$ und rad51 $1 \Delta$ bei UV-

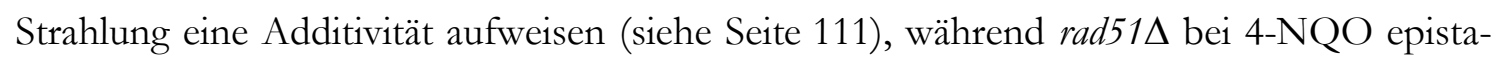


tisch zu mms $2 \Delta$ ist, kam die Vermutung auf, dass Mms2 einen Einfluss auf die direkte Reversion von UV-induzierten DNA-Schäden haben könnte. Eine Möglichkeit der direkten Schadensreversion, welche speziell für UV relevant ist, ist die direkte Reversion der Cyclobutanpyrimidindimere durch die Photolyase. Dieses Enzym wird in Hefe durch das Gen PHR1 codiert und ist in der Lage, den Cyclobutanring zwischen den Pyrimidinen durch Nutzung sichtbaren Lichts aufzuspalten (Green \& MacQuillan, 1980; Heelis et al., 1993). Um zu überprüfen, ob Mms2 einen Einfluss auf die Funktion von Phr1 hat, wurde die genetische Interaktion von mms $2 \Delta$ und $p h r 1 \Delta$ in Bezug auf die Sensitivität gegen verschiedene DNA-schädigende Agenzien getestet (UV, MMS, 4-NQO und Camptothecin). Während für die Bestrahlung mit UV-Licht keine Veränderung des mms2 $\Delta$-Phänotyps festzustellen war, zeigte sich interessanterweise ein Synergismus zwischen mms $2 \Delta$ und $p h r 1 \Delta$ bei der Sensitivität gegen 4-NQO und MMS (Daten nicht gezeigt). Da durch Inkubation mit 4NQO oder MMS keine Cyclobutanringe zwischen Pyrimidinen entstehen, welche von Phr1 aufgelöst werden könnten, erscheint solch ein sensitivierender Effekt durch eine phr1 $\Delta$ Deletion sehr fragwürdig. Daher wurde zunächst versucht, den Phänotyp mithilfe eines Wildtyp-PHR1-Allels zu komplementieren. Dazu wurde das Wildtyp-PHR1-Gen per PCR wie in „Methoden“ beschrieben amplifiziert und in den Vektor YIplac211 kloniert. Mit dem so erhaltenen „YIplac211 PHR1 flength“ wurden eine phr1 $\Delta m m s 2 \Delta$-, sowie eine phr1 $\Delta$-Mutante transformiert und ausgewählte Einzelklone auf ihre Sensitivität gegen 4NQO geprüft. Wie in Abb. $47 \mathrm{i}$ zu sehen ist, konnte das Plasmid jedoch die phr1 $\Delta$-Deletion nicht in Bezug auf den synergistischen Phänotyp komplementieren. Daher wurde zusätzlich versucht herauszufinden, ob der Phänotyp auf einer Hintergrundmutation beruht. Dazu wurde die phr1 $m$ ms $2 \Delta$-Mutante mit dem Wildtyp gekreuzt und drei Zygoten mithilfe eines Mikromanipulators isoliert. Die so erhaltenen Diplonten wurden auf Präsporulationsmedium angezogen und anschließend auf Sporulationsmedium transferiert. Die entstandenen Tetraden wurden dissektiert und insgesamt acht Doppelmutanten selektiert. Anschließend wurde die 4-NQO-Sensitivität dieser acht Segregaten im Vergleich zur ursprünglichen phr1 $1 \Delta$ ms $2 \Delta$-Mutante ermittelt. Das Ergebnis ist in Abb. 47 ii zu sehen.

Wildtyp
phrl




\section{ERGEBNISSE}

Vier von acht Segregaten zeigen eine erhöhte Sensitivität gegenüber der mms2 $\Delta$-Mutante, wie es auch zuvor für die Doppelmutante festgestellt werden konnte. Dagegen zeigen die anderen vier Segregate eine zu der mms $2 \Delta$-Einzelmutante vergleichbare Sensitivität gegen 4NQO. Da aus jeder Zygote zwei unterschiedliche Phänotypen für mms $2 \Delta p h r 1 \Delta$ segregieren, ist eine zufällige Hintergrundmutation in einer einzelnen Zygote als Quelle der unterschiedlichen Phänotypen gleichzeitig sehr unwahrscheinlich. Zusammengenommen sprechen die nicht mögliche Komplementation sowie die Segregation unterschiedlicher Phänotypen stark für eine Hintergrundmutation in der phr1 $\Delta$-Mutante, welche zu einem verstärkten mms2 $\Delta$-Phänotyp führt.

Insgesamt machen es die Daten der phr1 $\Delta$-Mutanten sehr unwahrscheinlich, dass Phr1 ein Bestandteil der Mms2-abhängigen Prozesse ist. Vielmehr scheint es, als wären die beobachteten Phänotypen in den $p h r 1$-Stämmen auf eine Hintergrundmutation zurückzuführen, welche synergistisch mit $m m s 2 \Delta$ ist.

\section{Untersuchungen zur Interaktion zwischen Mms2, homologer Rekombination und Transläsionssynthese}

\section{Untersuchungen $2 u \operatorname{mms} 2 \Delta \operatorname{rev} 3 \Delta \operatorname{rad} 51 \Delta$}

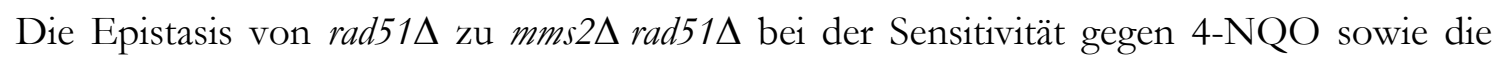
gleichzeitige Epistasis von rad51 $\Delta$ bei der spontanen Mutationsrate weisen darauf hin, dass Mms2 eine Funktion in einem fehlerfreien Prozess hat, welche Rad51-abhängig ist. Darüber hinaus macht es die Additivität bei MMS und UV-Bestrahlung sehr wahrscheinlich, dass Mms2 zusätzlich noch an einem weiteren Rad51-unabhängigen Prozess beteiligt ist. Um zusätzlich den Einfluss der Transläsionssynthese auf den Phänotyp von mms $2 \Delta$ rad51 $\Delta$ $\mathrm{zu}$ untersuchen, wurde die Sensitivität einer mms $2 \Delta \operatorname{rad} 51 \Delta \operatorname{rev} 3 \Delta$-Mutante gegen MMS, Camptothecin, 4-NQO und UV-Bestrahlung ermittelt. Wie für die anderen Agenzien wurde hierbei auch für die Messung der UV-Sensitivität ein drop-dilution-assay durchgeführt. Die Testergebnisse sind in Abb. 48 zu sehen.

Bei Camptothecin lässt sich weder für rev3 $\Delta$ noch für $m m s 2 \Delta$ rev3 $\Delta$ eine Sensitivität feststellen. Allerdings scheint die rev3 $\Delta$-Deletion die Sensitivität der rad51 $\Delta$-Mutante leicht zu verstärken. Gleichzeitig lässt sich eine leichte Suppression des rad51 - sowie des rev3 3 rad51 1 -Phänotyps durch mms $2 \Delta$ erkennen. Allerdings ist bereits auf der Kontrollplat-

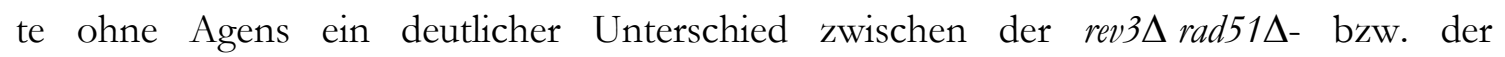

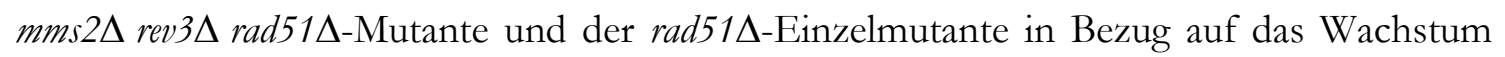
zu erkennen. Es wäre daher möglich, dass zumindest die leichten Unterschiede zwischen

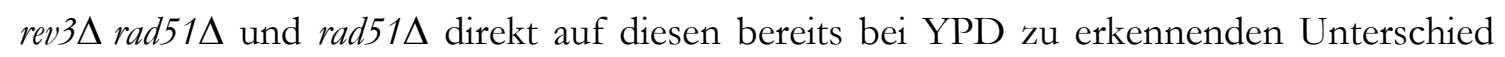
zurückzuführen ist. Allerdings lässt sich die Suppression von rad51 $\Delta$ durch mms $2 \Delta$ so nicht erklären und scheint daher tatsächlich ein auf der Deletion von MMS2 beruhender Phänotyp zu sein. 
Für 4-NQO zeigt sich, wie auch in den vorherigen Messungen, eine deutliche Sensitivität für mms $2 \Delta$ und eine noch stärkere Sensitivität für rad51 $\Delta$. Zusätzlich sind ebenfalls die bereits beobachtete Epistatis von rad51 $\Delta$ gegenüber mms $2 \Delta$ sowie der Synergismus zwischen $m m s 2 \Delta$ und rev3 $\Delta$ feststellbar. Darüber hinaus lässt sich für rev3 $\Delta$ rad51 $\Delta$ auch eine Epistasis gegenüber $m m s 2 \Delta$ vermuten. Allerdings ist rev3 $\Delta$ rad51 $\Delta$ bereits bei $0,005 \mu \mathrm{g} / \mathrm{ml} 4-\mathrm{NQO}$ so sensitiv, dass es schwer abzuschätzen ist, ob ein doch vorhandener schwacher Unterschied hier nur nicht erkennbar ist. Da jedoch bei 4-NQO anscheinend nur ein Rad51-abhängiger Weg durch die Deletion von MMS2 beeinflusst wird, erscheint eine Epistasis als wahrscheinlich: In rev3 $\Delta$ rad51 $\Delta$ ist der Rad51-abhängige Prozess bereits ausgeschaltet, weshalb die zusätzliche mms2 $\Delta$-Deletion keinen weiteren Einfluss auf die Sensitivität hat.

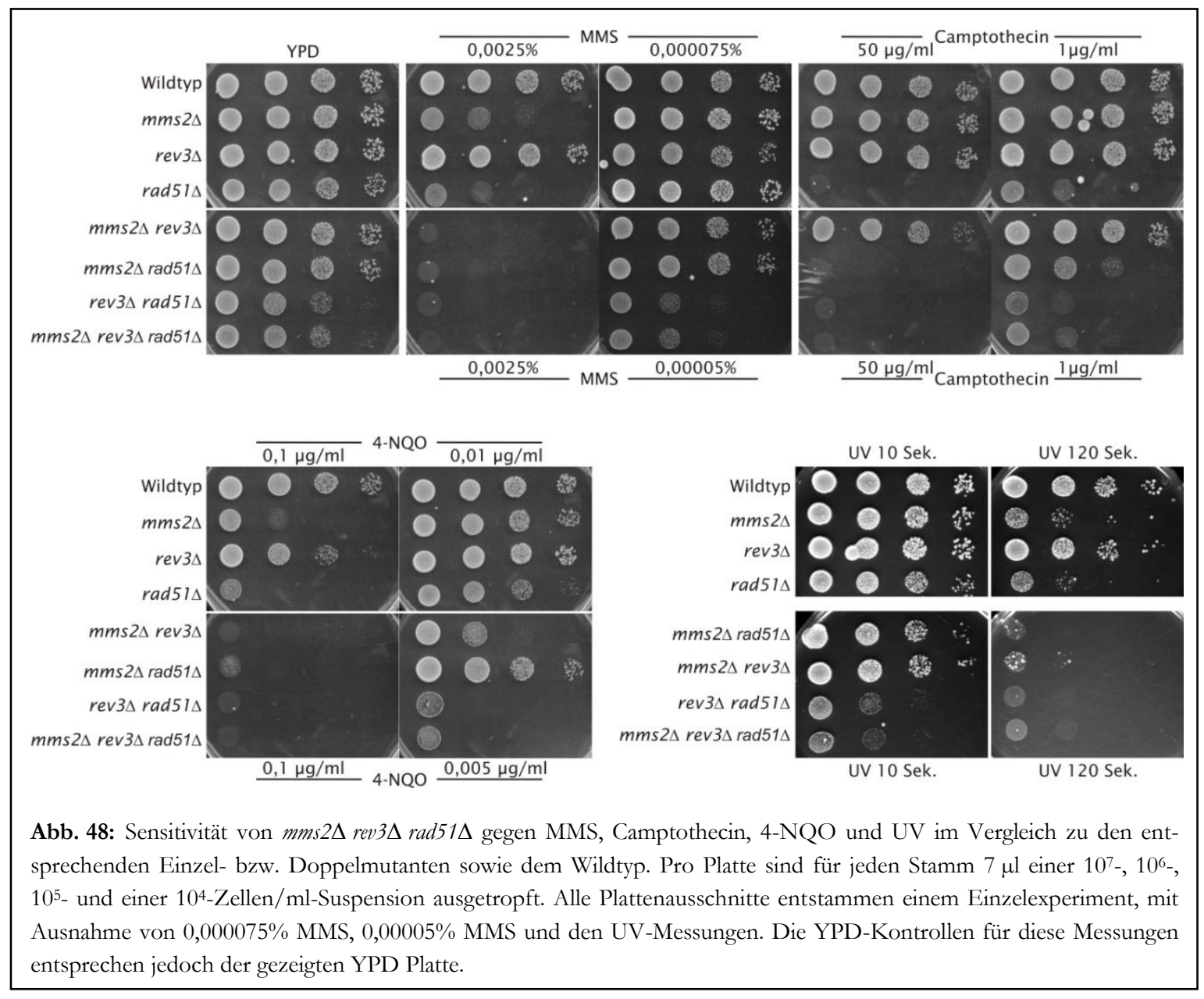

Auch für MMS zeigen sich der zuvor bereits festgestellte Synergismus zwischen mms $2 \Delta$ und rev3 $3 \Delta$ sowie die Additivität von mms $2 \Delta$ und $\operatorname{rad} 51 \Delta$. Interessanterweise ist dagegen die Tripelmutante mms $2 \Delta \operatorname{rev} 3 \Delta \operatorname{rad} 51 \Delta$ genauso sensitiv wie die rev3 $\Delta$ rad51 $\Delta$-Mutante. Es scheint daher sehr wahrscheinlich, dass rev3 $\Delta$ rad51 $\Delta$ hierbei epistatisch zu mms $2 \Delta$ ist. Demnach sind die nicht Rad51-abhängigen Prozesse, in die Mms2 involviert ist, zumindest in Bezug auf MMS-induzierte DNA-Schäden anscheinend von Rev3 abhängig. 


\section{ERGEBNISSE}

Ein ähnliches Bild zeigt sich für die Messung mit UV-Bestrahlung. Jedoch ist die Sensitivi-

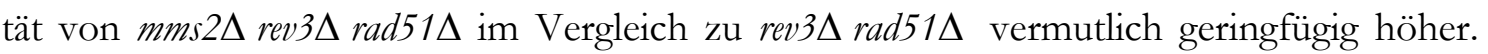
Um diesen minimalen Unterschied quantitativ nachzuprüfen, wurde von rev3 $\Delta$ rad51 $\Delta$ und mms $2 \Delta \operatorname{rev} 3 \Delta \operatorname{rad} 51 \Delta$ die Überlebensrate nach UV-Bestrahlung gemessen. Wie sich in Abb. 49 erkennen lässt, ist die Doppelmutante tatsächlich weniger sensitiv gegenüber der Bestrahlung mit UV-Licht, als die Tripelmutante. Jedoch scheint keine klare Additivität vorzuliegen, wie der Vergleich der $\lambda$-Werte mit einer hypothetischen Additionskurve zeigt (Abb. 49 ii). Vielmehr sind $m m s 2 \Delta$ und rev3 3 rad $51 \Delta$ subadditiv.
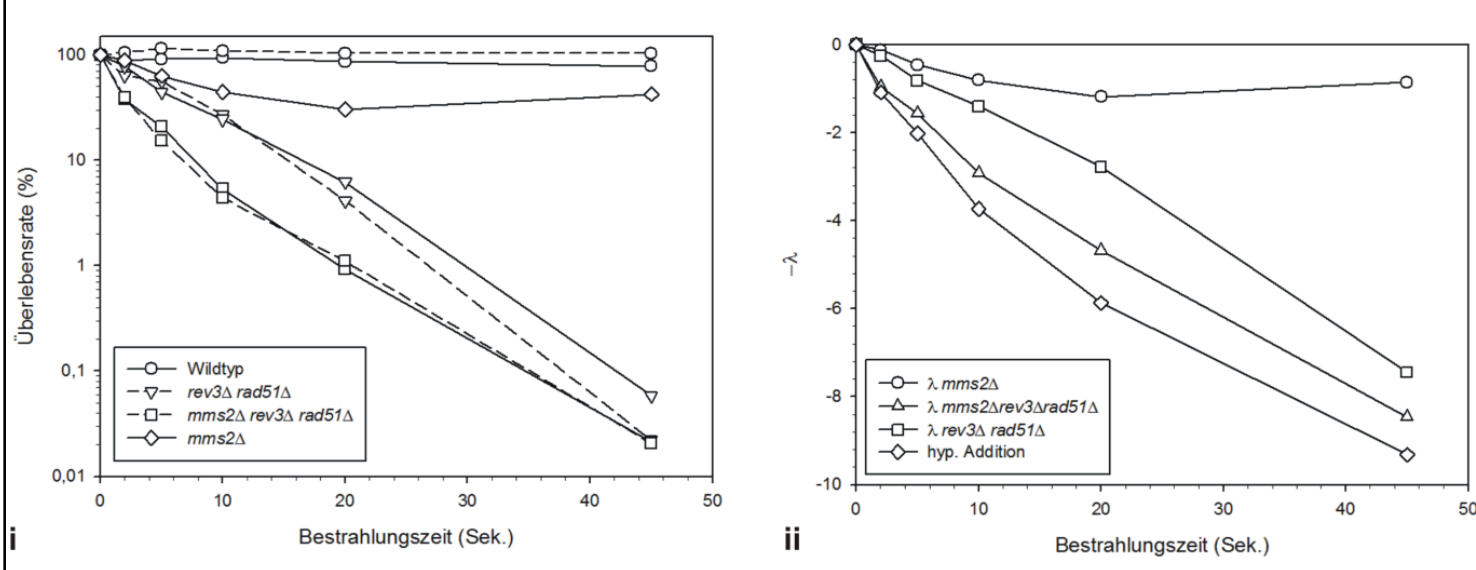

Abb. 49: i Überlebensrate von $m m s 2 \Delta \operatorname{rev} 3 \Delta \operatorname{rad} 1 \Delta$ und $\operatorname{rev} 3 \Delta \operatorname{rad} 51 \Delta$ nach UV-Bestrahlung. Dargestellt sind Daten aus zwei unabhängigen Messungen. Die zusammengehörigen Daten aus einer Messung sind durch eine gemeinsame Linienart hervorgehoben. Die Messung für mms $2 \Delta$ entstammt einer dritten unabhängigen Messung. ii Vergleich der $\lambda$-Werte von $m m s 2 \Delta$, mms $2 \Delta \operatorname{rev} 3 \Delta$ und mms $2 \Delta \operatorname{rev} 3 \Delta \operatorname{rad} 51 \Delta$ mit der hypothetischen Additionskurve von $m m s 2 \Delta$ und $\operatorname{rev} 3 \Delta \operatorname{rad} 51 \Delta . \lambda_{\mathrm{x}}=-\ln \left(\right.$ Überlebensrate $\left._{\mathrm{x}}\right)$. Zur besseren Vergleichbarkeit mit (i) wurden die negativen $\lambda$-Werte aufgetragen.

Mms2 scheint nach diesen Daten neben einer Beteiligung bei der homologen Rekombination auch eine Funktion bei Rev3-abhängigen Prozessen aufzuweisen, da das zusätzliche Entfernen von mms $2 \Delta$ in einer rev3 $\Delta$ rad51 $\Delta$-Mutante keinen Effekt auf die Sensitivität gegen MMS zu haben scheint. Allerdings scheint diese Funktion nur bedingt einen Einfluss auf die Umgehung oder Reparatur von UV-induzierten DNA-Schäden zu haben, da hier die rev3 $\Delta$-Deletion eine leichte Verstärkung des Phänotyps hervorruft.

\section{Untersuchungen $\approx u \operatorname{mms} 2 \Delta \operatorname{rad} 30 \Delta \operatorname{rad} 51 \Delta$}

Neben der Sensitivität von mms $2 \Delta \operatorname{rev} 3 \Delta \operatorname{rad5} 1 \Delta$ wurde auch die Sensitivität einer mms $2 \Delta$ rad30 $\mathrm{rad} 51 \Delta$-Mutante gegenüber UV-Bestrahlung anhand eines drop-dilution-assays gemessen. Das Ergebnis ist in Abb. 50 zu sehen.

Für keine der betrachteten Einzelmutanten kann bei den gemessenen Bestrahlungszeiten eine Sensitivität festgestellt werden. Für mms $2 \Delta \operatorname{rad} 51 \Delta$, $\operatorname{rad} 30 \Delta \operatorname{rad} 51 \Delta$ und $m m s 2 \Delta \operatorname{rad} 30 \Delta$ lässt sich dagegen eine Sensitivität nach 60 Sek. UV-Bestrahlung erkennen. Die

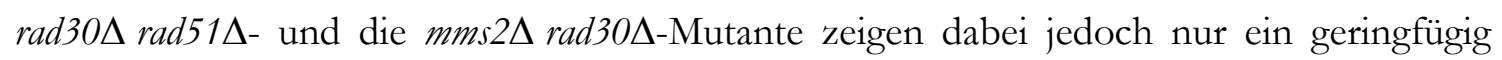
schlechteres Wachstum als die Einzelmutanten. mms $2 \Delta$ rad51 $\Delta$ ist dagegen deutlich sensiti- 
ver. Interessanterweise unterscheidet sich dies von den Verhältnissen bei der Sensitivität von mms $2 \Delta \operatorname{rev} 3 \Delta \mathrm{rad} 51 \Delta$ gegen UV. Dabei weist von den Doppelmutanten die

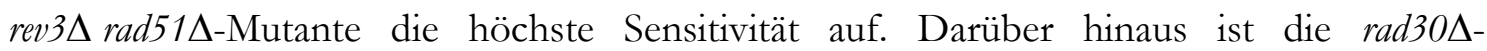
Tripelmutante deutlich sensitiver als die drei Doppelmutanten, was ebenfalls bei der rev $3 \Delta$ Tripelmutante nicht der Fall ist. Mms2 ist demnach sowohl synergistisch mit rad51 $\Delta$ als auch mit rad30 $\Delta$ und hat keinen Einfluss auf die Rad30-abhängige Umgehung von UVinduzierten Schäden. Vielmehr scheint Rad30 einen alternativen Weg darzustellen, dessen zusätzlicher Ausfall die Sensitivität noch steigert. Diese Daten unterstützt die Vermutung, dass Mms2 zumindest teilweise an einer Rev3-abhängigen Umgehung von UV-Schäden

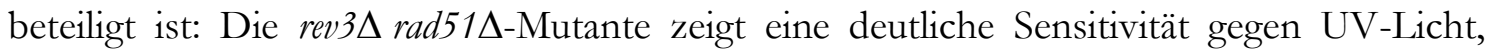
während $\mathrm{rad} 30 \Delta \mathrm{rad51 \Delta}$ nur schwach sensitiv ist (vergleiche Abb. 48 und Abb. 50). Gleichzeitig zeigt die zusätzliche Deletion von $M M S 2$ kaum eine Veränderung in rev3 $\operatorname{rad} 51 \Delta$, hat dafür aber einen starken Einfluss auf die Sensitivität von rad30 $\mathrm{rad} 51 \Delta$. Eine sehr plausible Erklärung hierfür ist, dass die Funktion von Rev3 bei der Umgehung von UVSchäden wichtiger für das Überleben einer Zelle ist als die von Rad30 und dass diese Funktion teilweise Mms2 benötigt. In der Tripelmutante mms $2 \Delta \operatorname{rad} 30 \Delta \operatorname{rad} 51 \Delta$ fällt somit zusätzlich der Mms2-abhängige Teil der Rev3-Funktion weg, was zu dem festgestellten Synergismus führt. In der mms $2 \Delta \operatorname{rev} 3 \Delta$ rad51 $1 \Delta$-Mutante dagegen ist dieser Teil bereits durch die Deletion von REV3 ausgeschaltet und hat deshalb keinen Einfluss mehr auf die Sensitivität. Allerdings scheint Mms2 zusätzlich noch einen Einfluss auf andere anhand dieser Daten nicht weiter einzugrenzende Prozesse zu haben, da rev3 $\Delta$ rad51 $\Delta$ nicht epistatisch zu $m m s 2 \Delta$ ist, sondern diese Mutationen subadditiv sind.

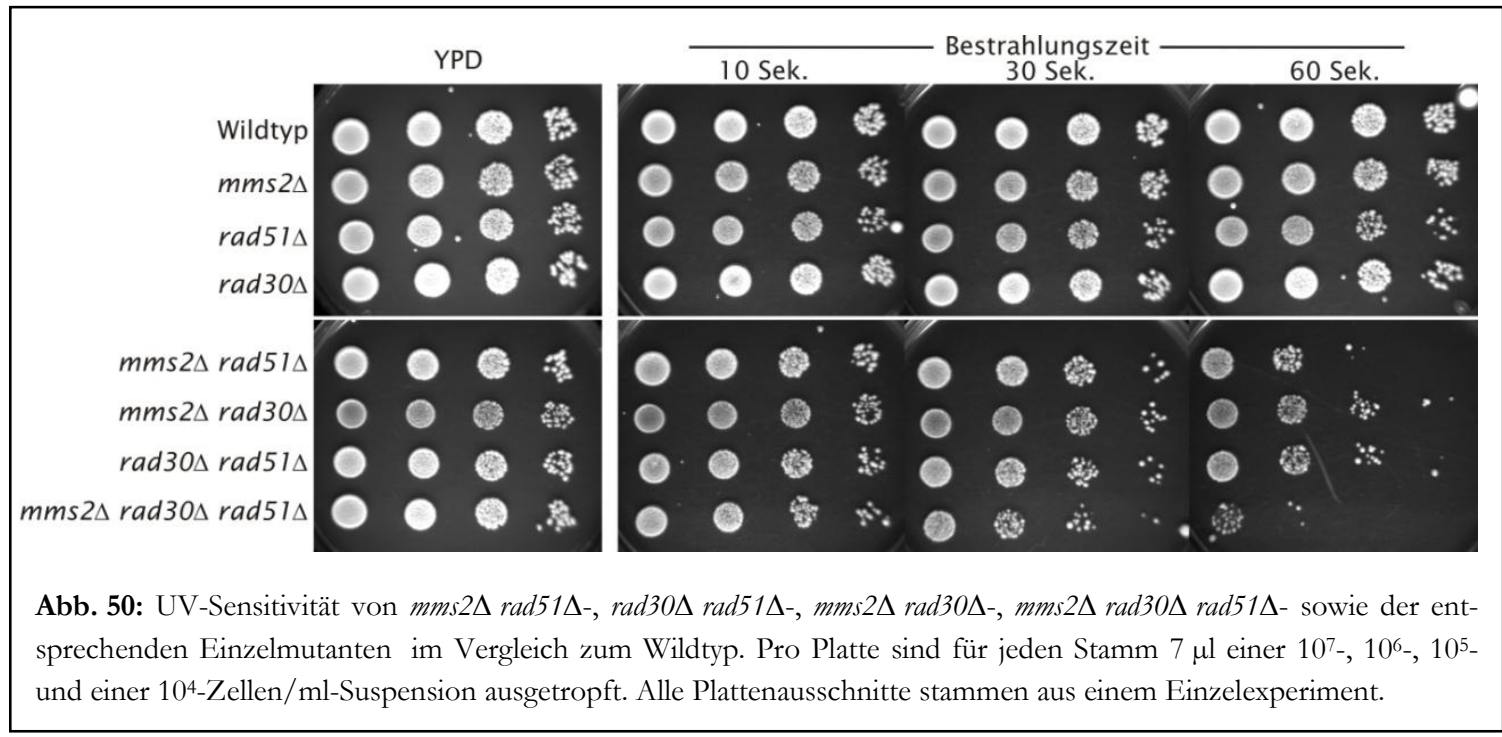

\section{Untersuchungen ₹u mms $2 \Delta \operatorname{rev} 3 \Delta \operatorname{mph} 1 \Delta$}

Wie bereits zuvor erwähnt bzw. dargelegt, ist auch Mph1 höchstwahrscheinlich an der Umgehung von DNA-Schäden durch homologe Rekombination beteiligt. Ebenfalls wurde die Interaktion von $m p h 1 \Delta$ mit mms $2 \Delta$ bereits gemessen. Für einen weiteren Einblick in die Funktion von Mms2 in Bezug auf Mph1 einerseits und Transläsionssynthese andererseits 


\section{ERGEBNISSE}

wurde zusätzlich die Sensitivität einer mms2 $\operatorname{rev3\Delta } m p h 1 \Delta$-Mutante gegen 4-NQO im Vergleich zu den entsprechenden Einzel- und Doppelmutanten gemessen. Das Ergebnis ist in Abb. $51 \mathrm{zu}$ sehen.

Die bereits für die Doppelmutante mms2 $\Delta m p h 1 \Delta$ festgestellte Additivität spiegelt sich hierbei auch in der Sensitivität der mms $2 \Delta m p h 1 \Delta$ rev3 $\Delta$-Tripelmutante wieder. Am wahrscheinlichsten ist es, dass die Additivität zwischen mms $2 \Delta$ und $m p h 1 \Delta$ auf einer voneinander unabhängigen Funktion beider Genprodukte bei der homologen Rekombination beruht. In diesem Fall wäre auch für die Trippelmutante im Vergleich zu der hier festgestellten eine noch größere Verstärkung der Sensitivität zu erwarten. Darüber hinaus ist die rev3 $\Delta$ mph1 $\Delta$ Doppelmutante interessanterweise weniger sensitiv als mms $2 \Delta m p h 1 \Delta$ und mms $2 \Delta$ rev $3 \Delta$, obwohl mph1 $\Delta$ und $m m s 2 \Delta$ in etwa die gleiche Sensitivität aufweisen. Man mag aufgrund dessen vermuten, dass der Ausfall von Mms2 unter bestimmten Bedingungen ein größeres Problem darstellt als der Ausfall von Mph1, allerdings mag es auch ein spezieller Fall bei der Sensitivität gegen 4-NQO sein. Zumindest ist eine Interpretation dieses Phänomens nur sehr spekulativ möglich.

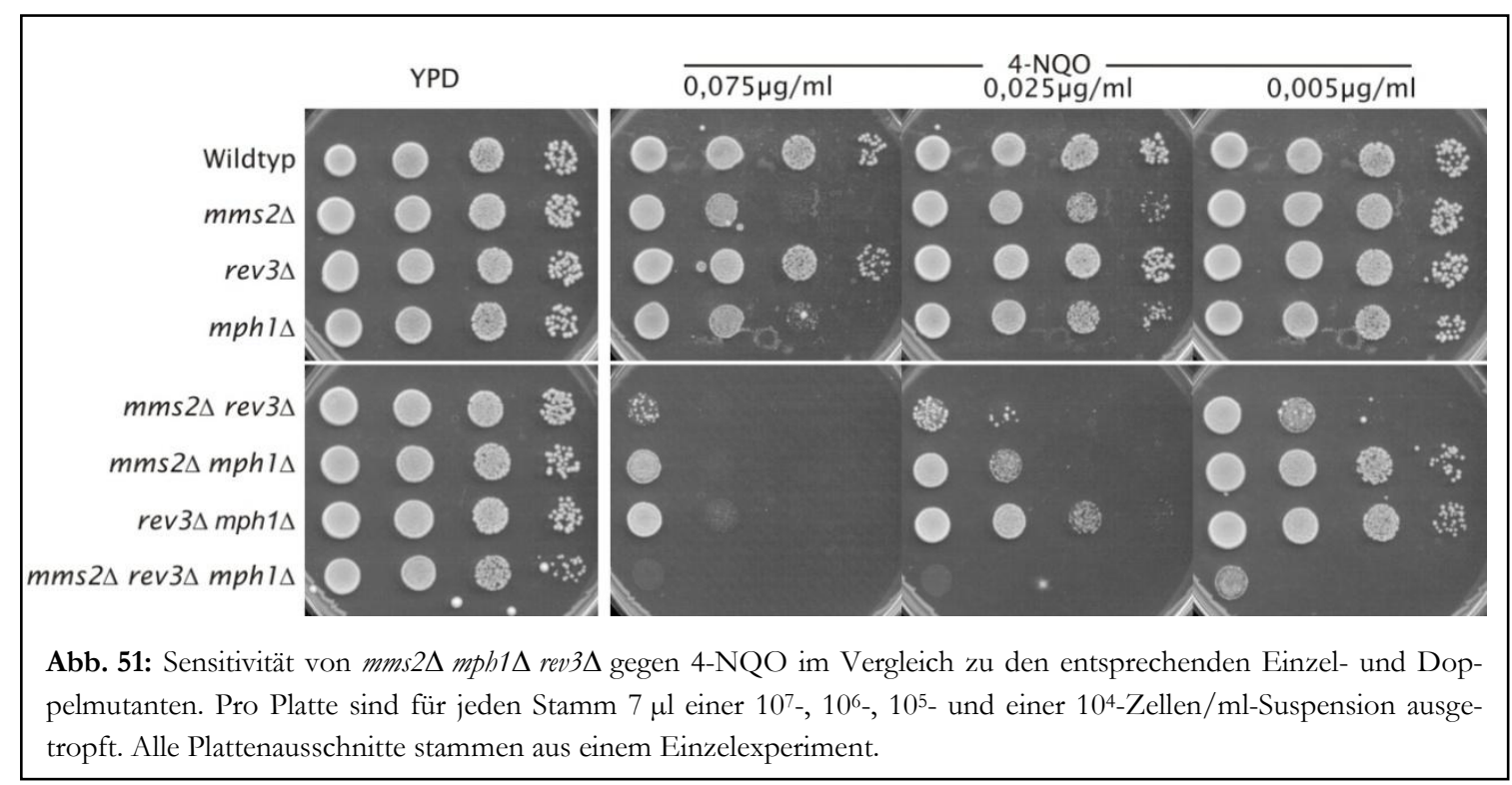

Unter Betrachtung aller hier präsentierten Daten lässt sich vermuten, dass die Polyubiquitinierung von PCNA durch Mms2/Ubc13 in irgendeiner Form die homologe Rekombination beeinflusst. Darüber hinaus machen die hier präsentierten Daten es wahrscheinlich, dass die Polyubiquitinierung zusätzlich einen Effekt auf Rev3-abhängige Prozesse hat, sowie auf einen oder mehrere nicht weiter einzugrenzende Prozesse. 


\section{DISKUSSION}

\section{UNTERSUCHUNG VON SCHWESTERCHROMATID-INTERAKTIONEN ANHAND DES KANKANMX4-MODULS}

Sowohl bei der Reparatur von Strangbrüchen als auch bei der fehlerfreien Umgehung von replikationsarretierenden DNA-Schäden ist eine Schwesterchromatid-Interaktion notwendig, um die benötigte Information aus einer alternativen Quelle zu rekonstruieren. Für die Analyse dieser Mechanismen und die Identifikation der an ihnen beteiligten Proteine ist daher ein experimentelles System von Nutzen, mit dem die Interaktion mit dem Schwesterchromatid gemessen werden kann. Da Schwesterchromatiden jedoch sequenzidentisch sind, ist die Messung einer solchen Interaktion nicht trivial. Es muss ein System genutzt werden, welches bei der Interaktion die Entstehung eines messbaren Fehlers ermöglicht. Zwei in der Literatur etablierte Module zur Messung solcher Interaktionen sind das his3$\Delta 5$ ' / his3- $\Delta$ 3'-Modul von Fasullo und Davis (Fasullo \& Davis, 1987) und das ade3$\Delta 5$ ' URA3/ade3- $\Delta 3$ '-Modul von Kadyk und Hartwell (Kadyk \& Hartwell, 1993). Eine schematische Darstellung der Module ist in Abb. $52 \mathrm{zu}$ sehen. Beide Systeme weisen dieselbe Grundstruktur auf: Das Gen für einen Prototrophiemarker wurde am 5'-Ende verkürzt, wodurch keine Prototrophie mehr vermittelt wird. Hinter diesen 5'-verkürzten Genabschnitt wurde anschließend ein am 3'-Ende verkürzter Abschnitt desselben Gens kloniert, wobei sich ein Teil der Gensequenz in beiden Fragmenten wiederholt (in Abb. 52 als dunkelgraue Fläche hervorgehoben). Zwischen beide Abschnitte wurde zusätzlich ein nicht codierender Abschnitt (Fasullo und Davis) bzw. ein funktionsfähiges URA3 (Kadyk und Hartwell) kloniert. Durch Rekombination zwischen den sich wiederholenden Sequenzen kann ein funktionsfähiges $A D E 3$ bzw. HIS3 entstehen (siehe Seite 86, Abb. 23 A).

Das in dieser Arbeit verwendete KanKanMX4-Modul weist einen vollständig zusammenhängenden ORF auf, welcher jedoch durch die direkte Duplikation eines internen Abschnitts im Leseraster verschoben ist und damit keine G418-Resistenz mehr vermitteln kann. Auch dieses Modul kann durch Rekombination mit dem Schwesterchromatid zu einem funktionsfähigen Gen revertiert werden (siehe Seite 68, Abb. 13 und Seite 86, Abb. 23 B). Durch den ungleichen Aufbau der Module lassen sich anhand der drei Systeme jedoch unterschiedliche Ereignisse erfassen.

\section{Das KanKanMX4-Modul kann SSA-, SDSA- und DBSR-Ereignisse de- tektieren}

Sowohl mit dem his3- $\Delta 5^{\prime} /$ his 3- $\Delta 3$ '- als auch mit dem ade3- $\Delta 5$ '/URA3/ade3- $\Delta 3$ '-Modul lassen sich vermutlich vorwiegend cross over messen, da für eine Genkonversion die Synthese am Schwesterchromatid über das komplette Modul hinaus notwendig ist, was wahrscheinlich eher selten geschieht. Ein einfaches cross over benötigt dagegen nur die Verlängerung über einen kurzen Bereich am Schwesterchromatid, um eine Reversion der Module hervorzurufen (vergleiche Seite 68, Abb. 13 und Seite 86, Abb. 23), und ist damit wahrscheinlich 


\section{DISKUSSION}

die hauptsächliche Quelle für Reversionsereignisse in diesen Modulen. Darüber hinaus lassen sich mit diesen beiden Modulen weder SSA noch primer template slippage erfassen. Mit dem KanKanMX4-Modul dagegen können theoretisch beide Ereignisse gemessen werden. Desweiteren ist es sehr wahrscheinlich, dass mit dem KanKanMX4-Modul häufiger Genkonversion detektiert werden als mit dem his3- $\Delta 5$ '/his3- $\Delta 3$ '- bzw. mit dem ade3$\Delta 5$ ' URA3/ade3- $\Delta 3$ '-Modul, da hierfür im KanKanMX4 die Synthese eines wesentlich kürzeren Fragments notwendig ist als in den anderen beiden Modulen.

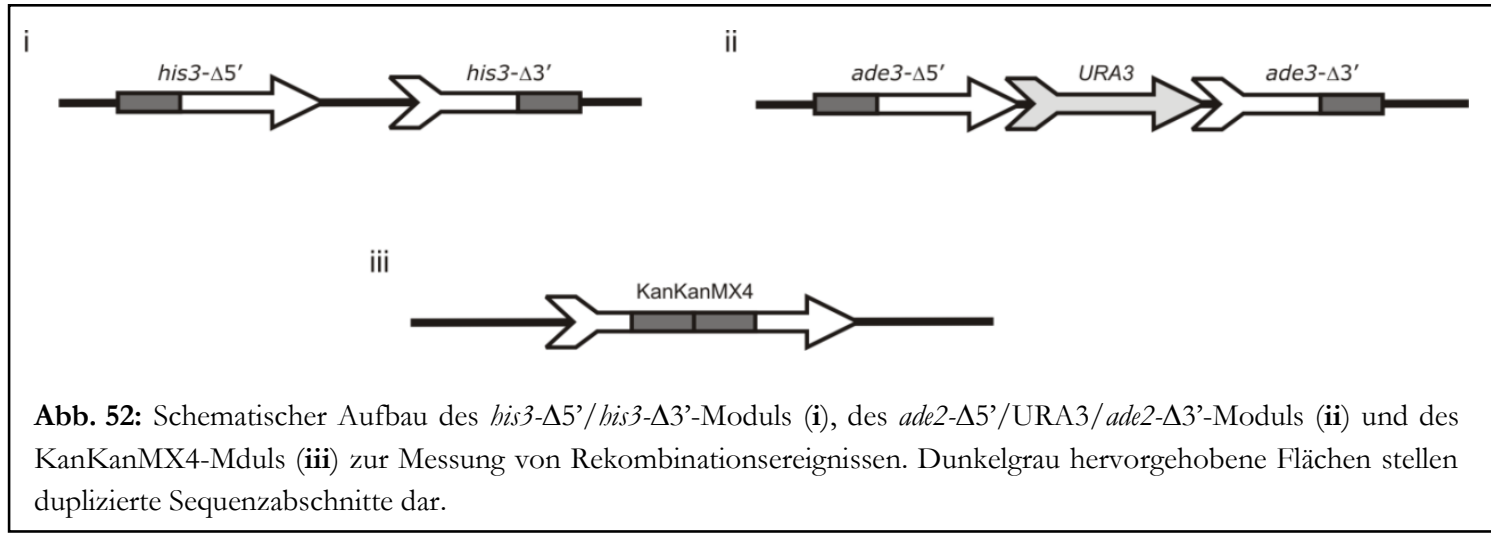

\section{Die spontanen Reversionen im KanKanMX4 stellen vermutlich zum großen Teil Rad51-abhängige Ereignisse dar, welche alternativ durch SSA ersetzt werden können}

Tatsächlich sind die hier präsentierten Daten konsistent mit diesen Vermutungen. Mit dem KanKanMX4-Modul lassen sich spontane Reversionsraten von ca. $1 \times 10^{-5}$ Reversionen pro Zelle im Wildtyp feststellen (Seite 69, Tab. 4). Dagegen liegen die spontanen Reversionsraten sowohl beim his3- $\Delta 5$ ' / his3- $\Delta 3$ '- als auch beim ade3- $\Delta 5$ ' / URA3/ade3- $\Delta 3$ '-Modul in etwa bei 1-2 × 10-6 (Fasullo \& Davis, 1987; Kadyk \& Hartwell, 1992). Die nächstliegende Erklärung für diese Differenz ist, dass es sich hierbei um Ereignisse handelt, welche durch SSA oder Genkonversion entstehen und im his3- $\Delta 5$ '/his3- $\Delta 3$ '- bzw. im ade3$\Delta 5$ ' URA3/ade3- $\Delta 3$ '-Modul gar nicht oder nur mit einer geringeren Frequenz erfasst werden. Dass es sich bei der Differenz um Ereignisse infolge von primer template slippage handelt, kann dagegen als sehr unwahrscheinlich angesehen werden, da die Reversionen des KanKanMX4 von Rad52 abhängig sind (Seite 69, Tab. 4 und Seite 75, Abb. 16), welches nicht an PTS beteiligt ist (Ripley, 1990). Gleichzeitig erscheint es aufgrund der in dieser Arbeit präsentierten Erhöhung der spontanen Reversionsrate in rad51 $\Delta$-Mutanten als wahrscheinlich, dass zumindest ein Teil der spontan auftretenden Reversionen über SSA entstehen. Da eine Reversion des KanKanMX4-Moduls in rad52D-Mutanten nicht mehr erfolgt (siehe Seite 69 und 73) ist es plausibel anzunehmen, dass die spontan in rad51 1 -Mutanten entstehenden Reversionen SSA-Ereignisse darstellen, welche zwar Rad52- aber nicht Rad51-abhängig sind. Die plausibelste Erklärung für die Erhöhung ist daher, dass in Abwesenheit von Rad51 Doppelstrangbrüche über Rad52-abhängiges SSA prozessiert werden. Eine Reversion des KanKanMX4 durch Genkonversion oder cross over setzt die Invasion in der zweiten Duplikation, ausgehend von einem Arrest in der ersten Duplikation voraus. 
Ein Arrest in der zweiten Sequenzwiederholung bzw. eine Invasion in der ersten Wiederholung führen dagegen nicht zu einer Reversion. Es führt daher nur eine von vier möglichen Ausgangssituationen zu einer Deletion. SSA dagegen führt im KanKanMX4-Modul per se zu einer Reversion. Demnach ist es durchaus denkbar, dass die Zunahme an SSA gegenüber den alternativen Mechanismen zu einer Erhöhung der spontanen Reversionsrate führt. Zusätzlich gestützt wird dieses Modell durch Ergebnisse früherer Arbeiten: Eine erhöhte Zahl an Rekombinationsereignissen kann für rad51 auch bezüglich der Rekombinationsrate am SUP4-o-locus beobachtet werden. Durch Analyse der Rekombinationsprodukte konnte dabei festgestellt werden, dass es sich in allen Fällen um Produkte handelt, welche durch SSA zustande gekommen waren (Shor et al., 2002). Auch wurde bereits in früheren Publikationen vermutet, dass die Deletion von RAD51 zu einer verstärkten Prozessierung von Doppelstrangbrüchen über SSA führt (McDonald \& Rothstein, 1994). Es scheint daher sehr plausibel, dass die Erhöhung der spontanen Reversionsrate in rad51 $\Delta$ auf eine Zunahme an SSA zurückzuführen ist, was gleichzeitig bedeutet, dass ein deutlicher Anteil der im Wildtyp beobachten Ereignisse auf Rad51-abhängige Invasion im Schwesterchromatid zurückzuführen sind.

Möglicherweise kommt es auch durch Abwesenheit von Rad51 zu einer Anhäufung von Doppelstrangbrüchen: Es wäre bspw. möglich, dass Schäden zunächst durch Synthese eines neuen primers hinter dem Schaden ausgelassen werden, da eine Rad51-abhängige Umgehung nicht mehr möglich ist (siehe Seite 15). Die so entstandene Einzelstranglücke kann zusätzlich nicht nach dem gap-filling-Modell aufgefüllt werden (Seite 15). Die somit persistierende Einzelstranglücke könnte geschnitten und der so entstandene Doppelstrangbruch anschließend über Rad52-abhängiges SSA repariert werden. Durch das Generieren der 3'Überhänge während der Reparatur kann hierbei der Schaden entfernt werden. Allerdings ist dies rein spekulativ, da es derzeit keine Evidenzen für einen solchen Mechanismus in vivo gibt. Unabhängig davon wäre jedoch auch in diesem Fall die erhöhte Frequenz abhängig von SSA, da die so entstandenen Doppelstrangbrüche ohne Rad51 über SSA repariert würden. Es scheint also, als beruhten die mit dem KanKanMX4 erfassten spontanen Ereignisse ausschließlich auf Mechanismen der homologen Rekombination, wobei zumindest ein Teil der beobachteten Ereignisse auf SSA zurückzuführen zu sein scheint.

\section{Durch Inkubation mit DNA-schädigenden Agenzien kann die Anzahl an Re- versionen gesteigert werden}

Spontane Reversionen entstehen aufgrund undefinierter DNA-Schäden, welche während des Wachstums im Medium sowohl endogen als auch exogen hervorgerufen werden. Die genaue Ursache für die spontanen Reversionen ist daher nicht bekannt. Durch Inkubation der Zellen mit einem DNA-schädigenden Agens kann jedoch die Ursache der betrachteten Reversionen genauer eingeschränkt werden: Je nach benutztem Agens ist das entstehende Schadensspektrum mehr oder weniger bekannt. Somit kann die Quelle der Reversionen auf einige mögliche Schadensarten eingegrenzt werden. Allerdings muss hierfür die Reversionsfrequenz nach Inkubation mit dem Agens deutlich den spontanen Hintergrund überschreiten, damit überhaupt ein wesentlicher Teil der Reversionen auf die Inkubation zurückzu- 


\section{DISKUSSION}

führen ist. Benutzt wurden hier die Agenzien 4-NQO, MMS und Camptothecin, wobei die Inkubation mit allen drei Agenzien zu einer Dosis-abhängigen Erhöhung der Reversionsfrequenz führte (Seiten 70, 87 und 90). Die Frequenzen nach Inkubation mit dem Agens lagen dabei bei allen drei Agenzien deutlich über dem spontanen Hintergrund (10- bis 13fach bei Camptothecin und 4-NQO, ca. 4-fach bei MMS, Daten nicht gezeigt), so dass es wahrscheinlich ist, dass die betrachteten induzierten Reversionen auf die, durch das jeweilige Agens hervorgerufenen, Schäden zurückzuführen sind. Besonders deutlich ist der Dosisabhängige Anstieg bei Camptothecin, wo die Reversionsfrequenz bereits bei sehr geringen Dosen an Agens deutlich ansteigt. Camptothecin inhibiert die Topoisomerase I, was zu dem vermehrten Auftreten von Einzelstrangbrüchen in der DNA führt (Avemann et al., 1988; Ferguson \& Baguley, 1996). Die Inkubation mit Camptothecin führt daher vermutlich vermehrt zu der Entstehung von Doppelstrangenden, welche durch run off-Synthese entstehen. Diese Enden werden wiederum wahrscheinlich ausschließlich über Rad51abhängige Invasion im Schwesterchromatid repariert (siehe Seite 9, Abb. 2), wie bspw. die hohe Sensitivität von rad51 gegen Camptothecin zeigt (Seite 121, Abb. 48). SSA kann dagegen bei Camptothecin-induzierten Schäden nicht stattfinden, da hier der zweite Teil des Chromosoms fehlt, wie er bei einem Doppelstrangbruch vorliegt (Krogh \& Symington, 2004). Demnach sind diese Daten eine gute Evidenz für die Vermutung, dass die beobachteten Reversionen auch über Rad51-abhängige Interaktion mit dem Schwesterchromatid durch homologe Rekombination entstehen können. Darüber hinaus legen sie nahe, dass unter anderem auch die Reinitiation der Replikation nach run off-Synthese zu einer Reversion führt.

Der etwas geringere Anstieg der induzierten Reversionsfrequenzen bei Inkubation mit MMS zeigt darüber hinaus, dass scheinbar auch die Alkylierung der Basen Mechanismen aktivieren kann, welche zu einer Reversion führen. N3-methyliertes Adenin (siehe Seite 88, Abb. 25) ist in der Lage, direkt einen Replikationsarrest hervorzurufen (Larson et al., 1985). Gleichzeitig können vor allem durch N7-Methylguanin sekundär AP-sites in der DNA entstehen, welche unter anderem einen Replikationsarrest hervorrufen können: N7Methylguanin wird durch eine spezifische N-Glykosylase im Rahmen der BER aus der DNA entfernt. Da N7-Methylguanin vermutlich das häufigste Produkt bei der Reaktion von DNA mit MMS ist, ist es daher sehr wahrscheinlich, dass durch Inkubation mit MMS vor allem AP-sites entstehen. Neben einem direkten Replikationsarrest können AP-sites durch $\beta$-Eliminierung an C1/C2 der Ribose auch vereinzelt Strangbrüche in der DNA bilden, welche run off-Synthese hervorrufen können. Allerdings ist das häufigste durch MMS hervorgerufene Ereignis vermutlich ein Replikationsarrest durch AP-sites. Wahrscheinlich führen alkylierende DNA-Schäden demnach durch direkt oder indirekt über $A P$-sites ausgelöste Replikationsarreste zu einer Reversion.

4-NQO führt vor allem zur Bildung von Aromaten-Basenaddukten und oxidativen Schäden. Zwar entstehen hierbei unter anderem auch Einzelstrangbrüche, jedoch erscheint eine Anhäufung von Replikationsarresten durch sperrige Addukte, wie sie bspw. auch bei 2-Acetylaminofluoren festzustellen ist (Pages et al., 2005), als sehr wahrscheinlich. Gestützt wird diese Vermutung vor allem durch die Tatsache, dass NER-defekte Mutanten eine 
deutliche Sensitivität gegen 4-NQO aufweisen (Prakash, 1976). Da durch NER keine Strangbrüche repariert werden können, ist es demnach sehr wahrscheinlich, dass der Großteil der durch 4-NQO induzierten Schäden keine Strangbrüche darstellt. Der deutliche Anstieg der 4-NQO-induzierten Reversionsfrequenzen legt daher nahe, dass es sich bei den betrachteten induzierten Reversionen um Ereignisse infolge von Replikationsarresten handelt. Darüber hinaus gibt der Vergleich der 4-NQO-induzierten Reversionsfrequenzen im KanKanMX4- und im his3- $\Delta 5$ ' / his3- $\Delta 3^{\prime}$-Modul Indizien dafür, dass durch Inkubation mit 4-NQO vor allem Genkonversionen induziert werden, anstelle von cross over. Zwar sind auch bei einem Replikationsarrest cross over denkbar und nicht nur bei der Reparatur von Doppelstrangbrüchen (siehe Seite 19, Abb. 4), jedoch scheinen diese nach einem Replikationsarrest nicht so gehäuft aufzutreten: Während die Inkubation mit 4-NQO die Reversionen im his3- $\Delta 5$ '/ his3- $\Delta 3$ '-Modul nur auf das ca. 2-fache des spontanen Hintergrunds steigern lässt, kann im KanKanMX4-Modul ein Anstieg auf das ca. 13-fache festgestellt werden (Daten nicht gezeigt). Mit dem his3- $\Delta 5$ '/ his3- $\Delta 3$ '-Modul werden vermutlich vor allem cross over detektiert. Eine Genkonversion mit diesem System zu messen ist wie zuvor bemerkt vermutlich schwierig, da eine Synthese über einen vergleichsweise großen Genabschnitt notwendig wäre (siehe Seite 84). Demnach spricht dieser gemessen Unterschied dafür, dass durch 4-NQO-induzierte Schäden vorwiegend Genkonversionen entstehen. Zusätzlich gestützt wird dies über die Tatsache, dass auch bei einem episomal lokalisiertem KanKanMX4-Modul in etwa dieselben induzierten Reversionsfrequenzen zu messen sind, wie bei dem chromosomal lokalisiertem (Rudolph, 2003). Da das episomal lokalisierte Plasmid eine Centromerbindesequenz aufweist, führen cross over hierbei zu dicentrischen Plasmiden. Da diese mitotisch instabil sind (Mann \& Davis, 1983), ist es also wahrscheinlich, dass der größte Teil an induzierten Reversionen im KanKanMX4-Modul durch Genkonversion oder durch die Reparatur von Doppelstrangenden nach run off-Synthese entstehen. Zum einen sollte letzteres jedoch durch 4-NQO nur zu einem geringen Teil induziert werden. Zum anderen sollte run off-Synthese sowohl im KanKanMX4- als auch im his3- $\Delta 5$ ' / his3- $\Delta 3$ '-Modul in etwa denselben Effekt haben, da hierbei weder die Anordnung noch die Größe des zwischen den Duplikationen liegenden Genabschnitts einen Einfluss auf die Häufigkeit der Reversion hat.

\section{Die induzierten Reversionsfrequenzen sind abhängig von der homologen Rekombination, jedoch nicht von einer Resolvase}

Wie die spontanen Reversionen, sind auch die induzierten Ereignisse vollständig von Rad52 abhängig, wie die Messung der induzierten Reversionsfrequenzen in rad52 $\Delta$ zeigen (Seite 73). Dagegen sind die 4-NQO-induzierten Reversionsfrequenzen in einer rad51 $\Delta$ Mutante nicht wie die spontanen Raten erhöht, sondern ebenfalls erniedrigt (Seite 73). Auch dies ist konsistent mit der zuvor dargelegten Vermutung, es handle sich bei den durch 4-NQO induzierten Reversionen im wesentlichen um Ereignisse infolge der Umgehung von replikationsarretierenden DNA-Schäden, wohingegen die spontanen Reversionen vermutlich sowohl durch die Reparatur von Doppelstrangbrüchen als auch durch run off-Synthese infolge von Einzelstrangbrüchen und die Umgehung von Replikationsarresten 


\section{DISKUSSION}

hervorgerufen werden: Während bei Doppelstrangbrüchen oder Läsionen, welche zu Doppelstrangbrüchen prozessiert werden, in Abwesenheit von Rad51 eine Zunahme an Rad52abhängigem SSA möglich ist, kann SSA nicht als Alternative bei Replikationsarresten oder Einzelstrangbrüchen fungieren, was zu der gemessenen Reduktion in rad51 $\Delta$ bei den induzierten Ereignissen führt. Zwar würden auch kollabierte Replikationsgabeln nach run offSynthese eine solche Reduktion in rad51 $1 \Delta$ hervorrufen, jedoch wären diese Ereignisse, wie bereits erwähnt, vermutlich im his3- $\Delta 5 \%$ his3- $\Delta 3$ '-Modul genauso häufig wie im KanKanMX4-Modul, was jedoch nicht der Fall ist.

Während rad51D einen deutlichen Effekt auf die 4-NQO-induzierten Reversionsfrequenzen hat, zeigt die Deletion von YEN1 annähernd keine Veränderungen im Vergleich zum Wildtyp (Seite 75). Yen1 ist die bei S. cerevisiae im Kern lokalisierte Resolvase (Ip et al., 2008) und ist für die Auflösung von Holliday-Junctions und damit bspw. bei der Generierung von cross over relevant. Da die beobachteten Ereignisse jedoch vermutlich im Wesentlichen keine cross over, sondern Genkonversionen darstellen, ist die Tatsache, dass yen1 $\Delta$ keinen deutlichen Phänotyp aufweist, nicht besonders erstaunlich. Allerdings könnte auch eine Genkonversion von der Funktion einer Resolvase abhängig sein, insofern Doppelstrangenden durch Schneiden eines Chicken Foots entstünden, wie er durch fork regression zustande kommt. Da yen $1 \Delta$ jedoch keine deutliche Reduktion der induzierten Reversionsfrequenzen aufweist, ist es eher unwahrscheinlich, dass ein Chicken Foot als Intermediat während der beobachteten Prozesse entsteht, welches durch eine Resolvase aufgelöst wird.

\section{Der Ausfall der Transläsionssynthese führt möglicherweise zu einer gering- fügig verstärkten Anhäufung an Reversionsereignissen}

Da es sich bei den beobachteten Ereignissen um Prozesse handelt, welche vermutlich eine fehlerfreie Umgehung von replikationsarretierenden DNA-Schäden darstellen, erscheint es sinnvoll, dass der Ausfall dieser Prozesse zu einer verstärkten Umgehung von DNASchäden durch Transläsionssynthese führt. Experimentell gestützt wird dies durch die er-

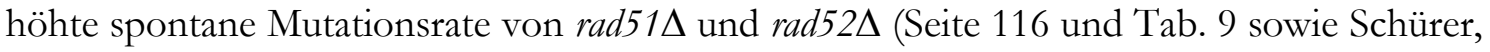
2003; Schürer et al. 2004). Es ist daher durchaus wahrscheinlich, dass im Umkehrschluss auch die induzierte Reversionsfrequenz durch Ausfall der Transläsionssynthese verstärkt werden kann. Allerdings sind die induzierten Reversionsfrequenzen in rev3 $\Delta$-Mutanten, wenn überhaupt, nur minimal erhöht (Seite 78). Es könnte daher möglicherweise tatsächlich der Fall sein, dass der Ausfall der Transläsionssynthese zumindest teilweise zu einem leichten Anstieg an Rekombinationsereignissen führt. Allerdings erscheint es plausibler, dass die Anzahl an Reversionen nicht durch Ausfall der Transläsionssynthese gesteigert werden kann. Dazu kommt, dass rev3 3 in Bezug auf die spontanen Reversionsraten (wenn überhaupt) eher eine leichte Reduktion als eine Erhöhung aufweist (Seite 81). Zusammen

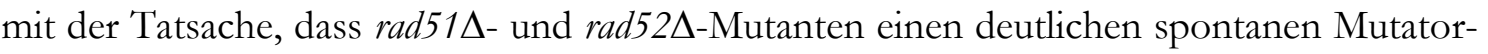
phänotyp aufweisen, erscheint es plausibel anzunehmen, dass der größte Anteil an replikationsarretierenden DNA-Schäden über homologe Rekombination umgangen wird, anstatt über Transläsionssynthese. Zwar könnten die nur sehr geringfügig vermehrt auftretenden 
Reversionsereignisse unter anderem darauf zurückzuführen sein, dass es sich bei den beobachteten Reversionen nur zu einem geringen Anteil um Ereignisse infolge von Replikationsarresten handelt, allerdings scheint dies zumindest für die induzierten Reversionsfrequenzen eher unwahrscheinlich, wie die zuvor dargelegten Daten vermuten lassen. Eventuell stellt Transläsionssynthese in S. cerevisiae daher weniger eine generelle Alternative für fehlerfreie Umgehung dar, sondern ist möglicherweise eher in speziellen Fällen relevant, in der fehlerfreie Umgehung durch Interaktion mit dem Schwesterchromatid nur noch begrenzt oder gar nicht möglich ist. Eine solche Situation kann bspw. bei einer starken Schädigung beider Chromatiden eintreten. Ist das alternative template ebenfalls geschädigt, kann eine fehlerfreie Umgehung durch Synthese am Schwesterchromatid vermutlich nicht erfolgen, da hier ebenfalls eineReplikationsarrest entstehen kann. In so einem Fall kann der Schaden nur über Transläsionssynthese umgangen werden.

Interessanterweise lässt sich durch die Deletion von $\mathrm{R} A D 30$, anstatt einer Erhöhung, vielmehr eine leichte Reduktion der induzierten Reversionsfrequenzen feststellen (Seite 76). Damit eine Reversion entstehen kann, muss eine Verlängerung am Schwesterchromatid stattfinden (einzige Ausnahme ist die Reparatur nach run off-Synthese, siehe Seite 68, Abb. 13). Da weiter für die Reversion nach einem Replikationsarrest anscheinend die Interaktion mit dem Schwesterchromatid über Rad51-vermittelte Invasion Voraussetzung ist, muss diese Verlängerung höchstwahrscheinlich an einem D-Loop stattfinden. Für menschliches Rad30 konnte biochemisch gezeigt werden, dass es das primer-Ende in einem $D$ Loop verlängern kann (McIlwraith et al., 2005). Demnach ist es durchaus plausibel anzunehmen, dass Rad30 in Hefe ebenfalls diese Reaktion katalysiert. In diesem Fall könnte die beobachtete Reduktion der Reversionsfrequenz auf eine verringerte Effizienz bei der Verlängerung am D-Loop zurückzuführen sein. Da außerdem bei einem Ausfall von Rad30 die Reparatur von Doppelstrangbrüchen über SDSA nicht mehr so effizient stattfinden kann, werden Doppelstrangbrüche vermutlich vermehrt über SSA repariert. Demnach wäre wie

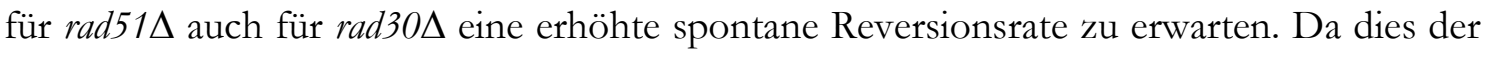
Fall ist (Seite 81), machen sowohl die spontane Reversionsrate als auch die induzierten Reversionsfrequenzen von rad30 $\mathrm{A}$ es wahrscheinlich, dass Rad30 tatsächlich an der homologen Rekombination beteiligt ist. Allerdings wäre in diesem Fall gleichzeitig zu vermuten, dass rad30 0 einen schwachen Mutatorphänotyp aufweist, was in Hefe nicht der Fall ist (Rudolph, 2003). Jedoch lässt sich zumindest in humanen Zellen tatsächlich eine leichte Erhöhung der Mutationsrate feststellen (Choi \& Pfeifer, 2005). Da Rad30 gleichzeitig eine Transläsionspolymerase ist und zusätzlich im Vergleich mit den anderen DNAPolymerasen die höchste Fehlerrate auf unbeschädigten template hat (Matsuda et al., 2000; Prakash et al., 2005), mag es durchaus sein, dass in Hefe ein schwacher Mutatorphänotyp gleichzeitig durch den parallelen Ausfall der Rad30-abhängigen Transläsionssynthese aufgehoben wird. Daher scheint es durchaus sinnvoll zu vermuten, dass Rad30 tatsächlich auch in Hefe die Verlängerung am D-Loop durchführen kann. Ist dies der Fall, so wäre dies auch eine mögliche Erklärung für die Tatsache, dass rad30 Mutanten, trotz des Ausfalls der Transläsionssynthese, kaum eine Reduktion der Mutationsrate aufweisen (McDonald et al., 1997): Da gleichzeitig die fehlerfreie Umgehung der Schäden durch homologe Rekombination ausfällt, könnte der dadurch entstehende Anstieg der Mutationsrate den erniedrigten 


\section{DISKUSSION}

Phänotyp von rad30 ausgleichen. Somit ist es zwar sehr wahrscheinlich, dass Rad30 die Verlängerung im D-Loop katalysieren kann, allerdings scheint Rad30 nicht essentiell für diesen Vorgang zu sein, da die Reduktion der induzierten Reversionsfrequenzen eher gering ausfällt. Es scheint daher ebenfalls plausibel, dass auch andere DNA-Polymerasen diese Funktion übernehmen können und Rad30 möglicherweise nur die präferentiell eingesetzte DNA-Polymerase hierbei ist.

Insgesamt scheint das KanKanMX4-Modul geeignet zu sein, um die Interaktion zwischen Schwesterchromatiden zu untersuchen: Die untersuchten Ereignisse sind abhängig von der homologen Rekombination und scheinen in Abhängigkeit der untersuchten Quelle von DNA-Schäden auf unterschiedliche Ereignisse zurückzuführen zu sein. Die Messung spontaner Ereignisse gibt die Möglichkeit, den Einfluss eines oder mehrerer Gene sowohl auf SSA als auch auf SDSA sowie die fehlerfreie Umgehung von replikationsarretierenden DNA-Schäden zu untersuchen. Die Messung 4-NQO-induzierter Reversionsereignisse dagegen scheint geeignet zu sein, um vorzugsweise die Beteiligung betrachteter Gene an der fehlerfreien Umgehung von replikationsarretierenden DNA-Schäden zu überprüfen. Durch Inkubation mit Camptothecin lässt sich außerdem eine Beteiligung von Genen an der Reparatur von kollabierten Replikationsgabeln nach run off-Synthese feststellen.

\section{Mph1 ist vermutlich an der Prozessierung von D-Loops beteiligt}

\section{Die Helikase Mph1 ist an der HR-abhängigen fehlerfreien Umgehung von replikationsarretierenden DNA-Schäden beteiligt}

Genetische Evidenzen für die Funktion von Mph1

mph1-Mutanten zeigen einen Rev3-abhängigen Mutatorphänotyp und eine deutliche Sensitivität gegenüber DNA-schädigende Agenzien wie MMS und 4-NQO. Dabei ist mph1 hypostatisch zu rad51, rad52, rad55 und rad54 bzgl. der Sensitivität gegen MMS und 4-NQO sowie hypostatisch zu rad51, rad52 und rad55 in Bezug auf die spontane Mutationsrate. rad54 ist dagegen bezogen auf spontane Mutationen subadditiv mit mph1 (Scheller et al., 2000; Schürer, 2003; Schürer et al., 2004). Demnach scheint Mph1 an der homologen Rekombination beteiligt zu sein. Da mph1 jedoch gleichzeitig kaum sensitiv gegenüber ionisierender Strahlung ist und sich auch weder ein Defekt in der mitotischen noch in der meiotischen Rekombination feststellen lässt, wurde postuliert, dass Mph1 hauptsächlich an der fehlerfreien Umgehung von replikationsarretierenden DNA-Schäden über homologe Rekombination beteiligt ist und keine oder nur eine untergeordnete Rolle bei der Reparatur von Doppelstrangbrüchen spielt. Die fehlende Sensitivität von $m p h 1$ gegenüber Camptothecin weist zusätzlich darauf hin, dass Mph1 wohl auch bei der Reparatur von kollabierten Replikationsgabeln eher unwichtig ist (Schürer et al.,2004).

Die induzierten Reversionsfrequenzen einer mph1D-Mutante weisen auf eine Funktion bei der fehlerfreien Umgehung von DNA-Schäden bin

Eine weitere wichtige Evidenz für die Beteiligung von Mph1 an der Umgehung von replikationsarretierenden DNA-Schäden ist die zunächst von Christian Rudolph festgestellte 132 | S e ite 
Reduktion der spontanen sowie der induzierten Reversionsfrequenzen in einer mph1Mutante. Auch in der vorliegenden Arbeit konnte eine solche Reduktion der induzierten Reversionsfrequenzen festgestellt werden (Seite 83). Jedoch ließ sich die von Christian Rudolph beobachtete Reduktion der spontanen Reversionsrate in mph1 nicht reproduzieren. Vielmehr zeigte sich hier eine leichte Erhöhung der Rate. Allerdings wurden die Raten bei Christian Rudolph mit einem Centromer-Plasmid unter selektiven Bedingungen (SCMedium) durchgeführt. Die hier ermittelten Raten dagegen wurden mit einem chromosomal integrierten Plasmid unter Anzucht in YPD ermittelt. Die unterschiedliche Lokalisation des Moduls könnte einen Einfluss auf die Entstehung einer Reversion haben (bspw. führen cross over in Centromer-Plasmiden zu dicentrischen und mitotisch instabilen Plasmiden; Mann \& Davis, 1983). Darüber hinaus ist es plausibel, dass beim Wachstum in einem synthetischen Medium generell ein anderes Schadensspektrum vorliegt als in Vollmedium. Es wäre also auch möglich, dass die Anzahl an Schäden, welche zu einer verstärkten Prozessierung durch SSA führen können, in Vollmedium höher ist. Da Mph1 Teil der Rad51abhängigen Rekombination ist, ist es durchaus denkbar, dass die in dieser Arbeit gemessene Erhöhung der spontanen Rate wie in rad51 $\Delta$ durch gehäuftes Auftreten von SSA entsteht.

Unabhängig davon lassen sich in mph1s deutlich weniger Reversionen durch MMS, 4-NQO und Camptothecin induzieren als im Wildtyp (Seiten 83, 87 und 90). Da sowohl MMS als auch 4-NQO vermutlich überwiegend Replikationsarreste hervorrufen, ist die Reduktion der durch diese Stoffe induzierten Reversionsfrequenzen in $m p h 1 \Delta$ eine weiteres Indiz für die Beteiligung von Mph1 an der Umgehung von replikationsarretierenden DNASchäden. Gleichzeitig zeigt die Reduktion der Camptothecin-induzierten Reversionsfrequenzen, dass Mph1 zumindest teilweise auch an der Reparatur einer kollabierten Replikationsgabel nach run off-Synthese beteiligt ist. Allerdings mag die Funktion von Mph1 hierbei eine eher untergeordneter Rolle in vivo spielen, da mph1, wie bereits erwähnt, keine erkennbare Sensitivität gegenüber Camptothecin aufweist.

Während die Reversionsfrequenz im KanKanMX4-Modul den vorliegenden Daten nach teilweise von der Funktion von Mph1 abhängig ist, hat die mph1 $\Delta$-Deletion anscheinend keinen oder nur einen sehr geringen Einfluss auf die Reversion des his3- $\Delta 5$ '/ his3- $\Delta 3$ 'Moduls (Seite 84). Da die mit diesem Modul gemessenen Reversionen vermutlich vorwiegend durch cross over entstehen, scheint Mph1 vor allem an einem Prozess beteiligt zu sein, welcher eher eine Genkonversion als ein cross over hervorruft.

\section{mph1 1 und rad51 sind subadditiv bei der Messung induzierter Reversionsfrequenzen}

Eine der wichtigsten Daten für die Interpretation der Funktion von Mph1 war die Epistasis von rad51 und rad52 gegenüber mph1 bei der Sensitivität gegen MMS und 4-NQO sowie der spontanen Mutationsrate (Scheller et al., 2000; Schürer et al., 2004). Interessanterweise zeigt sich bei der Messung induzierter Reversionsfrequenzen mit rad51 $\Delta$ keine Epistasis, sondern vielmehr eine Additivität oder Subadditivität (Seite 93). Mph1 scheint demnach eine Funktion zu haben, welche nicht ausschließlich Rad51-abhängig ist. Vielmehr scheint Mph1 an einem Prozess beteiligt zu sein, welcher auch in Abwesenheit von Rad51 noch durch Mph1 unterstützt wird. 


\title{
DISKUSSION
}

\section{Mph1 ist vermutlich an der Prozessierung eines $D$-Loops beteiligt}

\author{
Die Auflösung eines D-Loops als einzige Funktion von Mph1 ist nicht hinreichend, um alle \\ Phänotypen zu erklären
}

Nach neueren biochemischen Studien wird für Mph1 eine Funktion bei der Auflösung von D-Loops postuliert. In einer mph1-Mutante kann eine Zunahme von cross over-Ereignissen nach Induktion von Doppelstrangbrüchen durch HO-Endonuklease verzeichnet werden. Doppelstrangbrüche können sowohl über SDSA als auch DSBR repariert werden, wobei bei SDSA kein cross over, sondern nur eine Genkonversion erfolgen kann. Daher erscheint es wahrscheinlich, dass Mph1 an einem Prozess beteiligt ist, welcher cross over verhindert und Genkonversion fördert. Gleichzeitig konnte für gereinigtes Mph1 biochemisch gezeigt werden, dass es D-Loop-Strukturen auflösen kann (Prakash et al., 2009). Aufgrund dieser Daten erscheint es zunächst am wahrscheinlichsten, dass Mph1 als Helikase die Auflösung des D-Loops forciert, bevor sich eine Holliday-Junction bildet, und somit die Entstehung von cross over-Ereignissen verhindert. Allerdings ist eine solche Funktion nicht hinreichend, um die hier präsentierten Daten zu erklären. Bspw. wäre bei einer Funktion von Mph1 bei der Unterdrückung von cross over zu vermuten, dass die Anzahl an cross over zunähme. In diesem Fall sollte eine mph1 $\Delta$-Mutante im his3- $\Delta 5$ ' / his3- $\Delta 3$ '-Modul vermutlich eine erhöhte induzierte Reversionsfrequenz aufweisen, was jedoch nicht der Fall ist (Seite 84). Ebenfalls wäre es fraglich, warum mph1 $1 \Delta$ eine Sensitivität gegenüber MMS und 4-NQO aufweist. Die Unterdrückung von cross over zugunsten von Genkonversion kann zwar auch bei der Umgehung von DNA-Schäden eine Rolle spielen (siehe Seite 19, Abb. 4) und auch Doppelstrangbrüche können theoretisch durch die Inkubation mit diesen Substanzen entstehen, wenn es auch vermutlich seltener geschehen dürfte. Dennoch ist ein cross over nicht zwingend ein tödliches oder wachstumshemmendes Ereignis, weshalb eine mph1-Mutante in diesem Fall vermutlich kaum eine Sensitivität aufweisen sollte. Auch sollte keine so deutliche Reduktion der induzierten Reversionsfrequenzen in mph1 $1 \Delta \mathrm{zu}$ beobachten sein: Das Auflösen des D-Loops zugunsten einer Genkonversion wäre erst relevant, wenn die Verlängerung am Schwesterchromatid bereits erfolgt ist. An diesem Punkt ist der Schaden jedoch bereits unabhängig von der Art der Auflösung umgangen. Daher sollte die Deletion und damit einhergehend die bevorzugte Auflösung des D-Loops über cross over keinen Effekt auf die induzierte Reversionsfrequenz haben. Aus demselben Grund wäre für eine $m p h 1$ Mutante auch kein Rev3-abhängiger Mutatorphänotyp zu erwarten, da Transläsionssynthese als Alternative zu einer Umgehung durch homologe Rekombination nur einsetzen kann, bevor der Schaden bereits umgangen ist. Es ist daher sehr wahrscheinlich, dass Mph1 zumindest noch eine weitere Funktion aufweist, welche diese Phänotypen hervorruft.

\section{Mph1 hat vermutlich eine Funktion bei der Stabilisierung oder Vergrößerung eines D-Loops}

Die eingangs angesprochenen Daten und die induzierten Reversionsfrequenzen machen es sehr wahrscheinlich, dass Mph1 vor allem an der fehlerfreien Umgehung von replikationsarretierenden DNA-Schäden beteiligt ist. Darüber hinaus ist es aufgrund der Daten ebenfalls sehr naheliegend, dass Mph1 bereits eine Funktion vor der Verlängerung am Schwesterchromatid hat. Da Mph1 eine Helikase ist, sind zwei weitere Funktionen für die Beteili- 
gung von Mph1 bei der homologen Rekombination plausibel. Zum einen könnte Mph1 für das Ablösen des 3'-Endes eines in der Synthese arretierten Strangs vom template benötigt werden, was wiederum notwendig ist, um bei einem Replikationsarrest ein geeignetes 3'Ende für die Invasion im Schwesterchromatid zu erhalten. Sowohl der Mutatorphänotyp als auch die Reduktion der MMS- und 4-NQO-induzierten Reversionsfrequenzen lassen sich durch eine solche Funktion erklären. Allerdings erscheint es aufgrund der Reduktion der Camptothecin-induzierten Reversionsfrequenzen in mph1 $\Delta$ zumindest unwahrscheinlich, dass dies die einzige Funktion von Mph1 ist (Seite 90): Für die Reparatur der durch Camptothecin entstehenden Einzelstrangbrüche ist ein Ablösen des 3'-Endes nicht notwendig, da hierbei ein 3'-Überhang durch Zurückschneiden des Doppelstrangendes entstehet (vergleiche Seite 9, Abb 2 und Seite 19, Abb 4; Krogh \& Symington, 2004).

Eine zweite plausible Funktion von Mph1 ist eine Prozessierung des D-Loops vor der Verlängerung des invadierenden 3'-Endes, wobei auch hierfür zwei unterschiedliche Möglichkeiten denkbar sind. Dies sind die Stabilisierung des D-Loops einerseits und das Aufwinden des D-Loops in Syntheserichtung andererseits. Beides könnte Voraussetzung sein, um überhaupt eine Verlängerung des invadierten Stranges am Schwesterchromatid zu ermöglichen. Durch die Stabilisierung könnte erst das notwendige Zeitfenster geschaffen werden, in der die Polymerase das 3'-Ende im D-Loop binden kann. Die Vergrößerung des D-Loops in Syntheserichtung wiederum könnte notwendig sein, um der Polymerase das neue template überhaupt erst zugänglich zu machen. Beide Modelle können die hier präsentierten Daten sowie den Mutatorphänotyp von mph1 erklären. Jedoch weist die verringerte Camptothecininduzierte Reversionsfrequenz eher auf eine stabilisierende Funktion hin, da für die Reparatur nach run off-Synthese eine Verlängerung im D-Loop nicht notwendig ist. Gleichzeitig ist es prinzipiell möglich, dass Mph1 parallel beide Funktionen ausübt, bspw. in Form eines gleichzeitigen Aufschmelzens des D-Loops in beide Richtungen. Allerdings bleibt die Frage, inwiefern eine solche Funktion mit den von Prakash et al. gezeigten biochemischen Daten zu vereinbaren ist, da die dort verwendeten Substrate vermutlich nicht durch eine Helikaseaktivität, aufgelöst werden können, wie sie für das Aufschmelzen des D-Loops notwendig ist. Jedoch handelt es sich bei diesen Daten um in vitro-Experimente, deren Relevanz für die in vivo ablaufenden Ereignisse schwer abzuschätzen ist.

Dennoch ist nach diesen Daten das wahrscheinlichste Modell für die Funktion von Mph1 eine Prozessierung des D-Loops, welcher durch homologe Rekombination bei der Invasion im Schwesterchromatid bzw., soweit vorhanden, im homologen Chromosom entsteht. Allerdings weist die von Prakash et al. beobachtete Erhöhung der induzierten cross over in mph1s zumindest darauf hin, dass Mph1 zusätzlich eine Funktion hat, welche Genkonversion fördert.

\section{Mph1 und Rad54 sind möglicherweise beides Faktoren für die effiziente Bil- dung eines D-Loops}

Ein wichtiger Aspekt bei der Untersuchung von Mph1 könnte die Tatsache sein, dass $m p h 1$ zwar hypostatisch zu den Genen der HR in Bezug auf die Sensitivität gegen DNAschädigende Agenzien ist, jedoch in Bezug auf den spontanen Mutatorphänotyp eine Su- 


\section{DISKUSSION}

badditivität mit rad54 $\Delta$ aufweist. Auch sind sowohl rad54-als auch mph1-Mutanten weniger sensitiv als rad51-, rad55- oder rad52-Mutanten (Schürer, 2003). Beides deutet darauf hin, dass Rad54 und Mph1 eher unterstützend als notwendig für die homologe Rekombination sind. Die Subadditivität bei der spontanen Mutationsrate weist zusätzlich darauf hin, dass beide Proteine sich teilweise überschneidende Funktionen ausüben (Schürer, 2003).

\section{Das Rad54-Protein}

Rad54 ist eine ATP-abhängige Translokase, welche die Rad51-abhängige D-Loop-Bildung in vitro erleichtert (Petukhova et al., 1998). Es kann außerdem positiven, sowie negativen supercoil in dsDNA hervorrufen (Petukhova et al., 1999), was durch Anwesenheit von Rad51 stimuliert wird (Alexeev et al., 2003; Van Komen et al., 2000). Untersuchungen zur Rekombination zwischen MAT und HML zeigten weiter, dass in rad54-Mutanten zwar eine Paarung des Rad51-Filaments mit dem Doppelstrang zu beobachten ist, eine Verlängerung am invadierten 3'-Ende konnte jedoch nicht festgestellt werden (Sugawara et al., 2003). Aus diesem Grund wird vermutet, dass Rad54 in irgendeiner Form an der Prozessierung des D-Loops beteiligt ist, indem es bspw. durch die topologische Modifikation des ursprünglichen Doppelstrangs das weitere Aufschmelzen des D-Loops erleichtert. Neben der toplogischen Modifikation von dsDNA wurde ebenfalls gezeigt, dass die ATPase-Aktivität am Terminus des Rad51-Filaments im D-Loop stimuliert wird, was mit Auflösung des dsDNARad51-Filaments zu freiem Rad51 und freier DNA-Duplex einhergeht. Aus diesem Grund wurde postuliert, dass Rad54 für die Regulation des turn over des Rad51-Filaments notwendig ist (Kiianitsa et al., 2006; Solinger et al., 2002). Ohne Entfernen von Rad51 im D-Loop könnte die Bindung einer DNA-Polymerase an das 3'-Ende im D-Loop durch das gebundene Rad51 verhindert werden. Zumindest für ein RecA-Filament konnte bereits in vitro festgestellt werden, dass das 3'-Ende in einem D-Loop nicht in Anwesenheit von RecA durch eine DNA-Polymerase verlängert werden kann (Xu \& Marians, 2002). Tatsächlich konnten auch in einer kürzlich veröffentlichten Arbeit Evidenzen gefunden werden, dass die Verlängerung des invadierenden Stranges im D-Loop erst in Anwesenheit von Rad54 ermöglicht wird (Li \& Heyer, 2009). Es ist daher sehr plausibel, dass Rad54 notwendig ist, um das Rad51-Filament postsynaptisch aufzulösen und so das 3'-Ende für eine Polymerase zugänglich zu machen. Allerdings ist es ebenfalls denkbar, dass erst die topologische Modifikation des Doppelstrangs eine Voraussetzung für die Synthese ist, da so die Verdrängung des ursprünglichen Strangs erst möglich wird. In jedem Fall weisen die benannten Daten darauf hin, dass Rad54 in irgendeiner Form benötigt wird, um die Synthese an einem DLoop zu ermöglichen.

\section{Mph1 und Rad54 sind Faktoren, welche die Synthese am D-Loop erleichtern}

Sowohl für Mph1 als auch für Rad54 deuten die bisherigen Daten an, dass sie bei der Prozessierung des D-Loops beteiligt sind. Beide Proteine müssen eine Funktion vor der Verlängerung des invadierenden Stranges am D-Loop haben, wie der Mutatorphänotyp zeigt. Gleichzeitig machen die Daten für Rad54 es sehr wahrscheinlich, dass dieses Protein den D-Loop entweder topologisch verändert oder durch das Auflösen des Rad51-Filaments im D-Loop das 3'-Ende für die Synthese verfügbar macht. Für Mph1 deuten die Daten an, dass 
es in der Lage ist, den D-Loop aufzuschmelzen und so möglicherweise die Synthese am im D-Loop ermöglicht oder den D-Loop stabilisiert. Da beide Proteine demnach vermutlich dasselbe Substrat haben sind mehrere Modelle plausibel:

1. Mph1 und Rad54 unterstützen beide die Bildung des D-Loops, indem sie den DLoop stabilisieren.

2. Mph1 unterstützt die Stabilisierung des D-Loops und Rad54 regelt das turn over des Rad51-Filaments.

3. Mph1 erleichtert die Synthese im D-Loop und Rad54 stabilisiert den D-Loop.

4. Mph1 und Rad54 erleichtern beide die DNA-Synthese zur Verlängerung des invadierten Strangs sind aber nicht für die Stabilisierung von Bedeutung.

5. Mph1 und Rad54 sind jeweils beide für die Synthese und die Stabilisierung von Bedeutung.

Allerdings lässt sich anhand der bisherigen Daten nicht entscheiden, welche der fünf Möglichkeiten die wahrscheinlichste ist bzw. ob Mph1 trotz der bisherigen Indizien nicht doch eine andere Funktion aufweist als die Prozessierung eines D-Loops.

\section{UNTERSUCHUNGEN ZUM MECHANISMUS DER FEHLERFREIEN POSTREPLIKATIVEN REPARATUR}

Werden Zellen mit UV-Licht bestrahlt, so treten während der S-Phase verstärkt kurze Einzelstrangfragmente auf, was mithilfe eines alkalischen Saccharosegradienten beobachtet werden kann. Nach einiger Zeit lässt sich in Wildtyp-Zellen feststellen, dass diese Fragmente wieder verschwinden und anscheinend zu höhermolekularen Fragmenten prozessiert werden. Verstärkt wird der Effekt in einem NER-defekten Stamm, in dem die Anzahl an niedermolekularen Fragmenten enorm ansteigt (di Caprio \& Cox, 1981). Die niedermolekularen Fragmente repräsentieren wahrscheinlich DNA-Stücke wie Okazaki-Fragmente, welche aufgrund von Arresten der Replikation an DNA-Schäden nicht fertiggestellt und ligiert wurden. Die Prozesse, welche die Reparatur von kurzen Einzelstrangfragmenten zu höhermolekularen Einzelsträngen ermöglichen, indem sie einen Arrest aufheben bzw. den Schaden umgehen oder reparieren, werden als Postreplikative Reparatur (PRR) bezeichnet (Howard-Flanders et al., 1964). In Hefe konnten der PRR zum einen die Gene der rad6Epistasisgruppe und zum anderen die Gene der rad52-Epistasisgruppe zugeordnet werden (Prakash, 1981). Aufgrund der eingangs dargestellten Befunde wurden die Gene der rad6Epistasisgruppe als Bestandteil eines zu der homologen Rekombination alternativen Prozesses betrachtet und der Begriff der Postreplikativen Reparatur wurde als Synonym für die Rad6-abhängigen Prozesse benutzt. Bisher wurde die PRR mechanistisch aufgeteilt in die Transläsionssynthese und einen undefinierten fehlerfreien Mechanismus, welcher möglicherweise fork regression darstellt. 


\section{DISKUSSION}

\section{Die fehlerfreie PRR scheint nicht unabhängig von homologer Rekom- bination zu sein}

Polyubiquitinierung von PCNA am Lysin 164 gilt als Signal für die Induktion der fehlerfreien PRR und geschieht über das ubiquitinkonjugierende Heterodimer Mms2/Ubc13 (Hofmann \& Pickart, 1999) in Zusammenspiel mit der Ubiquitinligase Rad5 (Ulrich \& Jentsch, 2000). Sowohl MMS2 als auch UBC13 und RAD5 sind hypostatisch zu rad6 und rad18, weshalb die Gene der rad6-Epistasisgruppe zugeordnet werden. Die von den Genen dieser Gruppe abhängigen Prozesse werden als Postreplikative Reparatur bezeichnet (Broomfield et al., 1998; Ulrich \& Jentsch, 2000; Xiao et al., 1999). mms2 und ubc13 sind synergistisch mit rev3 in Bezug auf die Sensitivität gegen DNA-schädigende Agenzien wie UV, MMS und 4-NQO und weisen einen Mutatorphänotyp auf, was zu der Annahme führte, Mms2 und Ubc13 seien an einem fehlerfreien Zweig der PRR beteiligt (siehe Seite 109, Abb 39 sowie Broomfield et al., 1998; Brusky et al., 2000). Desweiteren zeigte sich für mms2 eine Additivität mit rad52 bei der Sensitivität gegen UV, was als hauptsächliches Indiz dafür gilt, dass die fehlerfreie PRR nicht von homologer Rekombination abhängt, sondern einen alternativen Mechanismus darstellt (Torres-Ramos et al., 2002). Eine weitere Evidenz für diese Vermutung ist, dass die Deletion von SRS2 zu einer Rad52-abhängigen Suppression der Sensitivität von rad6 führt (Ulrich, 2001). Srs2 ist eine Helikase, welche in vitro Rad51-ssDNA-Filamente auflösen kann und so vermutlich als Repressor der homologen Rekombination fungiert (Krejci et al., 2003; Veaute et al., 2003). Zusätzlich zeigen sowohl rad6 als auch rad18 und rad5 einen hyperrekombinativen Phänotyp (Liefshitz et al., 1998). Da die fehlerfreie PRR nach diesen Daten als eine Alternative zur homologen Rekombination gilt, wurde vermutet, dass es sich hierbei um fork regression handelt, da dieses das nächstliegende alternative Modell für eine fehlerfreie Umgehung von replikationsarretierenden DNA-Schäden ist (Torres-Ramos et al., 2002).

Interessanterweise zeigen jedoch sowohl mms $2 \Delta$ - als auch $u b c 13 \Delta$-Mutanten eine sehr deutliche Reduktion der 4-NQO-induzierten Reversionsfrequenzen, welche ähnlich stark ausfällt wie die in rad51s (Seite 96). Da die Reversionen aber vollständig von Rad52 und auch zu einem großen Anteil von Rad51 abhängig sind, erscheint es fragwürdig, dass die fehlerfreie PRR ausschließlich Mechanismen umfasst, welche von homologer Rekombination unabhängig sind.

\section{Die Reduktion induzierter Reversionsfrequenzen ist abhängig von der kata- lytischen Funktion des Mms2/Ubc13-Heterodimers}

Eine Möglichkeit, die Reduktion in mms $2 \Delta$ bzw. ubc13 $\Delta$ zu erklären, wäre eine Hintergrundmutation, wie sie bspw. bei der phr1 $\Delta$-Mutante aufgetreten ist. Da jedoch die $u b c 13 \Delta$ Deletion durch das Plasmid YIplac211-P13-UBC13 in Bezug auf die induzierten Reversionsfrequenzen komplementiert werden kann, kann ausgeschlossen werden, dass der Phänotyp von $u b c 13 \Delta$ auf einer Hintergrundmutation beruht (Seite 97). Vielmehr hat das Heterodimer Mms2/Ubc13 in irgendeiner Form einen Einfluss auf die von der homologen Rekombination abhängige Reversion der Sequenzduplikation im KanKanMX4. Eine nahelie- 


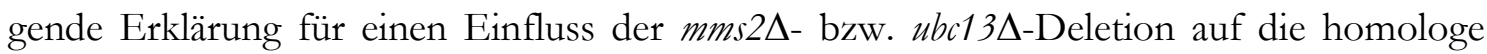
Rekombination, trotz einer Additivität zwischen mms 2 und rad52, ist eine strukturelle Funktion von Mms2/Ubc13 in einem Proteinkomplex, welcher unter anderem auch Proteine der homologen Rekombination beinhaltet. Der Verlust von Mms2 und Ubc13 könnte dann indirekt einen Einfluss auf die HR haben, indem der Komplex nicht mehr gebildet würde. Allerdings machen es die hier für eine $4 b c 13$ C87S- und eine ubi K63R-Mutante gezeigten Daten sehr unwahrscheinlich, dass die in mms $2 \Delta$ bzw. ubc13 $\Delta$ beobachtete Reduktion auf eine strukturelle Funktion zurückzuführen ist (Seiten 97 und 99). Vielmehr zeigen die Daten, dass es sich mit hoher Wahrscheinlichkeit um einen Effekt durch den Verlust an Lysin 63-verknüpften Poliubiquitinketten handelt. Die Reduktion in pol30 K164R lässt weiter vermuten, dass speziell der Verlust der Polyubiquitinierung von PCNA am Lysin 164 die Ursache für die beobachtete Reduktion der induzierten Reversionsfrequenzen ist (Seite 100). Der Unterschied in der Reduktion zwischen pol30 K164R und mms $2 \Delta$ ist dabei wahrscheinlich auf den gleichzeitigen Wegfall der Monoubiquitinierung des PCNA zurückzuführen, da diese die Transläsionssynthese stimuliert (Haracska et al., 2001), was möglicherweise zu einer leichten Zunahme an induzierten Reversionsfrequenzen führen kann (siehe rev3 $\Delta$ ). Eine weitere und vor allem eindeutigere Evidenz für die Vermutung, PCNA sei das für die Reduktion der induzierten Reversionsfrequenzen in $u b c 13 \Delta$ und mms $2 \Delta$ relevante Substrat, ist die gezeigte Epistasis von pol30 K164R gegenüber $u b c 13 \Delta$ bei der Sensitivität gegen 4-NQO (Seite 103). Hätte Mms2/Ubc13 noch ein weiteres relevantes Substrat, so wäre zu vermuten, dass sich die Sensitivität gegen 4-NQO in der pol30 K164R ubc13ADoppelmutante verstärkt, was jedoch nicht der Fall ist. Am wahrscheinlichsten nach diesen Daten ist daher, dass die Mms2/Ubc13-abhängige Polyubiquitinierung von PCNA am Lysin 164 in irgendeiner Form die homologe Rekombination beeinflusst.

Zusätzlich zu diesen Daten konnte ein interessantes Phänomen für eine pol30 K127RMutante beobachtet werden (Seite 100). Die induzierten Reversionsfrequenzen in dieser Mutante waren deutlich erniedrigt, deutlicher noch als für pol30 K164R. Eine Modifizierung durch Ubiquitinierung ist für dieses Lysin jedoch bisher nicht gefunden worden. Dagegen führt die SUMOylierung am Lysin 127 zu einer Unterdrückung der SchwesterchromatidKohäsion (Moldovan et al., 2006). Möglicherweise ist ein Fehlen der Kohäsine notwendig, um die Proteine der homologen Rekombination an eine arretierte Replikationsgabel zu rekrutieren bzw. einen Austausch mit dem Schwesterchromatid zu ermöglichen.

\section{mms 2 und rev3 sind synergistisch in Bezug auf die spontane Reversionsrate}

Die Vermutung, dass Mms2 an einem fehlerfreien Mechanismus beteiligt ist, beruht im wesentlichen auf dem Mutatorphänotyp von mms2 (Broomfield et al., 1998; Schürer et al., 2004) und dem Synergismus zwischen mms 2 und rev3 bei der Sensitivität gegen UV und MMS (s.o.). Im Rahmen der vorliegenden Arbeit konnte dieser Synergismus für die Sensitivität gegen MMS und UV-Licht reproduziert werden. Darüber hinaus konnte solch ein Synergismus auch bei der Sensitivität gegen 4-NQO gefunden werden (Seite 107) sowie ein

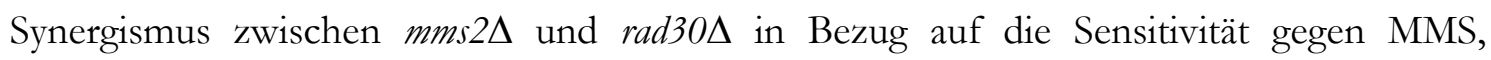
4-NQO und UV-Bestrahlung (Seite 107). Der in vorhergehenden Arbeiten beobachtete 


\section{DISKUSSION}

Effekt in mms 2 rev3 scheint daher nicht spezifisch für UV-Bestrahlung oder MMS zu sein und auch Rad30-abhängige Prozesse scheinen eine von Mms2 unabhängige und alternative Umgehung von DNA-Schäden darzustellen.

Interessanterweise lässt sich die Reduktion der induzierten Reversionsfrequenzen in mms $2 \Delta$ durch zusätzliches Deletieren von REV3 wieder annähernd auf Wildtyp-Niveau bringen (Seite 104). Allerdings ist gleichzeitig die spontane Reversionsrate in mms $2 \Delta$ rev $3 \Delta$ stark erhöht. Demnach ist es denkbar, dass der vermeintliche Anstieg der induzierten Reversionsfrequenzen eigentlich auf einen statistischen Effekt zurückzuführen ist, da bei einem derart hohen spontanen Hintergrund experimentell bedingte Schwankungen einen starken Einfluss auf die induzierte Reversionsfrequenz haben können. Allerdings lässt sich die rev $3 \Delta$-abhängige Erhöhung der induzierten Reversionsfrequenzen in mms $2 \Delta$ durch Transformation mit einem Wildtyp-REV3-Fragment teilweise supprimieren, was dies eher unwahrscheinlich macht.

\section{Polyubiquitinierung von PCNA scheint sowohl einen Rad51- als auch einen Rev3-abhängigen Prozess zu beeinflussen}

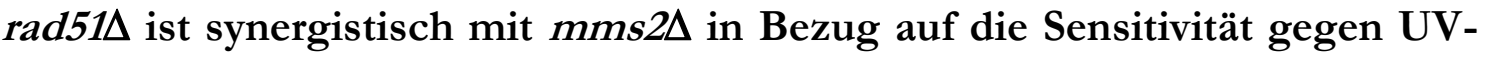
Bestrahlung und MMS, jedoch epistatisch bei 4-NQO

Die bisherige Annahme, die fehlerfreie PRR sei unabhängig von der homologen Rekombination, beruht vor allem auf einer Additivität von rad52 und mms 2 bei der Überlebensrate nach UV-Bestrahlung (s.o.). Auch für mms $2 \Delta$ rad51 $\Delta$ zeigt sich bezogen auf die Sensitivität und Überlebensrate gegenüber UV-Bestrahlung eine solche Additivität (Seite 111). Ähnliches konnte für die Überlebensrate nach Inkubation mit MMS gefunden werden (Seite 113). Auch hier sind mms $2 \Delta$ und rad51 $\Delta$ additiv, was am ehesten mit einer zur homologen Rekombination alternativen Funktion von Mms2 zu erklären ist.

Für die Inkubation mit 4-NQO dagegen zeigte sich ein anderes Bild. Sowohl beim dropdilution-assay als auch der Überlebensrate ist eine Epistatis von rad51 $1 \Delta$ zu beobachten (Seite 112). Es scheint daher, dass Mms2 unterschiedliche Prozesse stimuliert, von denen einer Rad51-abhängig ist. Die nicht von Rad51 abhängigen Prozesse scheinen außerdem nur bei bestimmten Schadenstypen eine Rolle zu spielen, welche nicht durch 4-NQO hervorgerufen werden, aber durch MMS und UV-Bestrahlung. Dies ist vor allem interessant in Bezug auf die Tatsache, dass die gemessene Reduktion der induzierten Reversionsfrequenzen ebenfalls bei Inkubation mit 4-NQO festgestellt werden konnte. Es erscheint demnach wahrscheinlich, dass die gemessene Reduktion in mms $2 \Delta$ vollständig auf die Funktion eines Rad51-abhängigen Prozesses zurückzuführen ist. Gleichzeitig lässt sich für die Sensitivität im drop-dilution-assay und die Überlebensrate bezüglich 4-NQO eine sehr schwache Verstär-

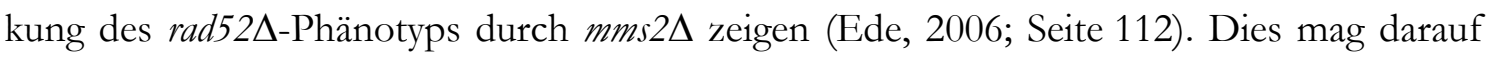
hinweisen, dass ein geringer Teil der durch 4-NQO induzierten Schäden unabhängig von Rad51 durch Rad52 prozessiert wird (bspw. über SSA). Dies wird auch dadurch gestützt,

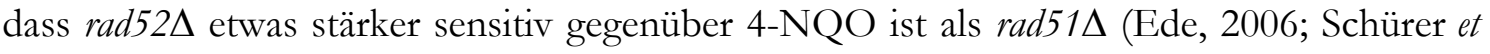


al. 2004). Möglich wäre jedoch auch, dass die verstärkte Sensitivität dadurch entsteht, dass Mms2 ausschließlich Prozesse beeinflusst, welche Rad51 - und nicht Rad52-abhängig sind. In diesem Fall wäre bspw. die Invasion im Schwesterchromatid durch Rad52 anstelle von Rad51 nicht von Mms2 beeinflusst, was ebenfalls beide Gegebenheiten erklären könnte. Ein weiteres Protein, welches eine Funktion in einem Rad51-abhängigen Prozess hat, ist, wie zuvor dargelegt wurde, Mph1. mms2 $\Delta$ ist jedoch additiv mit $m p h 1 \Delta$ in Bezug auf die Sensitivität gegen 4-NQO (Seite 114; Schürer et al., 2004). Eine Stimulation von Mph1 durch Mms2 kann daher als sehr unwahrscheinlich angesehen werden. Vielmehr scheint Mph1 an einem Prozess beteiligt zu sein, welcher nicht oder nur teilweise von Mms2 beeinflusst wird.

\section{Polyubiquitinierung von PCNA könnte sowohl HR als auch einen Rev3- abhängigen Mechanismus positiv stimulieren}

Für Mms2 wurde bisher vermutet, es sei ausschließlich an einem fehlerfreien Mechanismus der PRR beteiligt, was vor allem auf den Synergismus zwischen mms 2 und rev3 zurückgeführt wurde (s.o.). Gleichzeitig scheint Mms2 zwei unterschiedliche Wege zu beeinflussen, welche je nach Art der DNA-Schädigung entweder vollständig, gar nicht, oder teilweise von Rad51 abhängig ist. Es stellt sich daher die Frage, inwiefern dieser (oder diese) Rad51unabhängige(n) Prozess(e) ebenfalls fehlerfrei sind. Da rad51ડ in Bezug auf die Rev3-

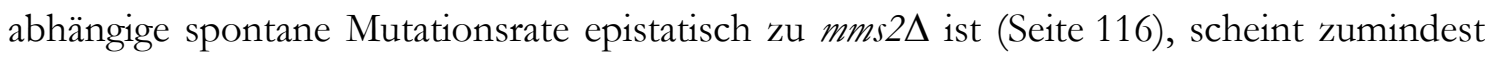
die fehlerfreie Umgehung von spontanen DNA-Schäden ausschließlich Rad51-abhängig zu sein, insofern Mms2 nicht zusätzlich in einem Prozess involviert ist, welcher per se nicht durch Transläsionssynthese ersetzt werden kann.

Das wichtigste Indiz für die Vermutung, dass Mms2 in mehr als einem Prozess involviert ist, ist die unterschiedliche genetische Interaktion von mms $2 \Delta$ und rad51 $\Delta$ in Bezug auf UVStrahlung und MMS einerseits und 4-NQO andererseits (s.o.). Interessanterweise lässt sich zumindest für MMS-induzierte Schäden zeigen, dass bei gleichzeitigem Ausschalten von Rev3 und Rad51 die Funktion von Mms2 nicht mehr relevant für die Überlebensfähigkeit ist, da die Tripelmutante mms $2 \Delta$ rev3 3 rad51 $1 \Delta$ genauso sensitiv ist wie die Doppelmutante rev3 $\Delta$ rad51 (Seite 120). Die wahrscheinlichste Erklärung für diese Epistasis ist, dass Mms2 sowohl an einem Rad51-abhängigen sowie an einem Rev3-abhängigen Prozess beteiligt ist. Ebenfalls unterstützt die hier präsentierte Subadditivität von mms $2 \Delta$ und

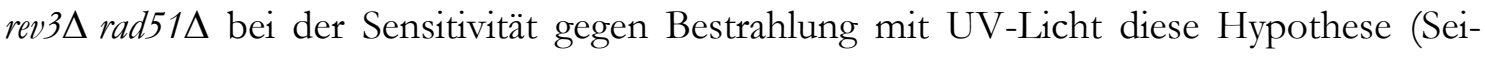
te 120), da eine Subadditivität auf eine sich teilweise überschneidende Funktion der Proteine hindeutet. Allerdings ist Rev3 vor allem für Transläsionssynthese notwendig, was sich darin zeigt, dass in rev3 $\Delta$ annähernd keine spontanen Mutationen mehr stattfinden (Lawrence, 2004). Dies lässt eigentlich vermuten, dass eine MMS2-Deletion den Mutatorphänotyp von $\operatorname{rad51\Delta }$ zumindest teilweise supprimieren müsste. Jedoch scheint die Funktion von Mms2 je nach Art des DNA-Schadens zu variieren, wie die genetische Interaktion von mms $2 \Delta$ und rad51 $\Delta$ in Bezug auf die Sensitivität gegen DNA-schädigende Agenzien zeigt. Es wäre daher möglich, dass die spontanen Schäden ähnlich wie die 4-NQO-induzierten ausschließlich über den Rad51-abhängigen Weg prozessiert werden. Einen tieferen Ein- 


\section{DISKUSSION}

blick hierzu könnte die Messung MMS- und UV-induzierter Mutationsfrequenzen geben. Sollte der Rev3-abhängige Prozess auf der Funktion von Rev3 bei der Transläsionssynthese beruhen, müsste der Mutatorphänotyp supprimiert werden. Da solche Daten jedoch bisher nicht vorliegen, kann hierüber nur spekuliert werden.

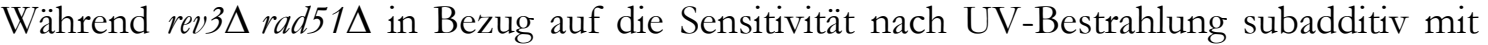

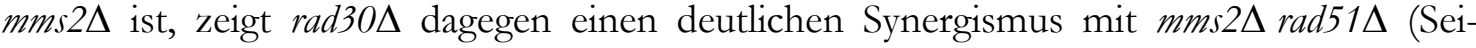
te 122). Dies ist vor allem in Bezug auf die Hypothese interessant, dass Mms2 in irgendeiner Form an der Rev3-abhängigen Transläsionssynthese beteiligt ist. Da Rad30 ebenfalls eine Transläsionspolymerase ist, scheint Mms2 nach diesem Ergebnis nicht an der TLS beteiligt zu sein. Für Rad30-abhängige TLS ist vermutlich die Funktion von Rev3 benötigt und somit sollten beide Tripelmutanten in etwa denselben Phänotyp aufweisen. Es wäre daher möglich, dass Rev3 eine weitere, möglicherweise fehlerfreie Funktion aufweist. Eine solche Funktion konnte für Rev3 bisher jedoch noch nicht gefunden werden (Waters et al., 2009). Allerdings wäre es auch möglich, dass Mms2 dennoch an der Rev3-abhängigen Transläsionssynthese beteiligt ist: Die Annahme, Rev3 sei für die Funktion von Rad30 notwendig, bezieht sich vor allem auf die Tatsache, dass rev3-Mutanten einen Defekt in der UV-induzierten Mutagenese aufweisen (Lemontt, 1971). Interessanterweise ist Rad30 jedoch in vitro in der Lage auch ohne Rev3 über Cyclobutanthymindimere hinweg zu synthetisieren (Johnson et al., 1999). Da diese vermutlich den Hauptbestandteil an UV-induzierten Schäden ausmachen (Friedberg et al., 2006), wäre es denkbar, dass hierbei auch in vivo die Funktion von Rev3 nicht zwingend notwendig ist. In diesem Fall könnte man postulieren,

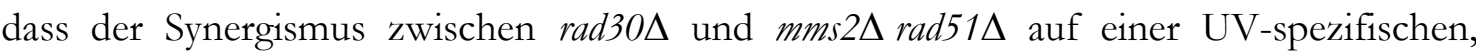
Rev3-unabhängigen Transläsionssynthese durch Rad30 beruht: Es wäre möglich, dass Rad30 ohne Hilfe von Rev3 Cyclobutanthymindimere überlesen kann, wohingegen sie bei anderen Schäden (unter anderem auch weiteren UV-induzierten, wie 6-4-Photoprodukt) weiterhin Rev3 benötigen würde. Da Rad30 solche Dimere fehlerfrei überlesen kann, wäre somit gleichzeitig auch die UV-induzierte Mutagenese teilweise weiter von Rev3 abhängig (Yagi et al., 2005).

Zusammengefasst wäre es möglich, dass die Polyubiquitinierung von PCNA durch Mms2 nicht nur homologe Rekombination, sondern auch die Funktion von Rev3 stimuliert und somit sowohl Transläsionssynthese als auch fehlerfreie Umgehung durch HR beeinflusst. Allerdings wäre es wie zuvor bemerkt in diesem Fall Voraussetzung, dass die spontanen Mutationen in mms2 über Mms2-unabhängige, aber Rev3-abhängige TLS entstünden. Somit bleibt die Interpretation dieser Daten weiterhin spekulativ und es müssten zunächst weitere Untersuchungen erfolgen, um diese Hypothese weiter stützen oder verwerfen zu können. Sinnvoll wären hierbei die bereits erwähnte Messung der MMS- und UVinduzierten Mutationsfrequenzen, aber auch die Untersuchung der Interaktion von mms $2 \Delta$ und rev1s wäre hier sehr von Nutzen: Rev1 ist für das Überlesen von AP-sites, wie sie durch MMS entstehen können, notwendig und darüber hinaus wird Rev3 vermutlich für die anschließende Verlängerung benötigt. Zusätzlich ist Rev1 unabhängig von ihrer katalytischen Funktion auch für Transläsionssynthese über 6-4-Photoprodukte nötig, was vermutlich auf der Interaktion von Rad30 und Rev1 beruht (Waters et al., 2009). Zeigt rev1 bei 
der Sensitivität gegen MMS eine ähnliche Interaktion mit mms $2 \Delta$ wie rev3 $\Delta$, so wäre dies ein wichtiger Hinweis darauf, dass Mms2 tatsächlich die Transläsionssynthese stimuliert.

Unabhängig von diesen Überlegungen, machen es die Daten dennoch sehr wahrscheinlich, dass die Polyubiquitinierung von PCNA durch Mms2 in irgendeiner Form sowohl HR als auch Rev3 positiv stimuliert. Gleichzeitig lassen die Daten vermuten, dass es noch weitere Prozesse gibt, in die Mms2 involviert ist und welche weder Rad51 noch Rev3 benötigen, jedoch ausschließlich bei UV-Bestrahlung relevant sind, da hier eine Subadditivität und keine Epistasis vorlieg.

\section{Genetische Evidenzen für die Beteiligung der homologen Rekombina- tion an der fehlerfreien PRR wurden kürzlich gezeigt}

\section{Der Shu-Komplex}

In früheren Arbeiten wurde die PRR mechanistisch aufgeteilt in die Transläsionssynthese und einen undefinierten fehlerfreien Mechanismus, welcher möglicherweise fork regression darstellt. In einer kürzlich veröffentlichten Arbeit wurden dagegen Daten vorgestellt, welche es sehr wahrscheinlich machen, dass an der fehlerfreien PRR auch Proteine der homologen Rekombination beteiligt sind, namentlich Shu1, Shu2, Psy3 und Csm2. Dieser Befund stützt sich vor allem auf einer Epistasis von mms 2 gegenüber shu1 in Bezug auf die Überlebensrate nach Inkubation mit MMS. Eine weiteres Indiz dafür, dass an der fehlerfreien PRR auch Gene der homologen Rekombination beteiligt sind, ist, dass mms2, wie auch shu1 und andere Gene der rad52-Epistasisgruppe, die Sensitivität von sgs1 gegen MMS und HU supprimiert (Ball et al., 2009). Es scheint daher, dass die Polyubiquitinierung von PCNA durch Mms2/Ubc13 direkten Einfluss auf die Aktivität des Shu-Komplexes und damit auf einen Teil der Proteine hat, welche an der homologen Rekombination beteiligt sind.

SHU1, SHU2, PSY3 und CSM2 sind Teil der rad52-Epistasisgruppe und vermutlich an der homologen Rekombination zwischen Schwesterchromatiden beteiligt (Mankouri et al., 2007). Aufgrund der Tatsache, dass eine Vierfachmutante genauso sensitiv ist wie die jeweiligen Einzelmutanten, ist es sehr wahrscheinlich, dass die Genprodukte einen funktionellen Proteinkomplex bilden. Gestützt wird diese Vermutung zusätzlich durch Two-HybridAnalysen (Shor et al., 2005). Wie rad51-, rad55- und rad54-Mutationen kann auch shu1 partiell das schlechte Wachstum einer top3 Y356F-Mutante sowie den HyperrekombinationsPhänotyp von sgs 1 und top3 supprimieren (Shor et al., 2005). Sgs1 ist eine Helikase, welche vermutlich in der Lage ist, doppelte Holliday-Junctions via branch migration ineinander laufen zu lassen, wodurch ein Hemikatenan entsteht. Solche Strukturen können von Top3 geschnitten werden, wodurch die beiden Stränge getrennt werden und die doppelte Holliday-Junction ohne einen materiellen Austausch aufgelöst wird. Für die humanen Homologen zu Sgs1 und Top3 sowie für das Homologe aus Drosophila konnte eine solche Funktionsweise bereits biochemisch gezeigt werden (Plank et al., 2006; Wu \& Hickson, 2003). Der Ausfall von Sgs1 und Top3 führt daher vermutlich zu einer erhöhten Rate an cross over, welche abhängig von der homologen Rekombination ist. Da der Ausfall von Shu1 zu einer Redukti- 


\section{DISKUSSION}

on dieser Ereignisse führt, wird auch für Shu1 eine Funktion bei der homologen Rekombination vermutet.

Neben der Suppression des Hyperrekombinations-Phänotyps von sgs 1 durch shu1 konnte sowohl für shu1 als auch für shu2, psy3 und csm2 eine Epistasis zu sgs1 bei der Sensitivität gegenüber MMS festgestellt werden (Mankouri et al., 2007). Darüber hinaus lässt sich in einer sgs1-Mutante nach Inkubation mit MMS eine Anhäufung an Strukturen feststellen, welche den sogenannten X-Arm in einem 2D-Gel bilden und vermutlich Intermediate der homologen Rekombination darstellen. Diese Anhäufung lässt sich jedoch durch Mutationen im RAD51 und RAD54 sowie in SHU1, SHU2, PSY3 und CSM2 wieder rückgängig machen (Mankouri et al., 2007), da die Intermediate ohne die Genprodukte dieser Gene nicht oder nur in geringem Maße entstehen können. Epistasisanalysen in Bezug auf die Überlebensrate nach Inkubation mit MMS zeigten außerdem eine Epistasis von rad51 und rad54 zu shu1. Es liegt daher die Vermutung nahe, dass der Shu-Komplex in irgendeiner Form an Rad51- und Rad54-abhängiger homologer Rekombination beteiligt ist.

Da rad54 epistatisch zu shu1 ist, erscheint es naheliegend, dass der Shu-Komplex in irgendeiner Form nach Rad54 an der Bildung oder Prozessierung des D-Loops beteiligt ist. Wie Mph1 und Rad54 scheint auch der Shu-Komplex an einem Punkt benötigt zu werden, an dem Transläsionssynthese noch als Alternative einsetzen kann, da shu1 einen Rev3abhängigen Mutatorphänotyp besitzt (Shor et al., 2005). Zusätzlich wird für Mph1 und Rad54 vermutet, dass sie parallele Funktionen bei der Prozessierung eines D-Loops haben (s.o.). Da gleichzeitig für den Shu-Komplex vermutet wird, dass seine Funktion von Rad54 abhängig ist (Mankouri et al., 2007; Shor et al., 2005), ist es plausibel anzunehmen, dass mph1 additiv zu den Shu-Genen ist. Insofern durch Mms2-abhängige Polyubiquitinierung von PCNA der Shu-Komplex stimuliert wird, wäre somit auch eine Additivität zwischen mph1 und mms2 plausibel, wie sie tatsächlich vorliegt (siehe Seite 115, Abb. 45). Dennoch bleibt eine Interpretation der Funktion des Shu-Komplexes anhand der bisherigen Daten in der Literatur sehr spekulativ.

\section{Ein Modell der fehlerfreien PRR}

Wie bereits erwähnt, konnte für die Gene des Shu-Komplex gezeigt werden, dass sie vermutlich Teil der fehlerfreien PRR sind. (Ball et al., 2009). Es scheint daher, dass die Polyubiquitinierung von PCNA durch Mms2/Ubc13 direkten Einfluss auf die Aktivität des ShuKomplexes und damit auf einen Teil der Proteine hat, welche an der homologen Rekombination beteiligt sind.

Allerdings kann diese Erkenntnis einige Phänomene nur teilweise erklären. Weder die Additivität zwischen Mutationen in Genen der HR und mms2 bzw. ubc13 (Torres-Ramos et al., 2002), die höhere Sensitivität von mms2 im Vergleich zu shu1, die höhere spontane Mutationsrate von mms 2 im Vergleich zu shu1, noch die Subadditivität von psy3 zu mms2 in Bezug auf die spontane Mutationsrate (Ball et al., 2009) lassen sich anhand eines Modells erklären, welches als einzige Funktion der Polyubiquitinierung von PCNA die Rekrutierung oder Stimulation des Shu-Komplexes postuliert. Daher wurde von den Autoren vermutet, dass der Einfluss auf den Shu-Komplex nur einen Teil der Funktion der fehlerfreien PRR dar- 
stellt. Die hier präsentierten Daten geben dagegen einen tieferen Einblick in die Funktionsweise der fehlerfreien PRR und sind konsistent mit der Annahme, die Polyubiquitinierung von PCNA führe zum einen zu einer Aktivierung der homologen Rekombination, was nach den Daten von Ball et al. bspw. über die Rekrutierung des Shu-Komplexes realisiert werden könnte. Zum anderen scheint parallel auch ein Rev3-abhängiger Mechanismus durch Polyubiquitinierung stimuliert zu werden, welcher möglicherweise die Funktion von Rev3 bei der Transläsionssynthese sein könnte. Durch dieses Modell lassen sich die zuvor aufgeführten Phänotypen im Wesentlichen erklären:

1. Die Additivität zwischen Mutanten der homologen Rekombination und mms2 lässt sich auf den gleichzeitigen Verlust des Einflusses der Polyubiquitinierung von PCNA auf Rev3 zurückführen. Die gleichzeitige Einschränkung beider Prozesse durch die Mutation von MMS2 führt zu einer Additivität. Gleichzeitig erscheint es in dieser Hinsicht plausibel, dass der Rev3-abhängige Weg oder HR je nach Art des Schadens in unterschiedlichem Maße eingesetzt werden, um die entsprechenden Schäden zu umgehen. Während bei MMS- und UV-induzierten DNA-Schäden Transläsionssynthese durchaus in einem deutlichen Ausmaß stattzufinden scheinen, wie die Additivität zwischen mms 2 und rad51 vermuten lässt, scheint bei 4-NQO-induzierten Schäden eher homologe Rekombination relevant zu werden. Gestützt wird dies auch durch die Tatsache, dass die induzierten Reversionsfrequenzen bei Inkubation mit MMS um den Faktor 10 geringer sind als bei Inkubation mit 4-NQO. Möglicherweise liegt dies an der Tatsache, dass sowohl AP-sites, wie sie durch MMS Inkubation entstehen, als auch UV-induzierte DNA-Schäden durch Rev1 bzw. Rad30 fehlerfrei überlesen werden können, wobei zumindest bei dem Überlesen einer $A P$-site vermutlich auch die Funktion von Rev3 zur Verlängerung von fehlgepaarten primer Enden benötigt wird (Waters et al., 2009).

2. Die geringere Sensitivität von shu1 im Vergleich zu mms2 lässt sich ebenfalls durch den gleichzeitigen Wegfall einer Stimulation zweier alternativer Prozesse erklären, da die gleichzeitige Schwächung zu einer höheren Sensitivität führen sollte als die Schwächung nur eines der Prozesse.

Die höhere spontane Mutationsrate von mms2 gegenüber shu1 sowie die Subadditivität von psy3 und mms 2 bei der Mutationsrate lassen sich dagegen nicht direkt durch das obige Modell erklären. Allerdings sind diese beiden Phänotypen konsistent mit der Annahme, dass zwar die Aktivität des Shu-Komplexes von Mms2 abhängig ist, die homologe Rekombination jedoch zusätzlich an anderer Stelle durch Mms2 stimuliert wird. Dies wird vor allem dadurch gestützt, dass rad51 bei der spontanen Mutationsrate epistatisch zu mms 2 ist.

Die Daten sind demnach am ehesten konsistent mit der Annahme, dass die Polyubiquitinierung von PCNA einen direkten Einfluss auf den Shu-Komplex und damit auf die homologe Rekombination sowie einen Einfluss auf Rev3 hat. Darüber hinaus wird die homologe Rekombination vermutlich auch an einer weiteren Stelle beeinflusst, welche nicht vom Shu-Komplex abhängig ist. Die Art, in der eine Stimulation dieser Prozesse durch Polyubiquitiniertes PCNA erreicht wird, bleibt weiterhin unklar, jedoch sind drei Modelle plausibel, welche schematisch in Abb. 53 dargestellt sind und im Folgenden näher betrachtet werden sollen. 


\section{DISKUSSION}

1. Sowohl Mono- als auch Polyubiquitinierung von PCNA haben einen direkten Einfluss auf die Komponenten, welche an der Umgehung von replikationsarretierenden DNA-Schäden beteiligt sind (Abb. 53 A). Ein bekanntes Beispiel hierfür ist die Stimulation von Pol $\eta$ durch monoubiquitiniertes PCNA. Durch die Monoubiquitinierung wird vermutlich die Bindung von Pol $\eta$ an PCNA verstärkt, weshalb die replikative Polymerase vom primer-Ende verdrängt werden kann (Watanabe et al., 2004). Die Interaktion mit Rev3 könnte dabei mit polyubiquitiniertem PCNA stattfinden, so dass durch monoubiquitiniertes PCNA Pol $\eta$ und durch anschließende Polyubiquitinierung Pol $\zeta$ rekrutiert wird, um die Verlängerung des nun fehlgepaarten primer-Endes zu ermöglichen. Zusätzlich könnte eine direkte Interaktion mit ubiquitiniertem PCNA auch für den Shu-Komplex möglich sein, wodurch die homologe Rekombination direkt beeinflusst würde.

2. Die Polyubiquitinierung von PCNA hat einen indirekten Einfluss sowohl auf Rev3 als auch homologe Rekombination, indem bspw. der DNA-damage-checkpoint durch polyubiquitiniertes PCNA aktiviert wird (Abb. 53 B). Infolge dieser Signalkaskade könnten in der homologen Rekombination und der Transläsionssynthese involvierte Proteine aktiviert oder verstärkt transkribiert werden.

3. Die Polyubiquitinierung selbst ist ausschließlich ein Signal für fehlerfreie Reparatur. Der beobachtete gleichzeitige Einfluss auf Rev3 könnte ein Artefakt sein, welcher auf das Fehlen von Mms2 zurückzuführen ist (Abb. 53 C). Durch die Abwesenheit des ubiquitinkonjugierenden Enzyms, aber gleichzeitige Bindung des Rad6/Rad18/Monoubi-PCNA-Komplexes durch die Ubiquitinligase Rad5 bzw. die Bindung des Heterodimers ohne anschließende Modifikation (wie es in einer ubi K63R-Mutante der Fall wäre) könnte eine Interakion zwischen monoubiquitiniertem PCNA und einer Transläsionspolymerase unterbunden werden. Dies setzt jedoch voraus, dass erfolgreiche Polyubiquitinierung in irgendeiner Form die Transläsionssynthese ermöglicht oder aber beide Stadien der Modifikation phasisch auftreten, da andernfalls unabhängig von der unterbundenen Interaktion bei polyubiquitiniertem PCNA ohnehin keine TLS mehr erfolgte.

Alle drei Modelle sind konsistent mit den präsentierten Daten, jedoch spricht die beobachtete verstärkte Interaktion von Pol $\eta$ mit monoubiquitiniertem PCNA eher für die Modelle 1 und 3. Allerdings lassen die Subadditivität von mms $2 \Delta$ und $\operatorname{rev} 3 \Delta \operatorname{rad} 51 \Delta$ sowie der Synergismus von mms $2 \Delta$ und $\operatorname{rad} 30 \Delta \operatorname{rad} 51 \Delta$ gleichzeitig Modell 3 eher unwahrscheinlich erscheinen, da es anscheinend noch einen weiteren Prozess gibt, welcher von Mms2 beeinflusst wird. Am wahrscheinlichsten erscheint daher Modell 1. Jedoch lässt sich anhand der hier präsentierten Daten nicht eindeutig zwischen diesen Möglichkeiten entscheiden.

Trotzdem die in dieser Arbeit präsentierten Daten einen tieferen Einblick in die Mechanismen der PRR geben konnten, ist eine genauere Aussage über die Funktion der PRR weiterhin nur sehr begrenzt möglich. Viele Fragen bleiben ungeklärt und müssen in kommenden Arbeiten genauer untersucht werden. Vor allem von Interesse sollte hierbei die Frage nach der Interaktion mit dem Shu-Komplex sein sowie die Klärung der Frage, ob es 


\section{DISKUSSION}

sich bei den beobachteten Phänotypen teilweise um ein Artefakt durch den Verlust von Mms2 handelt. Insofern durch diese Untersuchungen eingegrenzt werden kann, inwieweit eines oder mehrere der oben benannten Modelle zutreffen, wäre es anschließend vor allem interessant, die genaue Funktionsweise des Shu-Komplexes zu untersuchen. Zusätzlich bleibt die Frage, was zu der Subadditivität von mms $2 \Delta$ und rev3 $\Delta$ rad51 $1 \Delta$ führt, da diese es sehr wahrscheinlich macht, dass noch ein weiterer Prozess neben HR und Rev3 durch Polyubiquitinierung stimuliert wird.

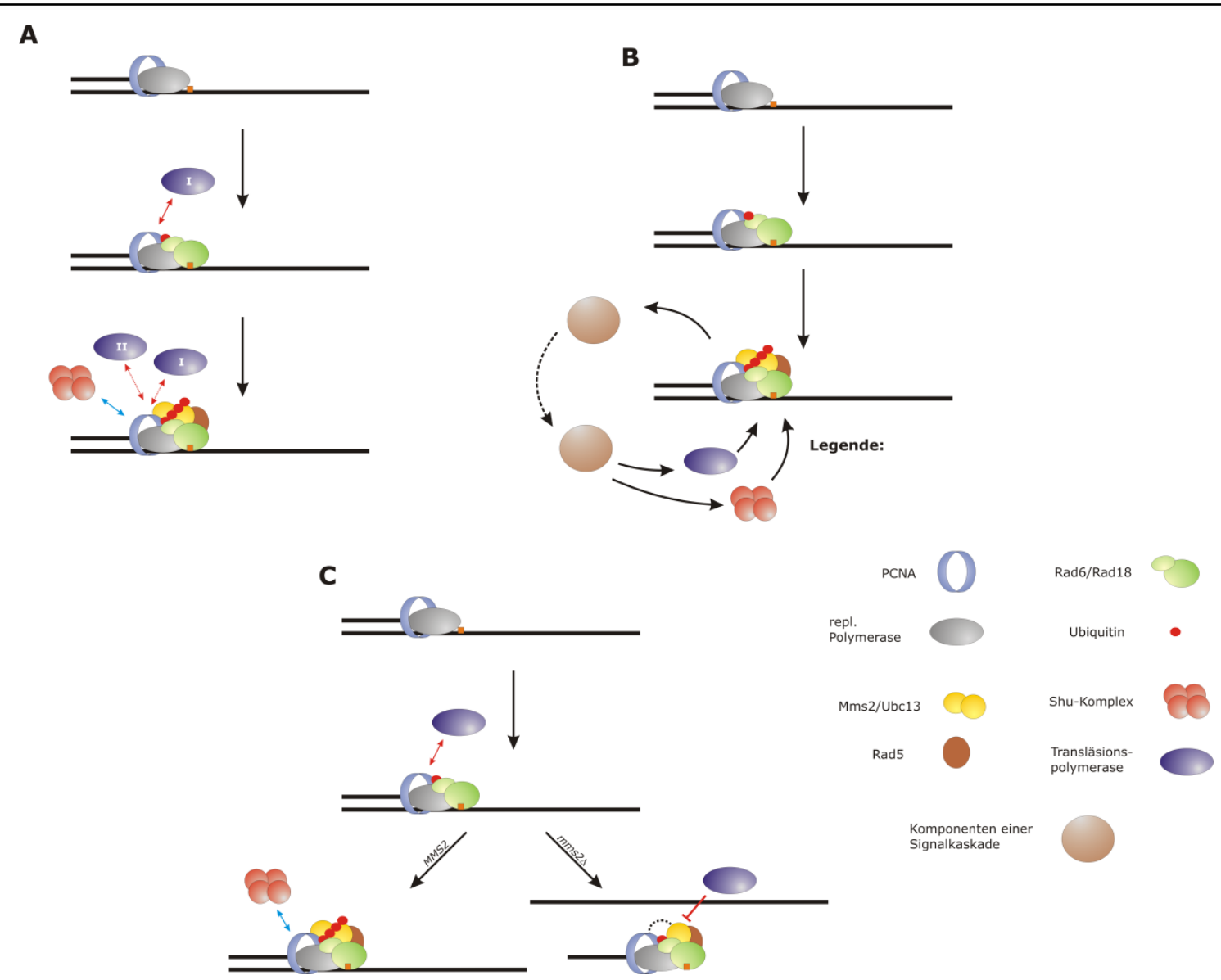

Abb. 53: Drei mögliche Modelle zur Regulation von Transläsionssynthese und homologer Rekombination durch Ubiquitinierung von PCNA. A Direkte Interaktion zwischen modifiziertem PCNA und dem Shu-Komplex bzw. einer Transläsionspolymerase. Durch Monoubiquitinierung des PCNA über Rad6 und Rad18 wird eine Transläsionspolymerase rekrutiert. Durch anschließende Polyubiquitinierung durch Mms2/Ubc13 und Rad5 wird der Shu-Komplex rekrutiert. Gleichzeitig kann möglicherweise immer noch die Transläsionspolymerase mit dem ubiquitinierten PCNA interagieren. Eventuell ist auch eine zweite Transläsionspolymerase (wie bspw. Rev3) erst jetzt an PCNA rekrutierbar. B Indirekte Interaktion durch Aktivierung einer Signalkaskade, bspw. des DNA-Damage-Checkpoint. Polyubiquitinierung durch Mms2/Ubc13 und Rad5 ist das Signal für die Induktion einer Kaskade. Als Resultat der Kaskade werden Transläsionspolymerasen und/oder der Shu-Komplex an die beschädigte Stelle rekrutiert. C Direkte Interaktion zwischen monoubiquitiniertem PCNA und einer Transläsionspolymerase sowie zwischen polyubiquitiniertem PCNA und dem Shu-Komplex. Die beobachtete genetische Interaktion zwischen TLS und mms2 ist hierbei auf das Fehlen von Mms2 zurückzuführen (rechts), da die Bindung von Rad5 und/oder Ubc13 an monoubiquitiniertes PCNA die Interaktion zwischen letzterem und einer Transläsionspolymerase unterbindet. 


\section{ZUSAMMENFASSUNG}

\section{ZUSAMMENFASSUNG}

Die Umgehung von replikationsarretierenden DNA-Schäden läuft in vivo mindestens über zwei Prozesse: homologe Rekombination durch Schwesterchromatid-Interaktion (SCI) und Postreplikative Reparatur (PRR). Die PRR wird zusätzlich in einen fehlerfreien und einen fehlerbehafteten Weg unterteilt. Für homologe Rekombination sind vor allem die Proteine Rad51 und Rad52 notwendig. Die fehlerbehaftete PRR erfolgt über Rev3- und Rad30abhängige Transläsionssynthese. Der Mechanismus der fehlerfreien PRR ist dagegen noch weitgehend unklar. Bekannt ist jedoch, dass die fehlerfreien Prozesse über Polyubiquitinierung des PCNA am Lysin 164 durch das Heterodimer Mms2/Ubc13 und Rad5 stimuliert werden. Die Polyubiquitinierung erfolgt über das Ubiquitin-interne Lysin 63. Nach bisheriger etablierter Lehrmeinung gelten die fehlerfreie Postreplikative Reparatur und homologe Rekombination als zwei voneinander unabhängige und alternativ einsetzbare Prozesse.

Die in dieser Arbeit gewonnenen Daten zeigen dagegen, dass es sich bei der fehlerfreien PRR nicht um HR-unabhängige Prozesse handeln kann:

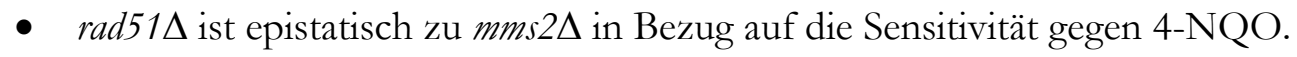

- $\quad \operatorname{rad51\Delta }$ ist epistatisch zu mms $2 \Delta$ in Bezug auf die spontanen Mutationsraten.

- Wie in rad51 $\Delta$-Mutanten ist die Rate spontaner Schwesterchromatid-Interaktionen in mms2 $\Delta$-Mutanten ist leicht erhöht.

- Die Frequenz 4-NQO-induzierter Schwesterchromatid-Interaktionen ist in mms2 $\Delta$ sowie in $u b c 13 \Delta$-Mutanten stark reduziert.

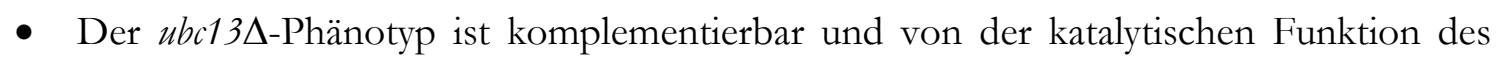
Ubc13-Proteins abhängig.

- Die Mutation des Ubiquitin-internen Lysin 63 führt zu einem mit ubc13s vergleichbaren Phänotyp.

- Die Mutation des Substrats (PCNA-K164R) führt zu einem ähnlichen Phänotyp wie in $m m s 2 \Delta$ und $u b c 13 \Delta$ und ist epistatisch zu $u b c 13 \Delta$ in Bezug auf die Sensitivität gegen 4-NQO.

Die Schwesterchromatid-Interaktionen wurden im Rahmen dieser Arbeit mit einem System gemessen, welches neu in der Arbeitsgruppe von Dr. W. Kramer entwickelt wurde. Es beruht auf der Messung einer G418-Resistenz als Folge der Reversion einer direkten Sequenzwiederholung. Anhand der in dieser Arbeit dargelegten Daten lässt sich zeigen, dass die mit diesem System gemessenen Ereignisse strikt von der homologen Rekombination abhängig sind:

- $\operatorname{rad52\Delta -Mutanten~weisen~weder~spontane~noch~4-NQO-induzierte~Reversionsereignisse~}$ auf.

- rad514-Mutanten weisen stark reduzierte 4-NQO-induzierte Reversionsfrequenzen auf. 
- Die spontane Reversionsrate in rad51 $\Delta$ ist erhöht, was vermutlich auf eine Anhäufung von SSA- gegenüber SDSA- bzw. DSBR-Ereignissen zurückzuführen ist.

Durch genetische Interaktionsstudien zwischen $\operatorname{rad} 30 \Delta$, $\operatorname{rev} 3 \Delta$, rad51 $1 \Delta$ und mms $2 \Delta$ konnten Evidenzen gefunden werden, welche es wahrscheinlich machen, dass die Polyubiquitinierung auch Rev3-abhängige Mechanismen stimuliert und einen Einfluss auf zusätzliche Prozesse hat:

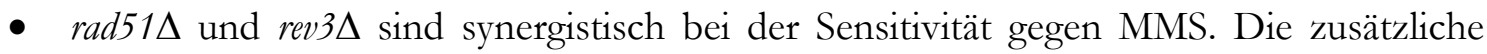
Deletion von mms $2 \Delta$ hat jedoch keinen weiteren Einfluss auf die Sensitivität.

- $\operatorname{rad51\Delta } \operatorname{rad} 30 \Delta$ und $m m s 2 \Delta$ sind additiv bis synergistisch bei der Sensitivität gegen UVStrahlung. mms $2 \Delta$ und $\operatorname{rad} 51 \Delta$ rev $3 \Delta$ sind dagegen nur subadditiv.

Für die Funktion von Mms2/Ubc13 wurden anhand dieser Daten als wahrscheinlichstes Modell eine Stimulation der Rev3-abhängigen Prozesse sowie der homologen Rekombination durch direkte Interaktion zwischen ubiquitiniertem PCNA und den beteiligten Proteinen vorgeschlagen.

Für Mph1, welches an der HR-abhängigen fehlerfreie Umgehung von replikationsarretierenden DNA-Schäden beteiligt ist, konnten die in dieser Arbeit gewonnenen Daten zeigen, das die kürzlich in der Literatur beschriebene Auflösung eines D-Loops nicht die einzige Funktion des Proteins sein kann:

- mph1 $1 \Delta$ weist eine Reduktion der Camptothecin-, MMS- und 4-NQO-induzierten Reversionsfrequenzen auf, wobei die Reduktion bei 4-NQO am deutlichsten ist.

- $\quad m p h 1 \Delta$ weist eine zu rad51 $1 \Delta$ vergleichbare Erhöhung der spontanen Reversionsrate auf.

- mph1 $\Delta$ weist kaum eine Reduktion der 4-NQO-induzierten Reversionsfrequenzen im his3- 45 ' / his3- $\Delta$ 3'-Modul (Fasullo \& Davis, 1987, Proc Natl Acad Sci USA, 84, 62156219) auf, welches vermutlich hauptsächlich cross over-Ereignisse detektiert. 


\section{LITERATUR}

\section{LITERATURVERZEICHNIS}

A

Abdulovic, A.L. and Jinks-Robertson, S. (2006) The in vivo characterization of translesion synthesis across UV-induced lesions in Saccharomyces cerevisiae: insights into Pol zeta- and Pol eta-dependent frameshift mutagenesis. Genetics, 172, 1487-1498.

Acharya, N., Haracska, L., Johnson, R.E., Unk, I., Prakash, S. and Prakash, L. (2005) Complex formation of yeast Rev1 and Rev7 proteins: a novel role for the polymerase-associated domain. Mol Cell Biol, 25, 9734-9740.

Acharya, N., Haracska, L., Prakash, S. and Prakash, L. (2007) Complex formation of yeast Rev1 with DNA polymerase eta. Mol Cell Biol, 27, 8401-8408.

Alexeev, A., Mazin, A. and Kowalczykowski, S.C. (2003) Rad54 protein possesses chromatin-remodeling activity stimulated by the Rad51-ssDNA nucleoprotein filament. Nat Struct Biol, 10, 182-186.

Alscher, R.G., Erturk, N. and Heath, L.S. (2002) Role of superoxide dismutases (SODs) in controlling oxidative stress in plants. J Exp Bot, 53, 1331-1341.

Andersen, P.L., Xu, F. and Xiao, W. (2008) Eukaryotic DNA damage tolerance and translesion synthesis through covalent modifications of PCNA. Cell Res, 18, 162-173.

Armstrong, J.D., Chadee, D.N. and Kunz, B.A. (1994) Roles for the yeast RAD18 and RAD52 DNA repair genes in UV mutagenesis. Mutat Res, 315, 281-293.

Asagoshi, K., Terato, H., Ohyama, Y. and Ide, H. (2002) Effects of a guanine-derived formamidopyrimidine lesion on DNA replication: translesion DNA synthesis, nucleotide insertion, and extension kinetics. J Biol Chem, 277, 14589-14597.

Avemann, K., Knippers, R., Koller, T. and Sogo, J.M. (1988) Camptothecin, a specific inhibitor of type I DNA topoisomerase, induces DNA breakage at replication forks. Mol Cell Biol, 8, 3026-3034.

Ayyagari, R., Impellizzeri, K.J., Yoder, B.L., Gary, S.L. and Burgers, P.M. (1995) A mutational analysis of the yeast proliferating cell nuclear antigen indicates distinct roles in DNA replication and DNA repair. Mol Cell Biol, 15, 4420-4429.

\section{B}

Badwey, J.A. and Karnovsky, M.L. (1986) Production of superoxide by phagocytic leukocytes: a paradigm for stimulus-response phenomena. Curr Top Cell Regul, 28, 183-208.

Bailly, V., Lauder, S., Prakash, S. and Prakash, L. (1997) Yeast DNA repair proteins Rad6 and Rad18 form a heterodimer that has ubiquitin conjugating, DNA binding, and ATP hydrolytic activities. J Biol Chem, 272, 23360-23365. 
Ball, L.G., Zhang, K., Cobb, J.A., Boone, C. and Xiao, W. (2009) The yeast Shu complex couples error-free post-replication repair to homologous recombination. Mol Microbiol, 73, 89-102.

Bashkirov, V.I., King, J.S., Bashkirova, E.V., Schmuckli-Maurer, J. and Heyer, W.D. (2000) DNA repair protein Rad55 is a terminal substrate of the DNA damage checkpoints. Mol Cell Biol, 20, 4393-4404.

Bauer, G.A. and Burgers, P.M. (1990) Molecular cloning, structure and expression of the yeast proliferating cell nuclear antigen gene. Nucleic Acids Res, 18, 261-265.

Bell, C.E. (2005) Structure and mechanism of Escherichia coli RecA ATPase. Mol Microbiol, 58, 358-366.

Beranek, D.T. (1990) Distribution of methyl and ethyl adducts following alkylation with monofunctional alkylating agents. Mutat Res, 231, 11-30.

Berger, J.M. (1998) Structure of DNA topoisomerases. Biochim Biophys Acta, 1400, 3-18.

Bjelland, S. and Seeberg, E. (2003) Mutagenicity, toxicity and repair of DNA base damage induced by oxidation. Mutat Res, 531, 37-80.

Blastyak, A., Pinter, L., Unk, I., Prakash, L., Prakash, S. and Haracska, L. (2007) Yeast Rad5 protein required for postreplication repair has a DNA helicase activity specific for replication fork regression. Mol Cell, 28, 167-175.

Boiteux, S. and Laval, J. (1983) Imidazole open ring 7-methylguanine: an inhibitor of DNA synthesis. Biochem Biophys Res Commun, 110, 552-558.

Branzei, D. and Foiani, M. (2007) Interplay of replication checkpoints and repair proteins at stalled replication forks. DNA Repair (Amst), 6, 994-1003.

Branzei, D. and Foiani, M. (2008) Regulation of DNA repair throughout the cell cycle. Nat Rev Mol Cell Biol, 9, 297-308.

Breen, A.P. and Murphy, J.A. (1995) Reactions of oxyl radicals with DNA. Free Radic Biol Med, 18, 1033-1077.

Broomfield, S., Chow, B.L. and Xiao, W. (1998) MMS2, encoding a ubiquitin-conjugatingenzyme-like protein, is a member of the yeast error-free postreplication repair pathway. Proc Natl Acad Sci U S A, 95, 5678-5683.

Broomfield, S., Hryciw, T. and Xiao, W. (2001) DNA postreplication repair and mutagenesis in Saccharomyces cerevisiae. Mutat Res, 486, 167-184.

Brusky, J., Zhu, Y. and Xiao, W. (2000) UBC13, a DNA-damage-inducible gene, is a member of the error-free postreplication repair pathway in Saccharomyces cerevisiae. Curr Genet, 37, 168-174.

Bucala, R., Model, P. and Cerami, A. (1984) Modification of DNA by reducing sugars: a possible mechanism for nucleic acid aging and age-related dysfunction in gene expression. Proc Natl Acad Sci U S A, 81, 105-109. 


\section{LITERATUR}

Budzowska, M. and Kanaar, R. (2009) Mechanisms of dealing with DNA damage-induced replication problems. Cell Biochem Biophys, 53, 17-31.

C

Canman, C.E. and Lim, D.S. (1998) The role of ATM in DNA damage responses and cancer. Oncogene, 17, 3301-3308.

Cassier-Chauvat, C. and Fabre, F. (1991) A similar defect in UV-induced mutagenesis conferred by the rad6 and rad18 mutations of Saccharomyces cerevisiae. Mutat Res, 254, 247-253.

Cavalieri, E., Frenkel, K., Liehr, J.G., Rogan, E. and Roy, D. (2000) Estrogens as endogenous genotoxic agents--DNA adducts and mutations. J Natl Cancer Inst Monogr, 75-93.

Chen, S., Davies, A.A., Sagan, D. and Ulrich, H.D. (2005) The RING finger ATPase Rad5p of Saccharomyces cerevisiae contributes to DNA double-strand break repair in a ubiquitinindependent manner. Nucleic Acids Res, 33, 5878-5886.

Choi, J.H. and Pfeifer, G.P. (2005) The role of DNA polymerase eta in UV mutational spectra. DNA Repair (Amst), 4, 211-220.

Cleland, W.W. (1964) Dithiothreitol, a New Protective Reagent for Sh Groups. Biochemistry, 3, 480-482.

Codon, A.C., Gasent-Ramirez, J.M. and Benitez, T. (1995) Factors Which Affect the Frequency of Sporulation and Tetrad Formation in Saccharomyces cerevisiae Baker's Yeasts. Appl Environ Microbiol, 61, 1677.

Conrad, M.N. and Newlon, C.S. (1983) Saccharomyces cerevisiae cdc2 mutants fail to replicate approximately one-third of their nuclear genome. Mol Cell Biol, 3, 1000-1012.

Cordonnier, A.M. and Fuchs, R.P. (1999) Replication of damaged DNA: molecular defect in xeroderma pigmentosum variant cells. Mutat Res, 435, 111-119.

Courcelle, J., Khodursky, A., Peter, B., Brown, P.O. and Hanawalt, P.C. (2001) Comparative gene expression profiles following UV exposure in wild-type and SOS-deficient Escherichia coli. Genetics, 158, 41-64.

\section{D}

Dani, G.M. and Zakian, V.A. (1983) Mitotic and meiotic stability of linear plasmids in yeast. Proc Natl Acad Sci US A, 80, 3406-3410.

di Caprio, L. and Cox, B.S. (1981) DNA synthesis in UV-irradiated yeast. Mutat Res, 82, 6985.

Dillingham, M.S. and Kowalczykowski, S.C. (2008) RecBCD enzyme and the repair of double-stranded DNA breaks. Microbiol Mol Biol Rev, 72, 642-671, Table of Contents.

Doublie, S., Tabor, S., Long, A.M., Richardson, C.C. and Ellenberger, T. (1998) Crystal structure of a bacteriophage T7 DNA replication complex at 2.2 A resolution. Nature, 391, 251-258. 
Duncan, J., Hamilton, L. and Friedberg, E.C. (1976) Enzymatic degradation of uracilcontaining DNA. II. Evidence for N-glycosidase and nuclease activities in unfractionated extracts of Bacillus subtilis. J Virol, 19, 338-345.

\section{$\mathbf{E}$}

Eddins, M.J., Carlile, C.M., Gomez, K.M., Pickart, C.M. and Wolberger, C. (2006) Mms2Ubc13 covalently bound to ubiquitin reveals the structural basis of linkage-specific polyubiquitin chain formation. Nat Struct Mol Biol, 13, 915-920.

Ede, C. (2006) Untersuchungen zur Rolle des Mph1-Proteins von Saccharomyces cerevisiae beim Informationsaustausch zwischen Schwesterchromatiden. Abteilung für molekulare Genetik und präparative Mikrobiologie Georg-August-Universität, Göttingen.

Entian, K.D., Schuster, T., Hegemann, J.H., Becher, D., Feldmann, H., Guldener, U., Gotz, R., Hansen, M., Hollenberg, C.P., Jansen, G., Kramer, W., Klein, S., Kotter, P., Kricke, J., Launhardt, H., Mannhaupt, G., Maierl, A., Meyer, P., Mewes, W., Munder, T., Niedenthal, R.K., Ramezani Rad, M., Rohmer, A., Romer, A., Hinnen, A. and et al. (1999) Functional analysis of 150 deletion mutants in Saccharomyces cerevisiae by a systematic approach. Mol Gen Genet, 262, 683-702.

Enyenihi, A.H. and Saunders, W.S. (2003) Large-scale functional genomic analysis of sporulation and meiosis in Saccharomyces cerevisiae. Genetics, 163, 47-54.

Essen, L.O. and Klar, T. (2006) Light-driven DNA repair by photolyases. Cell Mol Life Sci, 63, 1266-1277.

$\mathbf{F}$

Fasullo, M.T. and Davis, R.W. (1987) Recombinational substrates designed to study recombination between unique and repetitive sequences in vivo. Proc Natl Acad Sci U S A, 84, 6215-6219.

Ferguson, L.R. and Baguley, B.C. (1996) Mutagenicity of anticancer drugs that inhibit topoisomerase enzymes. Mutat Res, 355, 91-101.

Finley, D., Sadis, S., Monia, B.P., Boucher, P., Ecker, D.J., Crooke, S.T. and Chau, V. (1994) Inhibition of proteolysis and cell cycle progression in a multiubiquitination-deficient yeast mutant. Mol Cell Biol, 14, 5501-5509.

Fishman-Lobell, J., Rudin, N. and Haber, J.E. (1992) Two alternative pathways of doublestrand break repair that are kinetically separable and independently modulated. Mol Cell Biol, 12, 1292-1303.

Fortin, G.S. and Symington, L.S. (2002) Mutations in yeast Rad51 that partially bypass the requirement for Rad55 and Rad57 in DNA repair by increasing the stability of Rad51DNA complexes. Embo J, 21, 3160-3170.

Friedberg, E.C., Walker, G.C., Siede, W., Wood, R.D., Schultz, R.A. and Ellenberger, T. (2006) DNA Repair and Mutagenesis. ASM Press, Washington, D.C. 


\section{LITERATUR}

Friedl, A.A., Liefshitz, B., Steinlauf, R. and Kupiec, M. (2001) Deletion of the SRS2 gene suppresses elevated recombination and DNA damage sensitivity in rad5 and rad18 mutants of Saccharomyces cerevisiae. Mutat Res, 486, 137-146.

Futreal, P.A., Liu, Q., Shattuck-Eidens, D., Cochran, C., Harshman, K., Tavtigian, S., Bennett, L.M., Haugen-Strano, A., Swensen, J., Miki, Y. and et al. (1994) BRCA1 mutations in primary breast and ovarian carcinomas. Science, 266, 120-122.

\section{G}

Galiegue-Zouitina, S., Bailleul, B., Ginot, Y.M., Perly, B., Vigny, P. and LoucheuxLefebvre, M.H. (1986) N2-guanyl and N6-adenyl arylation of chicken erythrocyte DNA by the ultimate carcinogen of 4-nitroquinoline 1-oxide. Cancer Res, 46, 1858-1863.

Galiegue-Zouitina, S., Bailleul, B. and Loucheux-Lefebvre, M.H. (1985) Adducts from in vivo action of the carcinogen 4-hydroxyaminoquinoline 1-oxide in rats and from in vitro reaction of 4-acetoxyaminoquinoline 1-oxide with DNA and polynucleotides. Cancer Res, $45,520-525$.

Gangavarapu, V., Prakash, S. and Prakash, L. (2007) Requirement of RAD52 group genes for postreplication repair of UV-damaged DNA in Saccharomyces cerevisiae. Mol Cell Biol, 27, 7758-7764.

Gardner, E.J., Simmons, M.J. and Snustad, D.P. (1991) Principles of genetics. John Wiley \&Sons, Inc, New York.

Garg, P. and Burgers, P.M. (2005) Ubiquitinated proliferating cell nuclear antigen activates translesion DNA polymerases eta and REV1. Proc Natl Acad Sci U S A, 102, 18361-18366.

German, J. (1993) Bloom syndrome: a mendelian prototype of somatic mutational disease. Medicine (Baltimore), 72, 393-406.

Gietz, R.D. and Sugino, A. (1988) New yeast-Escherichia coli shuttle vectors constructed with in vitro mutagenized yeast genes lacking six-base pair restriction sites. Gene, 74, 527-534.

Goldstein, A.L. and McCusker, J.H. (1999) Three new dominant drug resistance cassettes for gene disruption in Saccharomyces cerevisiae. Yeast, 15, 1541-1553.

Goodman, M.F. (2002) Error-prone repair DNA polymerases in prokaryotes and eukaryotes. Annu Rev Biochem, 71, 17-50.

Goodman, M.F., Cai, H., Bloom, L.B. and Eritja, R. (1994) Nucleotide insertion and primer extension at abasic template sites in different sequence contexts. Ann N Y Acad Sci, 726, 132-142; discussion 142-133.

Green, G. and MacQuillan, A.M. (1980) Photorepair of ultraviolet-induced petite mutational damage in Saccharomyces cerevisiae requires the product of the PHR1 gene. J Bacteriol, 144, 826-829.

Guo, C., Fischhaber, P.L., Luk-Paszyc, M.J., Masuda, Y., Zhou, J., Kamiya, K., Kisker, C. and Friedberg, E.C. (2003) Mouse Rev1 protein interacts with multiple DNA polymerases involved in translesion DNA synthesis. Embo J, 22, 6621-6630. 
Gurtan, A.M. and D'Andrea, A.D. (2006) Dedicated to the core: understanding the Fanconi anemia complex. DNA Repair (Amst), 5, 1119-1125.

Guthrie, C. and Fink, G.R. (1991) Methods in Enaymology - Guide to Yeast Genetics and Molecular Biology. Academic Press Inc., San Diego.

\section{$\mathbf{H}$}

Hanahan, D. (1983) Studies on transformation of Escherichia coli with plasmids. J Mol Biol, 166, 557-580.

Haracska, L., Kondratick, C.M., Unk, I., Prakash, S. and Prakash, L. (2001a) Interaction with PCNA is essential for yeast DNA polymerase eta function. Mol Cell, 8, 407-415.

Haracska, L., Prakash, S. and Prakash, L. (2000a) Replication past O(6)-methylguanine by yeast and human DNA polymerase eta. Mol Cell Biol, 20, 8001-8007.

Haracska, L., Unk, I., Prakash, L. and Prakash, S. (2006) Ubiquitylation of yeast proliferating cell nuclear antigen and its implications for translesion DNA synthesis. Proc Natl Acad Sci U S A, 103, 6477-6482.

Haracska, L., Washington, M.T., Prakash, S. and Prakash, L. (2001b) Inefficient bypass of an abasic site by DNA polymerase eta. J Biol Chem, 276, 6861-6866.

Haracska, L., Yu, S.L., Johnson, R.E., Prakash, L. and Prakash, S. (2000b) Efficient and accurate replication in the presence of 7,8-dihydro-8-oxoguanine by DNA polymerase eta. Nat Genet, 25, 458-461.

Heelis, P.F., Kim, S.T., Okamura, T. and Sancar, A. (1993) The photo repair of pyrimidine dimers by DNA photolyase and model systems. J Photochem Photobiol B, 17, 219-228.

Heller, R.C. and Marians, K.J. (2006) Replication fork reactivation downstream of a blocked nascent leading strand. Nature, 439, 557-562.

Higgins, N.P., Kato, K. and Strauss, B. (1976) A model for replication repair in mammalian cells. J Mol Biol, 101, 417-425.

Hoege, C., Pfander, B., Moldovan, G.L., Pyrowolakis, G. and Jentsch, S. (2002) RAD6dependent DNA repair is linked to modification of PCNA by ubiquitin and SUMO. Nature, 419, 135-141.

Hofmann, R.M. and Pickart, C.M. (1999) Noncanonical MMS2-encoded ubiquitinconjugating enzyme functions in assembly of novel polyubiquitin chains for DNA repair. Cell, 96, 645-653.

Howard-Flanders, P., Boyce, R.P. and Theriot, L. (1966) Three loci in Escherichia coli K-12 that control the excision of pyrimidine dimers and certain other mutagen products from DNA. Genetics, 53, 1119-1136.

Howard-Flanders, P., Simson, E. and Theriot, L. (1964) The Excision of Thymine Dimers from DNA, Filament Formation and Sensitivity to Ultraviolet Light in Escherichia coli K-12. Mutat Res, 106, 219-226. 


\section{LITERATUR}

\section{I}

Ip, S.C., Rass, U., Blanco, M.G., Flynn, H.R., Skehel, J.M. and West, S.C. (2008) Identification of Holliday junction resolvases from humans and yeast. Nature, 456, 357-361.

Ivanov, E.L., Sugawara, N., Fishman-Lobell, J. and Haber, J.E. (1996) Genetic requirements for the single-strand annealing pathway of double-strand break repair in Saccharomyces cerevisiae. Genetics, 142, 693-704.

\section{J}

Janion, C. (2008) Inducible SOS response system of DNA repair and mutagenesis in Eschericbia coli. Int J Biol Sci, 4, 338-344.

Jarosz, D.F., Beuning, P.J., Cohen, S.E. and Walker, G.C. (2007) Y-family DNA polymerases in Escherichia coli. Trends Microbiol, 15, 70-77.

Jeggo, P.A. (1998) Identification of genes involved in repair of DNA double-strand breaks in mammalian cells. Radiat Res, 150, S80-91.

Johnson, R.D. and Symington, L.S. (1995) Functional differences and interactions among the putative RecA homologs Rad51, Rad55, and Rad57. Mol Cell Biol, 15, 4843-4850.

Johnson, R.E., Prakash, S. and Prakash, L. (1999) Efficient bypass of a thymine-thymine dimer by yeast DNA polymerase, Poleta. Science, 283, 1001-1004.

\section{$\mathbf{K}$}

Kadyk, L.C. and Hartwell, L.H. (1992) Sister chromatids are preferred over homologs as substrates for recombinational repair in Saccharomyces cerevisiae. Genetics, 132, 387-402.

Kadyk, L.C. and Hartwell, L.H. (1993) Replication-dependent sister chromatid recombination in rad1 mutants of Saccharomyces cerevisiae. Genetics, 133, 469-487.

Kagawa, W., Kurumizaka, H., Ikawa, S., Yokoyama, S. and Shibata, T. (2001) Homologous pairing promoted by the human Rad52 protein. J Biol Chem, 276, 35201-35208.

Kannouche, P.L., Wing, J. and Lehmann, A.R. (2004) Interaction of human DNA polymerase eta with monoubiquitinated PCNA: a possible mechanism for the polymerase switch in response to DNA damage. Mol Cell, 14, 491-500.

Kanugula, S. and Pegg, A.E. (2001) Novel DNA repair alkyltransferase from Caenorbabditis elegans. Environ Mol Mutagen, 38, 235-243.

Kc, S., Carcamo, J.M. and Golde, D.W. (2005) Vitamin C enters mitochondria via facilitative glucose transporter 1 (Glut1) and confers mitochondrial protection against oxidative injury. Faseb J, 19, 1657-1667.

Kelman, Z. and O'Donnell, M. (1995) Structural and functional similarities of prokaryotic and eukaryotic DNA polymerase sliding clamps. Nucleic Acids Res, 23, 3613-3620.

Kiianitsa, K., Solinger, J.A. and Heyer, W.D. (2006) Terminal association of Rad54 protein with the Rad51-dsDNA filament. Proc Natl Acad Sci U S A, 103, 9767-9772. 
Kim, S.B., Kim, I.S., Yeum, D.M. and Park, Y.H. (1991) Mutagenicity of Maillard reaction products from D-glucose-amino acid mixtures and possible roles of active oxygens in the mutagenicity. Mutat Res, 254, 65-69.

Kobayashi, T. and Horiuchi, T. (1996) A yeast gene product, Fob1 protein, required for both replication fork blocking and recombinational hotspot activities. Genes Cells, 1, 465474.

Kohda, K., Tada, M., Kasai, H., Nishimura, S. and Kawazoe, Y. (1986) Formation of 8hydroxyguanine residues in cellular DNA exposed to the carcinogen 4-nitroquinoline 1oxide. Biochem Biophys Res Commun, 139, 626-632.

Kooistra, R., Zonneveld, J.B., Watson, A.J., Margison, G.P., Lohman, P.H. and Pastink, A. (1999) Identification and characterisation of the Drosophila melanogaster O6-alkylguanineDNA alkyltransferase cDNA. Nucleic Acids Res, 27, 1795-1801.

Kool, E.T. (2002) Active site tightness and substrate fit in DNA replication. Annu Rev Biochem, 71, 191-219.

Krejci, L., Van Komen, S., Li, Y., Villemain, J., Reddy, M.S., Klein, H., Ellenberger, T. and Sung, P. (2003) DNA helicase Srs2 disrupts the Rad51 presynaptic filament. Nature, 423, 305-309.

Krishna, T.S., Kong, X.P., Gary, S., Burgers, P.M. and Kuriyan, J. (1994) Crystal structure of the eukaryotic DNA polymerase processivity factor PCNA. Cell, 79, 1233-1243.

Krogh, B.O. and Symington, L.S. (2004) Recombination proteins in yeast. Annu Rev Genet, 38, 233-271.

Kunkel, T.A. (1988) Exonucleolytic proofreading. Cell, 53, 837-840.

$\mathbf{L}$

Larimer, F.W., Ramey, D.W., Lijinsky, W. and Epler, J.L. (1978) Mutagenicity of methylated N-nitrosopiperidines in Saccharomyces cerevisiae. Mutat Res, 57, 155-161.

Larson, K., Sahm, J., Shenkar, R. and Strauss, B. (1985) Methylation-induced blocks to in vitro DNA replication. Mutat Res, 150, 77-84.

Lasko, D., Cavenee, W. and Nordenskjold, M. (1991) Loss of constitutional heterozygosity in human cancer. Annu Rev Genet, 25, 281-314.

Lawrence, C.W. (2004) Cellular functions of DNA polymerase zeta and Rev1 protein. Adv Protein Chem, 69, 167-203.

Lawrence, C.W. and Christensen, R.B. (1979) Metabolic suppressors of trimethoprim and ultraviolet light sensitivities of Saccharomyces cerevisiae rad6 mutants. J Bacteriol, 139, 866-876.

Lea, D.E. and Coulson, C.A. (1948) The distribution of mutants in bacterial populations. $J$ Genet, 49, 248-264.

Lee, A.T. and Cerami, A. (1987a) Elevated glucose 6-phosphate levels are associated with plasmid mutations in vivo. Proc Natl Acad Sci U S A, 84, 8311-8314. 


\section{LITERATUR}

Lee, A.T. and Cerami, A. (1987b) The formation of reactive intermediate(s) of glucose 6phosphate and lysine capable of rapidly reacting with DNA. Mutat Res, 179, 151-158.

Lemontt, J.F. (1971) Mutants of Yeast Defective in Mutation Induced by Ultraviolet Light. Genetics, 68, 21-33.

Lett, J.T., Stacey, K.A. and Alexander, P. (1961) Crosslinking of dry deoxyribonucleic acids by electrons. Radiat Res, 14, 349-362.

Li, X. and Heyer, W.D. (2009) RAD54 controls access to the invading 3'-OH end after RAD51-mediated DNA strand invasion in homologous recombination in Saccharomyces cerevisiae. Nucleic Acids Res, 37, 638-646.

Li, Y., Korolev, S. and Waksman, G. (1998) Crystal structures of open and closed forms of binary and ternary complexes of the large fragment of Thermus aquaticus DNA polymerase I: structural basis for nucleotide incorporation. Embo J, 17, 7514-7525.

Liefshitz, B., Steinlauf, R., Friedl, A., Eckardt-Schupp, F. and Kupiec, M. (1998) Genetic interactions between mutants of the 'error-prone' repair group of Saccharomyces cerevisiae and their effect on recombination and mutagenesis. Mutat Res, 407, 135-145.

Lim, D.S. and Hasty, P. (1996) A mutation in mouse rad51 results in an early embryonic lethal that is suppressed by a mutation in p53. Mol Cell Biol, 16, 7133-7143.

Lin, F.L., Sperle, K. and Sternberg, N. (1984) Model for homologous recombination during transfer of DNA into mouse L cells: role for DNA ends in the recombination process. Mol Cell Biol, 4, 1020-1034.

Lindahl, T. (1993) Instability and decay of the primary structure of DNA. Nature, 362, 709715.

Lindahl, T. and Barnes, D.E. (2000) Repair of endogenous DNA damage. Cold Spring Harb Symp Quant Biol, 65, 127-133.

Lindahl, T., Karran, P. and Wood, R.D. (1997) DNA excision repair pathways. Curr Opin Genet Dev, 7, 158-169.

Lindahl, T. and Nyberg, B. (1972) Rate of depurination of native deoxyribonucleic acid. Biochemistry, 11, 3610-3618.

Lottspeich, F. and Engels, J.W. (2006) Bioanalytik. Spektrum Akademischer Verlag, Heidelberg.

Love, J.D., Nguyen, H.T., Or, A., Attri, A.K. and Minton, K.W. (1986) UV-induced interstrand cross-linking of $\mathrm{d}(\mathrm{GT}) \mathrm{n} . \mathrm{d}(\mathrm{CA}) \mathrm{n}$ is facilitated by a structural transition. J Biol Chem, 261, 10051-10057.

Luo, G., Yao, M.S., Bender, C.F., Mills, M., Bladl, A.R., Bradley, A. and Petrini, J.H. (1999) Disruption of mRad50 causes embryonic stem cell lethality, abnormal embryonic development, and sensitivity to ionizing radiation. Proc Natl Acad Sci US A, 96, 7376-7381. 
Machwe, A., Xiao, L., Groden, J. and Orren, D.K. (2006) The Werner and Bloom syndrome proteins catalyze regression of a model replication fork. Biochemistry, 45, 1393913946.

Maher, V.M., Yang, J.L., Chen, R.H., McGregor, W.G., Lukash, L., Scheid, J.M., Reinhold, D.S. and McCormick, J.J. (1991) Use of PCR amplification of cDNA to study mechanisms of human cell mutagenesis and malignant transformation. Environ Mol Mutagen, 18, 239-244.

Majka, J. and Burgers, P.M. (2003) Yeast Rad17/Mec3/Ddc1: a sliding clamp for the DNA damage checkpoint. Proc Natl Acad Sci U S A, 100, 2249-2254.

Malkova, A., Ivanov, E.L. and Haber, J.E. (1996) Double-strand break repair in the absence of RAD51 in yeast: a possible role for break-induced DNA replication. Proc Natl Acad Sci US A, 93, 7131-7136.

Mankouri, H.W., Ngo, H.P. and Hickson, I.D. (2007) Shu proteins promote the formation of homologous recombination intermediates that are processed by Sgs1-Rmi1-Top3. Mol Biol Cell, 18, 4062-4073.

Mann, C. and Davis, R.W. (1983) Instability of dicentric plasmids in yeast. Proc Natl Acad Sci U S A, 80, 228-232.

Marnett, L.J. (2000) Oxyradicals and DNA damage. Carcinogenesis, 21, 361-370.

Matsuda, T., Bebenek, K., Masutani, C., Hanaoka, F. and Kunkel, T.A. (2000) Low fidelity DNA synthesis by human DNA polymerase-eta. Nature, 404, 1011-1013.

Matsuoka, S., Huang, M. and Elledge, S.J. (1998) Linkage of ATM to cell cycle regulation by the Chk2 protein kinase. Science, 282, 1893-1897.

McDonald, J.P., Levine, A.S. and Woodgate, R. (1997) The Saccharomyces cerevisiae RAD30 gene, a homologue of Escherichia coli $\operatorname{dinB}$ and umuC, is DNA damage inducible and functions in a novel error-free postreplication repair mechanism. Genetics, 147, 1557-1568.

McDonald, J.P. and Rothstein, R. (1994) Unrepaired heteroduplex DNA in Saccharomyces cerevisiae is decreased in RAD1 RAD52-independent recombination. Genetics, 137, 393-405.

McGlynn, P. and Lloyd, R.G. (2000) Modulation of RNA polymerase by (p)ppGpp reveals a RecG-dependent mechanism for replication fork progression. Cell, 101, 35-45.

McIlwraith, M.J., Vaisman, A., Liu, Y., Fanning, E., Woodgate, R. and West, S.C. (2005) Human DNA polymerase eta promotes DNA synthesis from strand invasion intermediates of homologous recombination. Mol Cell, 20, 783-792.

Meetei, A.R., Medhurst, A.L., Ling, C., Xue, Y., Singh, T.R., Bier, P., Steltenpool, J., Stone, S., Dokal, I., Mathew, C.G., Hoatlin, M., Joenje, H., de Winter, J.P. and Wang, W. (2005) A human ortholog of archaeal DNA repair protein Hef is defective in Fanconi anemia complementation group M. Nat Genet, 37, 958-963. 


\section{LITERATUR}

Mendenhall, M.D. and Hodge, A.E. (1998) Regulation of Cdc28 cyclin-dependent protein kinase activity during the cell cycle of the yeast Saccharomyces cerevisiae. Microbiol Mol Biol Rev, 62, 1191-1243.

Miki, Y., Swensen, J., Shattuck-Eidens, D., Futreal, P.A., Harshman, K., Tavtigian, S., Liu, Q., Cochran, C., Bennett, L.M., Ding, W. and et al. (1994) A strong candidate for the breast and ovarian cancer susceptibility gene BRCA1. Science, 266, 66-71.

Mimitou, E.P. and Symington, L.S. (2009) DNA end resection: Many nucleases make light work. DNA Repair (Amst), 8, 983-995.

Mitchell, D.L., Jen, J. and Cleaver, J.E. (1991) Relative induction of cyclobutane dimers and cytosine photohydrates in DNA irradiated in vitro and in vivo with ultraviolet- $\mathrm{C}$ and ultraviolet-B light. Photochem Photobiol, 54, 741-746.

Mitchell, D.L. and Nairn, R.S. (1989) The biology of the (6-4) photoproduct. Photochem Photobiol, 49, 805-819.

Moldovan, G.L., Pfander, B. and Jentsch, S. (2006) PCNA controls establishment of sister chromatid cohesion during S phase. Mol Cell, 23, 723-732.

Morimatsu, K. and Kowalczykowski, S.C. (2003) RecFOR proteins load RecA protein onto gapped DNA to accelerate DNA strand exchange: a universal step of recombinational repair. Mol Cell, 11, 1337-1347.

Morrison, A., Christensen, R.B., Alley, J., Beck, A.K., Bernstine, E.G., Lemontt, J.F. and Lawrence, C.W. (1989) REV3, a Saccharomyces cerevisiae gene whose function is required for induced mutagenesis, is predicted to encode a nonessential DNA polymerase. $J$ Bacteriol, $171,5659-5667$.

\section{$\mathbf{N}$}

Nair, D.T., Johnson, R.E., Prakash, L., Prakash, S. and Aggarwal, A.K. (2005) Rev1 employs a novel mechanism of DNA synthesis using a protein template. Science, 309, 22192222.

Nakatsuru, Y., Nemoto, N., Nakagawa, K., Masahito, P. and Ishikawa, T. (1987) O6methylguanine DNA methyltransferase activity in liver from various fish species. Carcinogenesis, 8, 1123-1127.

National-Research-Council, C.o.H.E.o.E.t.L.L.o.I.R.B.V. (1998) Health Effects of Exposure to Low Levels of Ionizing Radiations: Time for Reassessment? The National Academic Presses, Washington, D.C.

Nelson, J.R., Gibbs, P.E., Nowicka, A.M., Hinkle, D.C. and Lawrence, C.W. (2000) Evidence for a second function for Saccharomyces cerevisiae Rev1p. Mol Microbiol, 37, 549-554.

Nelson, J.R., Lawrence, C.W. and Hinkle, D.C. (1996a) Deoxycytidyl transferase activity of yeast REV1 protein. Nature, 382, 729-731.

Nelson, J.R., Lawrence, C.W. and Hinkle, D.C. (1996b) Thymine-thymine dimer bypass by yeast DNA polymerase zeta. Science, 272, 1646-1649. 
$\mathbf{O}$

O'Leary, J. and Muggia, F.M. (1998) Camptothecins: a review of their development and schedules of administration. Eur J Cancer, 34, 1500-1508.

Osman, F., Dixon, J., Doe, C.L. and Whitby, M.C. (2003) Generating crossovers by resolution of nicked Holliday junctions: a role for Mus81-Eme1 in meiosis. Mol Cell, 12, 761-774.

$\mathbf{P}$

Pages, V. and Fuchs, R.P. (2003) Uncoupling of leading- and lagging-strand DNA replication during lesion bypass in vivo. Science, 300, 1300-1303.

Pages, V., Janel-Bintz, R. and Fuchs, R.P. (2005) Pol III proofreading activity prevents lesion bypass as evidenced by its molecular signature within E.coli cells. J Mol Biol, 352, 501 509 .

Pegg, A.E. (1984) Methylation of the O6 position of guanine in DNA is the most likely initiating event in carcinogenesis by methylating agents. Cancer Invest, 2, 223-231.

Petukhova, G., Stratton, S. and Sung, P. (1998) Catalysis of homologous DNA pairing by yeast Rad51 and Rad54 proteins. Nature, 393, 91-94.

Petukhova, G., Stratton, S.A. and Sung, P. (1999a) Single strand DNA binding and annealing activities in the yeast recombination factor Rad59. J Biol Chem, 274, 33839-33842.

Petukhova, G., Van Komen, S., Vergano, S., Klein, H. and Sung, P. (1999b) Yeast Rad54 promotes Rad51-dependent homologous DNA pairing via ATP hydrolysis-driven change in DNA double helix conformation. J Biol Chem, 274, 29453-29462.

Pfander, B., Moldovan, G.L., Sacher, M., Hoege, C. and Jentsch, S. (2005) SUMO-modified PCNA recruits Srs2 to prevent recombination during S phase. Nature, 436, 428-433.

Phillips, D.H. (1983) Fifty years of benzo(a)pyrene. Nature, 303, 468-472.

Plank, J.L., Wu, J. and Hsieh, T.S. (2006) Topoisomerase IIIalpha and Bloom's helicase can resolve a mobile double Holliday junction substrate through convergent branch migration. Proc Natl Acad Sci U S A, 103, 11118-11123.

Plosky, B.S., Vidal, A.E., Fernandez de Henestrosa, A.R., McLenigan, M.P., McDonald, J.P., Mead, S. and Woodgate, R. (2006) Controlling the subcellular localization of DNA polymerases iota and eta via interactions with ubiquitin. Embo J, 25, 2847-2855.

Pomerantz, R.T. and O'Donnell, M. (2007) Replisome mechanics: insights into a twin DNA polymerase machine. Trends Microbiol, 15, 156-164.

Pommier, Y. (2006) Topoisomerase I inhibitors: camptothecins and beyond. Nat Rev Cancer, 6, 789-802.

Pommier, Y., Pourquier, P., Fan, Y. and Strumberg, D. (1998) Mechanism of action of eukaryotic DNA topoisomerase I and drugs targeted to the enzyme. Biochim Biophys Acta, 1400, 83-105. 


\section{LITERATUR}

Prakash, L. (1974) Lack of chemically induced mutation in repair-deficient mutants of yeast. Genetics, 78, 1101-1118.

Prakash, L. (1976) Effect of Genes Controlling Radiation Sensitivity on Chemically Induced Mutations in Saccharomyces cerevisiae. Genetics, 83, 285-301.

Prakash, L. (1981) Characterization of postreplication repair in Saccharomyces cerevisiae and effects of rad6, rad18, rev3 and rad52 mutations. Mol Gen Genet, 184, 471-478.

Prakash, R., Krejci, L., Van Komen, S., Schürer, K.A., Kramer, W. and Sung, P. (2005a) Saccharomyces cerevisiae MPH1 Gene, Required for Homologous Recombination-mediated Mutation Avoidance, Encodes a 3' to 5' DNA Helicase. J Biol Chem, 280, 7854-7860.

Prakash, R., Satory, D., Dray, E., Papusha, A., Scheller, J., Kramer, W., Krejci, L., Klein, H., Haber, J.E., Sung, P. and Ira, G. (2009) Yeast Mph1 helicase dissociates Rad51-made D-loops: implications for crossover control in mitotic recombination. Genes Dev, 23, 67-79.

Prakash, S., Johnson, R.E. and Prakash, L. (2005b) Eukaryotic translesion synthesis DNA polymerases: specificity of structure and function. Annu Rev Biochem, 74, 317-353.

Prakash, S. and Prakash, L. (2002) Translesion DNA synthesis in eukaryotes: a one- or two-polymerase affair. Genes Dev, 16, 1872-1883.

\section{$\mathbf{R}$}

Ramotar, D., Belanger, E., Brodeur, I., Masson, J.Y. and Drobetsky, E.A. (1998) A yeast homologue of the human phosphotyrosyl phosphatase activator PTPA is implicated in protection against oxidative DNA damage induced by the model carcinogen 4nitroquinoline 1-oxide. J Biol Chem, 273, 21489-21496.

Randall, S.K., Eritja, R., Kaplan, B.E., Petruska, J. and Goodman, M.F. (1987) Nucleotide insertion kinetics opposite abasic lesions in DNA. J Biol Chem, 262, 6864-6870.

Rattray, A.J. and Symington, L.S. (1994) Use of a chromosomal inverted repeat to demonstrate that the RAD51 and RAD52 genes of Saccharomyces cerevisiae have different roles in mitotic recombination. Genetics, 138, 587-595.

Redinbo, M.R., Stewart, L., Kuhn, P., Champoux, J.J. and Hol, W.G. (1998) Crystal structures of human topoisomerase I in covalent and noncovalent complexes with DNA. Science, 279, 1504-1513.

Rhaese, H.J. and Freese, E. (1968) Chemical analysis of DNA alterations. I. Base liberation and backbone breakage of DNA and oligodeoxyadenylic acid induced by hydrogen peroxide and hydroxylamine. Biochim Biophys Acta, 155, 476-490.

Ripley, L.S. (1990) Frameshift mutation: determinants of specificity. Annu Rev Genet, 24, 189-213.

Rose, M.D., Novick, P., Thomas, J.H., Botstein, D. and Fink, G.R. (1987) A Saccharomyces cerevisiae genomic plasmid bank based on a centromere-containing shuttle vector. Gene, $\mathbf{6 0}$, 237-243. 
Roush, A.A., Suarez, M., Friedberg, E.C., Radman, M. and Siede, W. (1998) Deletion of the Saccharomyces cerevisiae gene RAD30 encoding an Escherichia coli DinB homolog confers UV radiation sensitivity and altered mutability. Mol Gen Genet, 257, 686-692.

Rudolph, C. (2003) Untersuchungen zur Rolle des MPH1-Gens aus Saccharomyces cerevisiae bei der Reinitiation der Replikation nach schadensinduzierten Arresten. Georg-AugustUniversität, Göttingen.

Rydberg, B. and Lindahl, T. (1982) Nonenzymatic methylation of DNA by the intracellular methyl group donor S-adenosyl-L-methionine is a potentially mutagenic reaction. Embo J, 1, 211-216.

\section{$\mathbf{S}$}

Sagher, D. and Strauss, B. (1983) Insertion of nucleotides opposite apurinic/apyrimidinic sites in deoxyribonucleic acid during in vitro synthesis: uniqueness of adenine nucleotides. Biochemistry, 22, 4518-4526.

Salmon, J.-M., Pinón, R. and Gancedo, C. (1989) Isolation and Characterization of Mutants of Saccharomyces cerevisiae Able to Sporulate in the Presence of Glucose. Journal of General Microbiology, 135, 203-209.

Samson, L. (1992) The suicidal DNA repair methyltransferases of microbes. Mol Microbiol, 6, 825-831.

Sancar, A. (1996) DNA excision repair. Annu Rev Biochem, 65, 43-81.

Saran, M. and Bors, W. (1990) Radical reactions in vivo--an overview. Radiat Environ Biophys, 29, 249-262.

Sassanfar, M. and Samson, L. (1990) Identification and preliminary characterization of an O6-methylguanine DNA repair methyltransferase in the yeast Saccharomyces cerevisiae. J Biol Chem, 265, 20-25.

Scheller, J., Schürer, A., Rudolph, C., Hettwer, S. and Kramer, W. (2000) MPH1, a yeast gene encoding a DEAH protein, plays a role in protection of the genome from spontaneous and chemically induced damage. Genetics, 155, 1069-1081.

Schild, D., Johnston, J., Chang, C. and Mortimer, R.K. (1984) Cloning and mapping of Saccharomyces cerevisiae photoreactivation gene PHR1. Mol Cell Biol, 4, 1864-1870.

Schoket, B. (1999) DNA damage in humans exposed to environmental and dietary polycyclic aromatic hydrocarbons. Mutat Res, 424, 143-153.

Schürer, K.A. (2003) Zur Funktion des MPH1-Gens von Sacharomyces cerevisiae bei der rekombinativen Umgehung von replikationsarretierenden DNA-Schäden. Abteilung für molekulare Genetik und präparative Molekularbiologie. Georg-August-Universität, Göttingen, p. 128.

Schürer, K.A., Rudolph, C., Ulrich, H.D. and Kramer, W. (2004) Yeast MPH1 gene functions in an error-free DNA damage bypass pathway that requires genes from Homologous recombination, but not from postreplicative repair. Genetics, 166, 1673-1686. 


\section{LITERATUR}

Setlow, R.B. (1974) The wavelengths in sunlight effective in producing skin cancer: a theoretical analysis. Proc Natl Acad Sci U S A, 71, 3363-3366.

Setlow, R.B. and Carrier, W.L. (1966) Pyrimidine dimers in ultraviolet-irradiated DNA's. J Mol Biol, 17, 237-254.

Shor, E., Gangloff, S., Wagner, M., Weinstein, J., Price, G. and Rothstein, R. (2002) Mutations in homologous recombination genes rescue top3 slow growth in Saccharomyces cerevisiae. Genetics, 162, 647-662.

Shor, E., Weinstein, J. and Rothstein, R. (2005) A genetic screen for top3 suppressors in Saccharomyces cerevisiae identifies SHU1, SHU2, PSY3 and CSM2: four genes involved in error-free DNA repair. Genetics, 169, 1275-1289.

Sikorski, R.S. and Hieter, P. (1989) A system of shuttle vectors and yeast host strains designed for efficient manipulation of DNA in Saccharomyces cerevisiae. Genetics, 122, 19-27.

Singer, B. and Grunberger, D. (1983) Molecular biology of mutagens and carcinogens. Plenum Press, New York, N.Y.

Smela, M.E., Currier, S.S., Bailey, E.A. and Essigmann, J.M. (2001) The chemistry and biology of aflatoxin B(1): from mutational spectrometry to carcinogenesis. Carcinogenesis, 22, 535-545.

Smith, J. and Rothstein, R. (1999) An allele of RFA1 suppresses RAD52-dependent double-strand break repair in Saccharomyces cerevisiae. Genetics, 151, 447-458.

Solinger, J.A., Kiianitsa, K. and Heyer, W.D. (2002) Rad54, a Swi2/Snf2-like recombinational repair protein, disassembles Rad51:dsDNA filaments. Mol Cell, 10, 1175-1188.

Spence, J., Sadis, S., Haas, A.L. and Finley, D. (1995) A ubiquitin mutant with specific defects in DNA repair and multiubiquitination. Mol Cell Biol, 15, 1265-1273.

Stelter, P. and Ulrich, H.D. (2003) Control of spontaneous and damage-induced mutagenesis by SUMO and ubiquitin conjugation. Nature, 425, 188-191.

Sugawara, N., Wang, X. and Haber, J.E. (2003) In vivo roles of Rad52, Rad54, and Rad55 proteins in Rad51-mediated recombination. Mol Cell, 12, 209-219.

Sugiyama, T. and Kowalczykowski, S.C. (2002) Rad52 protein associates with replication protein A (RPA)-single-stranded DNA to accelerate Rad51-mediated displacement of RPA and presynaptic complex formation. J Biol Chem, 277, 31663-31672.

\section{$\mathbf{T}$}

Takahashi, Y., Kahyo, T., Toh, E.A., Yasuda, H. and Kikuchi, Y. (2001) Yeast Ull1/Siz1 is a novel SUMO1/Smt3 ligase for septin components and functions as an adaptor between conjugating enzyme and substrates. J Biol Chem, 276, 48973-48977.

Tanaka, K. and Wood, R.D. (1994) Xeroderma pigmentosum and nucleotide excision repair of DNA. Trends Biochem Sci, 19, 83-86. 
Thoma, F. (1999) Light and dark in chromatin repair: repair of UV-induced DNA lesions by photolyase and nucleotide excision repair. Embo J, 18, 6585-6598.

Tice, R.R. and Setlow, R.B. (1985) DNA repair and replication in aging organims and cells. In Finch, C.E. and Schneider, E.L. (eds.), Handbook of the Biology of Aging. Van Nostrand Reinhold, New York.

Torres-Ramos, C.A., Prakash, S. and Prakash, L. (2002) Requirement of RAD5 and MMS2 for postreplication repair of UV-damaged DNA in Saccharomyces cerevisiae. Mol Cell Biol, 22, 2419-2426.

Trincao, J., Johnson, R.E., Escalante, C.R., Prakash, S., Prakash, L. and Aggarwal, A.K. (2001) Structure of the catalytic core of S. cerevisiae DNA polymerase eta: implications for translesion DNA synthesis. Mol Cell, 8, 417-426.

Turesky, R.J. (1994) DNA adducts of heterocyclic aromatic amines, arylazides and 4nitroquinoline 1-oxide. LARC Sci Publ, 125, 217-228.

Tuteja, N. and Tuteja, R. (2004) Prokaryotic and eukaryotic DNA helicases. Essential molecular motor proteins for cellular machinery. Eur J Biochem, 271, 1835-1848.

$\mathbf{U}$

Ulrich, H.D. (2001) The srs 2 suppressor of UV sensitivity acts specifically on the RAD5and MMS2-dependent branch of the RAD6 pathway. Nucleic Acids Res, 29, 3487-3494.

Ulrich, H.D. (2003) Protein-protein interactions within an E2-RING finger complex. Implications for ubiquitin-dependent DNA damage repair. J Biol Chem, 278, 7051-7058.

Ulrich, H.D. and Jentsch, S. (2000) Two RING finger proteins mediate cooperation between ubiquitin-conjugating enzymes in DNA repair. Embo J, 19, 3388-3397.

V

Van Komen, S., Petukhova, G., Sigurdsson, S., Stratton, S. and Sung, P. (2000) Superhelicity-driven homologous DNA pairing by yeast recombination factors Rad51 and Rad54. Mol Cell, 6, 563-572.

Veaute, X., Jeusset, J., Soustelle, C., Kowalczykowski, S.C., Le Cam, E. and Fabre, F. (2003) The Srs2 helicase prevents recombination by disrupting Rad51 nucleoprotein filaments. Nature, 423, 309-312.

W

Wach, A., Brachat, A., Alberti-Segui, C., Rebischung, C. and Philippsen, P. (1997) Heterologous HIS3 marker and GFP reporter modules for PCR-targeting in Saccharomyces cerevisiae. Yeast, 13, 1065-1075.

Wach, A., Brachat, A., Pohlmann, R. and Philippsen, P. (1994) New heterologous modules for classical or PCR-based gene disruptions in Saccharomyces cerevisiae. Yeast, 10, 1793-1808.

Walker, J.M. (1984a) Methods in Molecular Biology - Nucleic Acids. Humana Press, Clifton. 


\section{LITERATUR}

Walker, J.M. (1984b) Methods in Molecular Biology - Proteins. Humana Press, Clifton.

Ward, J.F. (1988) DNA damage produced by ionizing radiation in mammalian cells: identities, mechanisms of formation, and reparability. Prog Nucleic Acid Res Mol Biol, 35, 95-125.

Watanabe, K., Tateishi, S., Kawasuji, M., Tsurimoto, T., Inoue, H. and Yamaizumi, M. (2004) Rad18 guides poleta to replication stalling sites through physical interaction and PCNA monoubiquitination. Embo J, 23, 3886-3896.

Waters, L.S., Minesinger, B.K., Wiltrout, M.E., D'Souza, S., Woodruff, R.V. and Walker, G.C. (2009) Eukaryotic translesion polymerases and their roles and regulation in DNA damage tolerance. Microbiol Mol Biol Rev, 73, 134-154.

Wijnhoven, S.W., Kool, H.J., van Teijlingen, C.M., van Zeeland, A.A. and Vrieling, H. (2001) Loss of heterozygosity in somatic cells of the mouse. An important step in cancer initiation? Mutat Res, 473, 23-36.

Windecker, H. and Ulrich, H.D. (2008) Architecture and assembly of poly-SUMO chains on PCNA in Saccharomyces cerevisiae. J Mol Biol, 376, 221-231.

Wittschieben, J.P., Reshmi, S.C., Gollin, S.M. and Wood, R.D. (2006) Loss of DNA polymerase zeta causes chromosomal instability in mammalian cells. Cancer Res, 66, 134-142.

Wooster, R., Bignell, G., Lancaster, J., Swift, S., Seal, S., Mangion, J., Collins, N., Gregory, S., Gumbs, C. and Micklem, G. (1995) Identification of the breast cancer susceptibility gene BRCA2. Nature, 378, 789-792.

Wu, L. and Hickson, I.D. (2003) The Bloom's syndrome helicase suppresses crossing over during homologous recombination. Nature, 426, 870-874.

Wyatt, M.D. and Pittman, D.L. (2006) Methylating agents and DNA repair responses: Methylated bases and sources of strand breaks. Chem Res Toxicol, 19, 1580-1594.

\section{$\mathbf{X}$}

Xiao, W., Chow, B.L., Fontanie, T., Ma, L., Bacchetti, S., Hryciw, T. and Broomfield, S. (1999) Genetic interactions between error-prone and error-free postreplication repair pathways in Saccharomyces cerevisiae. Mutat Res, 435, 1-11.

Xiao, Y. and Weaver, D.T. (1997) Conditional gene targeted deletion by Cre recombinase demonstrates the requirement for the double-strand break repair Mre11 protein in murine embryonic stem cells. Nucleic Acids Res, 25, 2985-2991.

Xu, L. and Marians, K.J. (2002) A dynamic RecA filament permits DNA polymerasecatalyzed extension of the invading strand in recombination intermediates. J Biol Chem, 277, 14321-14328.

\section{$\mathbf{Y}$}

Yagi, Y., Ogawara, D., Iwai, S., Hanaoka, F., Akiyama, M. and Maki, H. (2005) DNA polymerases eta and kappa are responsible for error-free translesion DNA synthesis activity 
over a cis-syn thymine dimer in Xenopus laevis oocyte extracts. DNA Repair (Amst), 4, 12521269.

Yamamoto, K., Inoue, S. and Kawanishi, S. (1993) Site-specific DNA damage and 8hydroxydeoxyguanosine formation by hydroxylamine and 4-hydroxyaminoquinoline 1oxide in the presence of $\mathrm{Cu}(\mathrm{II})$ : role of active oxygen species. Carcinogenesis, 14, 1397-1401.

Yano, K., Morotomi-Yano, K., Adachi, N. and Akiyama, H. (2009) Molecular mechanism of protein assembly on DNA double-strand breaks in the non-homologous end-joining pathway. J Radiat Res (Tokyo), 50, 97-108.

Yu, C.E., Oshima, J., Fu, Y.H., Wijsman, E.M., Hisama, F., Alisch, R., Matthews, S., Nakura, J., Miki, T., Ouais, S., Martin, G.M., Mulligan, J. and Schellenberg, G.D. (1996) Positional cloning of the Werner's syndrome gene. Science, 272, 258-262.

Yuasa, M.S., Masutani, C., Hirano, A., Cohn, M.A., Yamaizumi, M., Nakatani, Y. and Hanaoka, F. (2006) A human DNA polymerase eta complex containing Rad18, Rad6 and Rev1; proteomic analysis and targeting of the complex to the chromatin-bound fraction of cells undergoing replication fork arrest. Genes Cells, 11, 731-744.

\section{$\mathbf{Z}$}

Zegerman, P. and Diffley, J.F. (2009) DNA replication as a target of the DNA damage checkpoint. DNA Repair (Amst), 8, 1077-1088.

Zhang, Y., Yuan, F., Wu, X., Rechkoblit, O., Taylor, J.S., Geacintov, N.E. and Wang, Z. (2000) Error-prone lesion bypass by human DNA polymerase eta. Nucleic Acids Res, 28, 4717-4724.

Zhong, X., Garg, P., Stith, C.M., Nick McElhinny, S.A., Kissling, G.E., Burgers, P.M. and Kunkel, T.A. (2006) The fidelity of DNA synthesis by yeast DNA polymerase zeta alone and with accessory proteins. Nucleic Acids Res, 34, 4731-4742. 



\section{ANHANG}

\section{TESTSPALTUNGEN DER DURCH KLONIERUNG ERHALTENEN PlaS-}

MIDE

\section{YIplac128KanKanMX4}

Erwartete Bandenlängen bei korrekter Klonierung:

$\begin{array}{lrrr}\text { AflII: } & 6.017 \mathrm{bp} & \text { HaeII: } & 2.160 \mathrm{bp} \\ \text { AfIIII: } & 3.026 \mathrm{bp} & & 1.721 \mathrm{bp} \\ & 2.334 \mathrm{bp} & & 1.259 \mathrm{bp} \\ & 657 \mathrm{bp} & & 507 \mathrm{bp} \\ & & 370 \mathrm{bp}\end{array}$

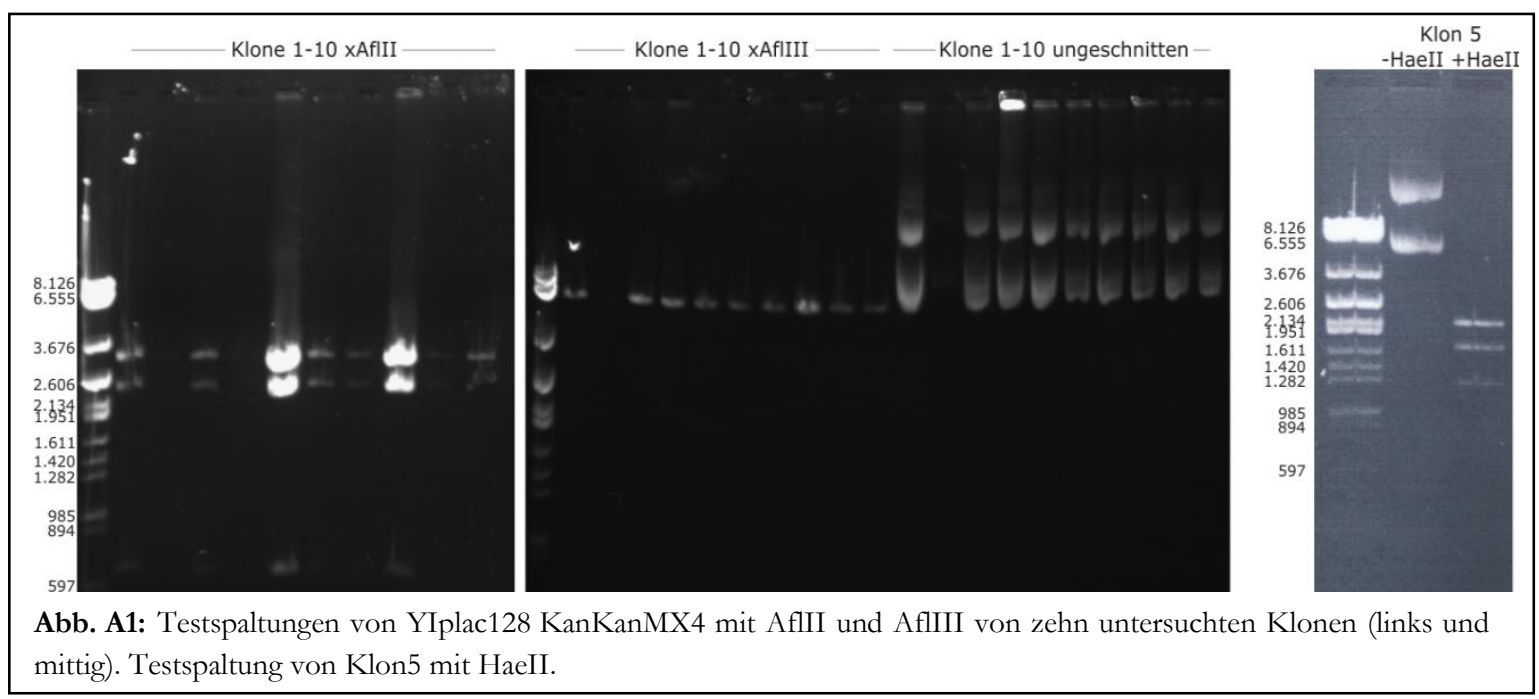

\section{YIplac128 $R E V$ 3 flength}

Erwartete Bandenlängen bei korrekter Klonierung:

\begin{tabular}{|c|c|c|c|c|c|c|}
\hline & pJA6 & & YIplac128 REV3 & & pJA6 & YIplac128 REV3 \\
\hline \multirow[t]{4}{*}{ NcoI: } & $7.052 \mathrm{bp}$ & & $8.116 \mathrm{bp}$ & AcuI: & $5.500 \mathrm{bp}$ & $3.519 \mathrm{bp}$ \\
\hline & $5.459 \mathrm{bp}$ & & $5.459 \mathrm{bp}$ & & $3.519 \mathrm{bp}$ & $2.918 \mathrm{bp}$ \\
\hline & $4.092 \mathrm{bp}$ & & $2.165 \mathrm{bp}$ & & $2.202 \mathrm{bp}$ & $1.706 \mathrm{bp}$ \\
\hline & $2.165 \mathrm{bp}$ & & & & $1.362 \mathrm{bp}$ & $1.662 \mathrm{bp}$ \\
\hline \multirow{7}{*}{ HincII: } & & & & & 1353 bp & $1.353 \mathrm{bp}$ \\
\hline & $5.802 \mathrm{bp}$ & 1.219 bp & $5.802 \mathrm{bp}$ & & $1.233 \mathrm{bp}$ & $1.233 \mathrm{bp}$ \\
\hline & $3.312 \mathrm{bp}$ & $1.202 \mathrm{bp}$ & $3.312 \mathrm{bp}$ & & $1.078 \mathrm{bp}$ & $1.078 \mathrm{bp}$ \\
\hline & $2.179 \mathrm{bp}$ & $1.036 \mathrm{bp}$ & $2.527 \mathrm{bp}$ & & $1.012 \mathrm{bp}$ & $1.012 \mathrm{bp}$ \\
\hline & $1.609 \mathrm{bp}$ & 746 bp & $1.863 \mathrm{bp}$ & & $723 \mathrm{bp}$ & $723 \mathrm{bp}$ \\
\hline & $1.511 \mathrm{bp}$ & $136 \mathrm{bp}$ & $1.202 \mathrm{bp}$ & & $536 \mathrm{bp}$ & $536 \mathrm{bp}$ \\
\hline & & $16 \mathrm{bp}$ & 1.034 bp & & $250 \mathrm{bp}$ & \\
\hline
\end{tabular}

Der Ausgangsvektor pJA6 wurde hierbei mitgespalten, da Reste dieses Vektors teilweise bei der Präparation des REV3-Fragments mitgeschleppt wurden. 


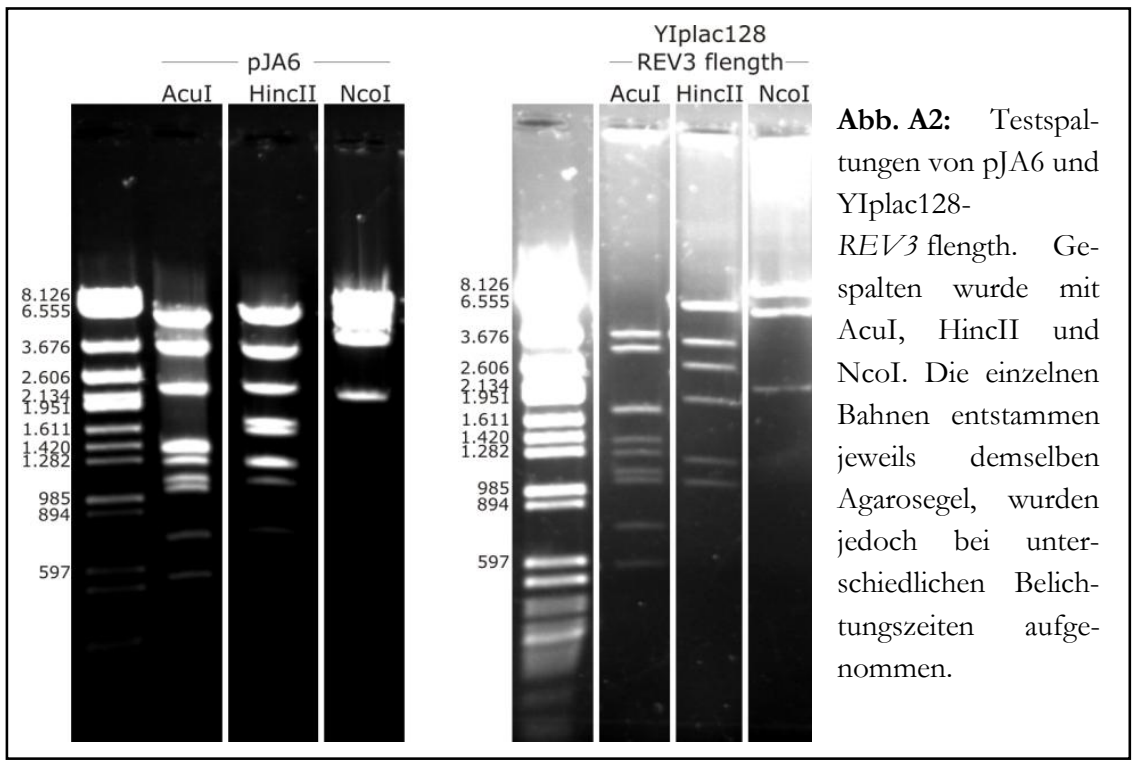

\section{YIplac211 PHR1 flength}

Erwartete Bandenlängen bei korrekter Klonierung:

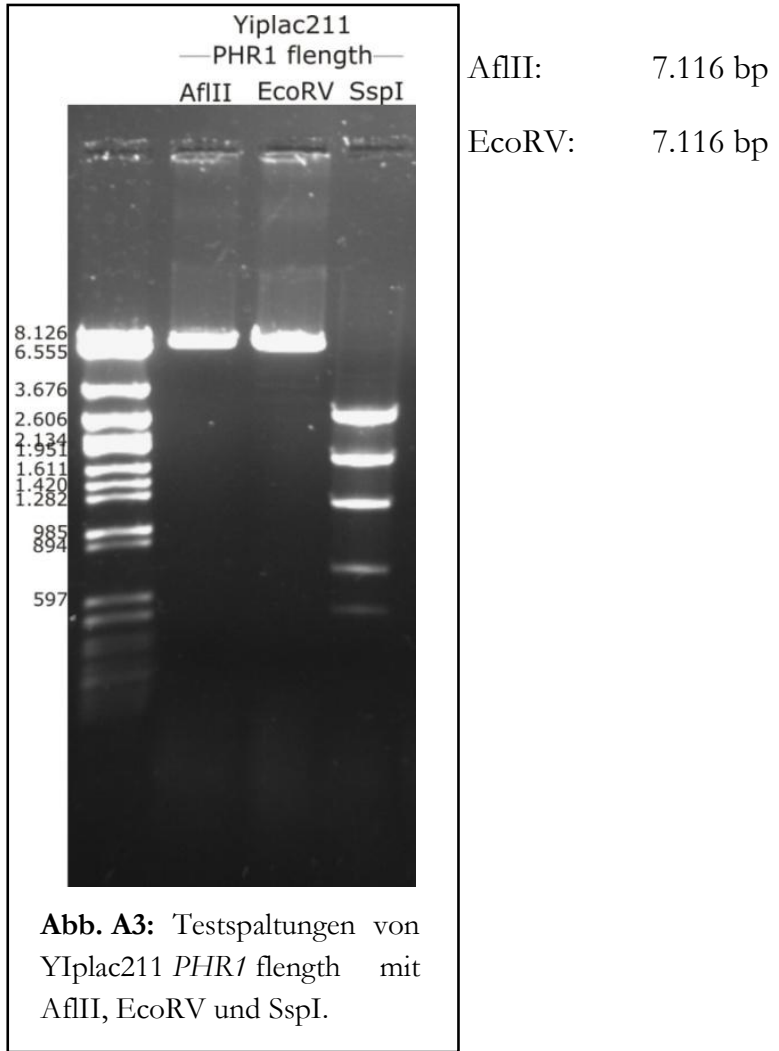

SspI: $\quad 2.740 \mathrm{bp}$

$1.814 \mathrm{bp}$

$1.263 \mathrm{bp}$

$753 \mathrm{bp}$

$546 \mathrm{bp}$ 


\section{VERZEICHNIS NICHT GEBRÄUCHLICHER ABKÜRZUNGEN}

ARS

BER

$\mathrm{bp}$

$\mathrm{DM}$

DMSO

DNA

dsDNA

DTT

dYT

EDTA

et al.

HR

$\mathrm{HU}$

$\mathrm{kb}$

$\mathrm{kU}$

LB

MW

NER

nt

$\mathrm{OD}_{600 \mathrm{~nm}}$

ORF

PCNA

PCR

Pre5

ROS

rpm

RT

SC

SCE

SCE (Puffer)

SCI

SDS

SDSA

SSA

ssDNA

TES

TLS

$\mathrm{U}$ autonomous replicating sequence

Basenexzisionsreparatur

Basenpaar

Dissektionsmedium

Dimethylsulfoxid

desoxyribuncleic acid

double stranded $D N A$

Dithiotreitol

double-yeast extract-tryptone

Ethylendiamintetraacetat

et alii

homologe Rekombination

Hydroxyurea (Hydroxyharnstoff)

Kilobasen

Kilounits

Luria Broth

molecular weight

Nukleotidexzisionsreparatur

Nukleotid(e)

optische Dichte bei $600 \mathrm{~nm}$

open reading frame

proliferating cell nuclear antigen

polymerase chain reaction

Presporulationsmedium 5

reactive oxigen species

rounds per minute

Raumtemperatur

synthetic complete

sisterchromatid exchange

sorbitol-citrat-EDTA

sisterchromatid interaction

sodium dodecyl sulfate

synthesis dependant strand annealing

single strand annealing

single stranded $D N A$

Tris-EDTA-SDS

Transläsionssynthese

Units 
ANHANG

$\mathrm{v} / \mathrm{v}$

$\mathrm{w} / \mathrm{v}$

$\mathrm{w} / \mathrm{w}$

YPD volume/volume

weight/ volume

weigth/weight

yeast extract-peptone-dextrose

iv | Seite 


\section{DANKSAGUNG}

3 1/2 Jahre und geschätzte 10.000 Agarplatten nach Beginn meiner Promotion ist dieses Schriftstück entstanden. In diesen Jahren sind mir einige Personen sehr ans Herz gewachsen, haben meine Ausbildung begleitet und mir mehr oder weniger beigestanden. Daher nutze ich diese letzten Seiten, um ein paar „Dankeschön“ loszuwerden.

Zunächst danke ich meinen Eltern Christiane und Reinhold, meiner Schwester Franziska und meiner Freundin Anna für das Aushalten meiner Person und gutes Zureden und für alles, was Familienmitglieder sonst noch so machen müssen. Und natürlich für die Unterstützung meiner Eltern in finanzieller Hinsicht.

Als nächstes danke ich vor allem meinem Doktorvater Wilfried für die langen wissenschaftlichen und philosophischen Diskussionen, die netten Poker- und Magic ${ }^{\mathrm{TM}}$-Abende und die nette freundschaftliche Atmosphäre bei der Arbeit. Auch danke ich ihm ganz besonders für die meiner Meinung nach exzellente wissenschaftliche Ausbildung, welche ich während meiner Diplomarbeit und Promotionszeit unter seiner Aufsicht genießen durfte. Die Arbeit im Labor 350 bzw. später im Labor $\pi$ hat mir, trotz der vielen arbeitstechnischen Rückschläge, sehr viel Spaß gemacht.

Herrn Prof. H.-J. Fritz danke ich vielmals für die Übernahme des Korreferats, die freundliche Aufnahme in der Abteilung und natürlich für die Bereitstellung einer wiss. HiWi-Stelle zur finanziellen Unterstützung. Auch bedanke ich mich für die wissenschaftlichen Anregungen in den wöchentlichen Montagsseminaren, welche mir teilweise sehr geholfen haben.

Dem Rest der Abteilung danke ich ebenfalls für die sehr freundliche Arbeitsatmosphäre und die netten Gespräche zwischendurch. Da die Anzahl an Personen, denen ich hierbei danken müsste, doch etwas größer ist, belasse ich es mal so ohne Namensnennung. Also darf sich jeder, der sich angesprochen fühlt, gerne auch angesprochen fühlen. Allerdings möchte ich dennoch gerne einen besonderen Dank an Marita, Anke und Bettina richten, welche mich immer gerne mit Rat und Tat unterstützt haben, ob mit Lebensweisheiten, Stiften oder fachlichen Ratschlägen. Und natürlich Angelika, welche immer dafür gesorgt hat, dass der Autoklaviermüll nie zu lange auf der Bench dahinvegetierte.

Meinen Praktikanten und Praktikantinnen danke ich für die tatkräftige Unterstützung bei der experimentellen Arbeit und wünsche ihnen viel Glück und alles Gute bei ihrem weiteren Werdegang.

Auch dem technischen Team (Olaf, Patrik, Gerhard und Jarek) sei gedankt, welches uns gerne zur Hilfe eilte, wenn wieder der Motor vom Inkubationsroller durchgebrannt ist, die Server vom Microsoft-Bug befallen waren, oder mal eben zum fünften Mal das halbe Stockwerk umgeräumt werden musste.

Zusätzlich danke ich noch der FAZIT-Stiftung für das Bereitstellen eines Stipendiums, welches es mir erst finanziell ermöglicht hat, die Promotion in Göttingen bis zum Ende durchzuführen. In diesem Zusammenhang möchte ich auch noch Herrn Dr. Harald 


\section{DANKSAGUNG}

Schneider danken für die freundliche Unterstützung im Grundstudium und für das Anfertigen eines Empfehlungsschreibens.

Als letztes muss ich wohl auch den Hefen vom Stamme CEN.PK2-1c danken, welche irgendwie nicht so ganz aus meiner Arbeit wegzudenken sind. Sie sind zwar echte Zicken, aber mir irgendwie doch ans Herz gewachsen.

Überhaupt nicht danke ich dagegen Bill Gates und Microsoft.

Am Ende bleibt nur noch festzuhalten: Wenn ich keine Stelle im wissenschaftlichen Bereich bekomme, kann ich ja immer noch eine Umzugsgesellschaft gründen. - Da hatten wir ja genügend Gelegenheiten in der Abteilung, dies zu üben.

Damit vielen Dank und alles Gute an die Abteilung.

Ich werde immer gerne zurückdenken!

P.S.: Wer Rechtschreibfehler findet, darf sie gerne behalten! 
"Die Feder ist mächtiger als das Schwert ... vor allem dann, wenn das Schwert sehr klein und die Feder besonders groß und spitz ist"

T. Pratchett 


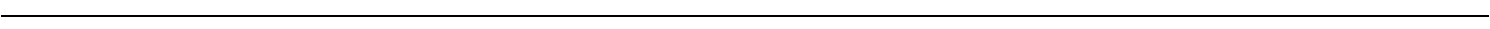




\section{Christopher Ede}

Geburtsdatum:

Geburtsort:

Staatsangehörigkeit:
16.02.1981

Göttingen

deutsch

\section{Promotion}

seit 2006

Promotionsstudent an der Georg-August-Universität seit Juli 2006. Titel der Dissertation: „Untersuchungen zur Funktion der Proteine Mph1 und Mms2 bei der fehlerfreien Umgehung von replikationsarretierenden DNA-Schäden“. Betreuung durch PD Dr. W. Kramer im Institut für Mikrobiologie und Genetik.

\section{Diplom}

$2005-2006$

Anfertigung der schriftlichen Diplomarbeit im Institut für Mikrobiologie und Genetik der Universität Göttingen bei PD Dr. W. Kramer. Thema: „Untersuchungen zur Rolle des Mph1 Proteins von Saccharomyces cerevisiae beim Informationsaustausch zwischen Schwesterchromatiden“. Mündliche Diplomprüfungen in Genetik, Zoologie und Botanik.

\section{Studium} 2001-2005

Studium der Biologie mit Hauptfach Genetik an der Georg-August-Universität Göttingen.

\section{Zivildienst}

Zivildienstleistender im Grenzdurchgangslager Friedland.

\section{weiterführende Schule}

1993-2000

Erlangung der Allgemeinen Hochschulreife am Hainberg Gymnasium in Göttingen.

\section{Orientierungs-Stufe}

Schüler an der Bertolt-Brecht-Schule in Göttingen.

Grundschule:

Schüler an der Grundschule Diemarden. 